\title{
IFA-226 AND IFA-239
}

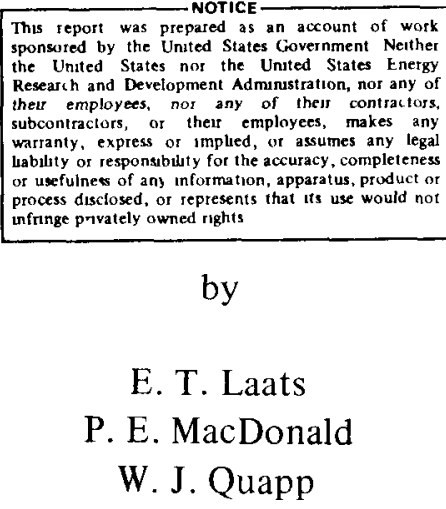

by

E. T. Laats

P. E. MacDonald

W. J. Quapp

\section{AEROJET NUCLEAR COMPANY}

Date Published - December 1975

PREPARED FOR THE

U.S. ENERGY RESEARCH AND DEVELOPMENT ADMINISTRATION

IDAHO OPERATIONS OFFICE

UNDER CONTRACT NO. E(10-1)-1375 


\section{ACKNOWLEDGMENTS}

Grateful acknowledgment is given to D. R. Coleman and W. F. Domenico for their numerous contributions which led to the final formulation of this report.

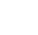




\section{DISCLAIMER}

This report was prepared as an account of work sponsored by an agency of the United States Government. Neither the United States Government nor any agency Thereof, nor any of their employees, makes any warranty, express or implied, or assumes any legal liability or responsibility for the accuracy, completeness, or usefulness of any information, apparatus, product, or process disclosed, or represents that its use would not infringe privately owned rights. Reference herein to any specific commercial product, process, or service by trade name, trademark, manufacturer, or otherwise does not necessarily constitute or imply its endorsement, recommendation, or favoring by the United States Government or any agency thereof. The views and opinions of authors expressed herein do not necessarily state or reflect those of the United States Government or any agency thereof. 


\section{DISCLAIMER}

Portions of this document may be illegible in electronic image products. Images are produced from the best available original document. 


\begin{abstract}
This report presents the experimental data which were obtained from the IFA-226 and IFA-239 test assemblies during operation in the Halden Boiling Water Reactor. Included are cladding elongation, fuel centerline temperature, internal gas pressure, and power history data from IFA-226 which were obtained from November 1971 through April 1974, and cladding elongation, diametral profile, and power history data from IFA-239 covering the period from March 1973 through April 1974.

The data, presented in the form of composite graphs, have been analyzed only to the extent necessary to assure that they are reasonable and correct. The intent of this report is to make available the uninterpreted data from these two tests for use in development and verification of analy tical models which evaluate fuel rod behavior.

A description of these mixed oxide fuel test assemblies and their instrumentation is presented in the early chapters of the text. Test pin fabrication history, instrument calibration data, assembly power calibration methods, and the neutron detector data reduction technique are included as appendices.
\end{abstract}




\section{SUMMARY}

The instrumented test assemblies IFA-226 and IFA-239 began operation in the Halden Boiling Water Reactor on November 24, 1971 and March 12, 1973, respectively. The use and management of these assemblies is being directed by Aerojet Nuclear Company for the United States Nuclear Regulatory Commission, who is a member of the $\operatorname{OECD}^{[\mathrm{a}]}$ Halden Reactor Project.

Test assembly IFA-226 consists of a vertically stacked train of two clusters of six fuel rods each. Each cluster is about 3.1 feet in length and 2.8 inches in diameter. The rods within each cluster are arranged in a hexagonal lattice. The assembly rods are cooled by natural circulation of heavy water at $240^{\circ} \mathrm{C}$ and $3.45 \times 10^{6} \mathrm{~N} / \mathrm{cm}^{2}$. Each fuel rod is composed of recycled plutonium-uranium oxide fuel material which is clad in zircaloy 4 . The density of the fuel varies from 92 to $96 \%$ of theoretical. The rod dimensions, except for length, are typical of those of pressurized water reactor reload fuel. IFA-226 is equipped with four primary in-pile instruments: elongation sensors, pressure transducers, fuel centerline thermocouples, self-powered neutron detectors.

IFA-239 is a single-rod test assembly which is used to determine fuel rod axial and diametral strains during transient and steady state reactor operation. The fuel rod is similar to those used in IFA-226. The coolant conditions are also similar.

The experimental data which are presented in this document cover the period from beginning-of-life through April 16, 1974. Data from the elongation sensors, neutron detectors, and fuel centerline thermocouples were collected at regular intervals using an IBM-1800 data collection system. During steady state fuel power operation, data were automatically collected every six hours. During transient operation, data were collected as often as every 15 minutes. The pressure transducer data from IFA-226 and the diametral profile data from IFA-239 were obtained on a demand basis. The frequency of data collection varied from a few minutes to several months.

[a] OECD - Organization for Economic Cooperation and Development. 


\section{CONTENTS}

ACKNOWLEDGMENTS .................... . . ii

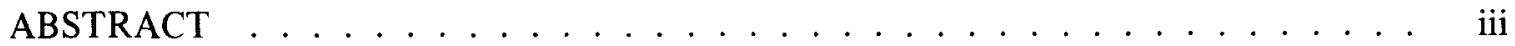

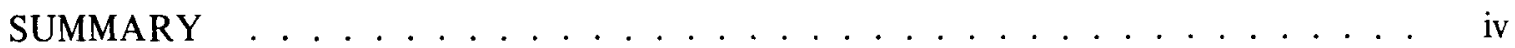

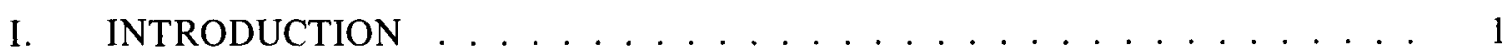

II. HALDEN BOILING WATER REACTOR . . . . . . . . . . . . . 3

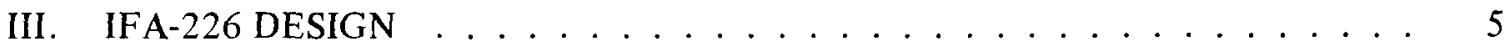

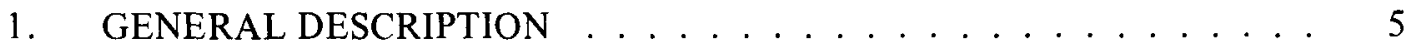

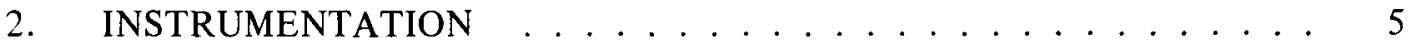

2.1 Elongation Sensors . . . . . . . . . . . . . . . . 9

2.2 Pressure Transducers . . . . . . . . . . . . . . . 9

2.3 Fuel Centerline Thermocouples . . . . . . . . . . . . . . 9

2.4 Self-Powered Neutron Detectors . . . . . . . . . . . . . 9

2.5 Additional Instrumentation . . . . . . . . . . . . 12

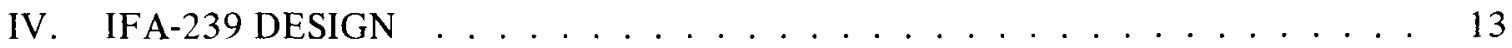

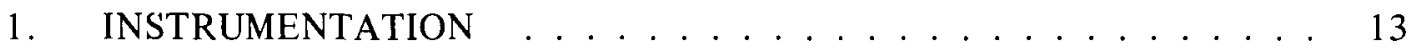

1.1 Diametral Profile Sensor . . . . . . . . . . . . . . . . 13

1.2 Elongation Sensor . . . . . . . . . . . . . . 18

1.3 Self-Powered Neutron Detectors . . . . . . . . . . . 18

1.4 Additional Instrumentation . . . . . . . . . . . . . . 18

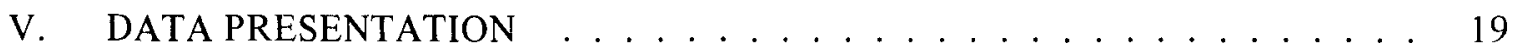

1. PRESENTATION OF DATA FROM IFA-226 . . . . . . . . . . . . 19

2. PRESENTATION OF DATA FROM IFA-239 . . . . . . . . . . . . . . 142

3. OPERATIONAL STATUS OF THE INSTRUMENTATION . . . . . 174

APPENDIX A - FABRICATION REPORT . . . . . . . . . . . . 175

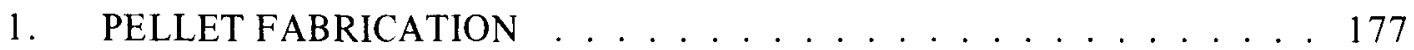

1.1 Pellet Starting Materials . . . . . . . . . . . . . . . 177

1.2 Final Pellet Fabrication . . . . . . . . . . . . . . . 177

1.3 Chemical Analysis . . . . . . . . . . . . . . . . . 178

1.4 Pellet Autoradiography and Metallography ............ 181 
2. CLADDING MATERIALS ..................... 182

3. ROD FABRICATION . . . . . . . . . . . . . . 195

4. INSTRUMENTATION INSERTION ................ 205

APPENDIX B - CALIBRATION RESULTS . . . . . . . . . . . . . 207

1. CLADDING ELONGATION SENSOR CALIBRATION . . . . . . . . 209

2. FUEL CENTERLINE THERMOCOUPLE CALIBRATION . . . . . . . 209

3. TURBINE FLOWMETER CALIBRATION . . . . . . . . . . 217

4. FISSION GAS PRESSURE TRANSDUCER CALIBRATION . . . . . . . 219

5. NEUTRON DETECTOR CHARACTERISTICS . . . . . . . . 225

6. DIAMETRAL PROFILE CALIBRATION (IFA-239) . . . . . . . . . 227

APPENDIX C - DATA REDUCTION TECHNIQUES . . . . . . . . . . . 231

1. IFA-226 NEUTRON DETECTOR DATA . . . . . . . . . . . . 233

2. IFA-239 NEUTRON DETECTOR DATA . . . . . . . . 235

\section{FIGURES}

1. HBWR Core Loading $14($ March 1974) . . . . . . . . . . . . . . 4

2. Diagram of Instrumented Fuel Assembly $226 \ldots \ldots \ldots$

3. Schematic diagram of four types of IFA-226 test rods . . . . . . . . . 7

4. Schematic diagram of a cladding elongation sensor $\ldots \ldots \ldots$

5. Schematic diagram of an IFA-226 pressure sensor . . . . . . . . . . 11

6. Diagram of Instrumented Fuel Assembly $239 \ldots \ldots \ldots$. . . . . . . . . . . 14

7. Schematic diagram of the IFA-239 diametral profile sensor . . . . . . . 15

8. Schematic diagram of the IFA-239 diameter gauge . . . . . . . . . 16

9. Schematic diagram of the IFA-239 long range linear transformer . . . . . . 17

10. Elongation history of IFA-226 test rods from November 1971 through January $1972 \ldots \ldots \ldots . \ldots \ldots$ 
11. Elongation history of IFA-226 test rods from March 1972 through

May $1972 \ldots \ldots \ldots \ldots . \ldots \ldots . \ldots \ldots$

12. Elongation history of IFA-226 test rods from May 1972 through

July $1972 \ldots \ldots \ldots \ldots$. . . . . . . . . . . . . . . . . . . . . . . . . . .

13. Elongation history of IFA-226 test rods from July 1972 through August $1972 \ldots \ldots \ldots \ldots$. . . . . . . . . . . . . . . . . . . . .

14. Elongation history of IFA-226 test rods from October 1972 through

January 1973

15. Elongation history of IFA-226 test rods from March 1973 through

May $1973 \ldots \ldots \ldots \ldots . \ldots \ldots$

16. Elongation history of IFA-226 test rods from June 1973 through

July $1973 \ldots \ldots \ldots$. . . . . . . . . . . . . . . . 29

17. Elongation history of IFA-226 test rods from August 1973 through

September $1973 \ldots \ldots \ldots$. . . . . . . . . . . . . 30

18. Elongation history of IFA-226 test rods from December 1973 through

January $1974 \ldots \ldots . \ldots \ldots 1$

19. Elongation history of IFA-226 test rods from February 1974 through

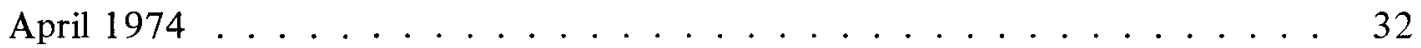

20. Fuel centerline temperature history of IFA-226 test rods from November 1971 through January $1972 \ldots \ldots 33$

21. Fuel centerline temperature history of IFA-226 test rods from March

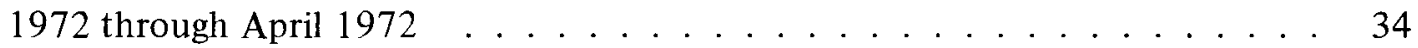

22. Fuel centerline temperature history of IFA-226 test rods from May 1972 through June $1972 \ldots \ldots$. . . . . . . . . . . . . . . . 35

23. Fuel centerline temperature history of IFA-226 test rods from July 1972. through August 1972

24. Fuel centerline temperature history of IFA-226 test rods from October 1972 through November 1972 . . . . . . . . . . . . . . . . . . . 37

25. Fuel centerline temperature history of IFA-226 test rods from December 1972 through January 1973

26. Fuel centerline temperature history of IFA-226 test rods from March 1973 through May $1973 \ldots \ldots \ldots$

27. Fuel centerline temperature history of IFA-226 test rods from June 1973 through August 1973 
28. Fuel centerline temperature history of IFA-226 test rods from August 1973 through September 1973

29. Peak power history of IFA-226 test rods from November 1971 through December 1971

30. Peak power history of IFA-226 test rods for January $1972 \ldots$. . . . . . . . . 43

31. Peak power history of IFA-226 test rods from March 1972 through April 1972

32. Peak power history of IFA-226 test rods from May 1972 through June 1972

33. Peak power history if IFA-226 test rods from July 1972 through August 1972

34. Peak power history of IFA-226 test rods from October 1972 through

November 1972

35. Peak power history of IFA-226 test rods from December 1972 through .January 1973

36. Peak power history of IFA-226 test rods from March 1973 through May 1973

37. Peak power history of IFA-226 test rods from June 1973 through July 1973 50

38. Peak power history of IFA-226 test rods from August 1973 through September 1973

39. Peak power history of IFA-226 test rods from December 1973 through January 1974

40. Peak power history of IFA-226 test rods from February 1974 through April 1974

41. Local power history at thermocouple location of IFA-226 test rods from November 1971 through January 1972

42. Average power history of IFA-226 test rods from November 1971 through December 1971

43. Average power history of IFA-226 test rods from January 1972 through March 1972

44. Average power history of IFA-226 test rods from April 1972 through June 1972 
45. Average power history of IFA-226 test rods from June 1972 through July $1972 \ldots \ldots \ldots \ldots$. . . . . . . . . . . . . . . . . 58

46. Average power history of IFA-226 test rods from August 1972 through October $1972 \ldots \ldots \ldots \ldots \ldots$

47. Average power history of IFA-226 test rods from November 1972 through December $1972 \ldots \ldots \ldots$. . . . . . . . . . . . . 60

48. Average power history of IFA-226 test rods from January 1973 through March 1973 ....................... 61

49. Average power history of IFA-226 test rods from April 1973 through May $1973 \ldots \ldots \ldots$. . . . . . . . . . . . . . 62

50. Average power history of IFA-226 test rods from June 1973 through July 1973

51. Average power history of IFA-226 test rods from August 1973 through September 1973

52. Average power history of IFA-226 test rods from December 1973 through January 1974

53. Average power history of IFA-226 test rods from February 1974 through March 1974

54. Average power history of IFA-226 test rods for April 1974 . . . . . . . . . . 67

55. Fission gas pressure history of IFA-226 test rods at high power levels . . . . . 68

56. Fission gas pressure history of IFA-226 test rods from November 1971 through January 1972

57. Fission gas pressure history of IFA-226 test rods from March 1972 through April 1972 . . . . . . . . . . . . . . . . . .

58. Fission gas pressure history of IFA-226 test rods from May 1972 through June $1972 \ldots \ldots \ldots \ldots \ldots$

59. Fission gas pressure history of IFA-226 test rods from July 1972 through August 1972

60. IFA-226 test rod elongation versus peak rod power from November 24, 1971 at 1000 hours through November 24,1971 at 2300 hours . . . . . . . . . . 73

61. IFA-226 test rod elongation versus peak rod power from November 25, 1971 at 0000 hours through November 26,1971 at 0200 hours . . . . . . . . . . .

62. IFA-226 test rod elongation versus peak rod power from November 26, 1971 at 0300 hours through November 16,1971 at 2200 hours 
63. IFA-226 test rod elongation versus peak rod power from November 27, 1971 at 0000 hours through November 27,1971 at 1300 hours . . . . . . . . . 76

64. IFA-226 test rod elongation versus peak rod power from December 21, 1971 at 1700 hours through December 22, 1971 at 1000 hours . . . . . . . 77

65. IFA-226 test rod elongation versus peak rod power from January 16, 1972 at 1200 hours through January 18,1972 at 0200 hours . . . . . . . . . 78

66. IFA-226 test rod elongation versus peak rod power from March 19, 1972 at 1600 hours through March 21,1972 at 1000 hours . . . . . . . . . . . . 79

67. IFA-226 test rod elongation versus peak rod power from March 21, 1972 at 1500 hours through March 23,1972 at 0000 hours . . . . . . . . . . . 80

68. IFA-226 test rod elongation versus peak rod power from May 20, 1972 at 1800 hours through May 22,1972 at 2200 hours . . . . . . . . . . . 81

69. IFA-226 test rod elongation versus peak rod power from August 7, 1972 at 0000 hours through August 8, 1972 at 1000 hours . . . . . . . . . 82

70. IFA-226 test rod elongation versus peak rod power from December 14, 1972 at 0000 hours through December 15,1972 at 1100 hours . . . . . . . .

71. IFA-226 test rod elongation versus peak rod power from March 14, 1973 at 1300 hours through March 16,1973 at 0500 hours . . . . . . . . . . . 84

72. IFA-226 test rod elongation versus peak rod power from August 2, 1973 at 0900 hours through August 2,1973 at 2000 hours . . . . . . . . . 85

73. IFA-226 test rod fuel centerline temperature versus local rod power at thermocouple location from November 24, 1971 at 1000 hours through November 24,1971 at 2300 hours . . . . . . . . . . . . . . . . 86

74. IFA-226 test rod fuel centerline temperature versus local rod power at thermocouple location from November 25,1971 at 0000 hours through November 26, 1971 at 0200 hours . . . . . . . . . . . . . .

75. IFA-226 test rod fuel centerline temperature versus local rod power at thermocouple location from November 26, 1971 at 0300 hours through November 26, 1971 at 2200 hours . . . . . . . . . . . . . . .

76. IFA-226 test rod fuel centerline temperature versus local rod power at thermocouple location from November 27, 1971 at 0000 hours through November 27, 1971 at 1300 hours . . . . . . . . . . . . . . .

77. IFA-226 test rod fuel centerline temperature versus local rod power at thermocouple location from December 21, 1971 at 1700 hours through December 22, 1971 at 1000 hours . . . . . . . . . . . . . 
78. IFA-226 test rod fuel centerine temperature versus local rod power at thermocouple location from January 16,1972 at 1200 hours through January 18,1972 at 0200 hours . . . . . . . . . . . . . . . . 91

79. IFA-226 test rod fuel centerline temperature versus local rod power at thermocouple location from March 19,1972 at 1600 hours through March 21, 1972 at 1000 hours . . . . . . . . . . . . . . . 92

80. IFA-226 test rod fuel centerline temperature versus local rod power at thermocouple location from March 21, 1972 at 1500 hours through March 23, 1972 at 0000 hours . . . . . . . . . . . . . 93

81. IFA-226 test rod fuel centerline temperature versus local rod power at thermocouple location from May 20,1972 at 1800 hours through

May 22, 1972 at 2000 hours . . . . . . . . . . . . . . . . . 94

82. IFA-226 test rod fuel centerline temperature versus local rod power at thermocouple location from June 5, 1972 at 0600 hours through June 7,1972 at 1800 hours . . . . . . . . . . . . . . . . . . . .

83. IFA-226 test rod fuel centerline temperature versus local rod power at thermocouple location from August 7, 1972 at 0000 hours through

August 8,1972 at 1000 hours . . . . . . . . . . . . 96

84. IFA-226 test rod fuel centerline temperature versus local rod power at thermocouple location from October 26, 1972 at 1500 hours through October 27,1972 at 2250 hours . . . . . . . . . . . . . . . .

85. IFA-226 test rod fuel centerline temperature versus local rod power at thermocouple location from October 27,1972 at 2350 hours through October 29,1972 at 1400 hours . . . . . . . . . . . . . . . . .

86. IFA-226 test rod fuel centerline temperature versus local rod power at thermocouple location from December 14,1972 at 0000 hours through December 15, 1972 at 1100 hours . . . . . . . . . . . . .

87. IFA-226 test rod fuel centerline temperature versus local rod power at thermocouple location from January 15,1972 at 2000 hours through January 19,1973 at 0800 hours . . . . . . . . . . . . . . . .

88. IFA-226 test rod fuel centerline temperature versus local rod power at thermocouple location from March 14, 1973 at 1300 hours through March 16, 1973 at 0500 hours . . . . . . . . . . . . . . . 101

89. IFA-226 test rod fuel centerline temperature versus local rod power at thermocouple location from July 7, 1973 at 0000 hours through July 8,1973 at 0600 hours 
90. IFA-226 test rod fuel centerline temperature versus local rod power at thermocouple location from July 12, 1973 at 0000 hours through

July 13,1973 at 0800 hours . . . . . . . . . . . . . . . . . . 103

91. IFA-226 test rod fuel centerline temperature versus local rod power at thermocouple location from August 2, 1973 at 0900 hours through

August 2,1973 at 2000 hours . . . . . . . . . . . . . . 104

92. IFA-226 test rod fuel centerline temperature versus local rod power at thermocouple location from September 24, 1973 at 0000 hours through

September 24, 1973 at 1900 hours . . . . . . . . . . . 105

93. IFA-226 test rod fuel centerline temperature versus local rod power at thermocouple location from September 25,1973 at 1600 hours through September 26, 1973 at 1300 hours . . . . . . . . . . . . 106

94. IFA-226 test rod fuel centerline temperature versus local rod power at thermocouple location from October 26,1973 at 2000 hours through October 27, 1973 at 2000 hours . . . . . . . . . . . . . . . . 107

95. IFA-226 test rod fuel centerline temperature versus local rod power at thermocouple location from December 6,1973 at 1200 hours through December 8, 1973 at 1600 hours . . . . . . . . . . . . 108

96. IFA-226 assembly axial flux profile at 1200 hours on November $24,1971 \ldots 109$

97. IFA-226 assembly axial flux profile at 0000 hours on November $25,1971 \ldots 110$

98. IFA-226 assembly axial flux profile at 2100 hours on November $25,1971 \ldots 11$

99. IFA-226 assembly axial flux profile at 0400 hours on November $27,1971 \ldots 112$

100. IFA-226 assembly axial flux profile at 1800 hours on November $28,1971 \ldots 113$

101. IFA-226 assembly axial flux profile at 1800 hours on December $2,1971 \ldots 114$

102. IFA-226 assembly axial flux profile at 1800 hours on December $8,1971 \ldots 115$

103. IFA-226 assembly axial flux profile at 1800 hours on December $12,1971 \ldots 116$

104. IFA-226 assembly axial flux profile at 0000 hours on December $23,1971 \ldots 117$

105. IFA-226 assembly axial flux profile at 1200 hours on March $20,1972 \ldots 118$

106. IFA-226 assembly axial flux profile at 0000 hours on March $31,1972 \ldots 119$

107. IFA-226 assembly axial flux profile at 0000 hours on April 12, $1972 \ldots \ldots$

108. IFA-226 assembly axial flux profile at 0000 hours on April 23, $1972 \ldots$. . . . 121 
109. IFA-226 assembly axial flux profile at 0000 hours on June $2,1972 \ldots \ldots$

110. IFA-226 assembly axial flux profile at 0000 hours on July $1,1972 \ldots \ldots$

111. IFA-226 assembly axial flux profile at 0000 hours on July $30,1972 \ldots \ldots$

112. IFA-226 assembly axial flux profile at 0000 hours on August 26, $1972 \ldots 125$

113. IFA-226 assembly axial flux profile at 1800 hours on October $31,1972 \ldots 126$

114. IFA-226 assembly axial flux profile at 0000 hours on December $23,1972 \ldots 127$

115. IFA-226 assembly axial flux profile at 0000 hours on January $17,1973 \ldots 128$

116. IFA-226 assembly axial flux profile at 0000 hours on March 28, 1973 . . . . 129

117. IFA-226 assembly axial flux profile at 0000 hours on April 3, $1973 \ldots 130$

118. IFA-226 assembly axial flux profile at 0000 hours on May $4,1973 \ldots \ldots 131$

119. IFA-226 assembly axial flux profile at 0000 hours on June $25,1973 \ldots \ldots$

120. IFA-226 assembly axial flux profile at 1800 hours on June $30,1973 \ldots \ldots$

121. IFA-226 assembly axial flux profile at 0000 hours on July $16,1973 \ldots \ldots$

122. IFA-226 assembly axial flux profile at 0000 hours on August $23,1973 \ldots 135$

123. IFA-226 assembly axial flux profile at 0000 hours on December 26,1973 . . 136

124. IFA-226 assembly axial flux profile at 0000 hours on January $28,1974 \ldots 137$

125. IFA-226 assembly axial flux profile at 0000 hours on February $28,1974 \ldots 138$

126. IFA-226 assembly axial flux profile at 1200 hours on March 1, $1974 \ldots 139$

127. IFA-226 assembly axial flux profile at 0600 hours on March $25,1974 \ldots \ldots$

128. IFA-226 assembly axial flux profile at 0000 hours on April 15,1974 . . . . 141

129. Axial distance traveled by diameter gauge . . . . . . . . . . . . . 144

130. Diametral profile of IFA-239 calibration $\operatorname{rod}-$ Run $1 \ldots \ldots$. . . . . 145

131. Diametral profile of IFA-239 calibration rod -- Run 2 . . . . . . . . . 146

132. IFA-239 diametral profile at 1631 hours on March 12, $1973 \ldots \ldots$. . . . . 147

133. IFA-239 diametral profile at 1645 hours on March 12, $1973 \ldots \ldots$. . . . . 148 
134. IFA-239 diametral and axial flux profiles at 2124 hours on March $12,1973 \ldots \ldots \ldots \ldots \ldots \ldots \ldots$

135. IFA-239 diametral and axial flux profiles at 0042 hours on March $13,1973 \ldots \ldots \ldots \ldots \ldots 151 \ldots \ldots \ldots \ldots \ldots \ldots$

136. IFA-239 diametral and axial flux profiles at 0054 hours on March $13,1973 \ldots \ldots \ldots \ldots \ldots 15$

137. IFA-239 diametral and axial flux profiles at 0907 hours on March 13,1973

138. IFA-239 diametral and axial flux profiles at 0923 hours on March 13,1973

139. IFA-239 diametral and axial flux profiles at 1609 hours on March 13,1973

140. IFA-239 diametral and axial flux profiles at 1625 hours on March 13,1973

141. IFA-239 diametral and axial flux profiles at 1721 hours on March

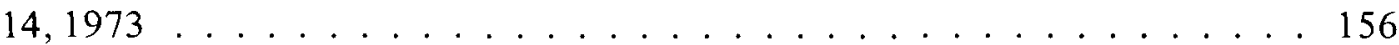

142. IFA-239 diametral and axial flux profiles at 1734 hours on March

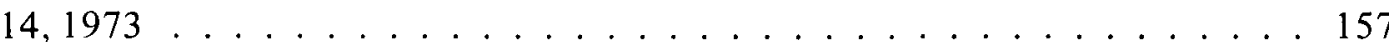

143. IFA-239 diametral and axial flux profiles at 2212 hours on March $14,1973 \ldots \ldots \ldots \ldots 158 \ldots \ldots \ldots \ldots \ldots$

144. IFA-239 diametral and axial flux profiles at 2220 hours on March $14,1973 \ldots \ldots \ldots \ldots \ldots \ldots$

145. IFA-239 diametral and axial flux profiles at 0001 hours on March $15,1973 \ldots \ldots \ldots \ldots \ldots$

146. IFA-239 diametral and axial flux profiles at 0009 hours on March 15,1973

147. IFA-239 diametral and axial flux profiles at 0108 hours on March

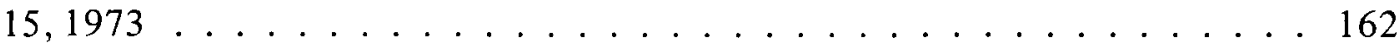

148. IFA-239 diametral and axial flux profiles at 0121 hours on March 15,1973

149. IFA-239 diametral and axial flux profiles at 1258 hours on March

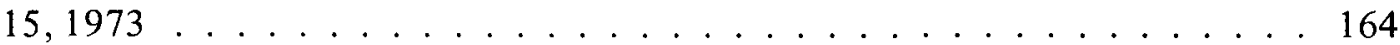

150. IFA-239 diametral and axial flux profiles at 1312 hours on March

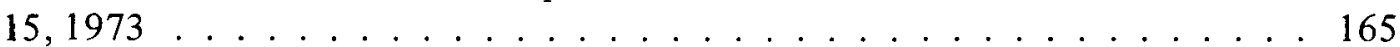


151. IFA-239 diametral profile at 0930 hours on March 16,1973 . . . . . . 166

152. IFA-239 diametral profile at 0942 hours on March 16,1973 . . . . . . . . 167

153. IFA-239 elongation history from March 1973 through April $1973 \ldots \ldots$. . . . . 168

154. IFA-239 elongation history from May 1973 through June $1973 \ldots$. . . . . . 169

155. IFA-239 elongation history from July 1973 through August $1973 \ldots$. . . . . 170

156. IFA-239 elongation history from September 1973 through December 1973 . . 171

157. IFA-239 elongation history from January 1974 through February 1974 . . . 172

158. IFA-239 elongation history from March 1974 through April 1974 . . . . . . . 173

A-1. Fuel pellet autoradiography . . . . . . . . . . . . . . . . 183

A-2. Fuel pellet metallography - radial section . . . . . . . . . . . . . . . . 184

A-3. Fuel pellet metallography -- axial section . . . . . . . . . . . . 185

A-4. Lot 84003 hydride orientation . . . . . . . . . . . . . . . . 190

A-5. Lot 74001 hydride orientation .................. . 191

A-6. Typical weld metallography of cladding . . . . . . . . . . . . . 196

A-7. Dimensional profile of $\operatorname{Rod} \mathrm{AG} \ldots \ldots . \ldots 199$

A-8. Dimensional profile of $\operatorname{Rod} \mathrm{AH} \ldots \ldots . \ldots . \ldots 200$

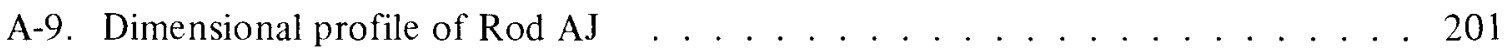

A-10. Dimensional profile of $\operatorname{Rod} \mathrm{AK} \ldots \ldots . \ldots 202$

A-11. Dimensional profile of $\operatorname{Rod} \mathrm{AM} \ldots \ldots . \ldots . \ldots 203$

A-12. Dimensional profile of $\operatorname{Rod} \mathrm{AO} \ldots \ldots . \ldots . \ldots 204$

B-1. Calibration curve at $240^{\circ} \mathrm{C}$ for the elongation sensor on IFA-226 Test

$\operatorname{Rod} \mathrm{AG} \ldots \ldots \ldots \ldots \ldots . \ldots \ldots$

B-2. Calibration curve at $240^{\circ} \mathrm{C}$ for the elongation sensor on IFA-226 Test

$\mathrm{Rod} \mathrm{AH} \ldots \ldots \ldots \ldots . \ldots \ldots 211$

B-3. Calibration curve at $240^{\circ} \mathrm{C}$ for the elongation sensor on IFA-226 Test

Rod AJ . . . . . . . . . . . . . . . . 212 
B-4. Calibration curve at $240^{\circ} \mathrm{C}$ for the elongation sensor on IFA-226 Test $\operatorname{Rod} \mathrm{AK} \ldots \ldots \ldots \ldots \ldots . \ldots \ldots . \ldots \ldots$

B-5. Calibration curve at $240^{\circ} \mathrm{C}$ for the elongation sensor on IFA-226 Test Rod AM . . . . . . . . . . . . . . . . . . 214

B-6. Calibration curve at $240^{\circ} \mathrm{C}$ for the elongation sensor on IFA-226 Test $\mathrm{Rod} \mathrm{AO} \ldots \ldots \ldots \ldots 215$

B-7. Calibration curve at $240^{\circ} \mathrm{C}$ for the elongation sensor on IFA-226 Test Rod B-6 . . . . . . . . . . . . . . . 216

B-8. Wiring diagram of a fuel centerline thermocouple . . . . . . . . . . 217

B-9. Calibration curves for the IFA-226 inlet and outlet flowmeters . . . . . . 218

B-10. Switch point consistency of the pressure transducer in Rod AA . . . . . . . 220

B-11. Switch point consistency of the pressure transducer in Rod AB . . . . . . 221

B-12. Switch point consistency of the pressure transducer in Rod AC . . . . . . . 222

B-13. Switch point consistency of the pressure transducer in Rod AD . . . . . . . . . 223

B-14. Switch point consistency of the pressure transducer in Rod AE . . . . . . . . 224

B-15. Calibration curve for the diameter gauge transformer $\ldots \ldots 228$

B-16. Calibration curve for the long range linear transformer . . . . . . . . . 229

\section{TABLES}

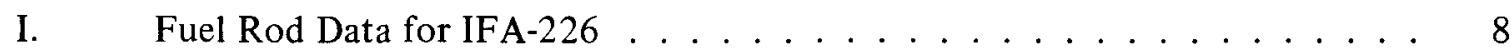

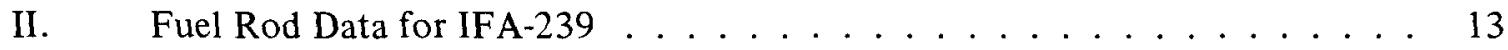

III. Internal Rod Pressure for IFA-226 from November 20, 1971 through August $28,1972 \ldots \ldots \ldots 21$

IV. Times When In-Pile Diametral Profile Data were Obtained . . . . . . . . 143

V. Operational Status of IFA-226 and IFA-239 Instrumentation as of

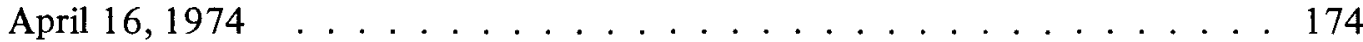

A-I. Pu Isotopic Content and Associated Burnup . . . . . . . . . . . . . . 178

A-II. Plutonium Nitrate Impurities . . . . . . . . . . . . . . . . . 179 
A-III. Depleted $\mathrm{UO}_{2}$ Powder Impurities . . . . . . . . . . . . . 180

A-IV. Isotope Content of Fuel Pellets ................. 181

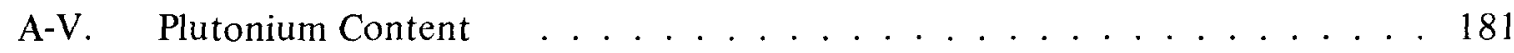

A-VI. Fuel Pellet Impurities . . . . . . . . . . . . . . . 182

A-VII. Description, Properties, and Test Results for Sandvik Cladding --

First Lot . . . . . . . . . . . . . . . . . 186

A-VIII. Description, Properties, and Test Results for Sandvik Cladding --

Second Lot . . . . . . . . . . . . . . . . . . . . . . 188

A-IX. Results of Physical and Chemical Analysis of Plain End Plug

Bar Stock . . . . . . . . . . . . . . . . . 192

A-X. Results of Chemical Analysis of Halden Instrumentation

Bar Stock ....................... 193

A-XI. Results of Physical and Chemical Analysis of Grooved End Plug

Bar Stock . . . . . . . . . . . . . . . . . . 194

A-XII. Fuel Pellet Data . . . . . . . . . . . . . . . . 197

A-XIII. Tube and Plenum Data . . . . . . . . . . . . . . 198

A-XIV. Finished Assembly Data . . . . . . . . . . . . . . . . 205

B-I. IFA-226 Neutron Detector Characteristics . . . . . . . . . 226 


\section{USNRC-OECD HALDEN PROJECT FUEL BEHAVIOR TEST PROGRAM -- EXPERIMENT DATA REPORT FOR TEST ASSEMBLIES \\ IFA-226 AND IFA-239}

\section{INTRODUCTION}

Understanding the performance of light-water reactor fuel under normal and accident conditions is a major objective of the United States Nuclear Regulatory Commission's (USNRC) reactor safety research program. An extensive program has been defined -centered on out-of-pile and in-pile experiments and their analyses - with the goal of verifying analytical codes. These codes are intended for use in predicting transient fuel performance during a wide range of accident types and conditions, at any time during the normal useful life of a fuel rod.

Analysis of fuel behavior during an accident depends critically upon knowledge of fuel rod conditions during normal (steady state) operation. Especially important are the temperature distributions of the fuel pellets, the internal gas pressure and composition, the amount of restructuring and cracking of the pellets, and the mechanical strains and irradiation damage in the cladding. All of these variables are affected by the rod design variables at beginning-of-life and, subsequently, by the degree of burnup and the power history.

This document presents the data which were obtained during the steady state irradiation of two test assemblies in the Halden Boiling Water Reactor (HBWR) located in Halden, Norway. Cladding elongation, fuel centerline temperature, rod internal pressure, and fuel rod diameter data are presented as functions of power and time for rods with various initial pellet-to-cladding gap sizes and fuel densities. These data will facilitate development of analytical models describing:

(1) Fuel pellet-cladding mechanical interactions as a function of power, burnup, fuel density, and initial pellet-cladding diametral gap

(2) Fuel density, pellet-cladding gap, and temperature effects on fission gas release and rod internal pressure

(3) Pellet-to-cladding gap, fuel density, and irradiation effects on the temperature of mixed oxide fuels

(4) Fuel rod axial and diametral strains as functions of power and burnup.

The instrumented fuel assemblies IFA-226 and IFA-239 were designed, fabricated, and initially irradiated in the HBWR by Nuclear Fuel Services, Incorporated (NFS) of Rockville, Maryland. In 1974, these two assemblies and all of their existing data were 
acquired from NFS by the USNRC. The continued use and management of these assemblies is being directed by Aerojet Nuclear Company under the USNRC's participation in the $\mathrm{OECD}^{[\mathrm{a}]}$ Halden reactor project.

Test assembly IFA-226 contains 12 mixed plutonium-uranium oxide fuel rods about 33 inches long arranged in two clusters. Irradiation of this assembly began November 24, 1971. The assembly contains six cladding extensometers (LVDTs) ${ }^{\text {[b] }}$, four fuel centerline thermocouples, five fuel rod internal pressure sensors, eight self-powered neutron detectors, and various thermal-hydraulic power calibration equipment. IFA-239 contains one mixed oxide test rod, one fuel rod diameter gauge (LVDT), one cladding extensometer, and various power sensors. Irradiation of IFA-239 began March 12, 1973.

Data which were obtained from beginning-of-life through April 16, 1974 (or until instrument failure) are presented in this report. During this time, IFA-226 and IFA-239 attained a burnup of about $20,000 \mathrm{MWd} / \mathrm{tU}$ and $12,300 \mathrm{MWd} / \mathrm{tU}$ (assembly average values), respectively.

Section II of this report describes the HBWR. Sections III and IV describe the designs of IFA-226 and IFA-239, respectively. Section V presents the data obtained from these assemblies. Appendix A describes the test rod fabrication processes, Appendix B describes the assembly and test rod instrumentation calibration procedures, and Appendix $\mathrm{C}$ describes the data reduction techniques.

[a] OECD - Organization for Economic Cooperation and Development.

[b] Linear Variable Differential Transformer. 


\section{HALDEN BOILING WATER REACTOR}

Operation of the Halden Boiling Water Reactor is sponsored through an international agreement among the appropriate government agencies of Norway, Denmark, Finland, Italy, Japan, Germany, the Netherlands, Sweden, and the USA. The Electric Power Research Institute, USA, is also a member. Combustion Engineering, Inc., General Electric Company, United States Nuclear Regulatory Commission, and Companhia Brasileira de Tecnologia Nuclear, Brazil, participate as associated parties.

The reactor is operated with a water temperature of $240^{\circ} \mathrm{C}$ and a pressure of $3.45 \mathrm{x}$ $10^{6} \mathrm{~N} / \mathrm{m}^{2}$. The core consists of about 60 assemblies. Of these assemblies, 15 to 20 are either driver assemblies or nonfueled instrumented assemblies. The remaining are test assemblies fabricated by either the Halden project or the various members.

The majority of the test assemblies are cooled by natural circulation of nearly saturated heavy water. The specific hydraulic conditions depend upon assembly design and amount of inlet throttling (most of the test assemblies are cooled by fluid which acquires a significant void fraction while progressing up the flow channel). A limited number of high power Halden test assemblies are operated with forced circulation of heavy water subcooled 10 to $15^{\circ} \mathrm{C}$. The region between test assemblies serves as the return flow path for the coolant. Typical reactor steady state operating conditions are:

Core Power
Coolant Pressure
Coolant Inlet Temperature
Coolant Saturation Temperature
Natural Circulation Flow Rate
Forced Circulation Flow Rate
Axial Power Peaking Factor
Thermal Flux
Fast Flux $(>1 \mathrm{MeV})$
Core Active Length
Maximum Test Assembly Outside Diameter
Core Configuration

Core Power

Coolant Inlet Temperature

Coolant Saturation Temperature

Natural Circulation Flow Rate

Axial Power Peaking Factor

Thermal Flux

Fast Flux $(>1 \mathrm{MeV})$

Maximum Test Assembly Outside Diameter

Core Configuration

$$
\begin{aligned}
& 12 \mathrm{MW} \\
& 3.45 \times 10^{6} \mathrm{~N} / \mathrm{m}^{2} \\
& 237^{\circ} \mathrm{C} \\
& 240^{\circ} \mathrm{C} \\
& 0.5 \text { to } 21 / \mathrm{sec} \\
& 2 \text { to } 41 / \mathrm{sec} \\
& 1.2 \text { to } 1.7 \\
& 3 \text { to } 3.6 \times 10^{13} \mathrm{n} / \mathrm{cm}^{2}-\mathrm{sec} \\
& 5 \times 10^{11} \mathrm{n} / \mathrm{cm}^{2}-\mathrm{sec} \\
& 1.7 \mathrm{~m} \\
& 73 \mathrm{~mm}
\end{aligned}
$$

open hexagonal lattice.

IFA-226 and IFA-239 were cooled by natural circulation of the heavy water except during power calibration (the first few days of operation) when forced circulation of subcooled coolant was used. Figure 1 shows the core locations of IFA-226 and IFA-239.

The HBWR normally operates on a four-month schedule having three months of irradiation followed by one month of shutdown for repair and exchange of test assemblies. However, special tests and emergency repairs often require brief shutdowns of the reactor during the three-month irradiation periods. 


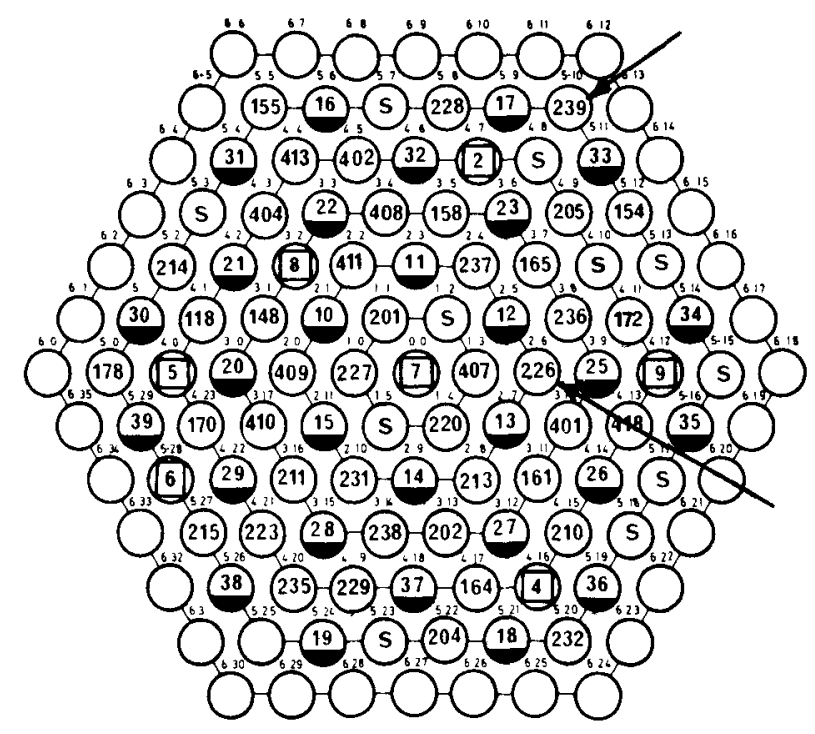

\begin{tabular}{|l|l|l|l|}
\hline HBWR IY CORE LOADING NO 14 & Date March-74 \\
\hline (19) & Control rod (CS 19) & total 29 \\
\hline (202) & Instrumented fuel assembly (IFA- 202) &. & 43 \\
\hline (5) Standard third charge assembly &, & 11 \\
\hline (3) & Neutron detector rig (PEI-303) & 7 \\
\hline
\end{tabular}

Fig. 1 HBWR Core Loading 14 (March 1974). 


\section{IFA-226 DESIGN}

This section presents a general description of the IFA-226 test rod geometry, the steady state full power coolant conditions, and the basic in-pile assembly instrumentation.

\section{GENERAL DESCRIPTION}

The instrumented fuel assembly IFA-226 consists of a vertically stacked train of two clusters of six fuel rods each. Each cluster is about 3.1 feet in length and 2.8 inches in diameter. The rods within each cluster are arranged in a hexagonal lattice. A diagram of IFA-226 is presented in Figure 2 and a schematic diagram of each of the four types of test rods within the assembly is shown in Figure 3.

As mentioned, the test assembly is generally cooled by natural circulation of heavy water. When the assembly is operating at high, steady state power levels, the nominal inlet flow rate of the coolant is about $2 \mathrm{l} / \mathrm{sec}$, and the coolant inlet temperature is about $237^{\circ} \mathrm{C}$. The nominal coolant pressure and the saturation temperature are $3.45 \times 10^{6} \mathrm{~N} / \mathrm{m}^{2}$ and $240^{\circ} \mathrm{C}$, respectively.

The test rod fuel is fabricated from recycled plutonium oxide powder which is blended with depleted $\left(0.20 \mathrm{wt} \% \mathrm{U}^{235}\right)$ uranium oxide powder. This mixed oxide material (9.5 wt $\% \mathrm{PuO}_{2}$ ) is pressed and sintered into pellet form and clad with zircaloy 4 . A complete fabrication history is presented in Appendix A and the final pellet and rod dimensions are listed in Table I. The dimensions, except for length, are typical of those of pressurized water reactor reload fuel.

\section{INSTRUMENTATION}

The experimental data are obtained from the following in-pile sensors:

(1) elongation sensors

(2) pressure transducers

(3) fuel centerline thermocouples

(4) self-powered neutron detectors.

The pressure transducers and elongation sensors were manufactured, attached to the fuel pins, and calibrated at the Halden Project. The fuel centerline thermocouples were manufactured by Continental Sensing, Inc., of Melrose Park, Illinois, and were installed in the test pins by the Halden Project. The self-powered neutron detectors were obtained from AB Atomenergi of Sweden and are located among the test rods at selected axial and radial positions. Results of the instrument calibration test are reported in Appendix B. 


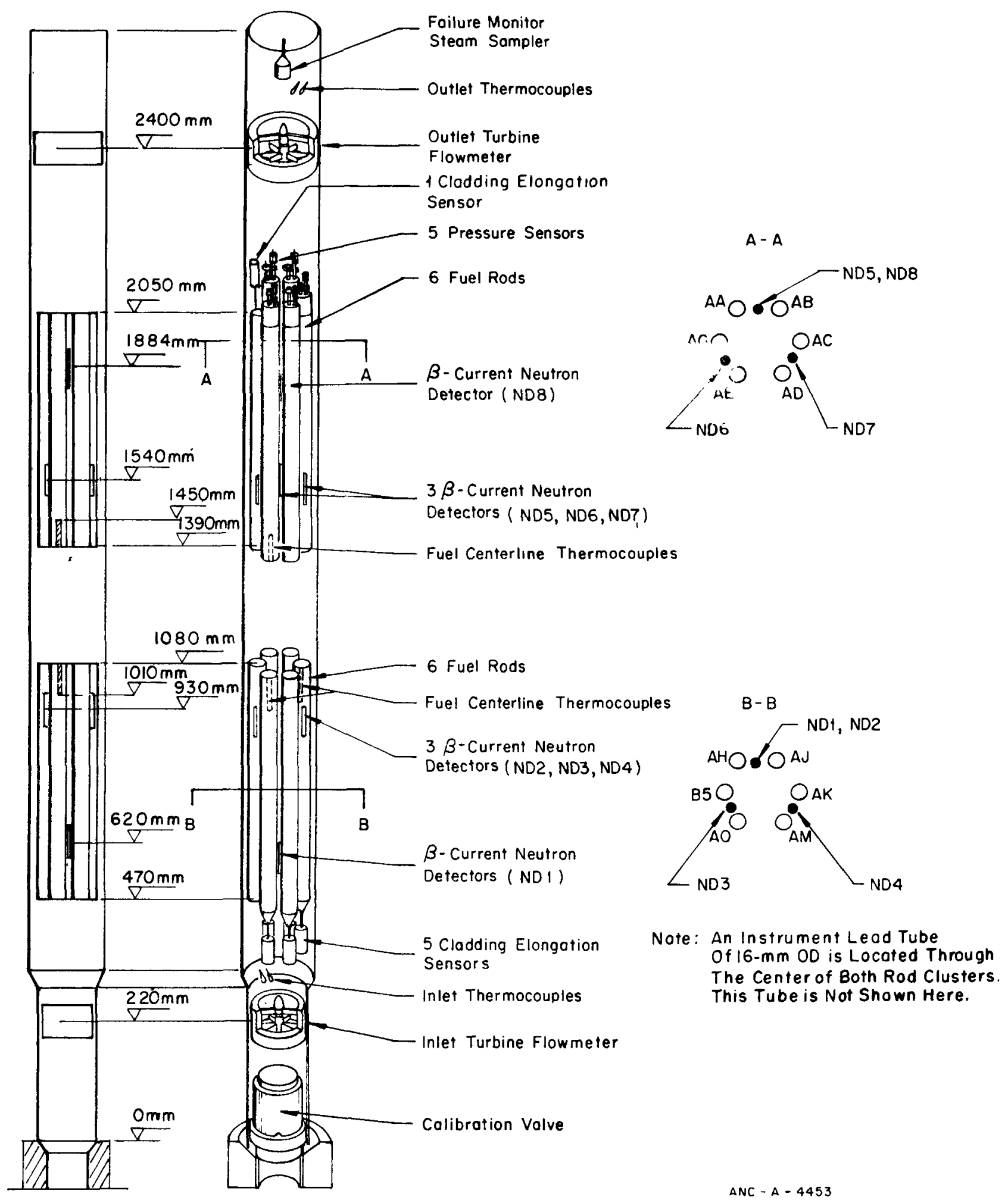

Fig. 2 Diagram of Instrumented Fuel Assembly 226. 

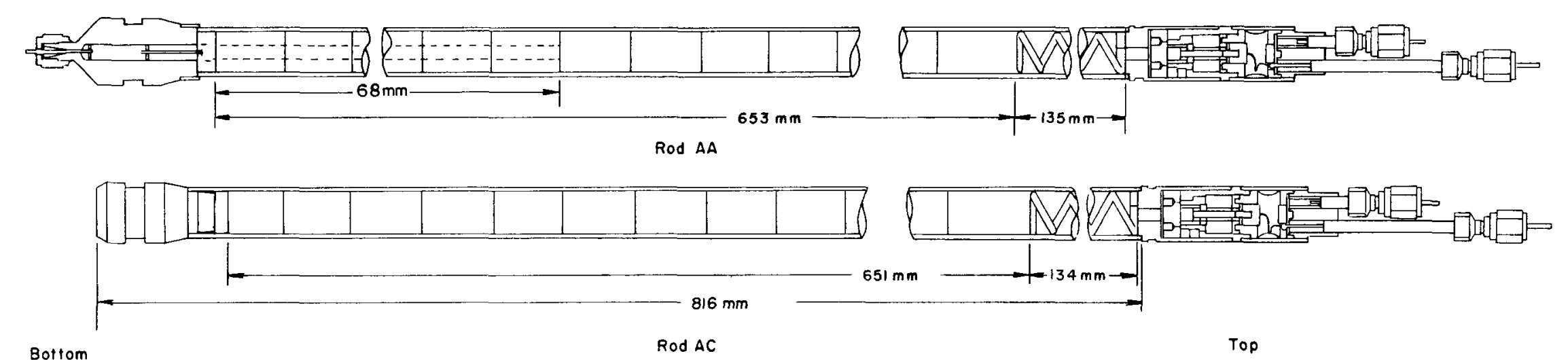

Bottom

Top
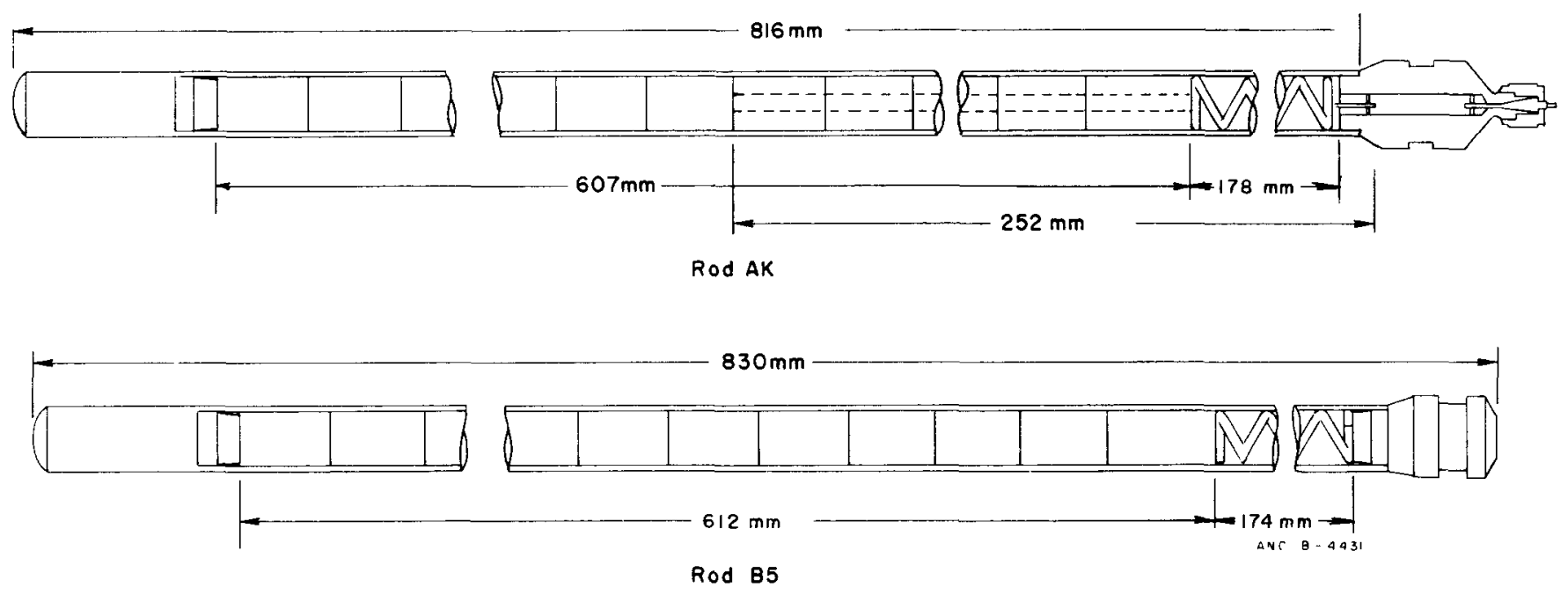

Fig. 3 Schematic diagram of four types of IFA-226 test rods. 
TABLE I

FUEL ROD DATA FOR IFA-226

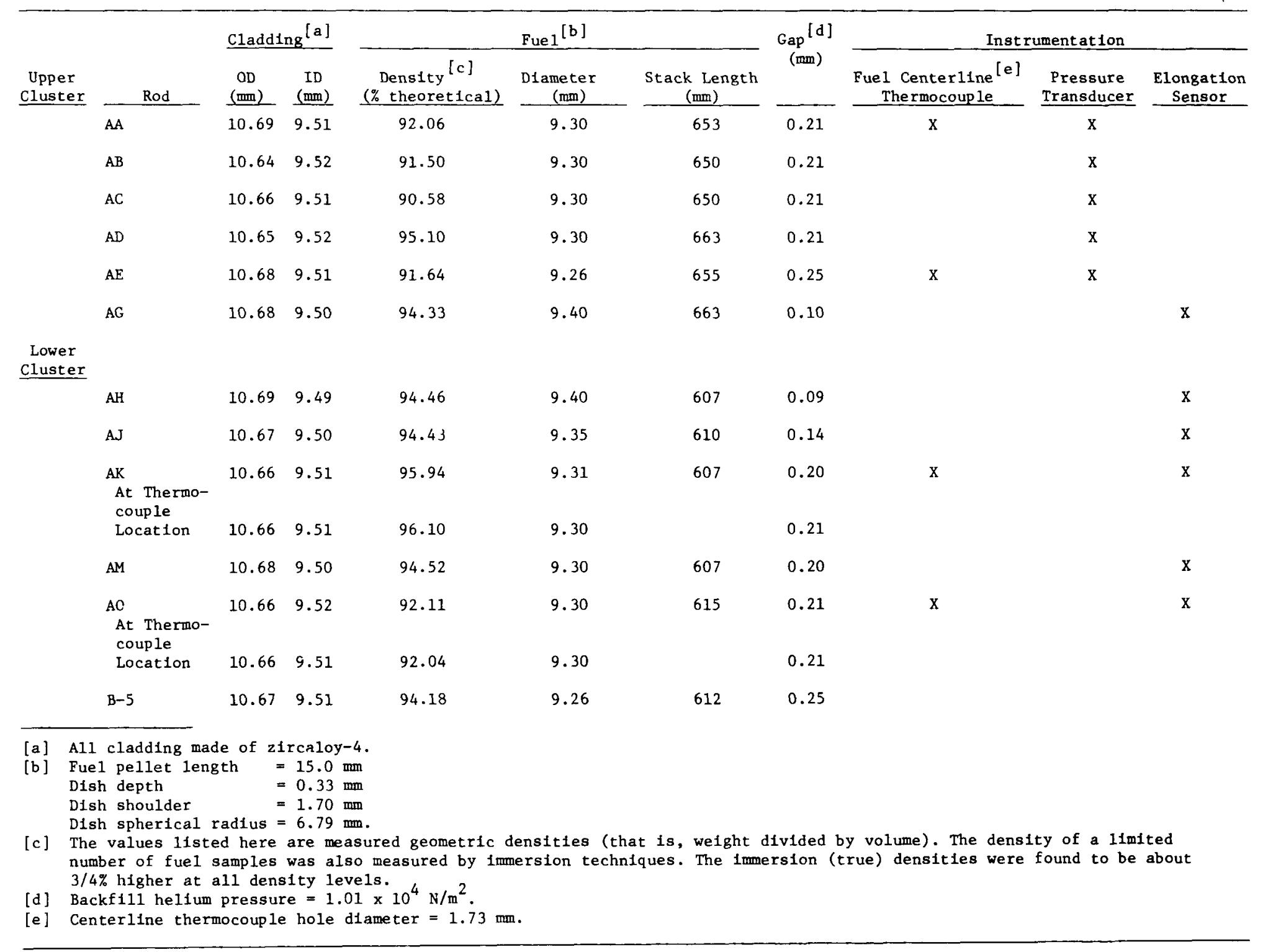




\section{$2.1 \quad$ Elongation Sensors}

Linear variable differential transformers are used to measure the cladding elongation of six of the IFA-226 test rods. Each differential transformer (elongation sensor) consists of coaxial primary and secondary coils with a movable ferritic core in the center. The core is spring-loaded against the end of the fuel rod. Displacement of the core due to cladding axial movement influences the voltage induced in the secondary coils and provides a readable signal. A drawing of the elongation sensor used in IFA-226 is shown in Figure 4.

Five of the elongation sensors are placed on the lower cluster rods and one sensor is placed on an upper cluster rod. The elongation sensors are concentrated in the bottom cluster because the neutron flux in IFA-226 is skewed toward the bottom of the core and, therefore, the highest power and the hottest pellets are located in the lower cluster near the top of the fuel stack. As a result, the transition from free thermal expansion of the cladding-to-fuel-induced thermal expansion is more abrupt. In the top cluster, the hottest pellet in each rod is at the bottom of the fuel stack, and the transition is more gradual.

\section{$2.2 \quad$ Pressure Transducers}

Five fuel rods in the upper cluster of IFA-226 are instrumented with Halden Project internal pressure transducers. The sensing mechanism in the transducer is a thin platinum membrane which is exposed on one side to internal rod gas of unknown pressure, whereas the other side is exposed to externally-controlled helium gas pressure. The pressure balance across the membrane is indicated by the opening of an electrical circuit between the membrane and a contact normally resting against the membrane. Figure 5 presents a schematic diagram of a pressure transducer.

\subsection{Fuel Centerline Thermocouples}

Two of the IFA-226 lower cluster test rods which are instrumented with elongation sensors, and two of the upper cluster test rods which are instrumented with fission gas pressure sensors, also contain fuel centerline thermocouples. These thermocouples are composed of $\mathrm{W} / 3 \mathrm{wt} \% \mathrm{Re}-\mathrm{W} / 25 \mathrm{wt} \% \mathrm{Re}$ with $\mathrm{BeO}$ insulation and molybdenum sheathing. The ends of the thermocouples in the upper cluster are located approximately $0.068 \mathrm{~m}$ above the bottom of the respective fuel stacks. The ends of the two thermocouples in the lower cluster are located approximately $0.246 \mathrm{~m}$ below the top of the respective plenums at essentially the rod axial peak power position.

\subsection{Self-Powered Neutron Detectors}

The assembly power is monitored by eight beta-current, self-powered neutron detectors. Each detector utilizes vanadium as the emitter.

Of the eight detectors, four are axially distributed within the two clusters in order to measure the axial flux distribution. Two additional detectors are mounted within each cluster to facilitate measurement of the radial flux distribution. The locations of the eight neutron detectors are shown in Figure 2. 


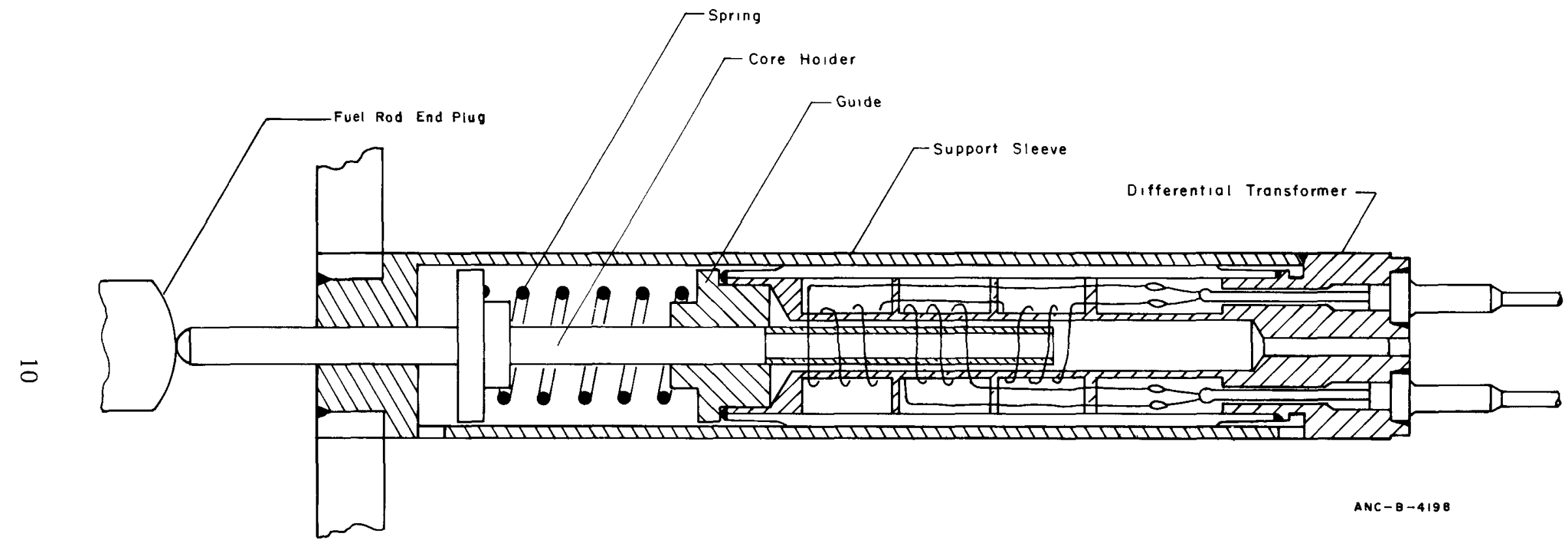

Fig. 4 Schematic diagram of a cladding elongation sensor. 


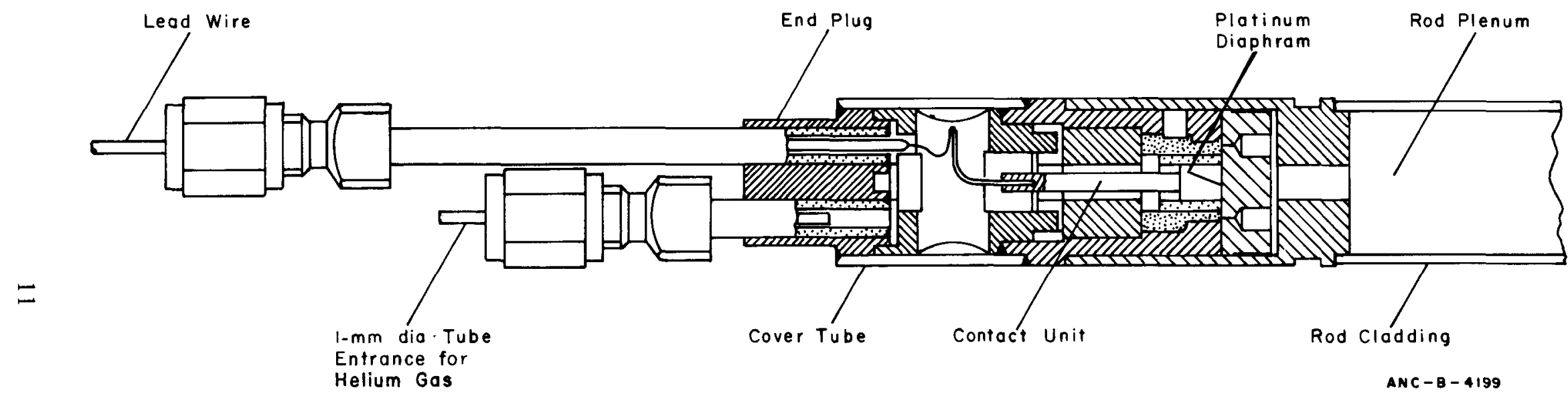

Fig. 5 Schematic diagram of an IFA-226 pressure sensor. 


\subsection{Additional Instrumentation}

In addition to the sensors mentioned, two turbine flowmeters and four coolant thermocouples are built into the assembly. A flowmeter and two thermocouples are located at the inlet and the outlet of the coolant flow channel. These instruments are required in order to calibrate the neutron detectors using thermal-hydraulic techniques (Appendix C). 


\section{IFA-239 DESIGN}

IFA-239 is a single-rod test assembly which has been used to determine the axial and diametral strains of spare IFA-226 Rod B6. A diagram of IFA-239 is presented in Figure 6. The dimensions of Test Rod B6 are listed in Table II and in Appendix A.

TABLE II

FUEL ROD DATA FOR IFA-239

\begin{tabular}{|c|c|c|c|c|c|}
\hline \multicolumn{2}{|c|}{ Cladding $^{[a]}$} & \multicolumn{3}{|c|}{ Fue1 [b] } & \multirow{2}{*}{$\begin{array}{l}\operatorname{Gap}^{[\mathrm{d}]} \\
(\mathrm{mil}) \\
\end{array}$} \\
\hline $\begin{array}{c}\text { OD } \\
(\mathrm{mm})\end{array}$ & $\begin{array}{c}\text { ID } \\
(\mathrm{mm}) \\
\end{array}$ & $\begin{array}{c}\text { Density }[\mathrm{c}] \\
(\% \text { theoretical }) \\
\end{array}$ & $\begin{array}{c}\text { Diameter } \\
(\mathrm{mm})\end{array}$ & $\begin{array}{c}\text { Stack Length } \\
(\mathrm{mm}) \\
\end{array}$ & \\
\hline 10.69 & 9.51 & 95.30 & 9.40 & 607 & 0.11 \\
\hline \multicolumn{6}{|c|}{$\begin{array}{l}\text { [a] Cladding made of zircaloy }-4 . \\
\text { [b] Fuel pellet length }=15.0 \mathrm{~mm} \\
\begin{array}{ll}\text { Dish depth } & =0.33 \mathrm{~mm} \\
\text { Dish shoulder } & =1.70 \mathrm{~mm}\end{array} \\
\begin{array}{l}\text { Dish spherical radius }=6.79 \mathrm{~mm} . \\
\text { [c] Value listed is measured geometric density (that is, weight divided } \\
\text { by volume). }\end{array} \\
\text { [d] Backfill helium pressure }=1.01 \times 10^{4} \mathrm{~N} / \mathrm{m}^{2} .\end{array}$} \\
\hline
\end{tabular}

IFA-239 is cooled by natural circulation of heavy water. When the assembly is operating at high, steady state power levels, the nominal inlet flow rate of the coolant is approximately $0.5 \mathrm{l} / \mathrm{sec}$. The coolant pressure and saturation temperature are $3.45 \times 10^{6}$ $\mathrm{N} / \mathrm{m}^{2}$ and $240^{\circ} \mathrm{C}$, respectively.

\section{INSTRUMENTATION}

Experimental data have been obtained from three principal types of in-pile instrumentation: a diametral profile sensor, a cladding axial elongation sensor, and self-powered neutron detectors.

\subsection{Diametral Profile Sensor}

The diametral profile of the B6 test rod is determined from data generated by two instruments: a diameter gauge (linear variable differential transformer) and an axial position indicator (long range linear transformer) which is attached to the diameter gauge. A schematic diagram of the diametral profile sensor is shown in Figure 7. Diagrams of the diameter gauge and the long range linear transformer are presented in Figures 8 and 9, respectively. 


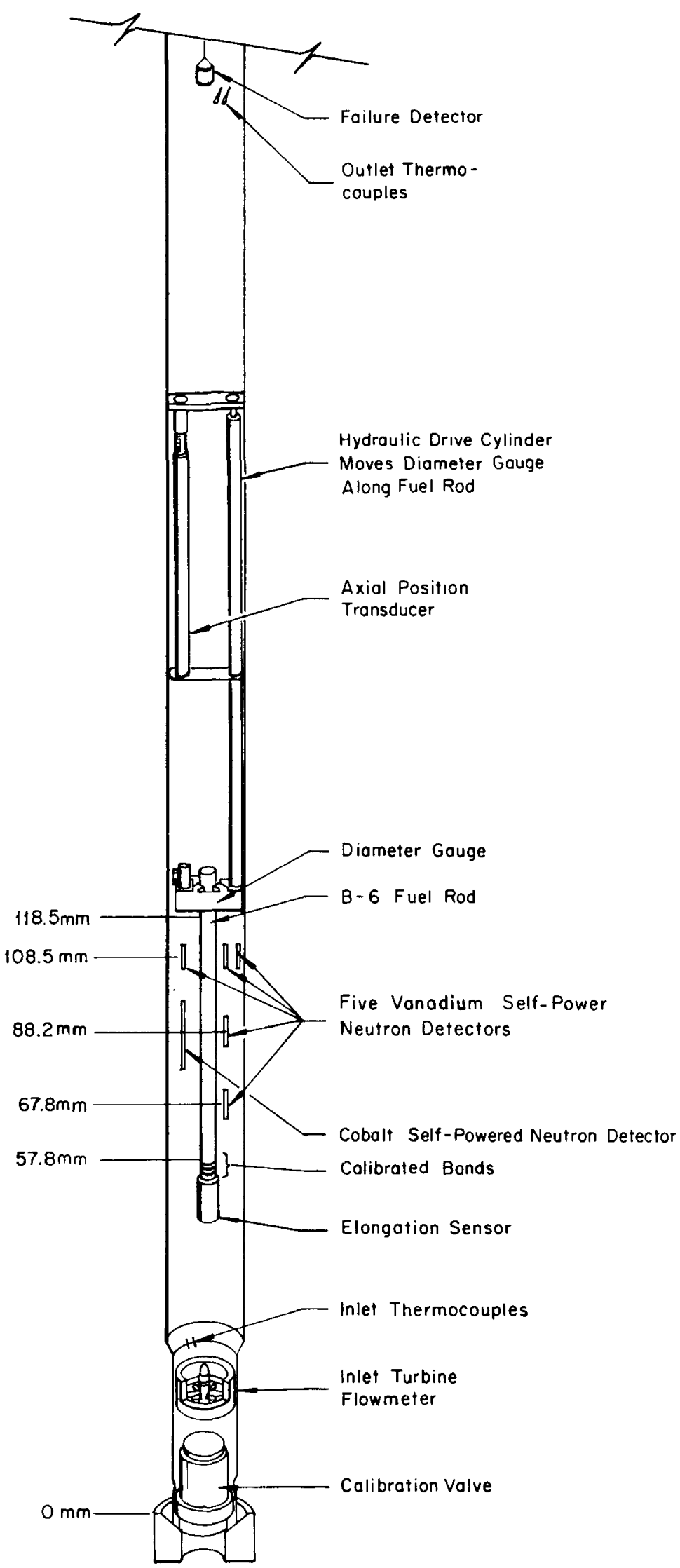

ANC $-A-4441$

Fig. 6 Diagram of Instrumented Fuel Assembly 239. 


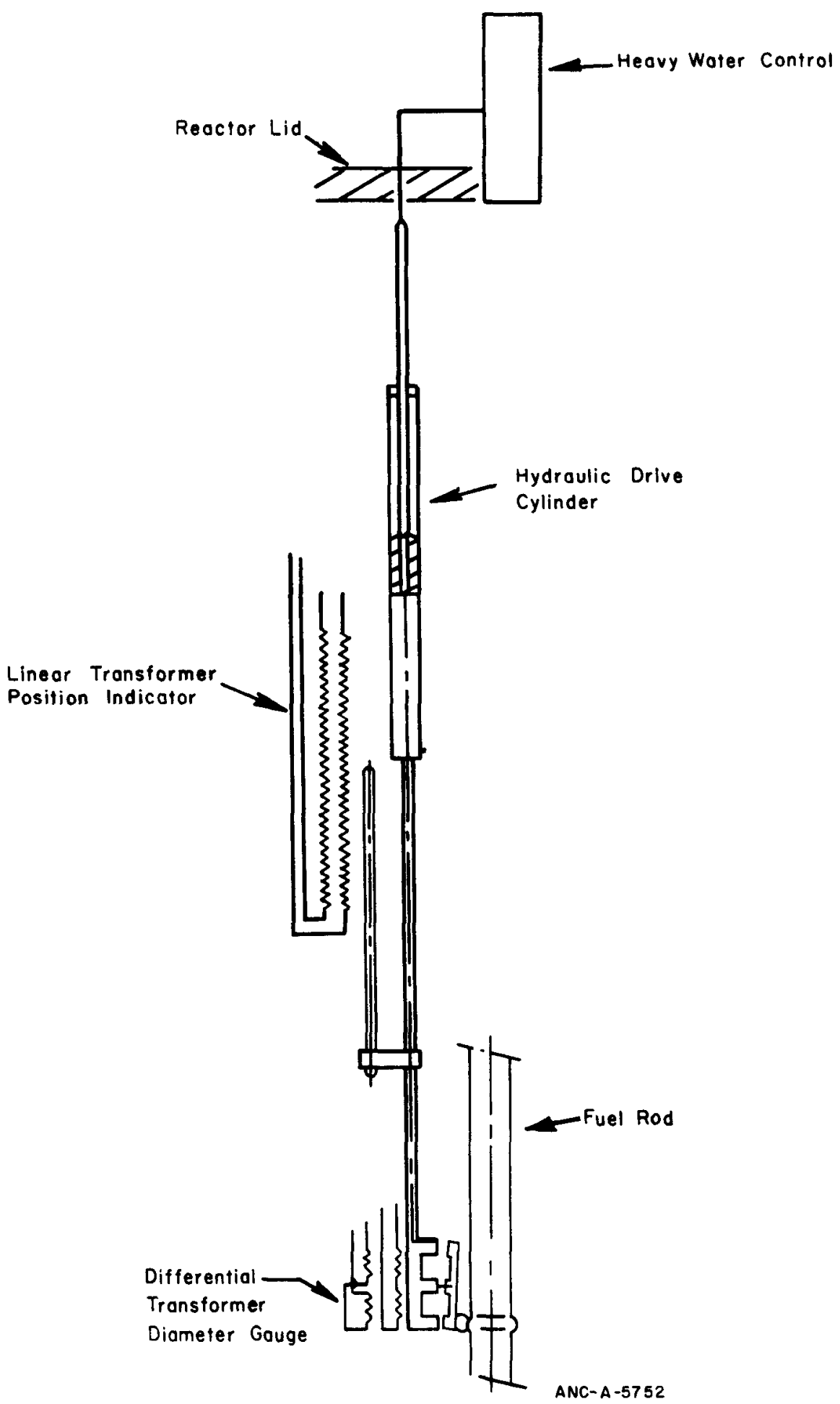

Fig. 7 Schematic diagram of the IFA-239 diametral profile sensor. 


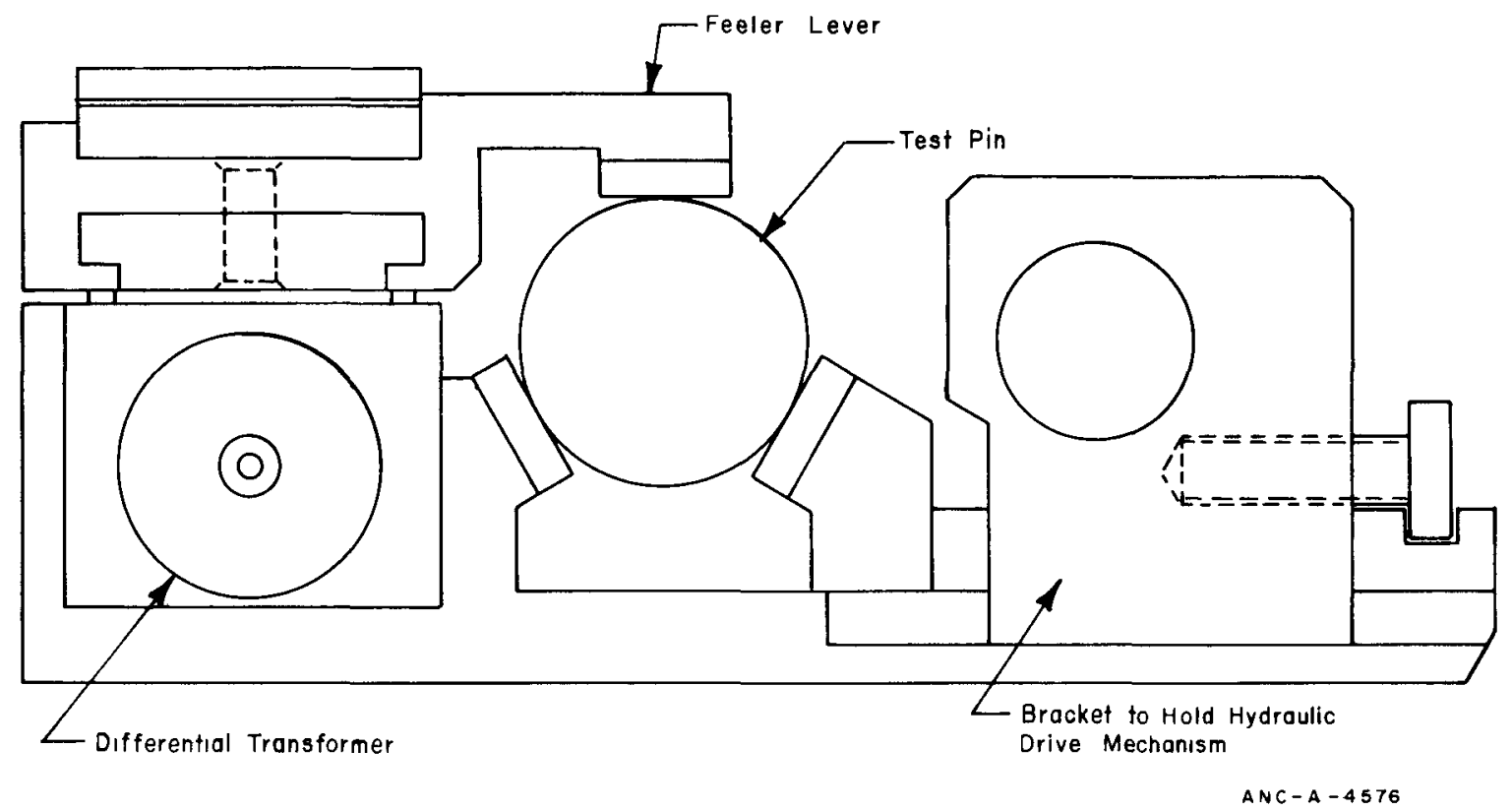

Fig. 8 Schematic diagram of the IFA-239 diameter gauge. 


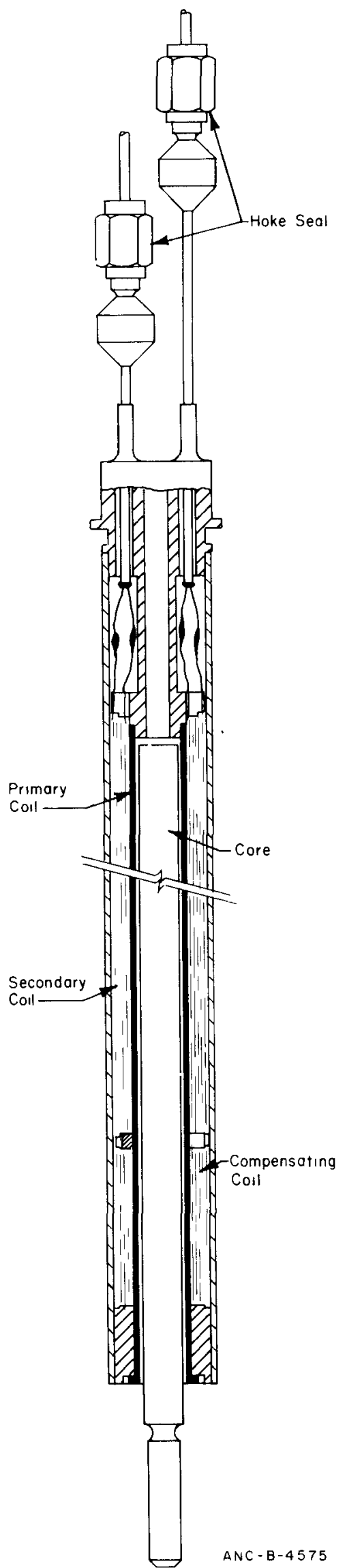

Fig. 9 Schematic diagram of the IFA-239 long range linear transformer. 
Diametral profile data were not obtained on a regularly scheduled basis, but rather, the data were obtained upon demand and primarily during the startup period. When data were desired, the diameter gauge was moved slowly and continuously along the length of the test rod and the measured rod diameter and the corresponding axial elevation were simultaneously recorded. The diameter gauge traveled the entire length of the test rod in about four to six minutes. This time period was small relative to changes of the assembly power level.

Whenever the diameter gauge made a full length sweep of the test rod, the diameter of three calibrated bands was also measured. The bands had been machined during assembly fabrication, onto the structure supporting the lower end of the test rod. Measurement of these bands during the experiment serves as an additional source of calibration data to assure the correct conversion of the diametral profile data to usable units.

\subsection{Elongation Sensor}

The axial elongation sensor used in IFA-239 is identical to the sensors which are used in IFA-226 and are described in Section III.

\subsection{Self-Powered Neutron Detectors}

Six self-powered neutron detectors are distributed axially and radially about the test rod. Of the six detectors, five are vanadium self-powered detectors which are identical to those used if IFA-226. The remaining neutron detector uses cobalt as the emitter. The cobalt detector did not provide reliable data after beginning-of-life operation.

\subsection{Additional Instrumentation}

An inlet turbine flowmeter and thermocouples located at the inlet and the outlet of the flow channel were used to calibrate the neutron detectors using thermal-hydraulic techniques. A description of the calibration and data reduction procedures is presented in Appendix C. 


\section{DATA PRESENTATION}

The experimental data that were obtained from IFA-226 and IFA-239 are presented in the following figures. These data cover the period from beginning-of-life (November 24, 1971 and March 12, 1973, respectively) through April 16, 1974.

Data from the elongation sensors, neutron detectors, and fuel centerline thermocouples were collected at regular intervals using an IBM-1800 data collection system. During steady state full power operation, these data were automatically collected every six hours. When a change of power was occurring, the data were collected as often as every 15 minutes. The pressure data from IFA-226 and the diametral profile data from IFA-239 were obtained on a demand basis. The frequency of data collection varied from a few minutes to several months.

The data points that are shown on all figures have been connected by a curve or a series of curves in order to more clearly indicate the trend of the data. When data were not available during operating periods, a curve or set of curves were drawn to represent the best estimate of the missing data.

Prior to the loading of IFA-226 and IFA-239 into the HBWR, the instrumentation in these assemblies was calibrated in order to ensure that accurate, reproducible data could be obtained. The results of the instrument calibration are presented in Appendix B.

\section{PRESENTATION OF DATA FROM IFA-226}

The data obtained from the IFA-226 instrumentation are presented in Figures 10 through 128. Processing and analysis of the elongation sensor data, fuel centerline thermocouple data, and fission gas pressure data were performed to the extent necessary to assure that the data are understandable, reasonable, and correct. However, no effort was made to correct the thermocouple readings for the effects of neutron irradiation. The neutron detector data have been interpreted and analyzed in order to provide assembly and individual rod power history and flux profile data. The method which was used to analyze the neutron detector data is presented in Appendix C.

The elongation histories of Test Rods AG, $\mathrm{AH}, \mathrm{AJ}, \mathrm{AK}, \mathrm{AM}$, and $\mathrm{AO}$ are presented in Figures 10 through 19. The fuel centerline temperature histories of Rods AA, AE, AO, and $A K$ are shown in Figures 20 through 28. Also included in these figures is the assembly power history as determined from the neutron detector data. Since all thermocouples had failed by December 1973, no temperature data are shown for the operating period from December 1973 through April 1974.

The neutron detector data were used to determine the test pin power history. The peak power histories of the rods which are equipped with elongation sensors are presented 
in Figures 29 through 40. The local power histories of Rods AA, AE, AO, and AK at the thermocouple location are given in Figure 41, which covers the period from beginning-of-life through January 1972. The average power histories of the rods equipped with pressure sensors are presented in Figures 42 through 54.

The fission gas pressure data for Rods $\mathrm{AA}, \mathrm{AB}, \mathrm{AC}, \mathrm{AD}$, and $\mathrm{AE}$ are presented in Figures 55 through 59, and also in Table III. As can be seen, additional data which were obtained after April 16, 1974, have been added to Figure 55 for completeness. In order to present the fission gas pressure history in a more meaningful manner, only the data which were obtained at high assembly power levels (between 250 and $300 \mathrm{~kW}$ ) are shown in Figure 55. The data obtained at lower power levels have been omitted. The use of a range of assembly power values rather than a single value was necessary because fission gas pressure data were not frequently obtained at any single high power level throughout the lifetime of the assembly.

In order to increase the usefulness of the elongation sensor and fuel centerline temperature data, Figures 60 through 72 present rod elongation versus peak rod power during various time intervals. Also, Figures 73 through 95 present fuel centerline temperature versus rod power at the thermocouple location during various time intervals. The elongation sensor and fuel centerline temperature data which are shown on these graphs were obtained from the elongation and temperature history graphs (Figures 10 through 28).

The last group of graphs which have been included for IFA-226 show the axial flux profile of the assembly at various times throughout the lifetime. These profiles are presented in Figures 96 through 128. In order to determine the cluster axial flux profiles from these figures, note should be taken of the fact that the top and bottom of the lower cluster fuel are located at elevations of 42.6 and 18.6 inches, respectively. The top and bottom of the upper cluster fuel are located at elevations of 80.6 and 54.7 inches, respectively. 
TABLE III

INTERNAL ROD PRESSURE FOR IFA-226

FROM NOVEMBER 20, 1971 THROUGH AUGUST 28, 1972

\begin{tabular}{|c|c|c|c|c|c|c|c|c|c|}
\hline \multirow{3}{*}{1971} & \multirow[b]{2}{*}{ Date } & \multirow{3}{*}{$\begin{array}{l}\text { Time } \\
\frac{(\mathrm{hr})}{1730}\end{array}$} & \multirow{3}{*}{$\frac{\begin{array}{c}\text { Moderator } \\
\text { Temperature }\left({ }^{\circ} \mathrm{C}\right)\end{array}}{115}$} & \multirow{3}{*}{$\begin{array}{c}\text { Assembly } \\
\text { Power }(\mathrm{kW}) \\
0\end{array}$} & \multicolumn{5}{|c|}{ Internal Rod Pressure (atm-gauge) } \\
\hline & & & & & \multirow{2}{*}{$\frac{\overline{A A}}{0.40}$} & \multirow{2}{*}{$\frac{\mathrm{AB}}{0.39}$} & \multirow{2}{*}{$\frac{\mathrm{AC}}{0.30}$} & \multirow{2}{*}{$\begin{array}{l}\frac{A D}{\text { Valve }} \\
\text { Closed }\end{array}$} & \multirow{2}{*}{$\frac{\mathrm{AE}}{0.31}$} \\
\hline & November 20 & & & & & & & & \\
\hline & November 21 & 0200 & 150 & 0 & 0.50 & 0.43 & 0.38 & $\begin{array}{l}\text { Valve } \\
\text { Closed }\end{array}$ & 0.37 \\
\hline & November 21 & 1030 & 192 & 0 & 0.87 & 0.78 & 0.78 & $\begin{array}{l}\text { Valve } \\
\text { Closed }\end{array}$ & 0.75 \\
\hline & November 23 & 1300 & 209 & 0 & 0.92 & & 0.81 & $\begin{array}{l}\text { Valve } \\
\text { Closed }\end{array}$ & 0.89 \\
\hline & November 23 & 2355 & 240 & 5 & 1.20 & 1.10 & 1.02 & $\begin{array}{l}\text { Valve } \\
\text { Closed }\end{array}$ & 1.05 \\
\hline & November 24 & 1220 & 240 & 47 & 1.12 & 1.02 & 0.97 & $\begin{array}{l}\text { Valve } \\
\text { Closed }\end{array}$ & 0.90 \\
\hline & November 24 & 1430 & 240 & 75 & 1.38 & 1.29 & 1.23 & $\begin{array}{l}\text { Valve } \\
\text { Closed }\end{array}$ & 1.03 \\
\hline & November 24 & 1715 & 240 & 115 & 1.22 & 1.14 & 1.04 & $\begin{array}{l}\text { Valve } \\
\text { Closed }\end{array}$ & 0.83 \\
\hline & November 24 & 1920 & 240 & 197 & 1.21 & 1.15 & 1.04 & $\begin{array}{l}\text { Valve } \\
\text { Closed }\end{array}$ & 0.89 \\
\hline & November 24 & 2130 & 240 & 246 & 1.40 & 1.32 & 1.23 & $\begin{array}{l}\text { Valve } \\
\text { Closed }\end{array}$ & 1.03 \\
\hline & November 24 & 2350 & 240 & 262 & 1.34 & 1.31 & 1.23 & $\begin{array}{l}\text { Valve } \\
\text { Closed }\end{array}$ & 1.10 \\
\hline & November 25 & 0250 & 240 & 256 & 1.47 & 1.43 & 1.32 & $\begin{array}{l}\text { Valve } \\
\text { Closed }\end{array}$ & 1.13 \\
\hline & November 25 & 0400 & 240 & 251 & 1.37 & 1.32 & 1.23 & $\begin{array}{l}\text { Valve } \\
\text { Closed }\end{array}$ & 1.04 \\
\hline & November 25 & 1030 & 240 & 249 & 1.44 & 1.32 & 1.22 & $\begin{array}{l}\text { Valve } \\
\text { Closed }\end{array}$ & 1.12 \\
\hline & November 25 & 1540 & 240 & 203 & 1.31 & 1.24 & 1.14 & $\begin{array}{l}\text { Valve } \\
\text { Closed }\end{array}$ & 0.97 \\
\hline & November 25 & 1715 & 240 & 181 & 1.37 & 1.35 & 1.33 & $\begin{array}{l}\text { Valve } \\
\text { Closed }\end{array}$ & 1.10 \\
\hline & November 25 & 1940 & 240 & 160 & 1.16 & 1.13 & 1.00 & $\begin{array}{l}\text { Valve } \\
\text { Closed }\end{array}$ & 0.83 \\
\hline & November 25 & 2230 & 240 & 133 & 1.10 & 1.07 & 0.96 & $\begin{array}{l}\text { Valve } \\
\text { Closed }\end{array}$ & 0.76 \\
\hline & November 25 & 2310 & 240 & 111 & 1.11 & 1.10 & 0.97 & $\begin{array}{l}\text { Valve } \\
\text { Closed }\end{array}$ & 0.76 \\
\hline & November 26 & 0330 & 240 & 85 & 0.93 & 0.92 & 0.76 & $\begin{array}{l}\text { Valve } \\
\text { Closed }\end{array}$ & 0.61 \\
\hline & November 26 & 0402 & 240 & 96 & 0.89 & 0.87 & 0.78 & $\begin{array}{l}\text { Valve } \\
\text { Closed }\end{array}$ & 0.65 \\
\hline & November 26 & 1300 & 240 & 168 & 0.99 & 0.97 & 0.87 & $\begin{array}{l}\text { Valve } \\
\text { Closed }\end{array}$ & 0.72 \\
\hline & November 26 & 2025 & 240 & 254 & 1.08 & 1.02 & 0.92 & $\begin{array}{l}\text { Valve } \\
\text { Closed }\end{array}$ & 0.81 \\
\hline & November 27 & 1140 & 240 & 76 & 0.84 & 0.82 & 0.71 & Valve & 0.57 \\
\hline & December 1 & 1030 & 240 & 268 & 1.18 & 1.13 & 1.02 & $\begin{array}{l}\text { Valve } \\
\text { Closed }\end{array}$ & 0.89 \\
\hline & December 2 & 1830 & 240 & 258 & 1.15 & 1.03 & 0.94 & $\begin{array}{l}\text { Valve } \\
\text { Closed }\end{array}$ & 0.82 \\
\hline & December 3 & 1320 & 240 & 256 & 0.99 & 0.98 & 0.98 & $\begin{array}{l}\text { Valve } \\
\text { Closed }\end{array}$ & 0.73 \\
\hline & December 6 & 0015 & 240 & 168 & 0.92 & 0.87 & 0.71 & $\begin{array}{l}\text { Valve } \\
\text { Closed }\end{array}$ & 0.57 \\
\hline & December 6 & 2300 & 227 & 172 & 0.62 & 0.56 & 0.50 & $\begin{array}{l}\text { Valve } \\
\text { Closed }\end{array}$ & 0.32 \\
\hline & December 8 & 0900 & 240 & 177 & 0.81 & 0.73 & 0.67 & $\begin{array}{l}\text { Valve } \\
\text { Closed }\end{array}$ & 0.48 \\
\hline & December 13 & 1200 & 240 & 265 & 1.06 & 0.99 & 0.90 & $\begin{array}{l}\text { Valve } \\
\text { Closed }\end{array}$ & 0.70 \\
\hline & December 18 & 1300 & 240 & 258 & 1.21 & 1.03 & 0.99 & $\begin{array}{l}\text { Valve } \\
\text { Closed }\end{array}$ & 0.76 \\
\hline & December 20 & 1320 & 240 & 239 & 0.96 & 0.92 & 0.85 & $\begin{array}{l}\text { Valve } \\
\text { Closed }\end{array}$ & 0.63 \\
\hline & December 21 & 1630 & 222 & 31 & 0.61 & 0.55 & 0.48 & $\begin{array}{l}\text { Valve } \\
\text { Closed }\end{array}$ & 0.24 \\
\hline & December 28 & 2210 & 240 & 249 & 0.99 & 0.94 & 0.87 & $\begin{array}{l}\text { Valve } \\
\text { Closed }\end{array}$ & 0.62 \\
\hline
\end{tabular}


TABLE III (contd.)

\begin{tabular}{|c|c|c|c|c|c|c|c|c|c|}
\hline \multirow{3}{*}{1972} & \multirow[b]{2}{*}{ Date } & \multirow{2}{*}{$\begin{array}{l}\text { Time } \\
\text { (hr) } \\
\end{array}$} & \multirow{2}{*}{$\begin{array}{c}\text { Moderator } \\
\text { Temperature }\left({ }^{\circ} \mathrm{C}\right) \\
\end{array}$} & \multirow{2}{*}{$\begin{array}{c}\text { Assembly } \\
\text { Power (kW) } \\
\end{array}$} & \multicolumn{2}{|c|}{ Internal $\mathrm{Rc}$} & \multicolumn{3}{|c|}{ Pressure (atm-gauge) } \\
\hline & & & & & $\mathrm{AA}$ & $\mathrm{AB}$ & $\mathrm{AC}$ & $A D$ & $\mathrm{AE}$ \\
\hline & January 3 & 1240 & 240 & 246 & 1.00 & 0.98 & 0.89 & $\begin{array}{l}\text { Valve } \\
\text { Closed }\end{array}$ & 0.63 \\
\hline & January 8 & 1220 & 236 & 47 & 0.60 & 0.58 & 0.53 & $\begin{array}{l}\text { Valve } \\
\text { Closed }\end{array}$ & 0.21 \\
\hline & January 16 & 1530 & 240 & 43 & 0.71 & 0.63 & 0.58 & $\begin{array}{l}\text { Valve } \\
\text { Closed }\end{array}$ & 0.29 \\
\hline & January 17 & 1210 & 240 & 184 & 0.82 & 0.76 & 0.69 & $\begin{array}{l}\text { Valve } \\
\text { Closed }\end{array}$ & 0.42 \\
\hline & January 18 & 2130 & 240 & 262 & 0.99 & 0.95 & 0.87 & $\begin{array}{l}\text { Valve } \\
\text { Closed }\end{array}$ & 0.65 \\
\hline & March 19 & 0800 & 240 & 10 & 0.58 & 0.61 & 0.51 & 0.72 & 0.21 \\
\hline & March 19 & 1340 & 226 & 21 & 0.57 & 0.60 & 0.54 & 0.69 & 0.26 \\
\hline & March 19 & 2110 & 240 & 77 & 0.70 & 0.76 & 0.67 & 0.80 & 0.30 \\
\hline & March 20 & 0240 & 240 & 144 & 0.78 & 0.81 & 0.75 & 0.88 & 0.33 \\
\hline & March 20 & 0700 & 240 & 175 & 0.84 & 0.86 & 0.81 & 0.92 & 0.38 \\
\hline & March 21 & 1500 & 225 & 4 & 0.54 & 0.57 & 0.53 & 0.68 & 0.26 \\
\hline & March 22 & 0300 & 240 & 136 & 0.76 & 0.78 & 0.73 & 0.86 & 0.35 \\
\hline & March 22 & 0920 & 240 & 198 & 0.85 & 0.87 & 0.82 & 0.92 & 0.30 \\
\hline & March 22 & 1400 & 240 & 158 & 0.89 & 0.84 & 0.80 & 0.90 & 0.30 \\
\hline & March 22 & 2340 & 240 & 62 & 0.67 & 0.69 & 0.65 & 0.80 & 0.25 \\
\hline & March 23 & 1220 & 240 & 183 & 0.82 & 0.84 & 0.80 & 0.91 & 0.28 \\
\hline & Apri1 15 & 1310 & 240 & 248 & 0.84 & 0.87 & 0.80 & 0.91 & 0.34 \\
\hline & April 24 & 1720 & 223 & 72 & 0.48 & 0.55 & 0.50 & 0.63 & 0.04 \\
\hline & April 25 & 1200 & 240 & 269 & 0.95 & 0.99 & 0.98 & 1.03 & 0.40 \\
\hline & May 2 & 1020 & 240 & 271 & 0.93 & 1.02 & 1.01 & 1.05 & 0.40 \\
\hline & May 11 & 1940 & 240 & 274 & 0.99 & 1.10 & 1.10 & 1.11 & 0.50 \\
\hline & May 19 & 1310 & 240 & 275 & 0.97 & 1.13 & 1.17 & 1.11 & 0.55 \\
\hline & May 21 & 1730 & 185 & 20 & 0.48 & 0.63 & 0.63 & 0.64 & 0.07 \\
\hline & May 22 & 1630 & 240 & 267 & 0.99 & 1.18 & 1.21 & 1.15 & 0.59 \\
\hline & May 28 & 2330 & 226 & 266 & 0.61 & 0.75 & 0.76 & 0.76 & 0.20 \\
\hline & May 30 & 1530 & 240 & 260 & 1.07 & 1.29 & 1.35 & 1.24 & 0.59 \\
\hline & June 25 & 2220 & 240 & 268 & 1.12 & 1.40 & 1.51 & 1.29 & 0.78 \\
\hline & July 8 & 1330 & 236 & 268 & 1.27 & 1.48 & 1.60 & 1.31 & 0.79 \\
\hline & August 7 & 1530 & 232 & 4 & 0.90 & 1.30 & 1.28 & 1.03 & 0.67 \\
\hline & August 16 & 1110 & 236 & 265 & 1.34 & -- & 1.98 & 1.48 & 1.33 \\
\hline & Augus $t 25$ & 1130 & 236 & 261 & 1.38 & -- & 2.04 & 1.32 & 1.40 \\
\hline & August 26 & 1210 & 228 & 20 & 0.88 & -- & 1.40 & 0.78 & 0.81 \\
\hline & August 28 & 0745 & 80 & 0 & 0.50 & -- & 0.75 & 0.19 & 0.08 \\
\hline
\end{tabular}



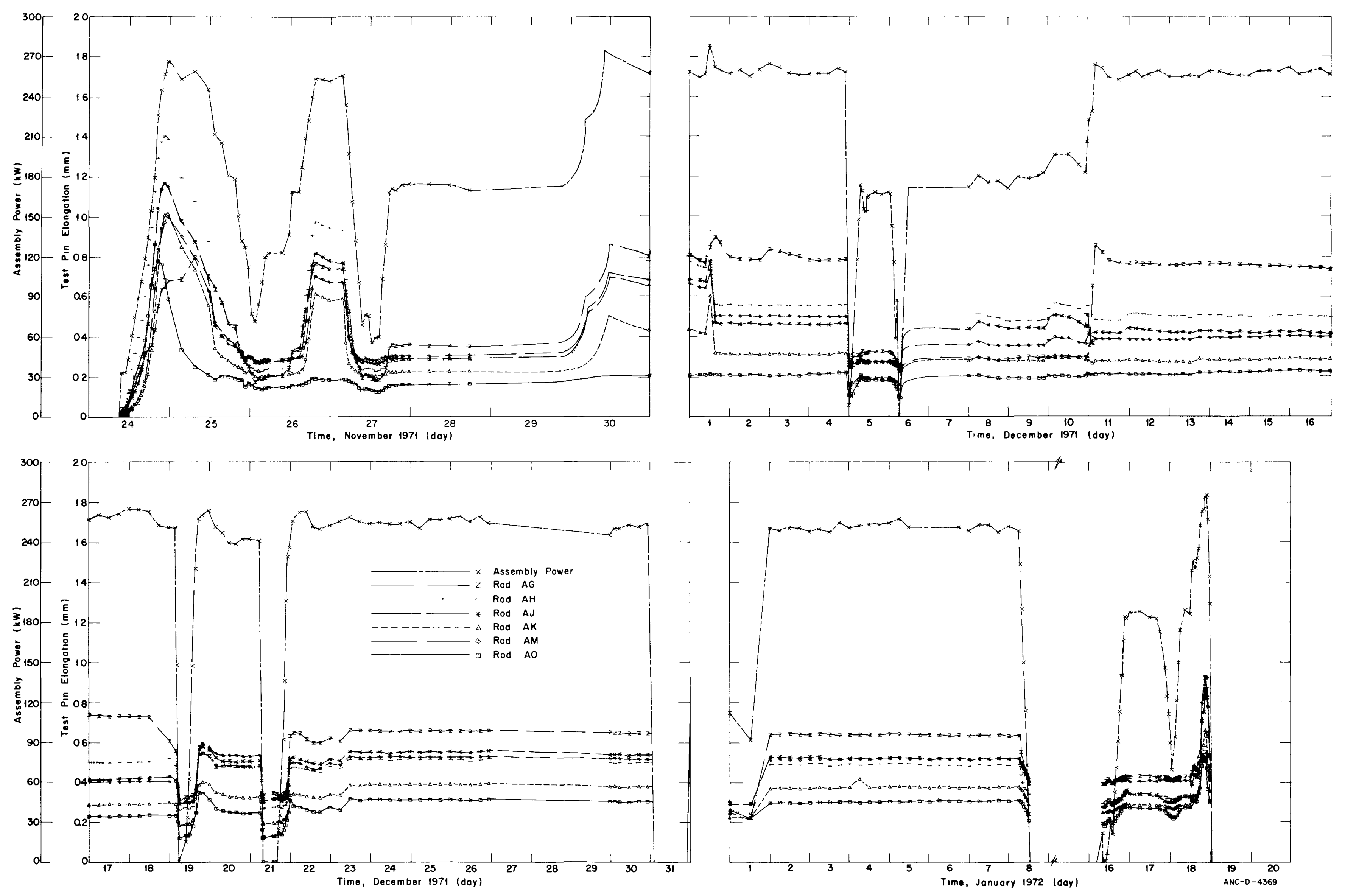

Fig. 10 Elongation history of IFA-226 test rods from November 1971 through January 1972. 

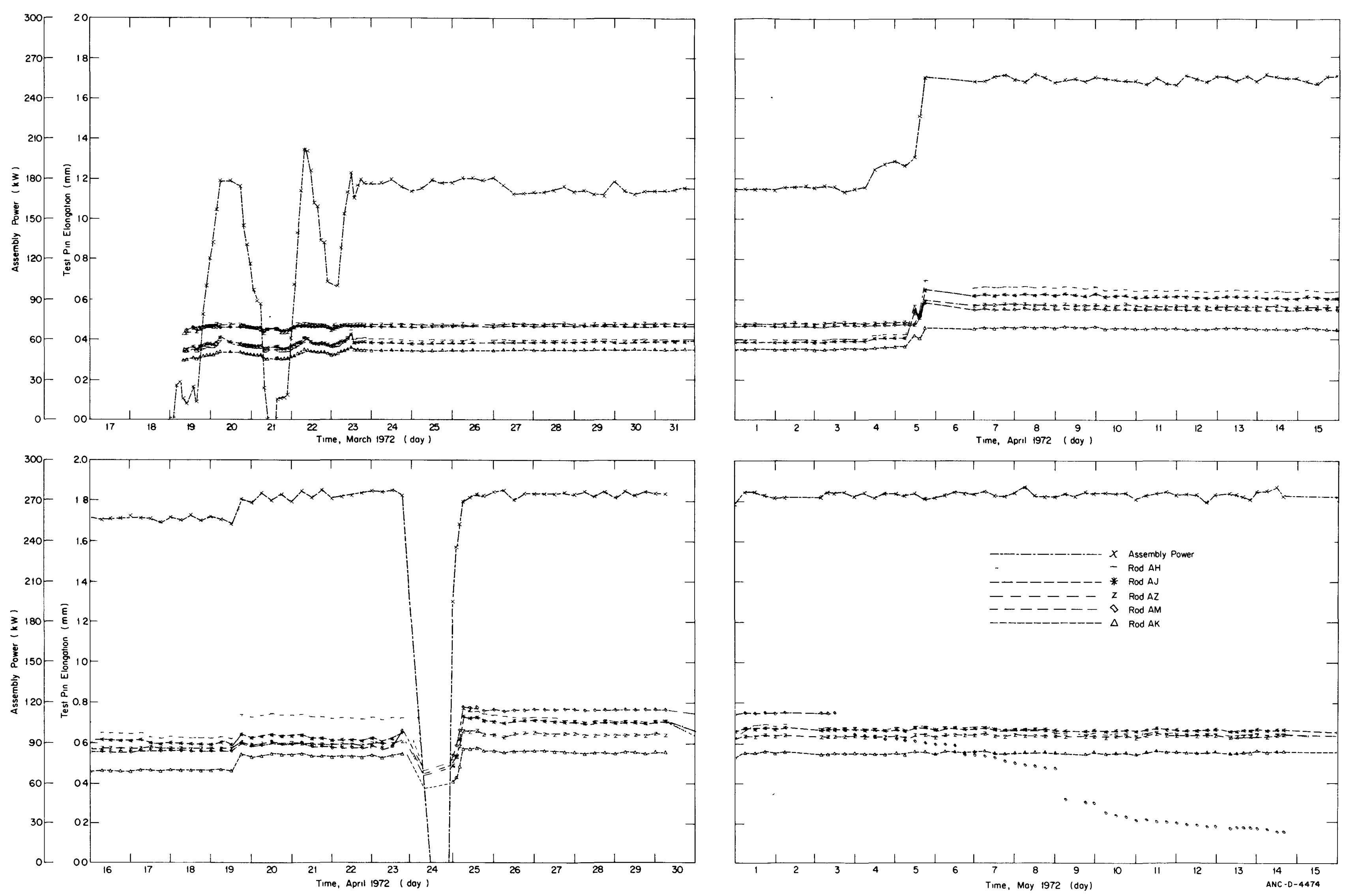
Fig. 11 Elongation history of IFA-226 test rods from March 1972 through
May 1972 . 

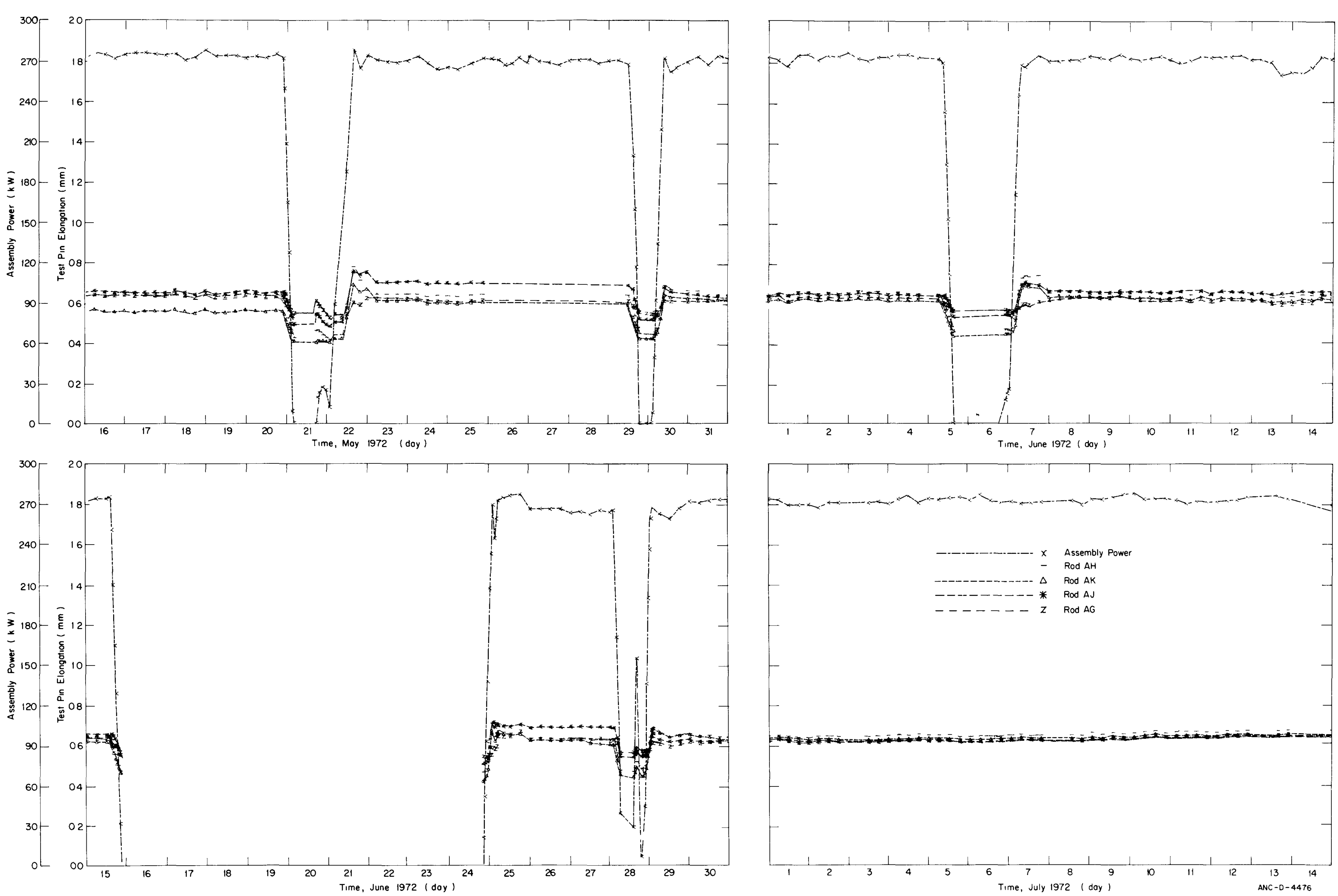

Fig. 12 Elongation history of IFA-226 test rods from Mav 1972 through July 1972. 

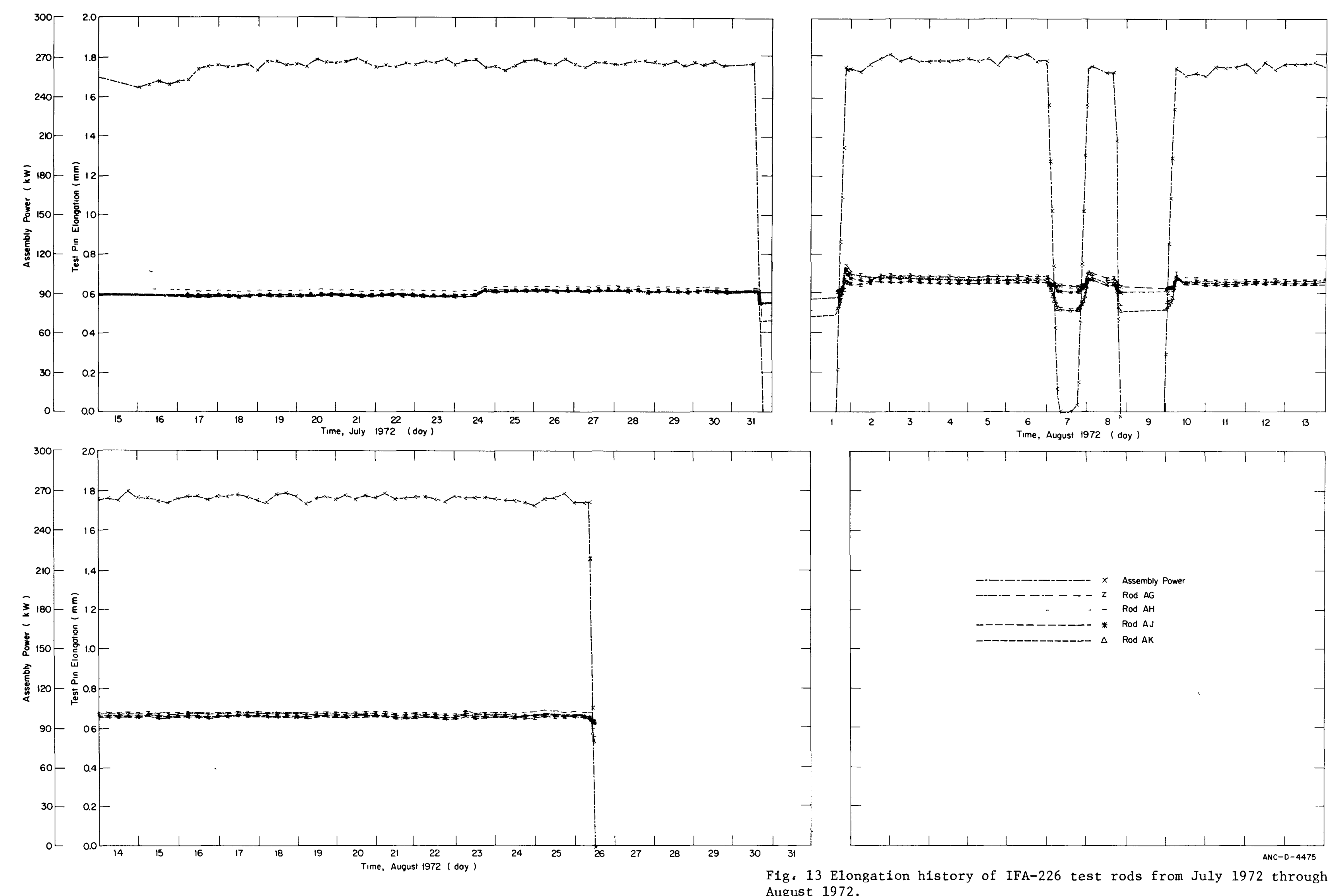

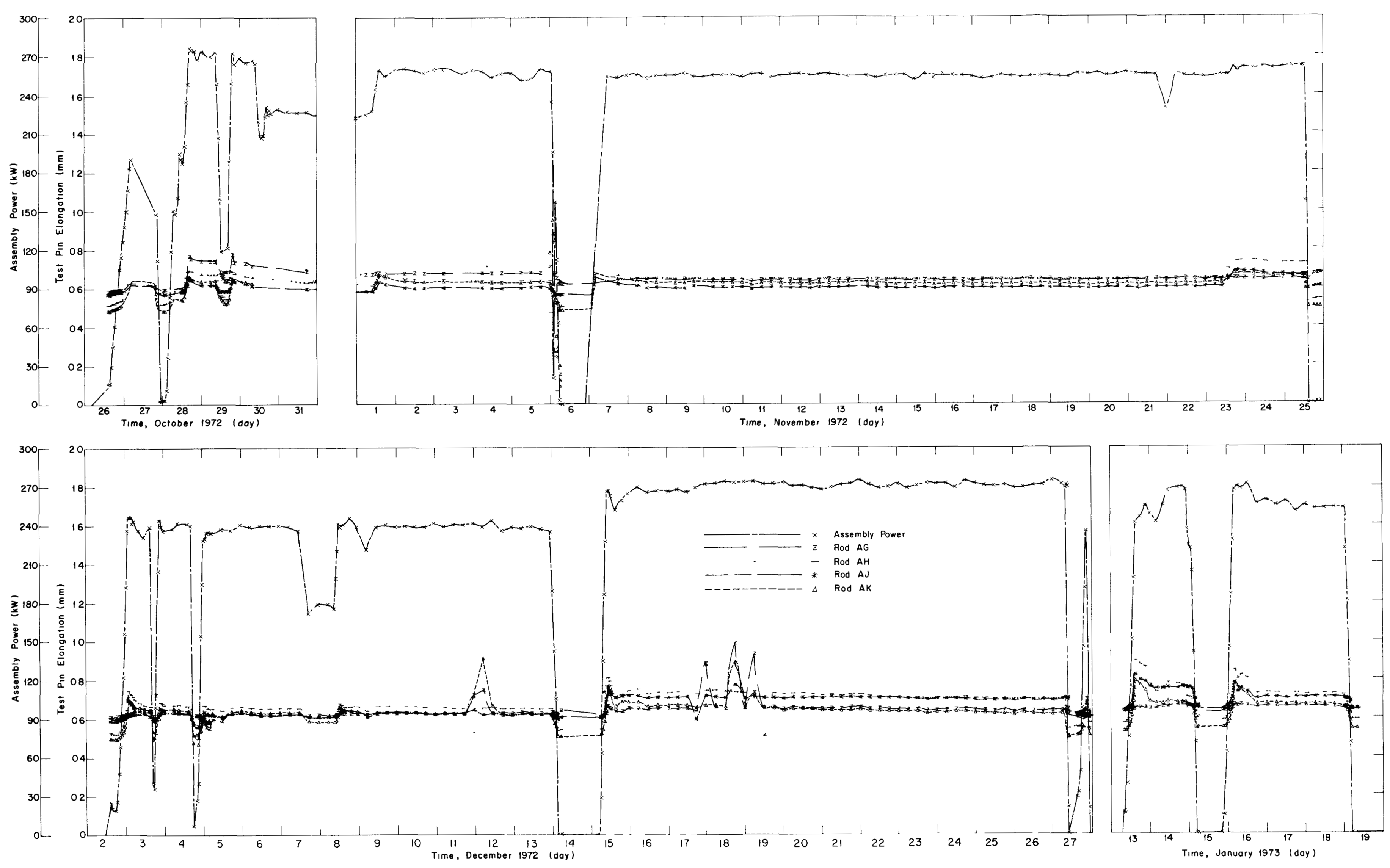

Fig. 14 E1ongation history of IFA-226 test rods from October 1972 through
January 1973 . 

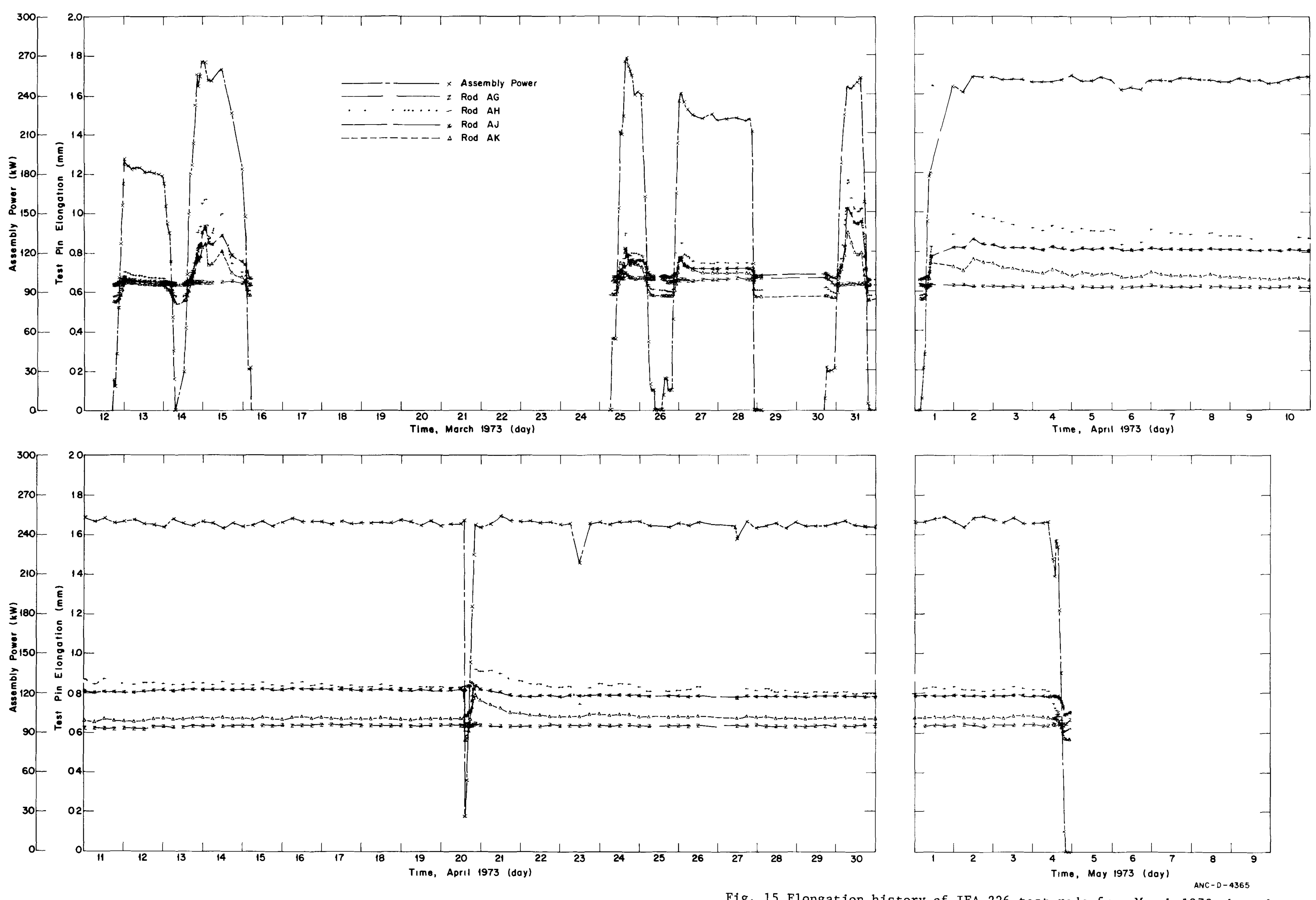

May 1973. 

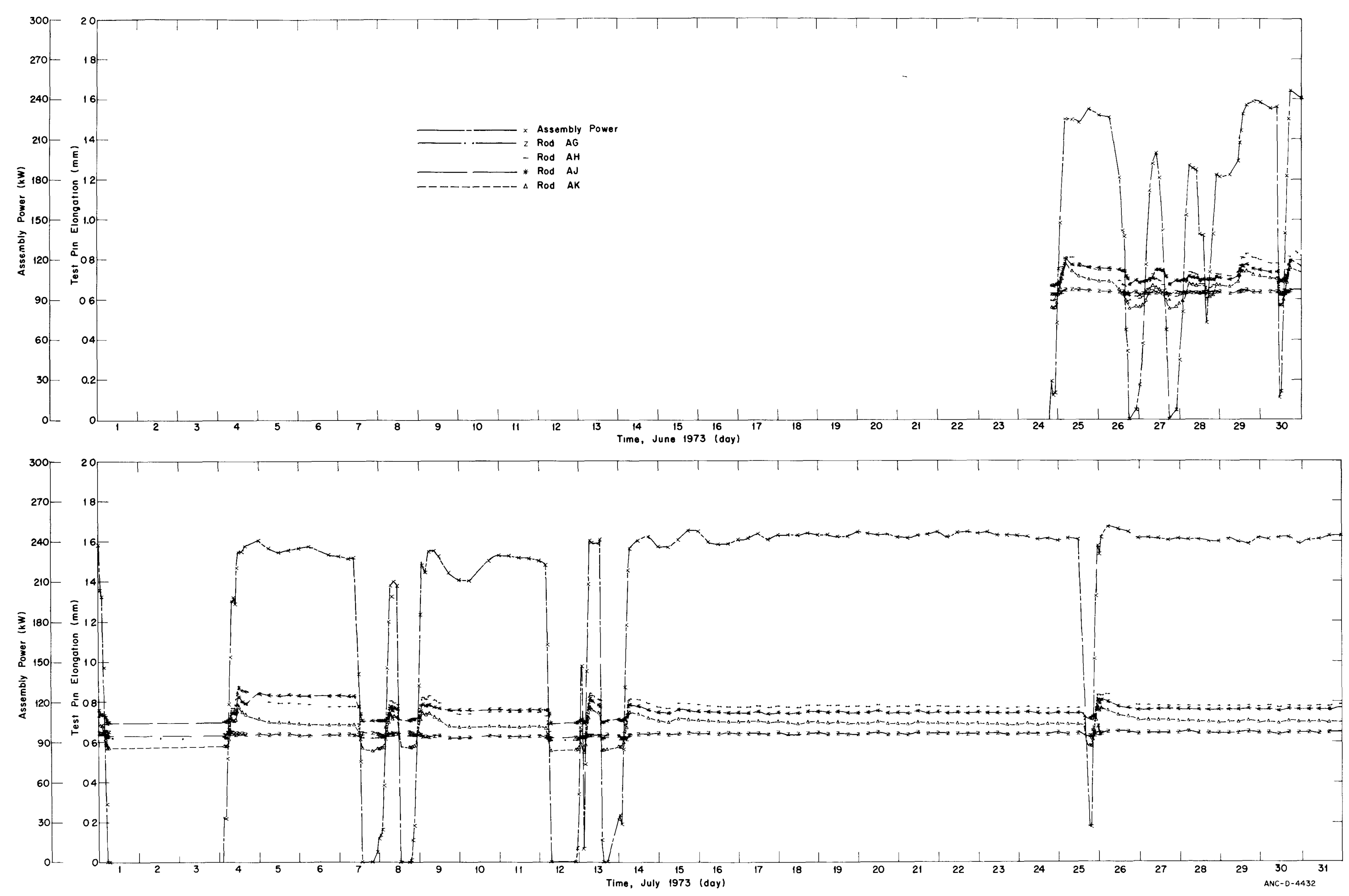

Fig. 16 Elongation history of IFA-226 test rods from June 1973 through Ju1y 1973. 

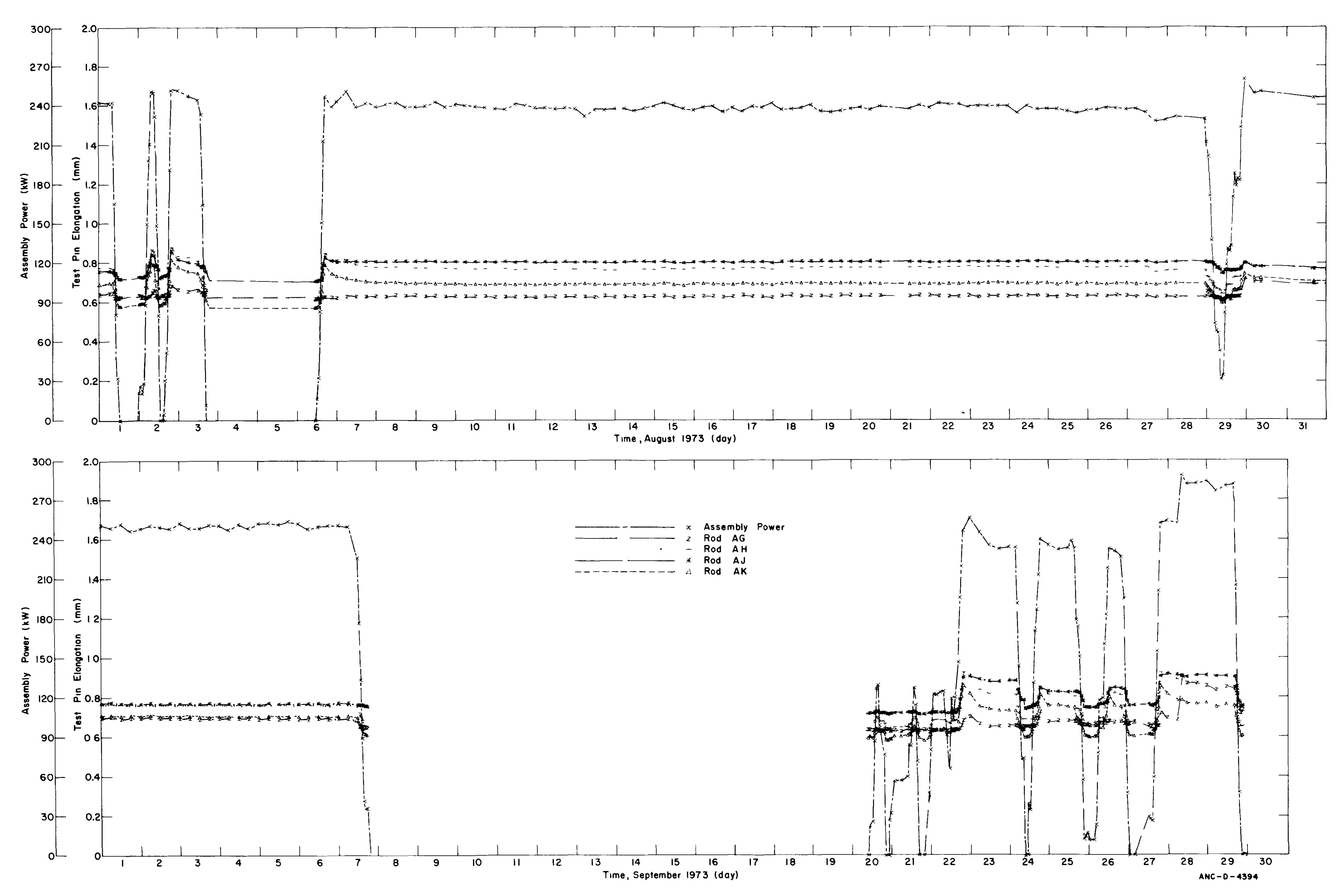

Fig. 17 Elongation history of IFA-226 test rods from August 1973 through September 1973. 

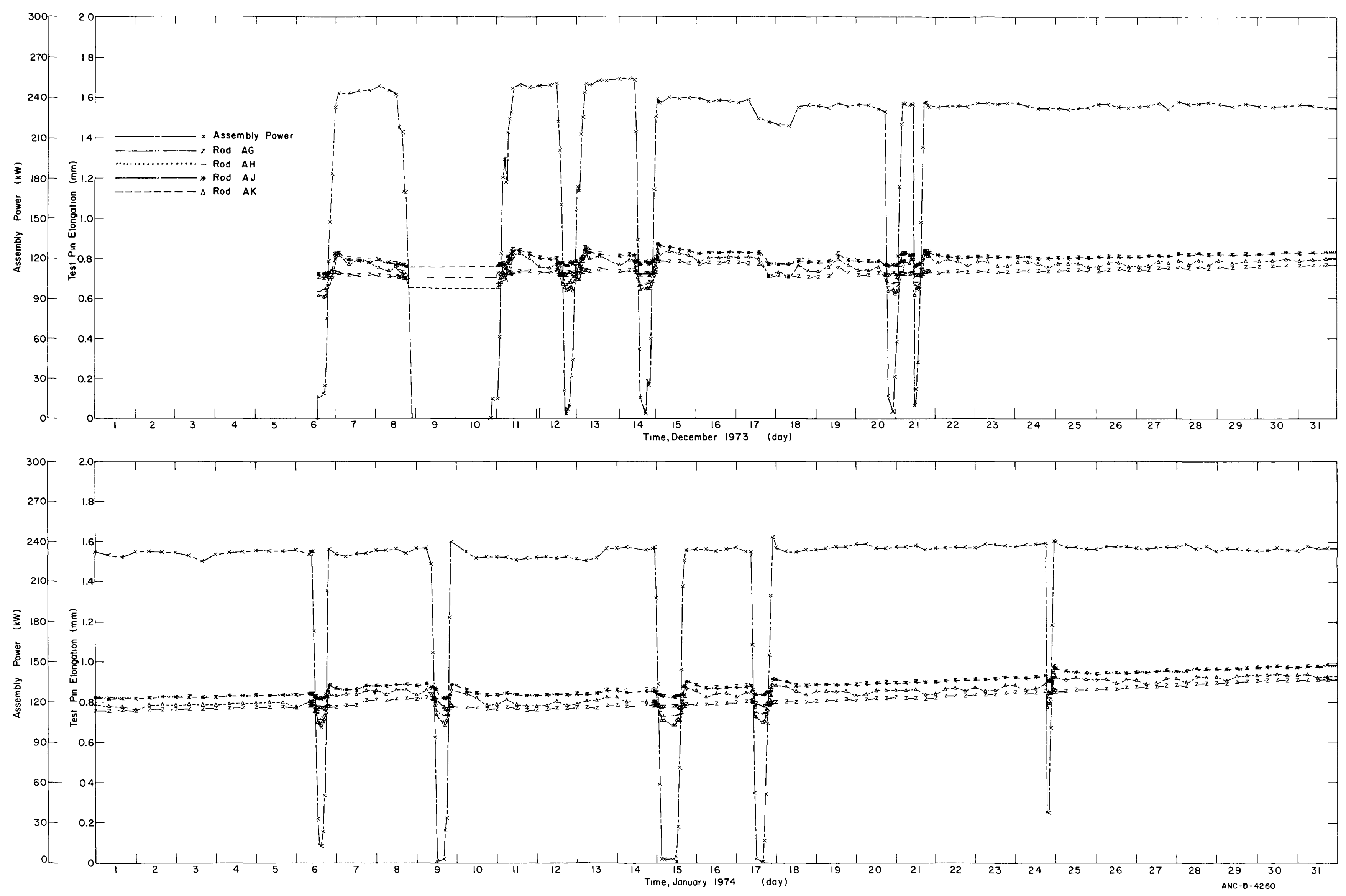

Fig. 18 Elongation history of IFA-226 test rods from December 1973 through January 1974. 

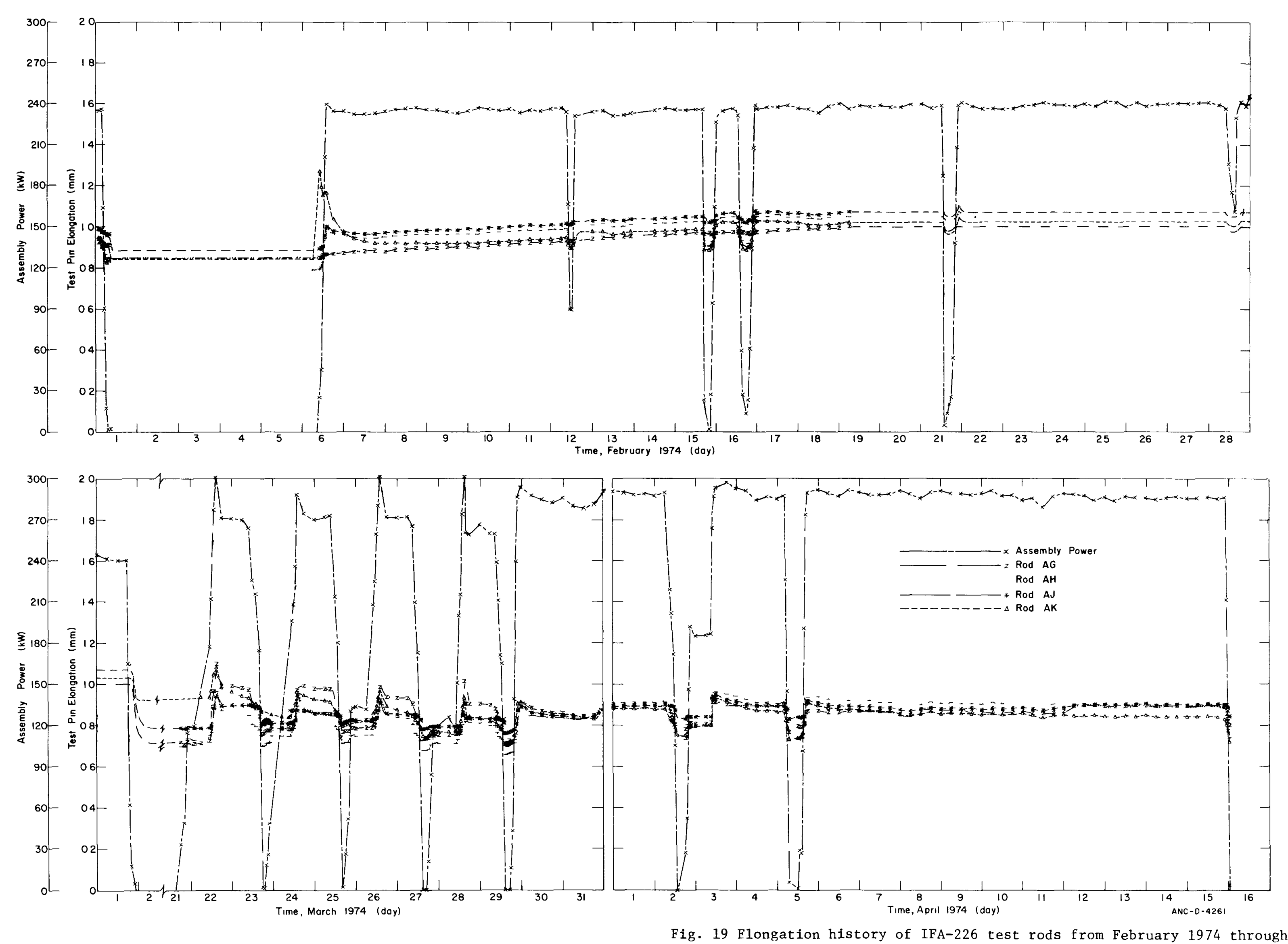
Fig. 19 Flongation history of IFA-226 test rods from February 1974 through April 1974. 

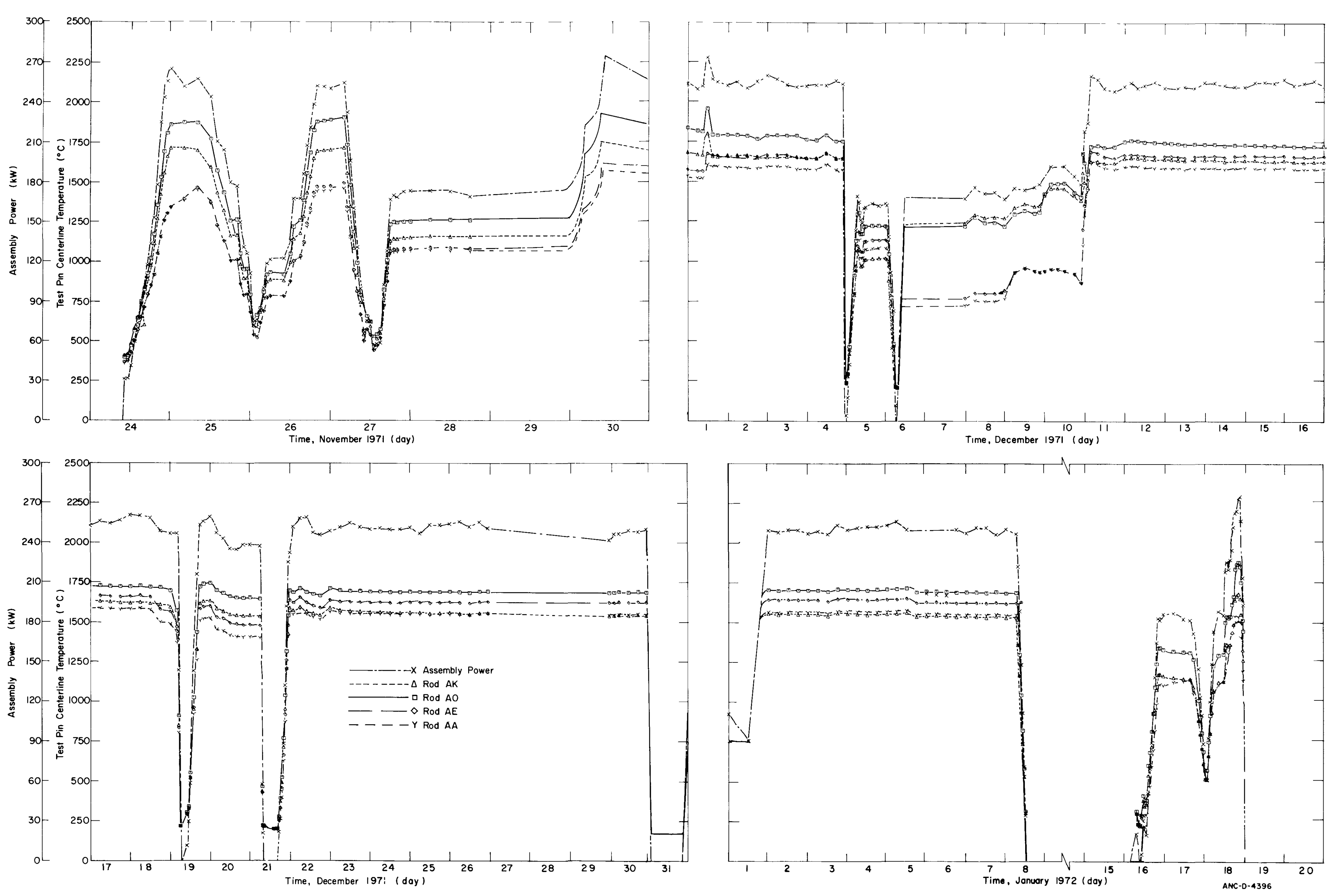

Fig. 20 Fuel centerline temperature history of IFA-226 test rods from November 1971 through January 1972. 

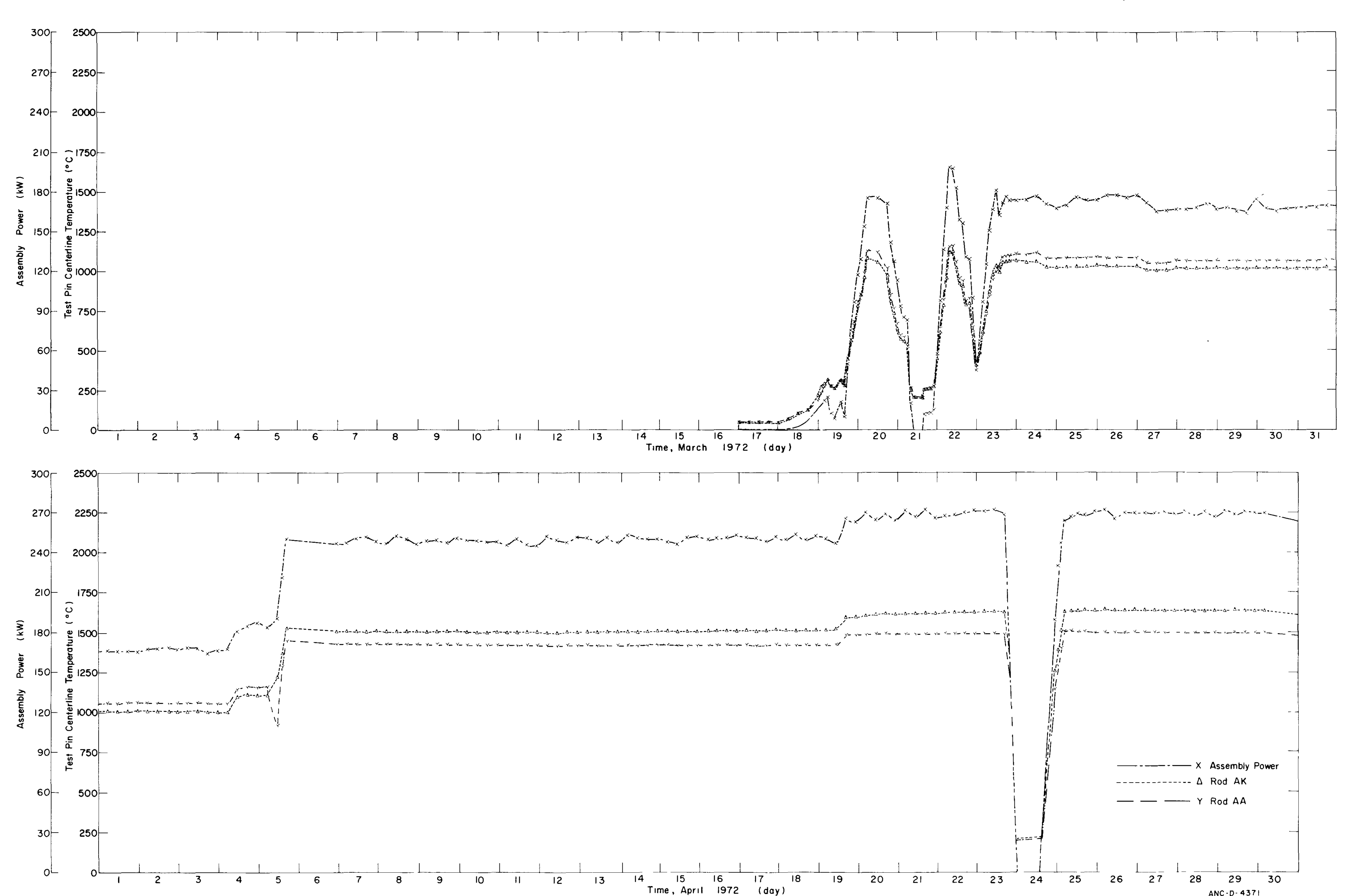

Fig. 21 Fuel centerline temperature history of IFA-226 test rods from March 1972 through Apri1 1972. 

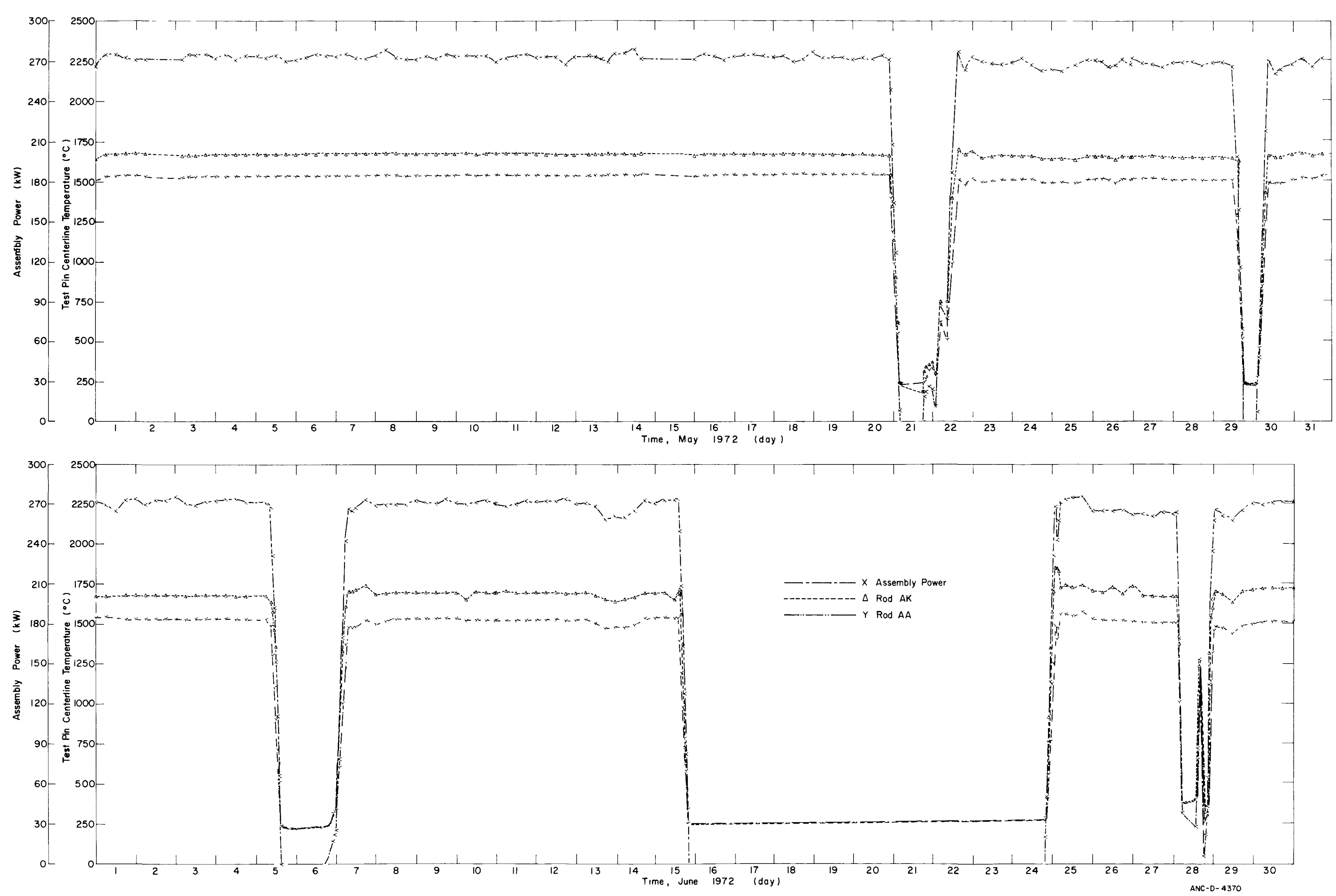

Fig. 22 Fuel centerline temperature history of IFA-226 test rods from May 1972 through June 1972 . 

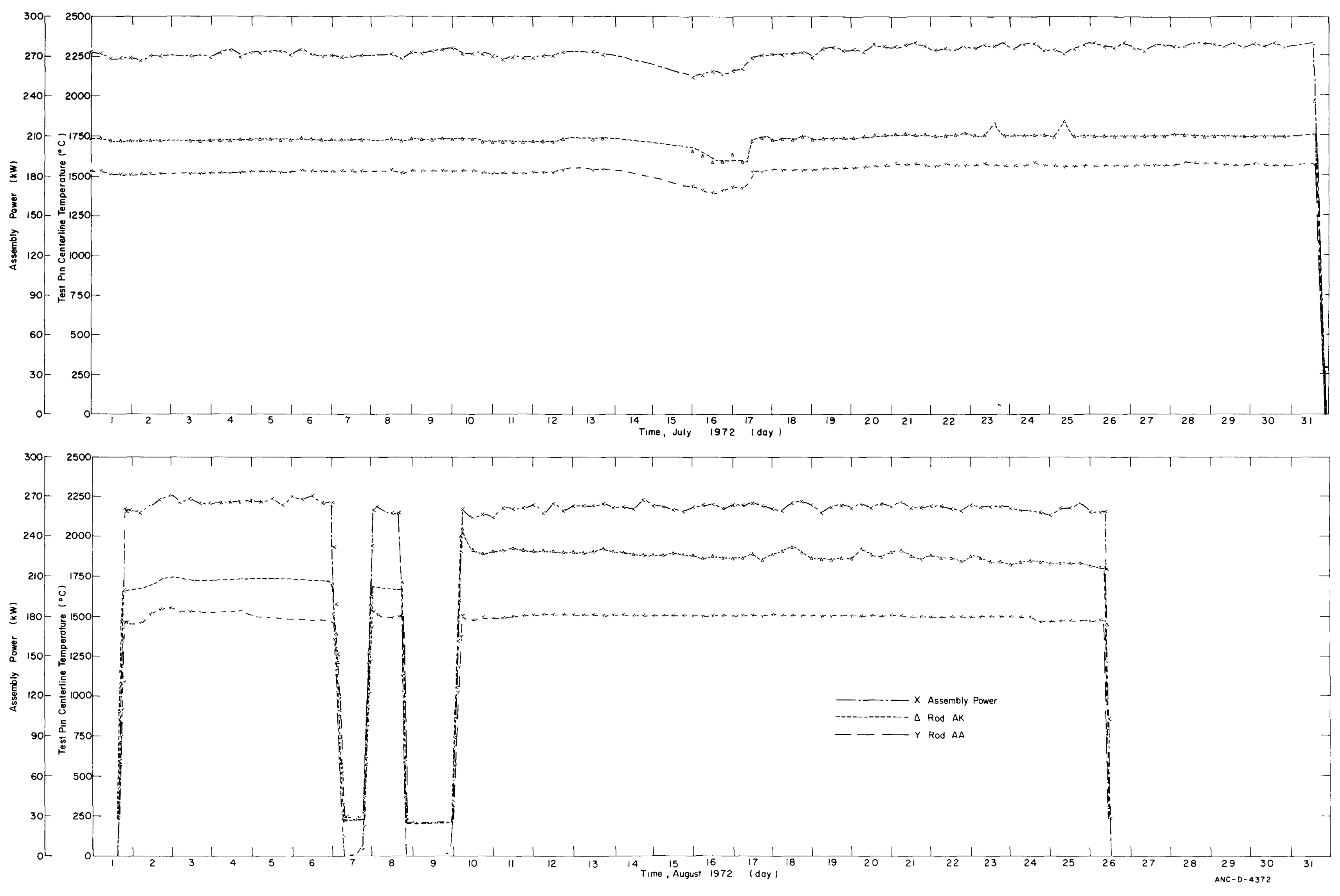

Fig. 23 Fuel centerline temperature history of IFA-226 test rods from July 1972 through August 1972. 

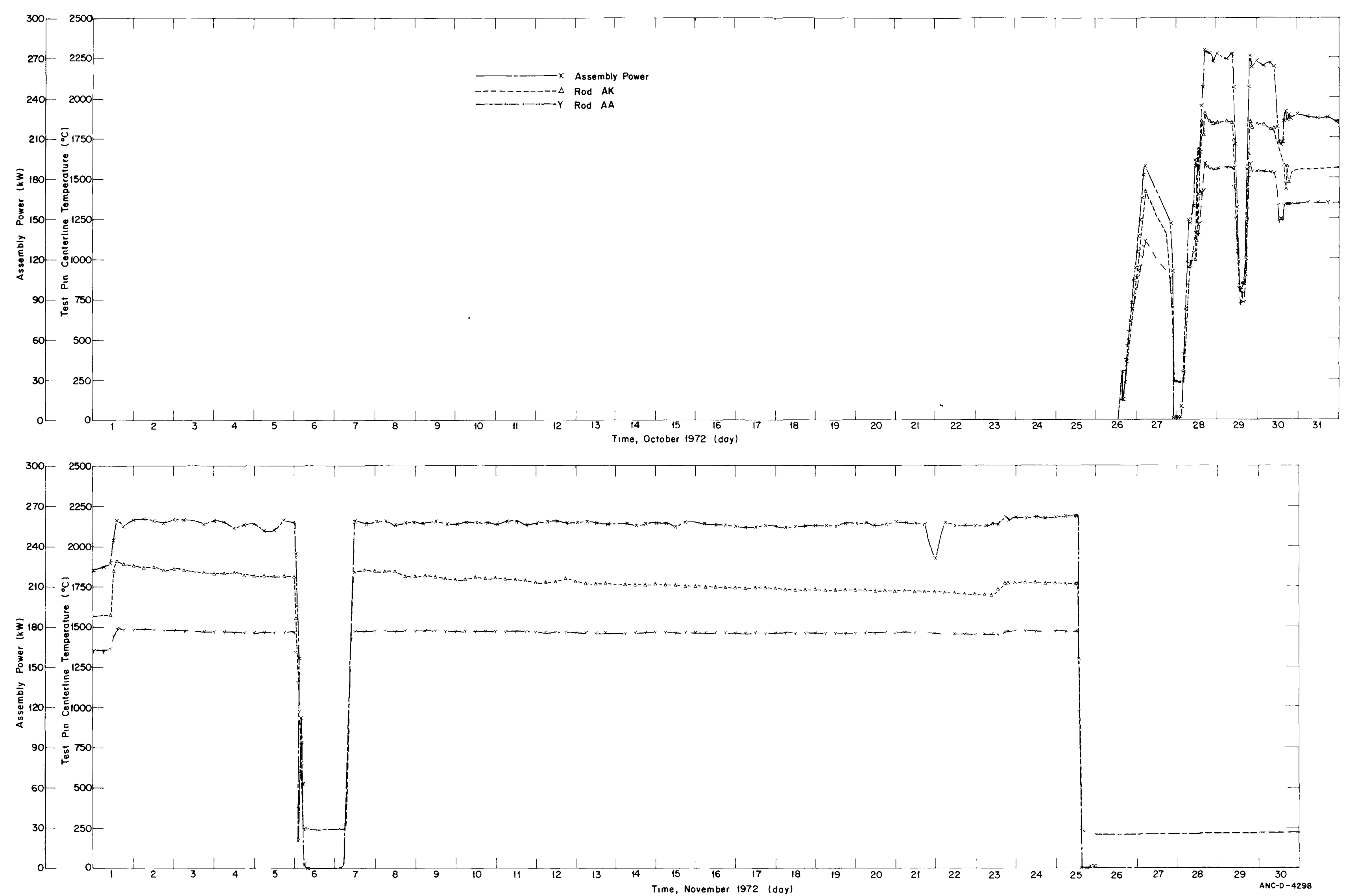

Fig. 24 Fuel centerline temperature history of IFA-226 test rods from October 1972 through November 1972. 

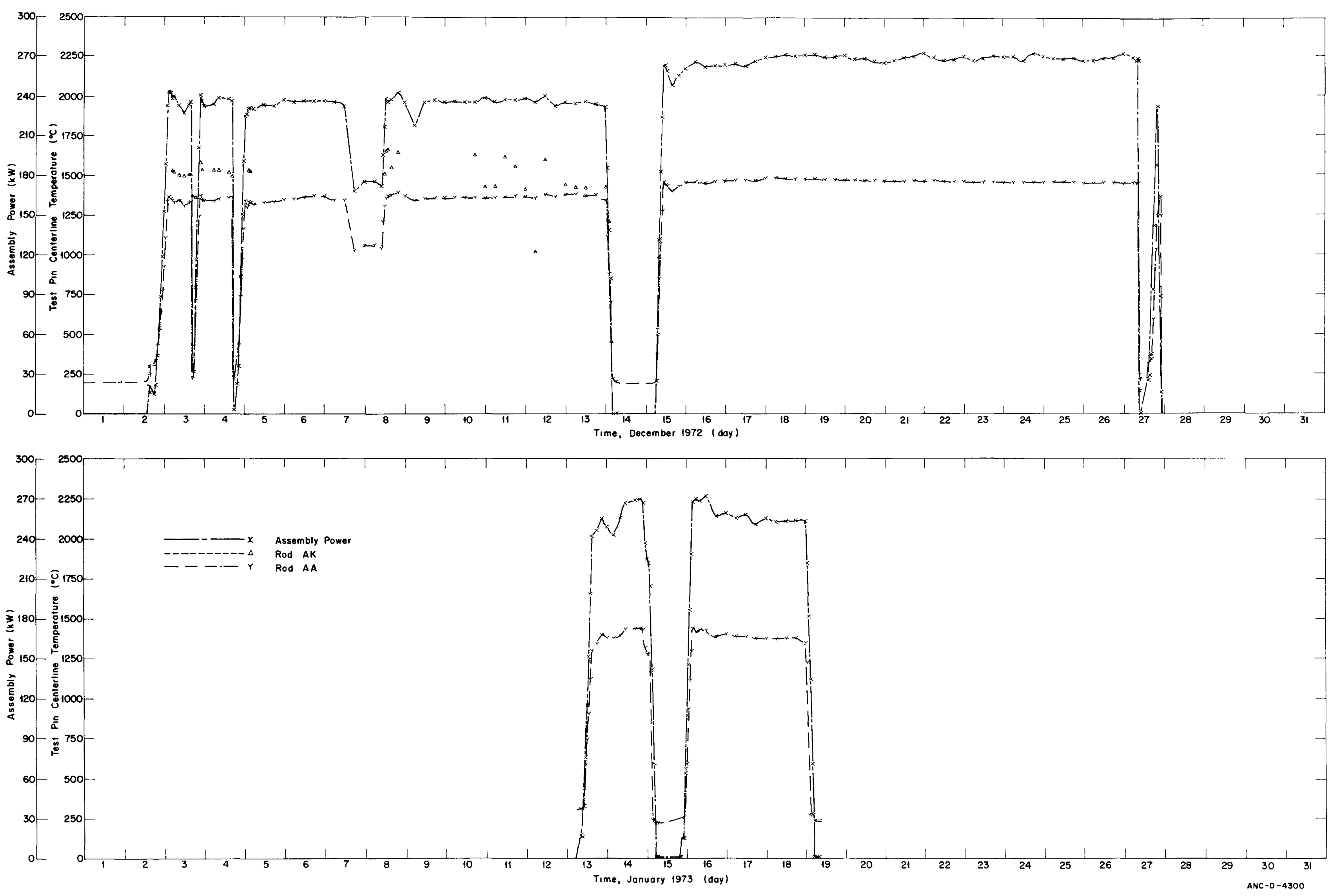

Fig. 25 Fuel centerline temperature history of IFA-226 test rods from December 1972 through January 1973. 

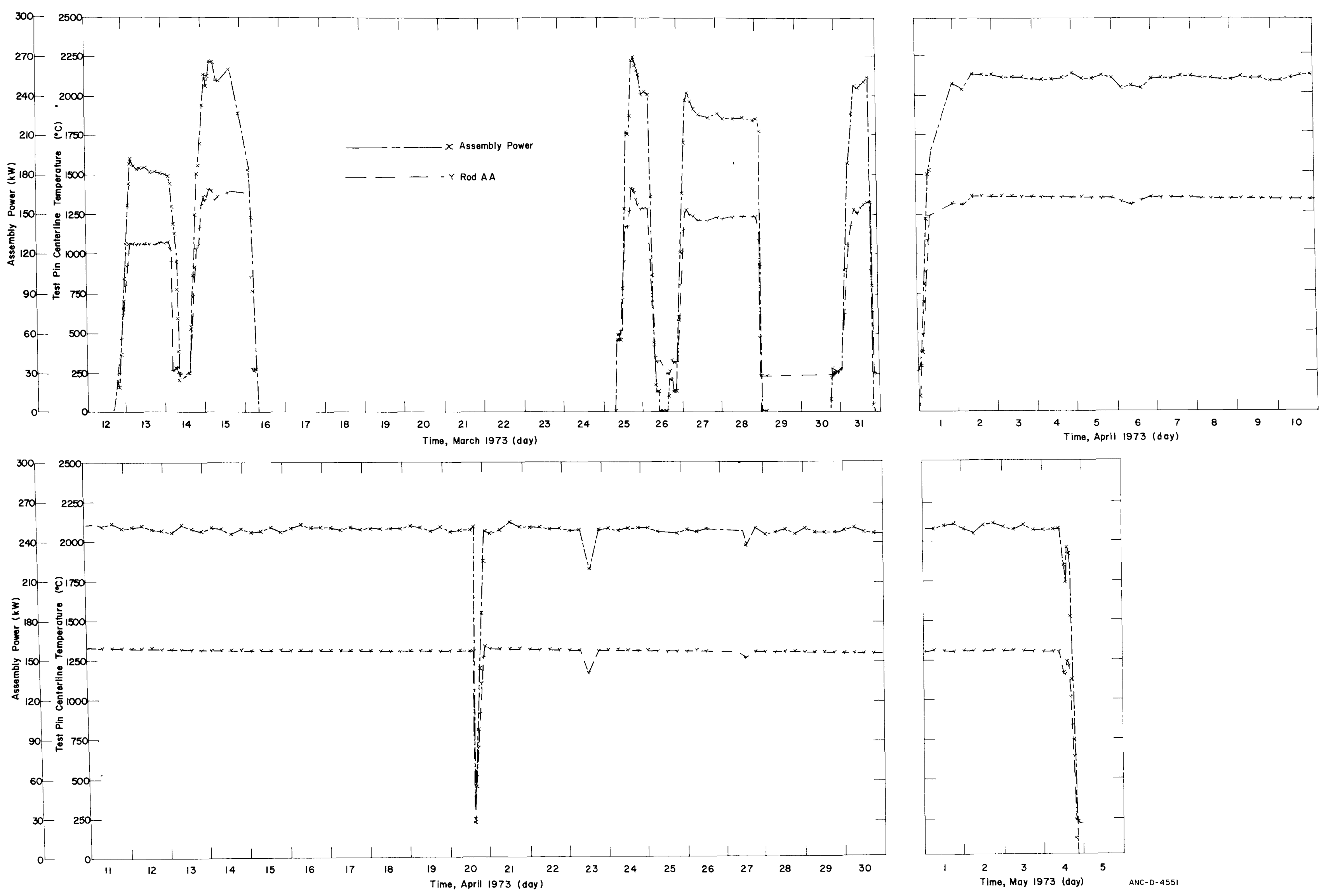

Fig. 26 Fuel centerline temperature history of IFA-226 test rods from March 1973 through May 1973. 

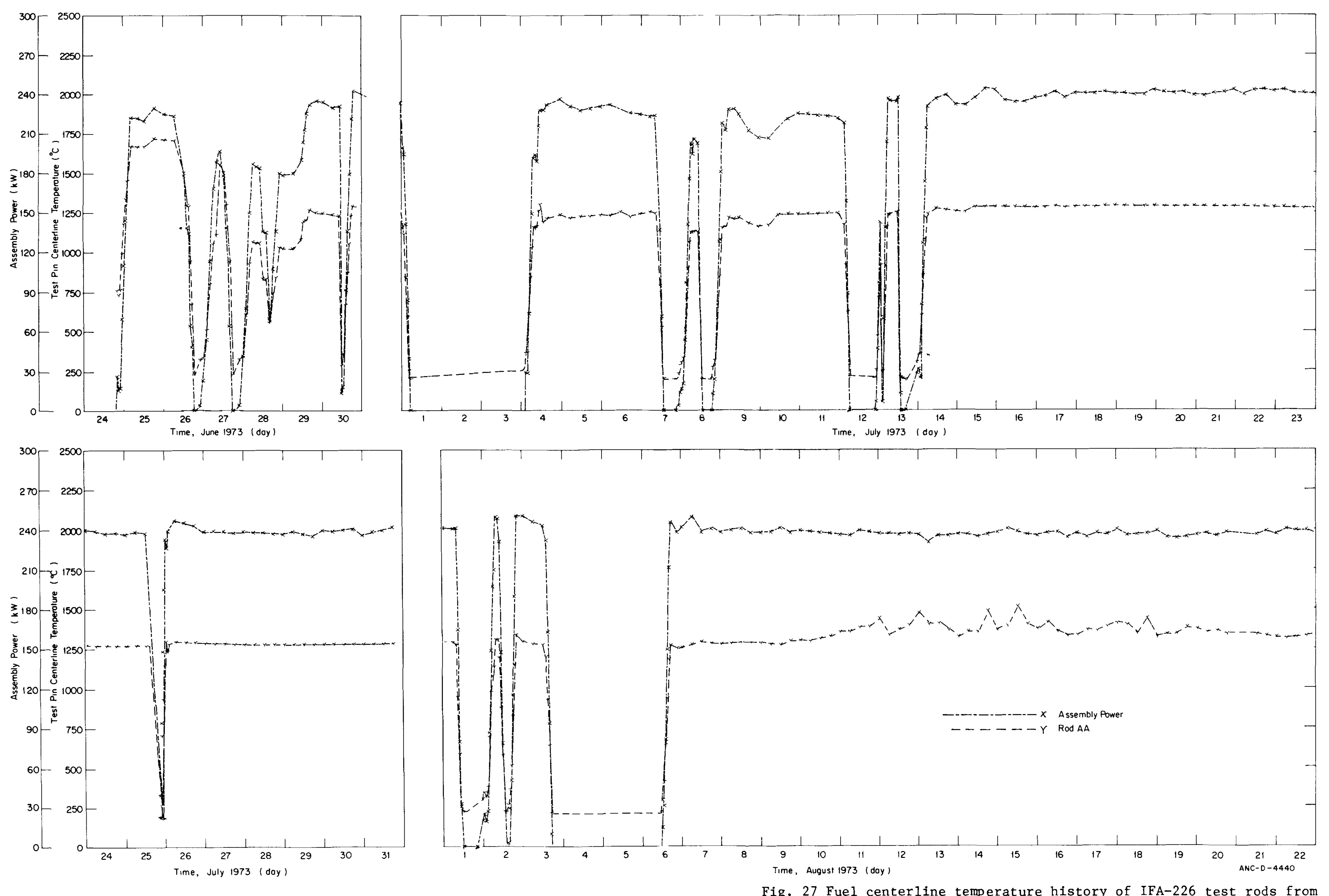

Fig. 27 Fuel centerline temperature history of IFA-226 test rods from June 1973 through August 1973. 

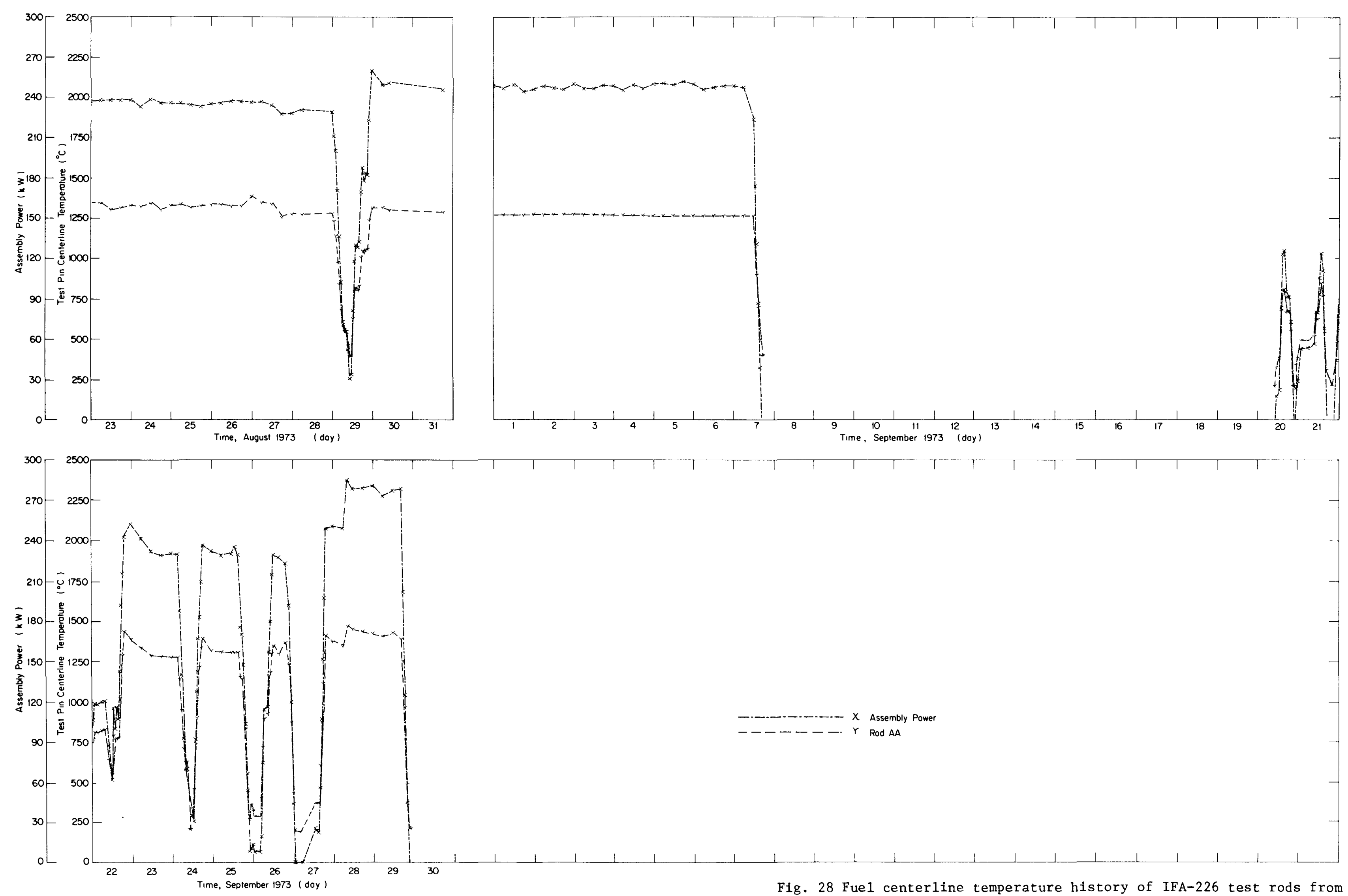

-

$r$ pod AA

August 1973 through 

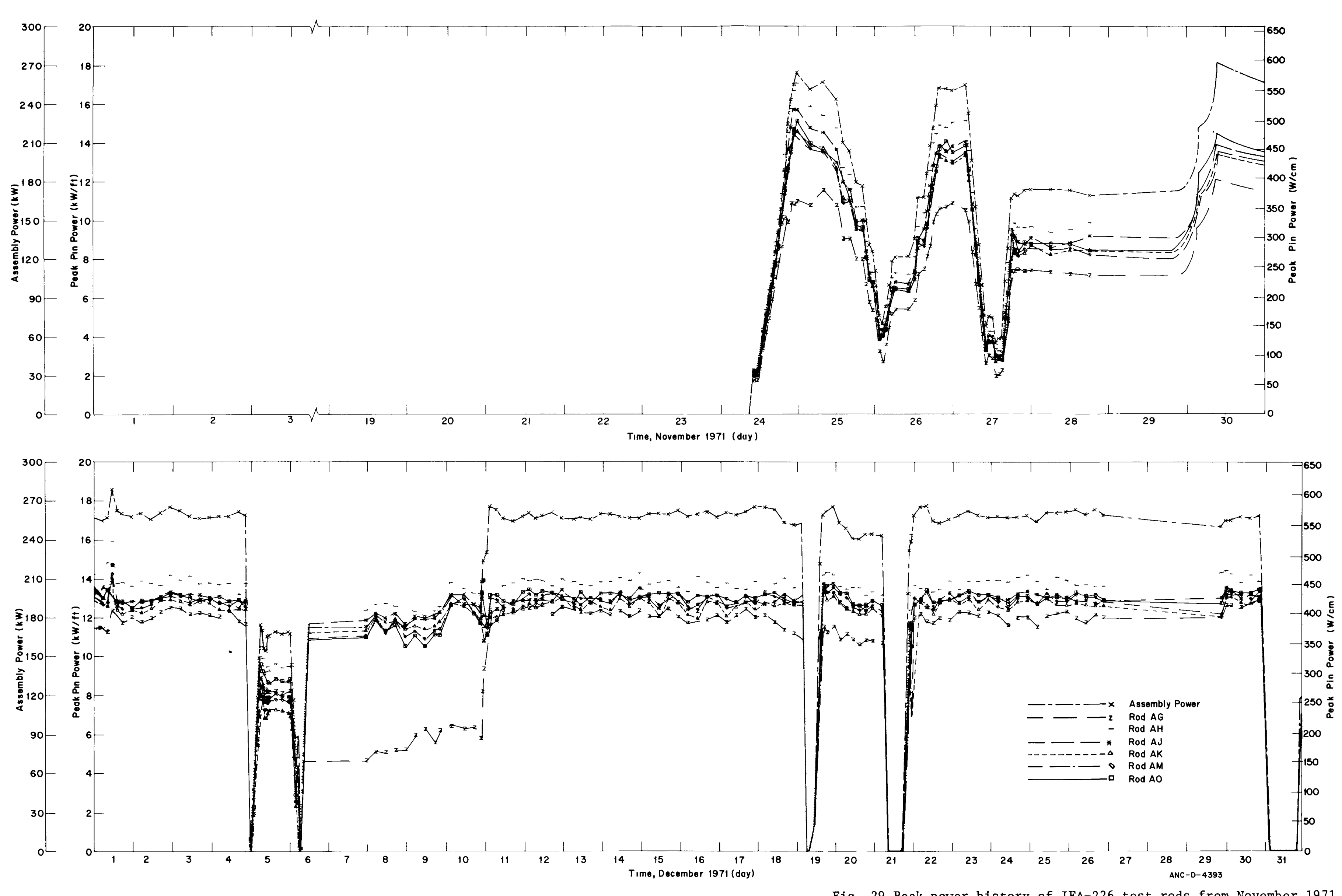

Fig. 29 Peak power history of IFA-226 test rods from November 1971 through December 1971. 


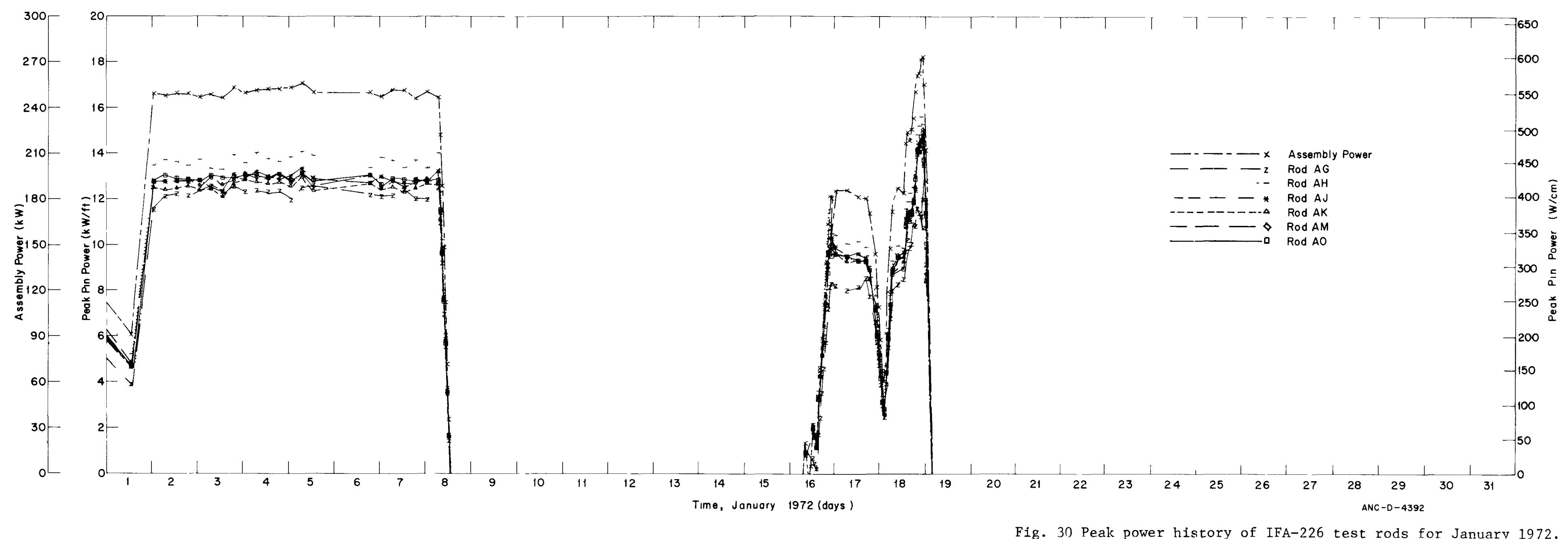



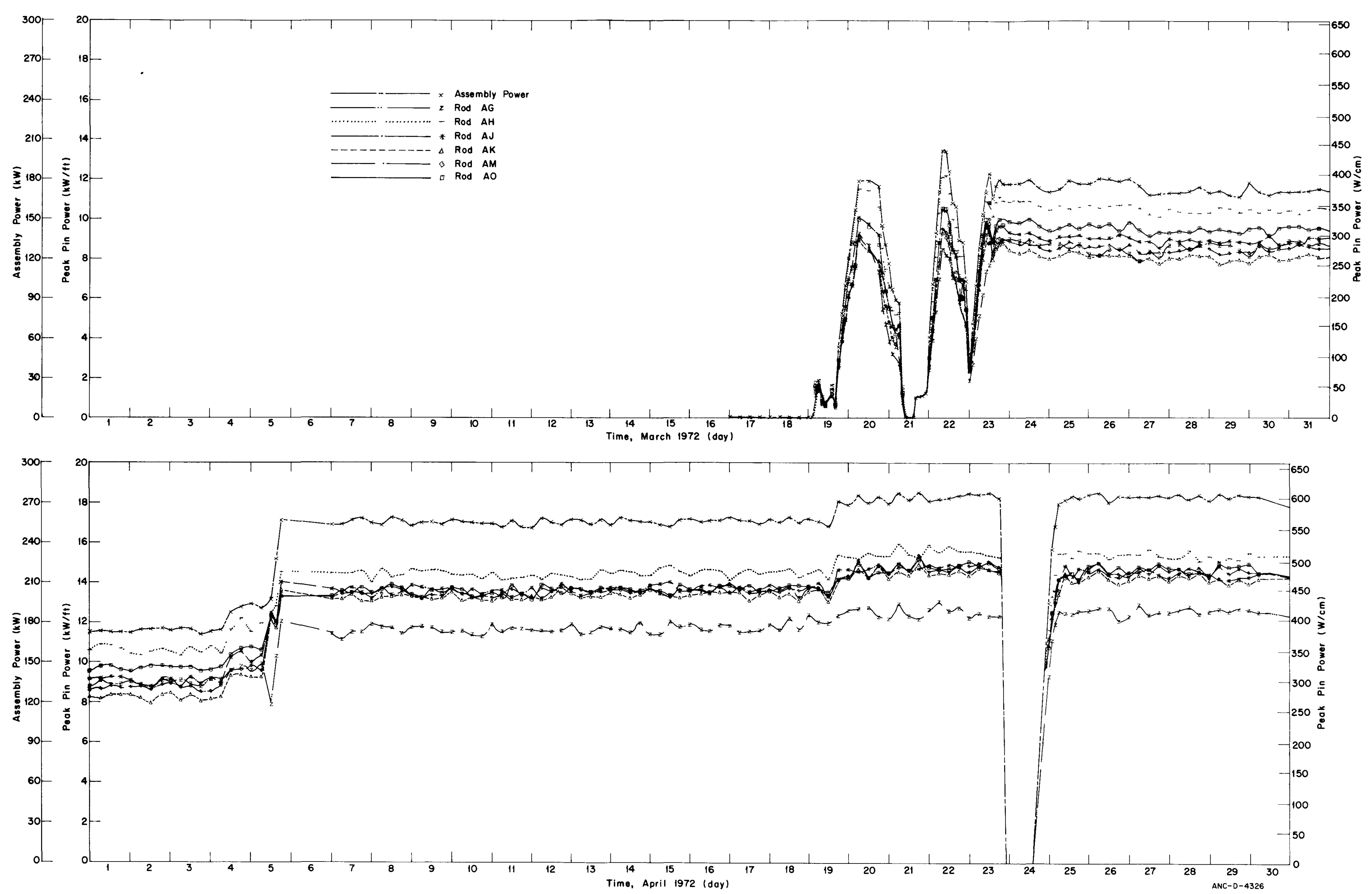

Fig. 31 Peak power history of IFA-226 test rods from March 1972 through Apri1 1972. 

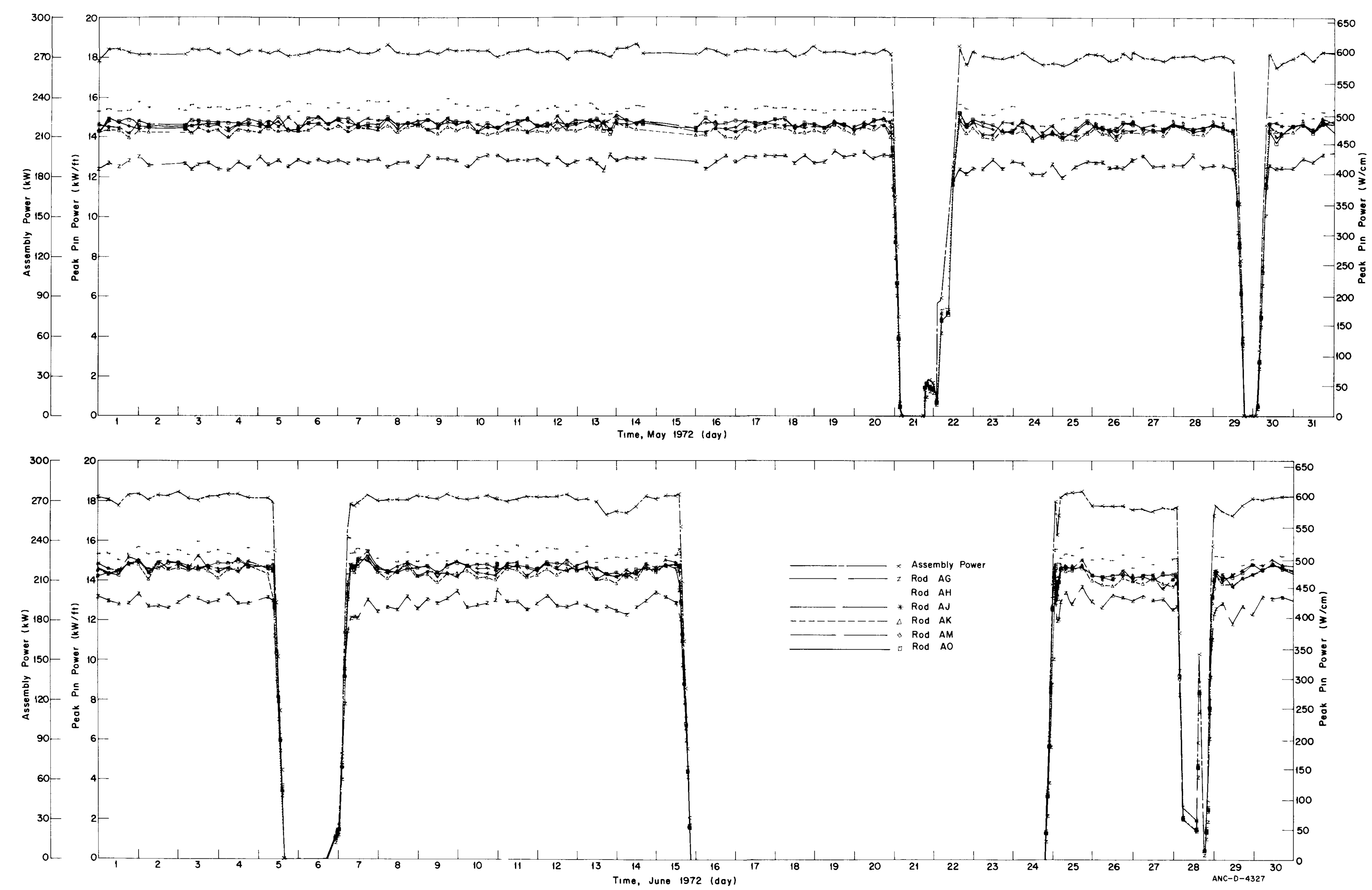

Fig. 32 Peak power history of IFA-226 test rods from May 1972 through June 1972. 

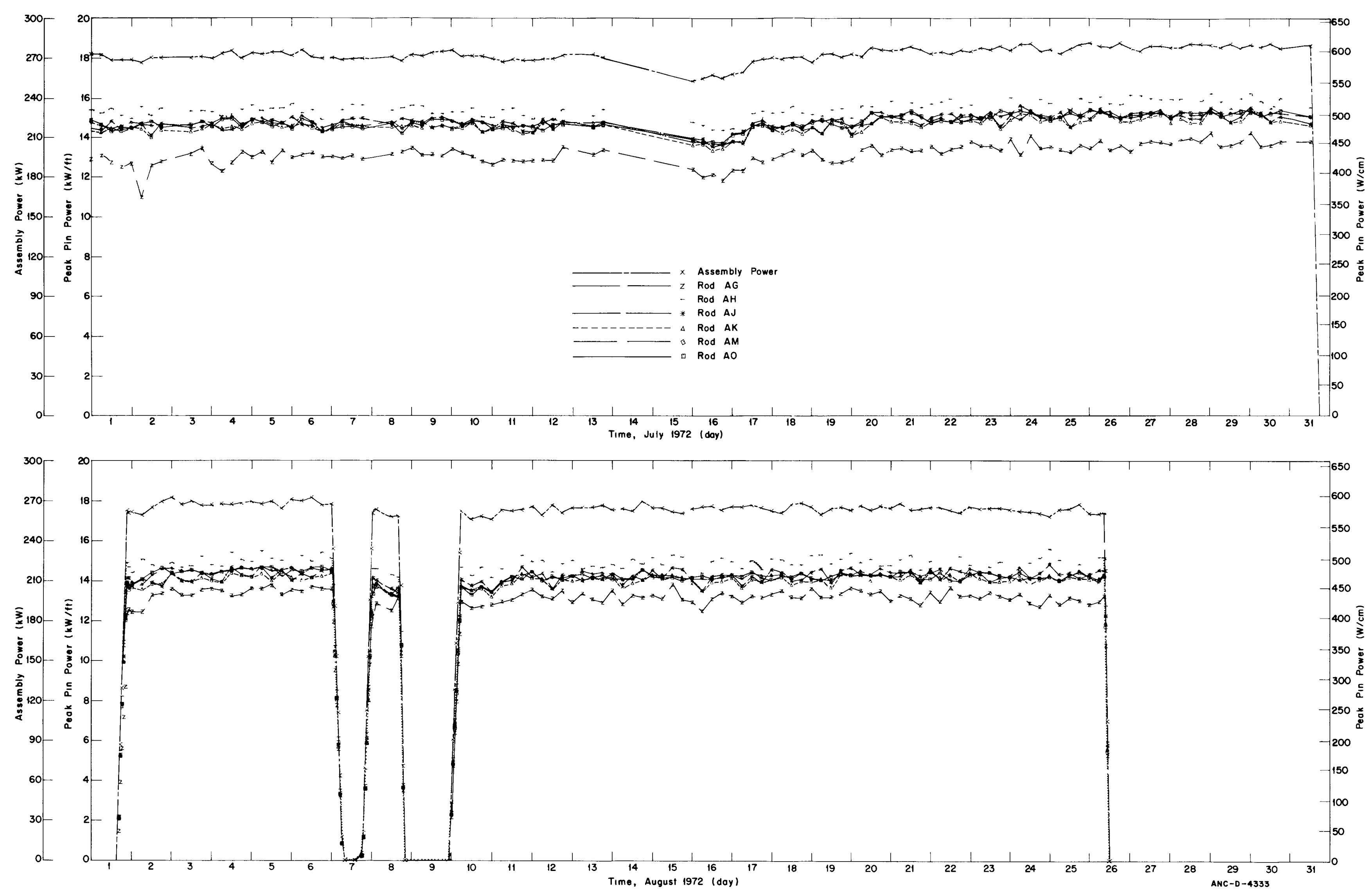

Fig. 33 Peak power history of IFA-226 test rods from July 1972 through August 1972. 

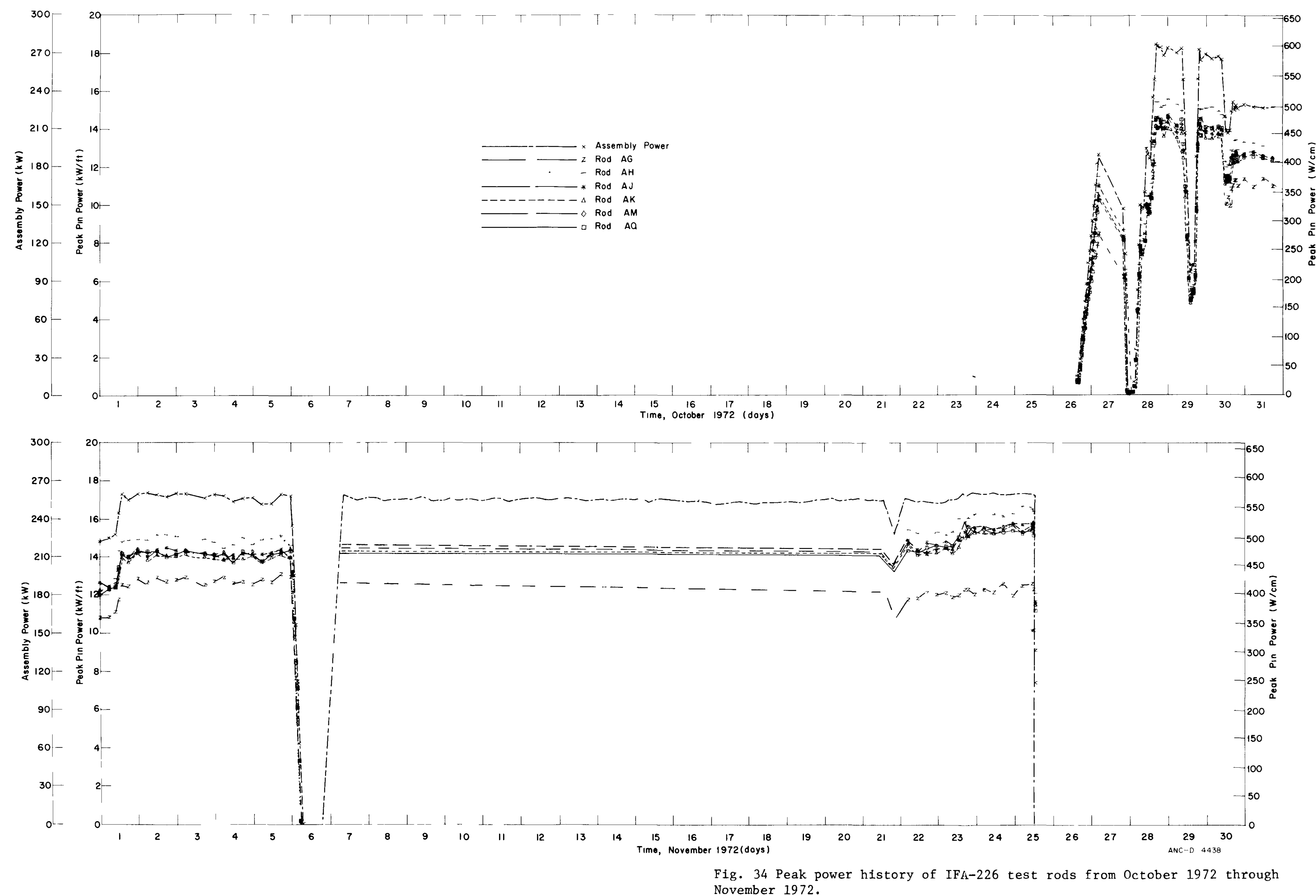
Fig. 34 Peak power history of IFA-226 test rods from October 1972 through
November 1972. 

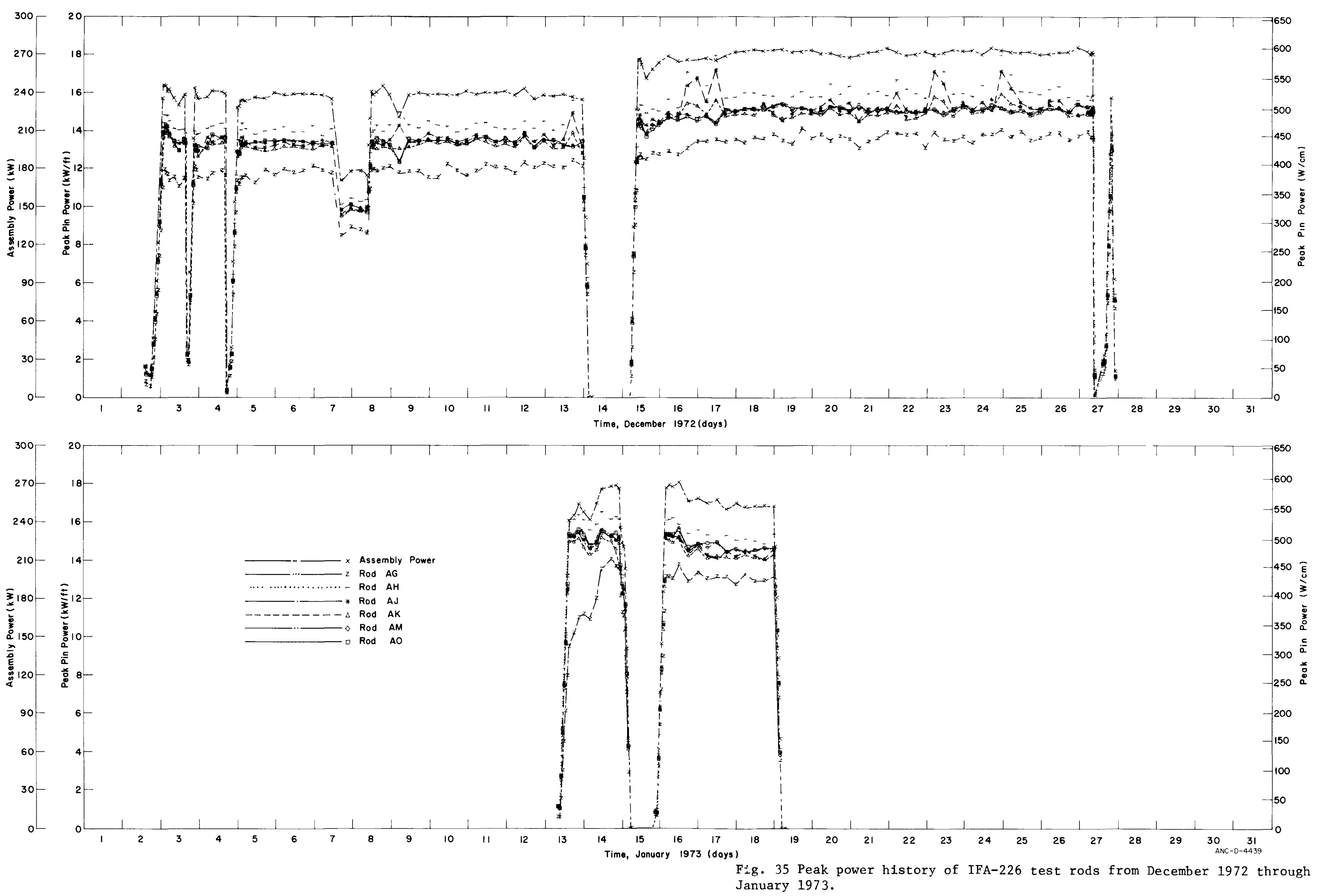

48 

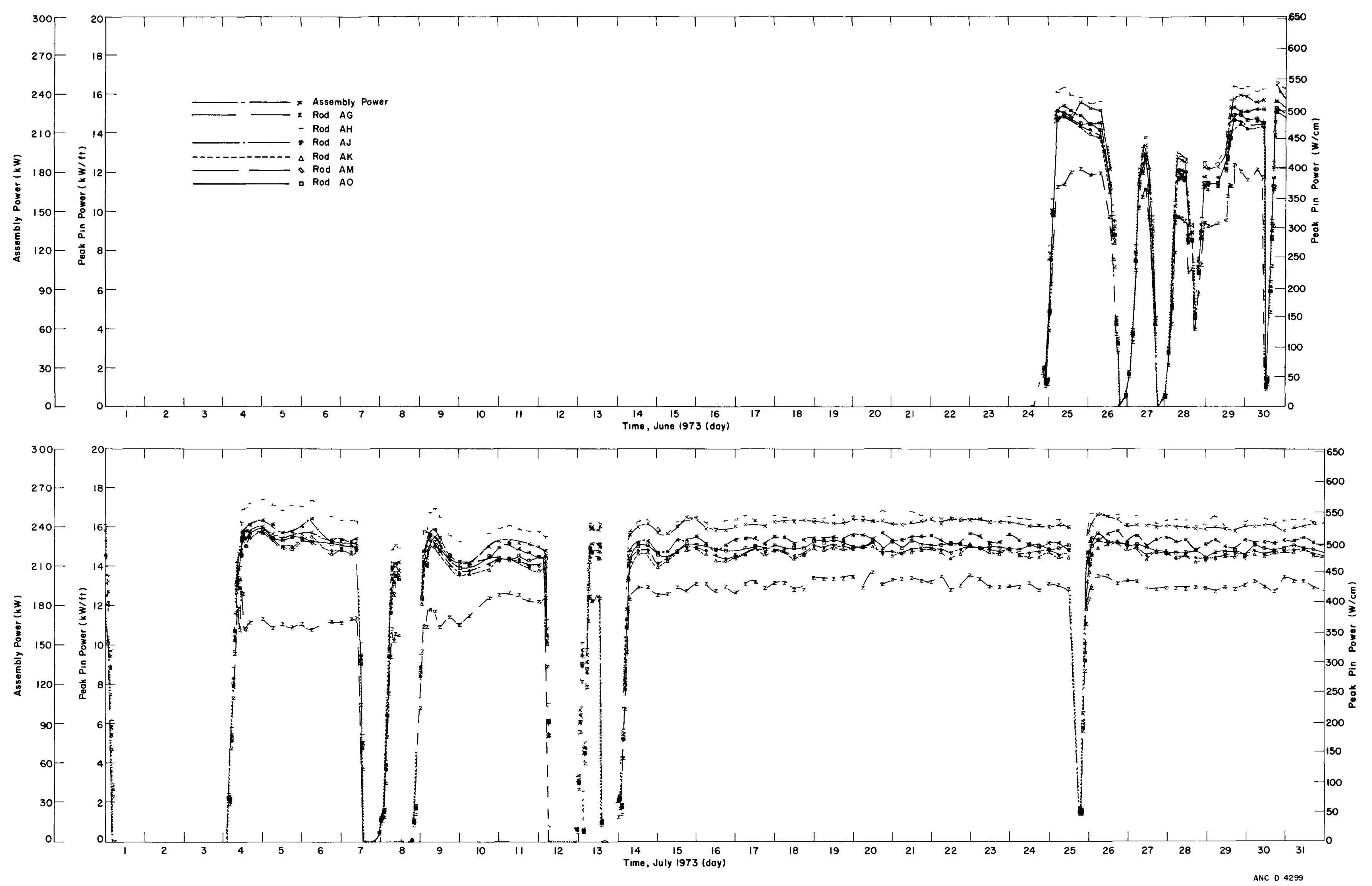

Fig. 37 Peak power history of IFA-226 test rods from June 1973 through Ju1y 1973. 

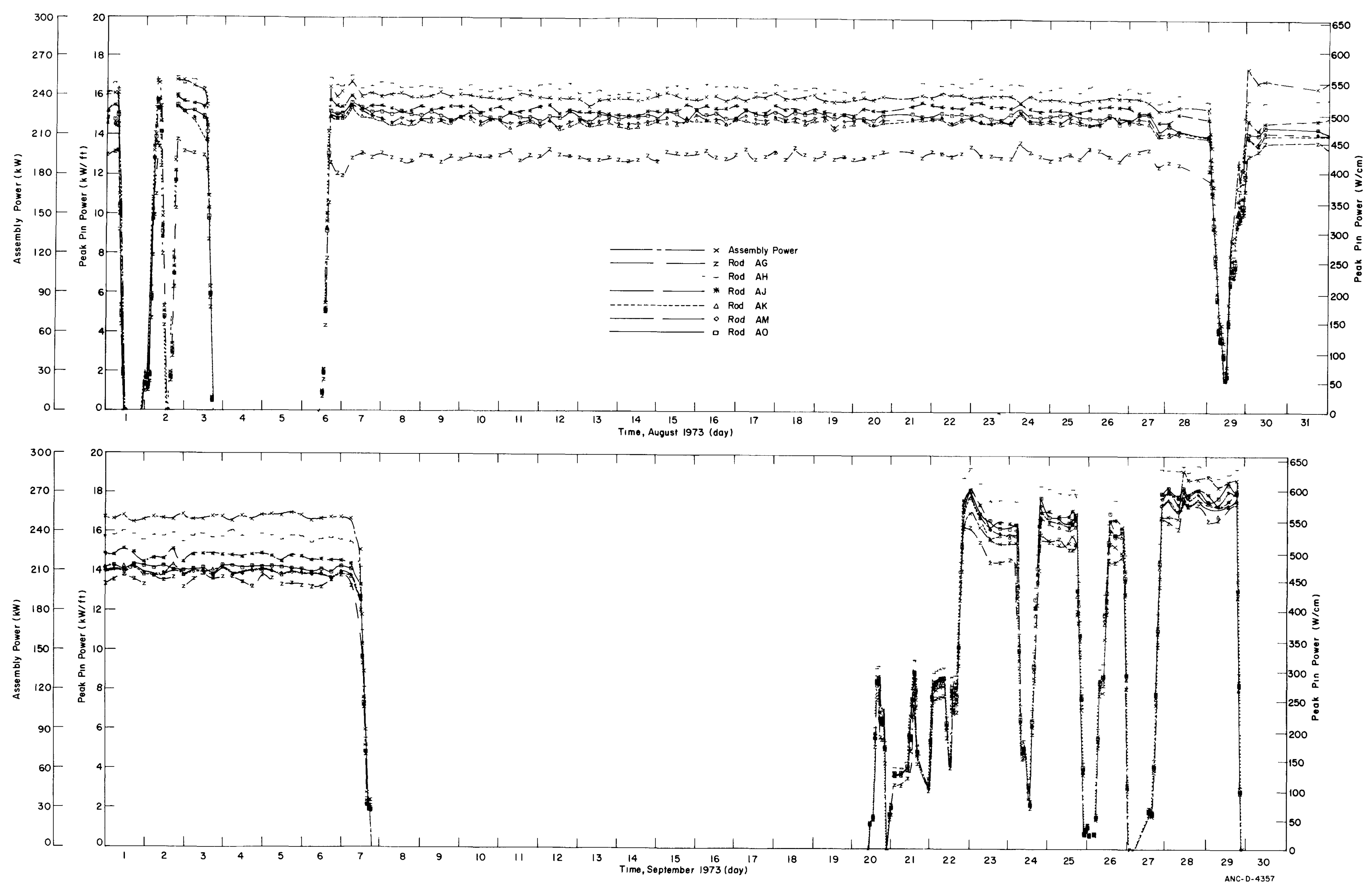

Fig. 38 Peak power history of IFA-226 test rods from August 1973 through September 1973. 

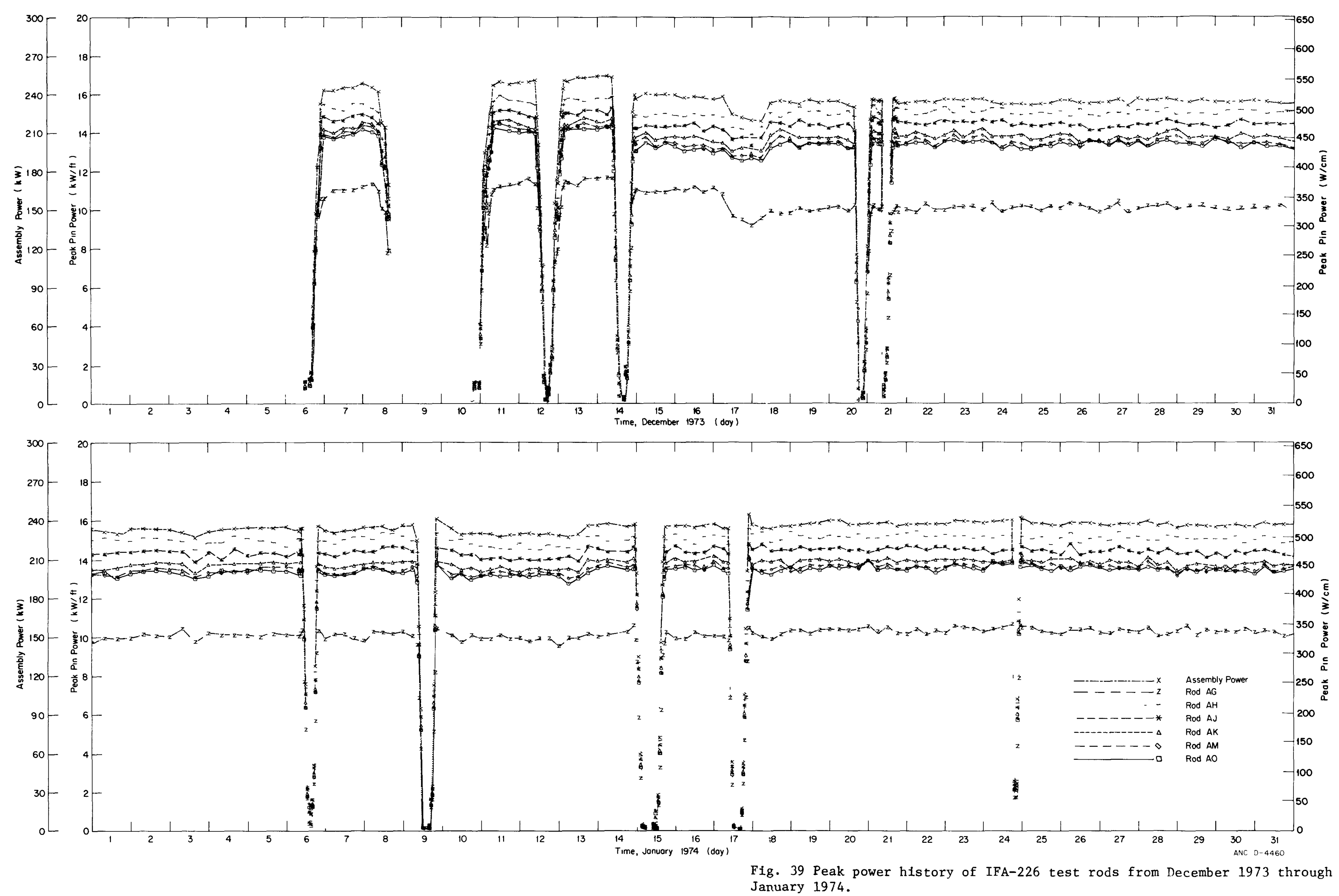

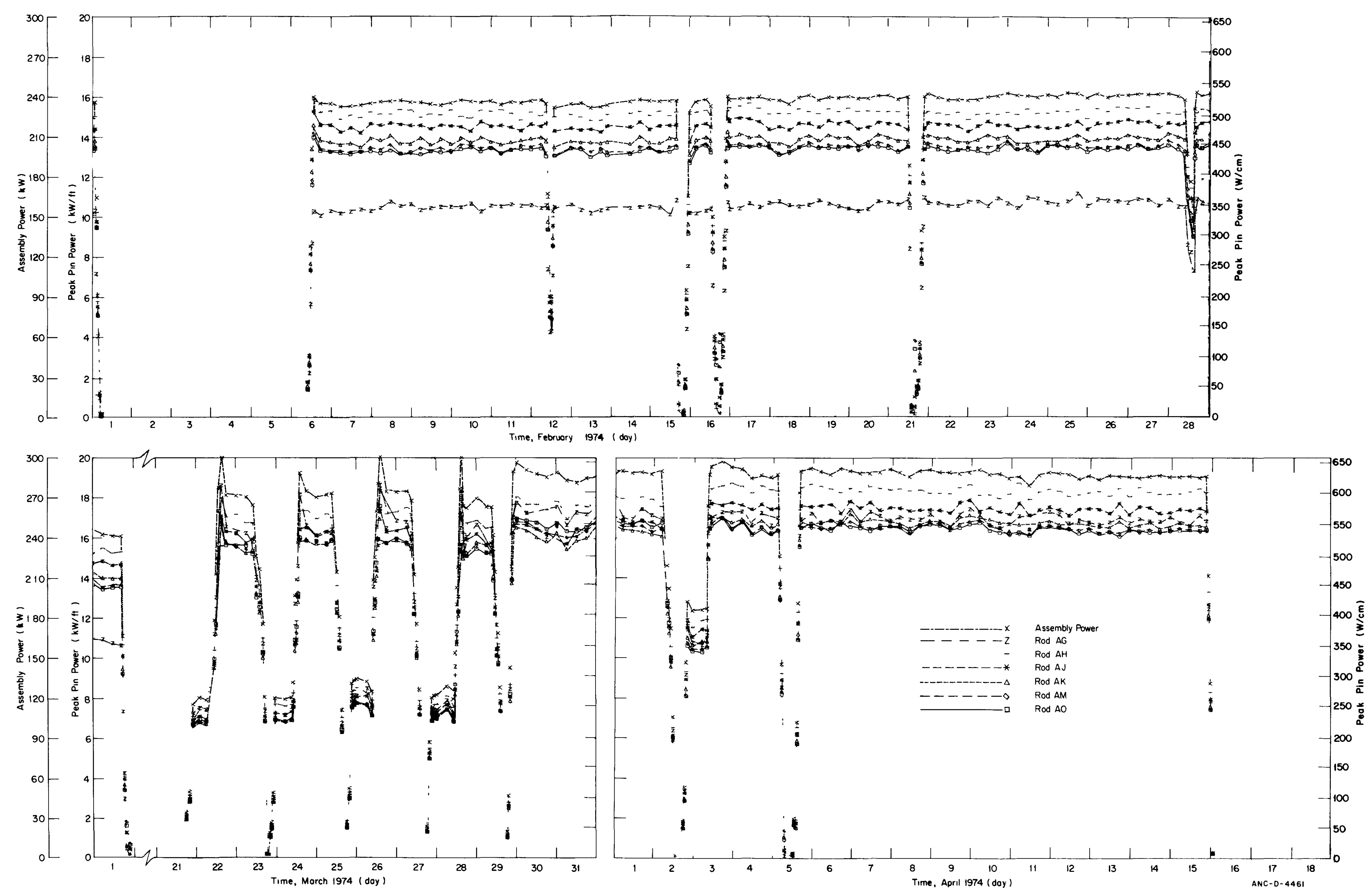

Fig. 40 Peak power history of IFA-226 test rods from February 1974 through Apri1 1974. 

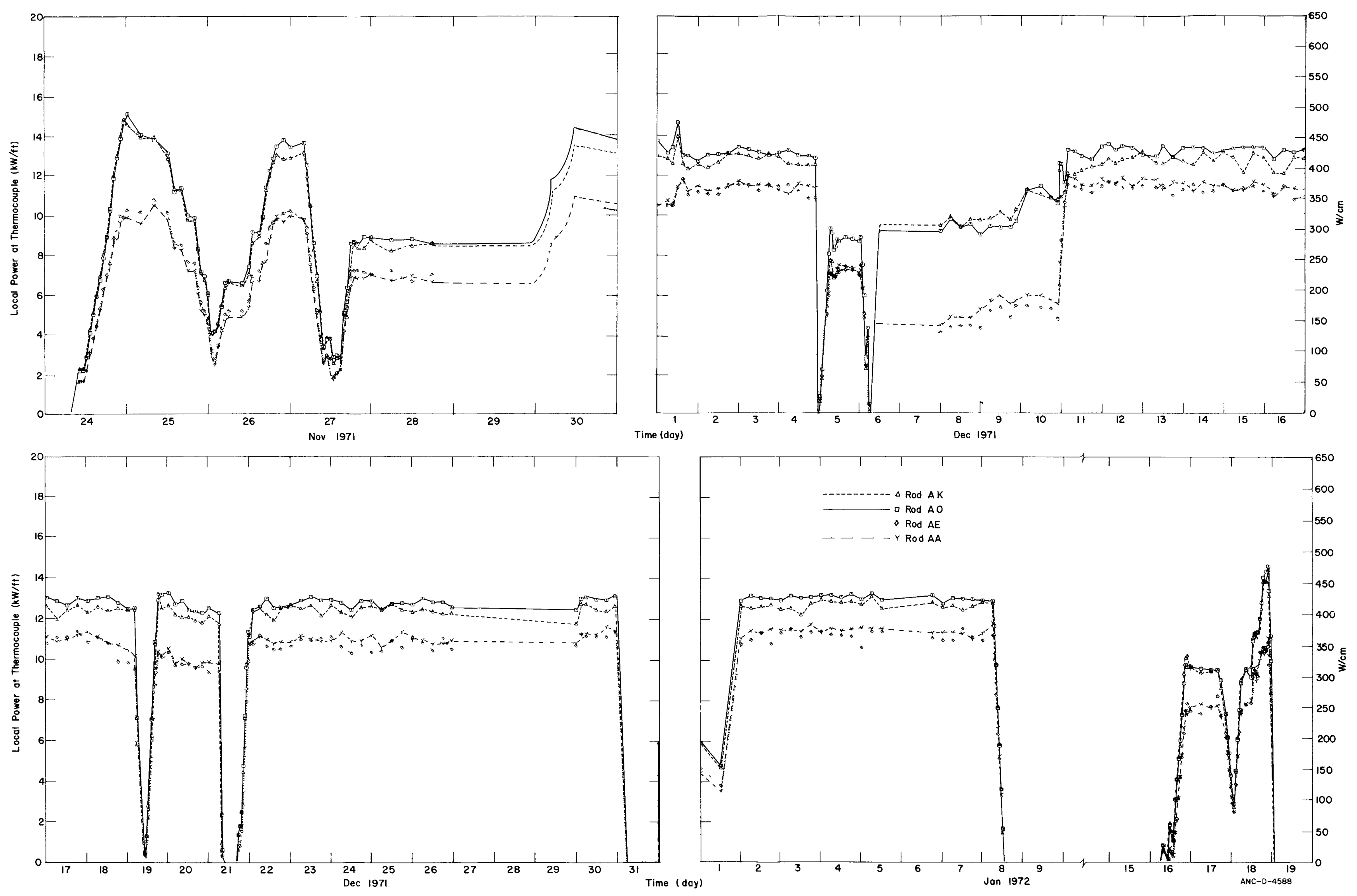

Fig. 41 Local power history at thermocouple location of IFA-226 test rods from November 1971 through January 1972. 

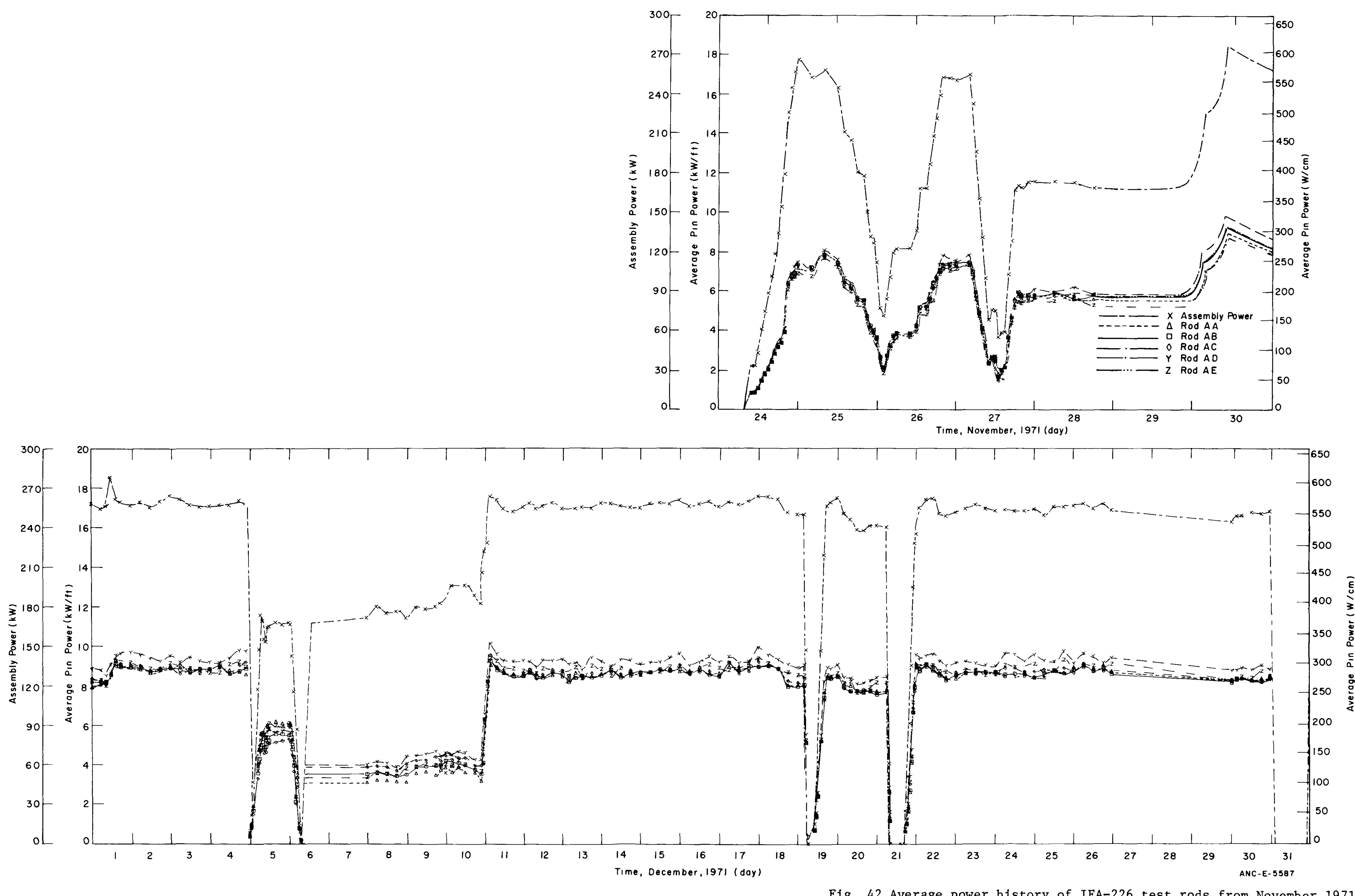

Fig. 42 Average power history of IFA-226 test rods from November 1971 

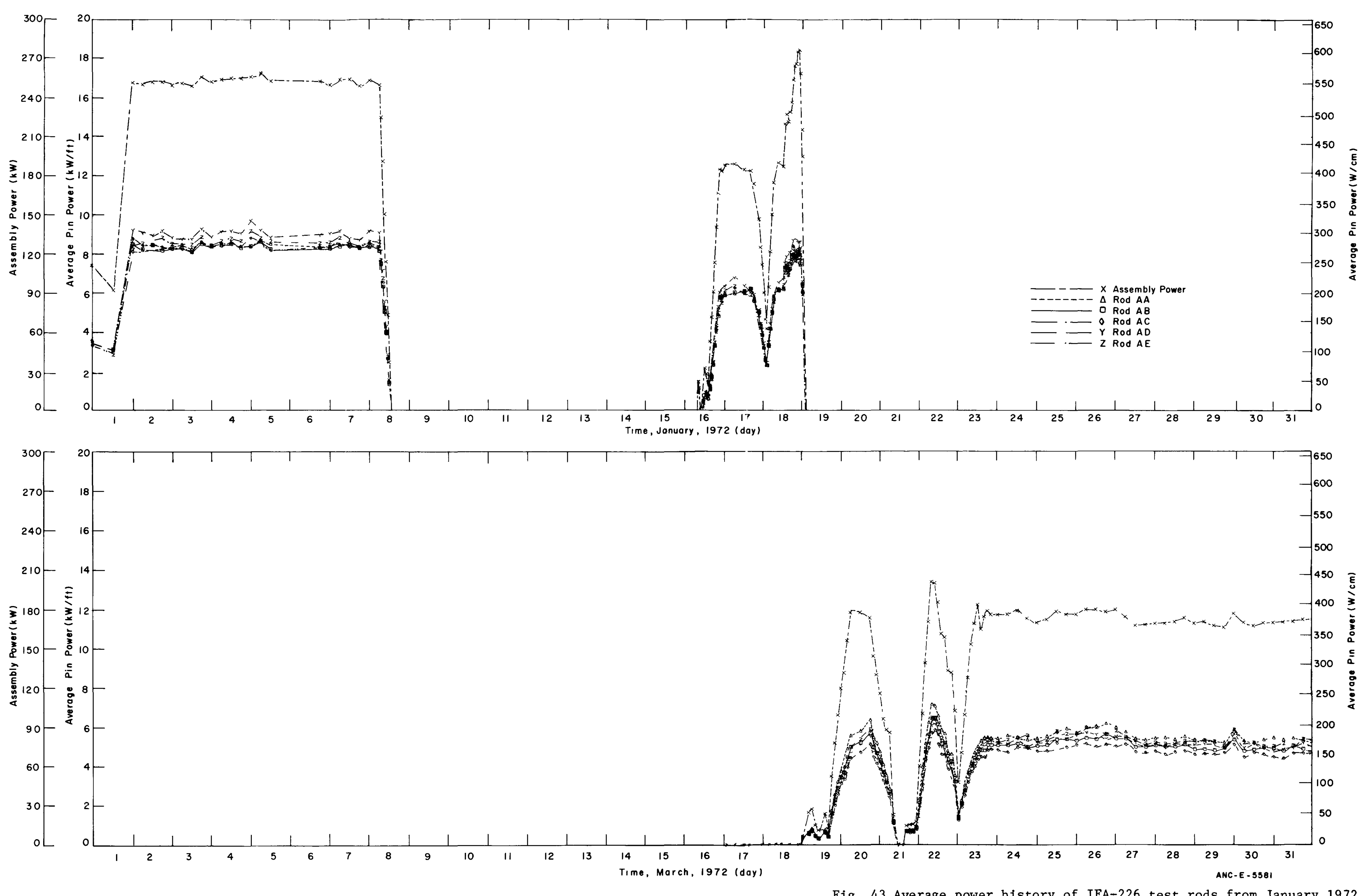

Fig. 43 Average power history of IFA-226 test rods from January 1972 through March 1972. 

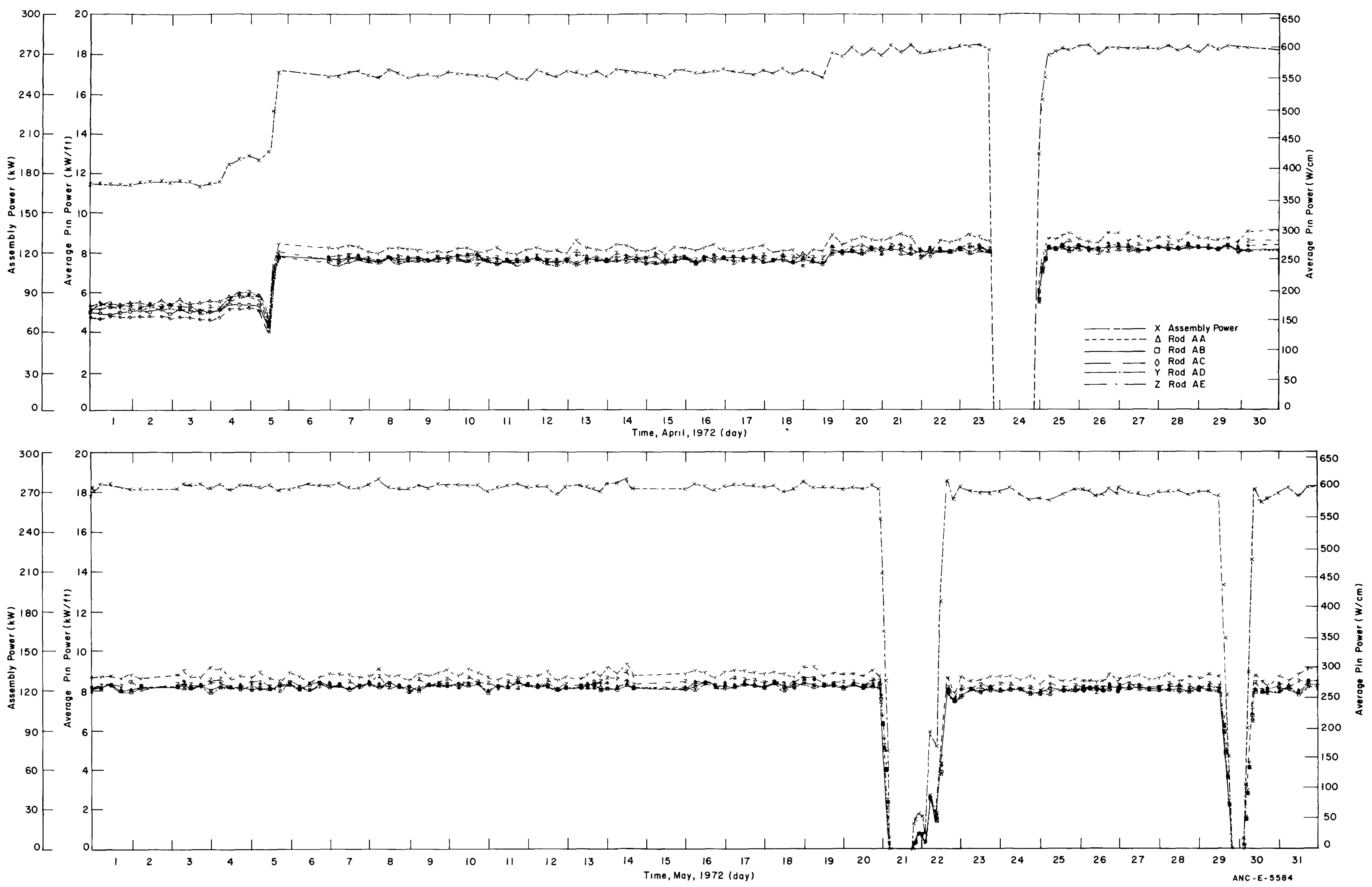

Fig. 44 Average power history of IFA-226 test rods from April 1972 through June 1972. 

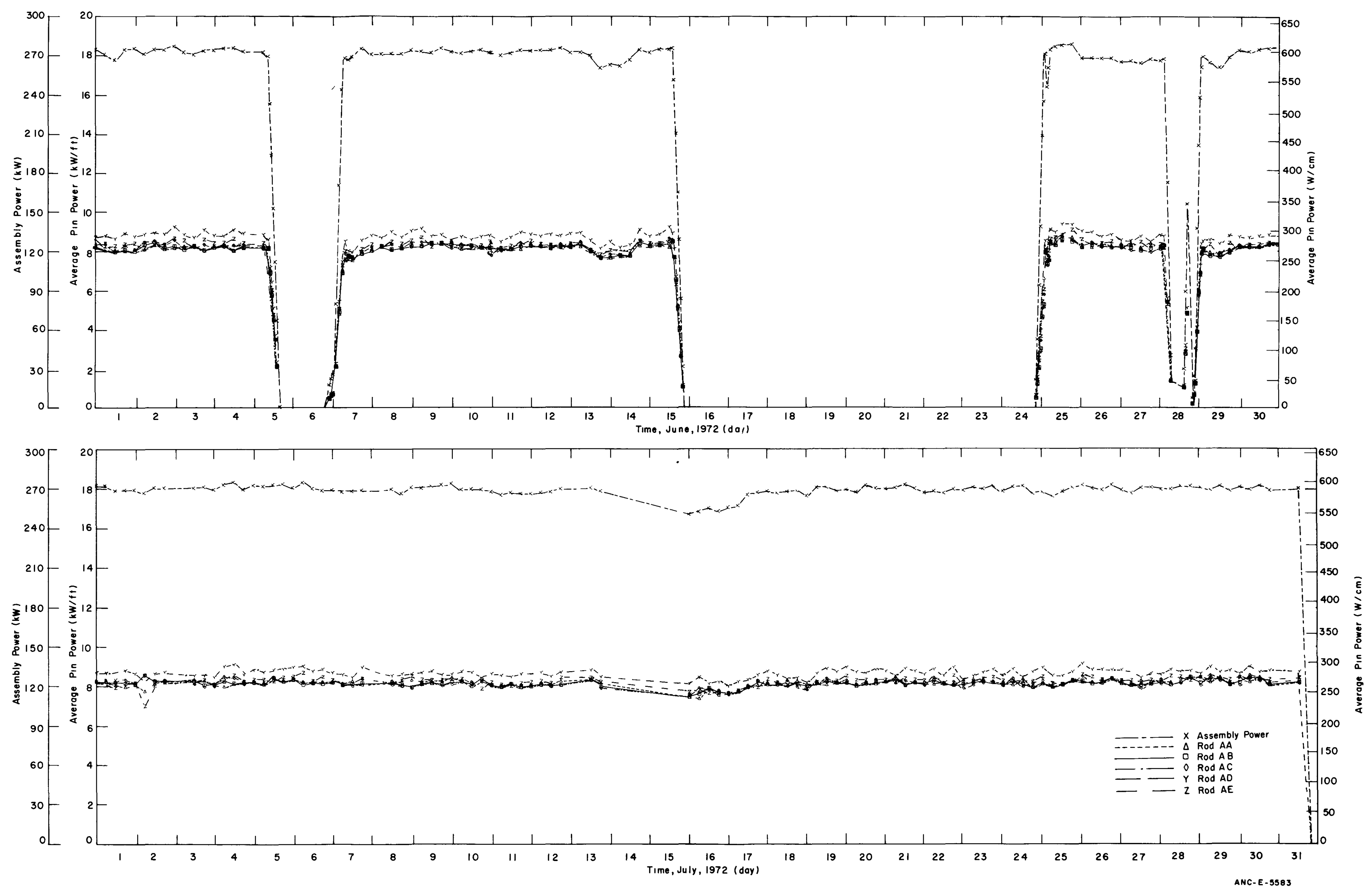

Fig. 45 Average power history of IFA-226 test rods from June 1972 through July 1972. 

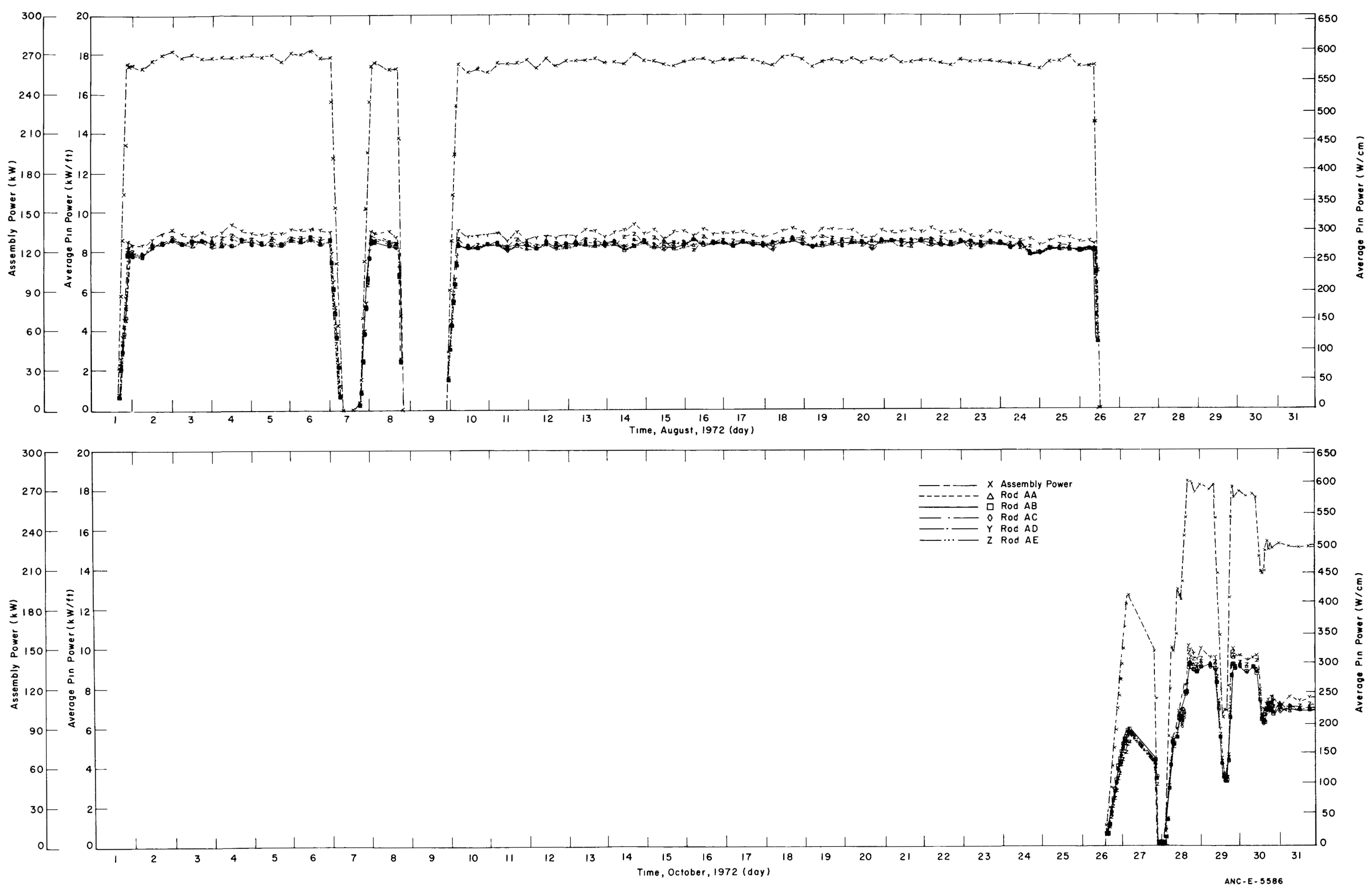

Fig. 46 Average power history of IFA-226 test rods from August 1972 through October 1972. 

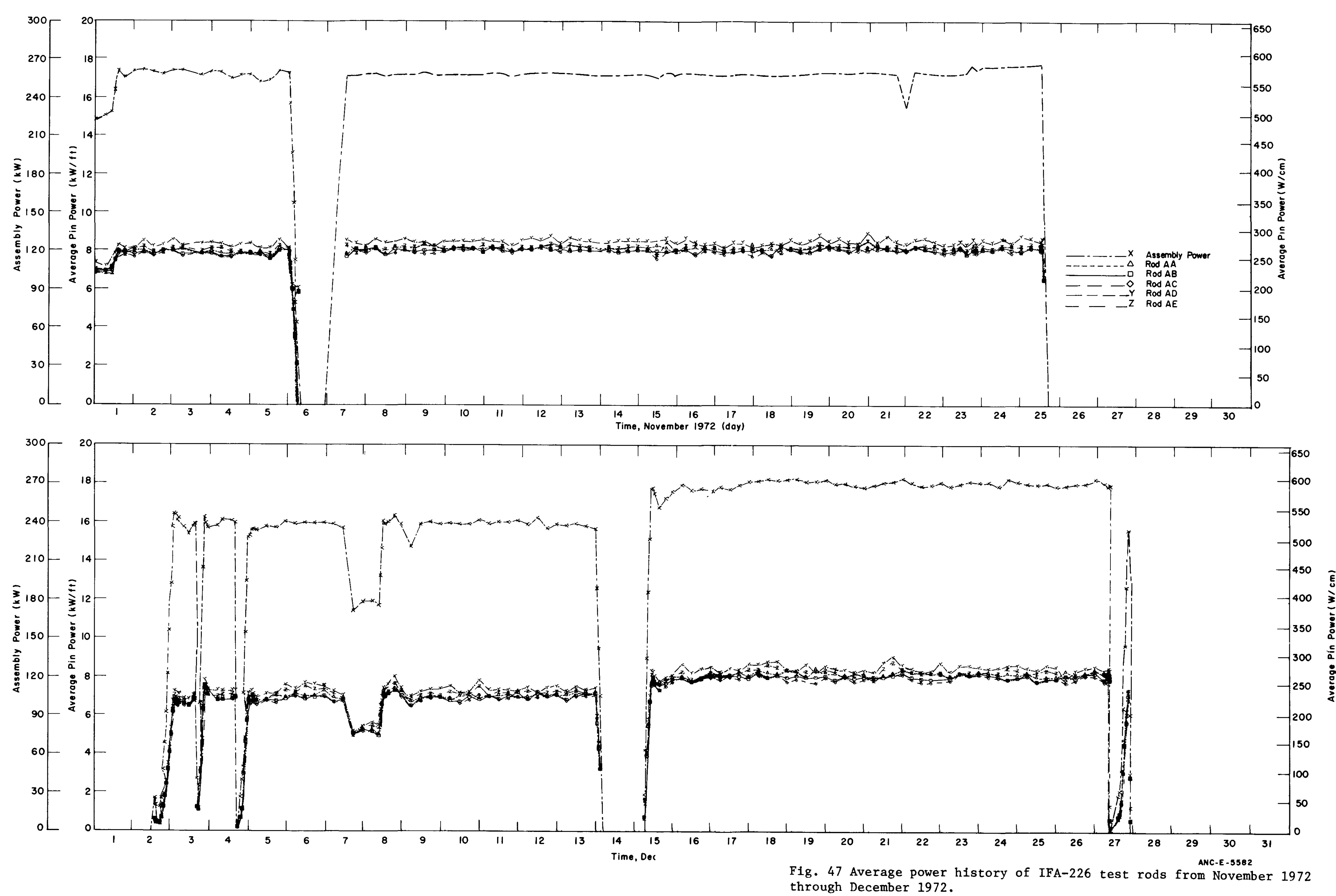

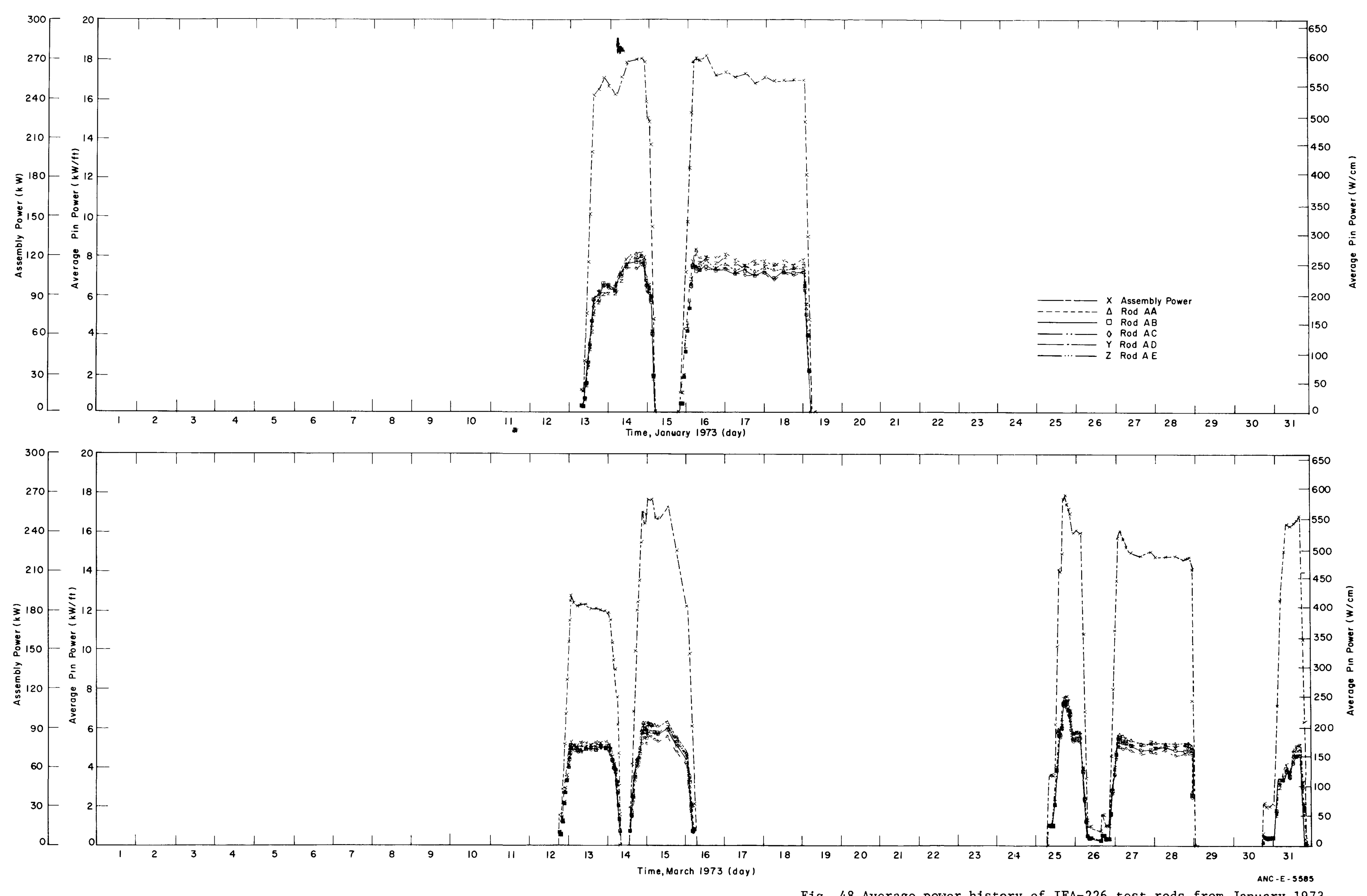

Fig. 48 Average power history of IFA-226 test rods from January 1973 through March 1973. 

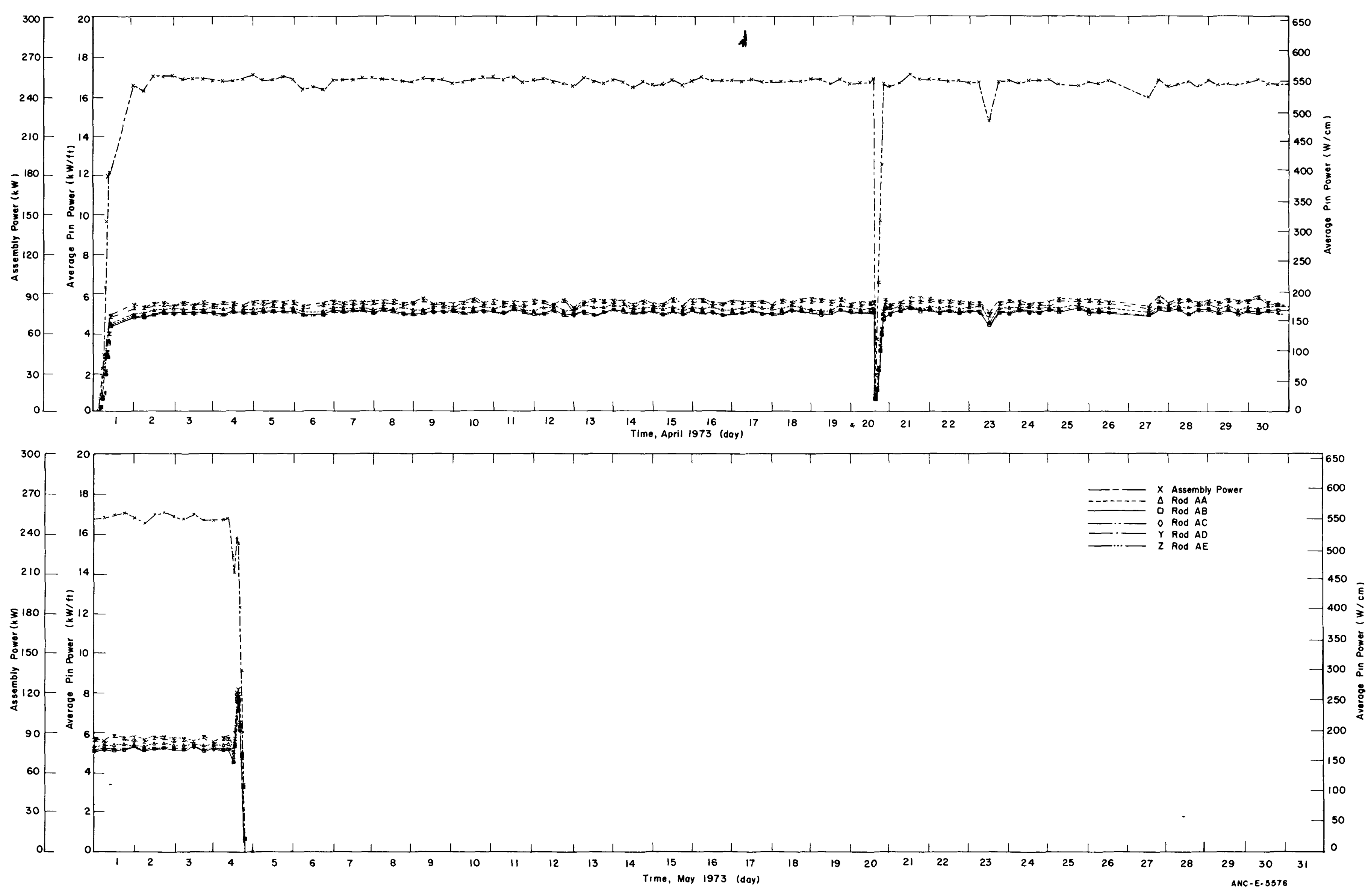

F1g. 49 Average power history of IFA-226 test rods from April 1973 through May 1973. 

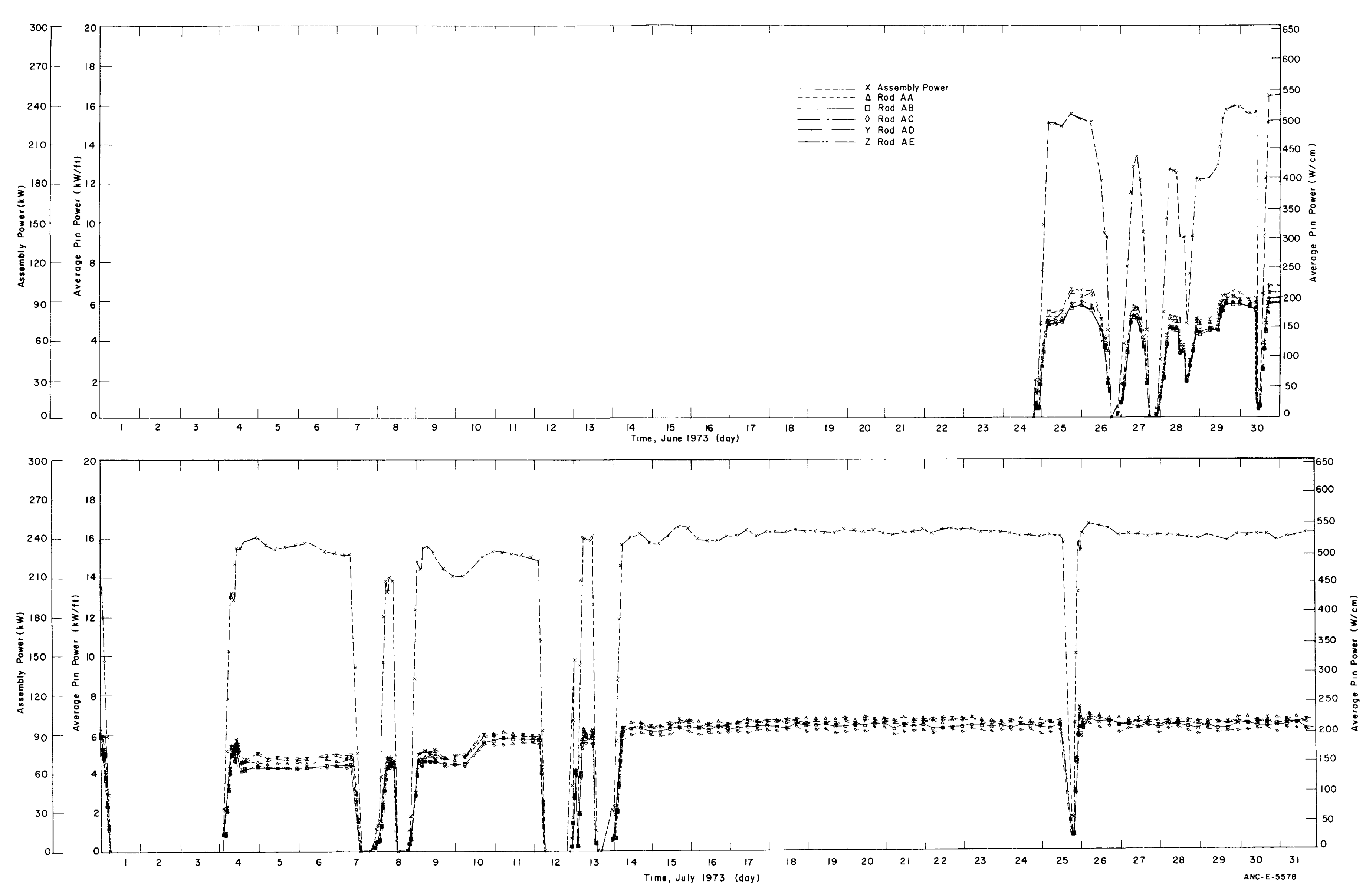

Fig. 50 Average power history of IFA-226 test rods from June 1973 through Ju1y 1973. 

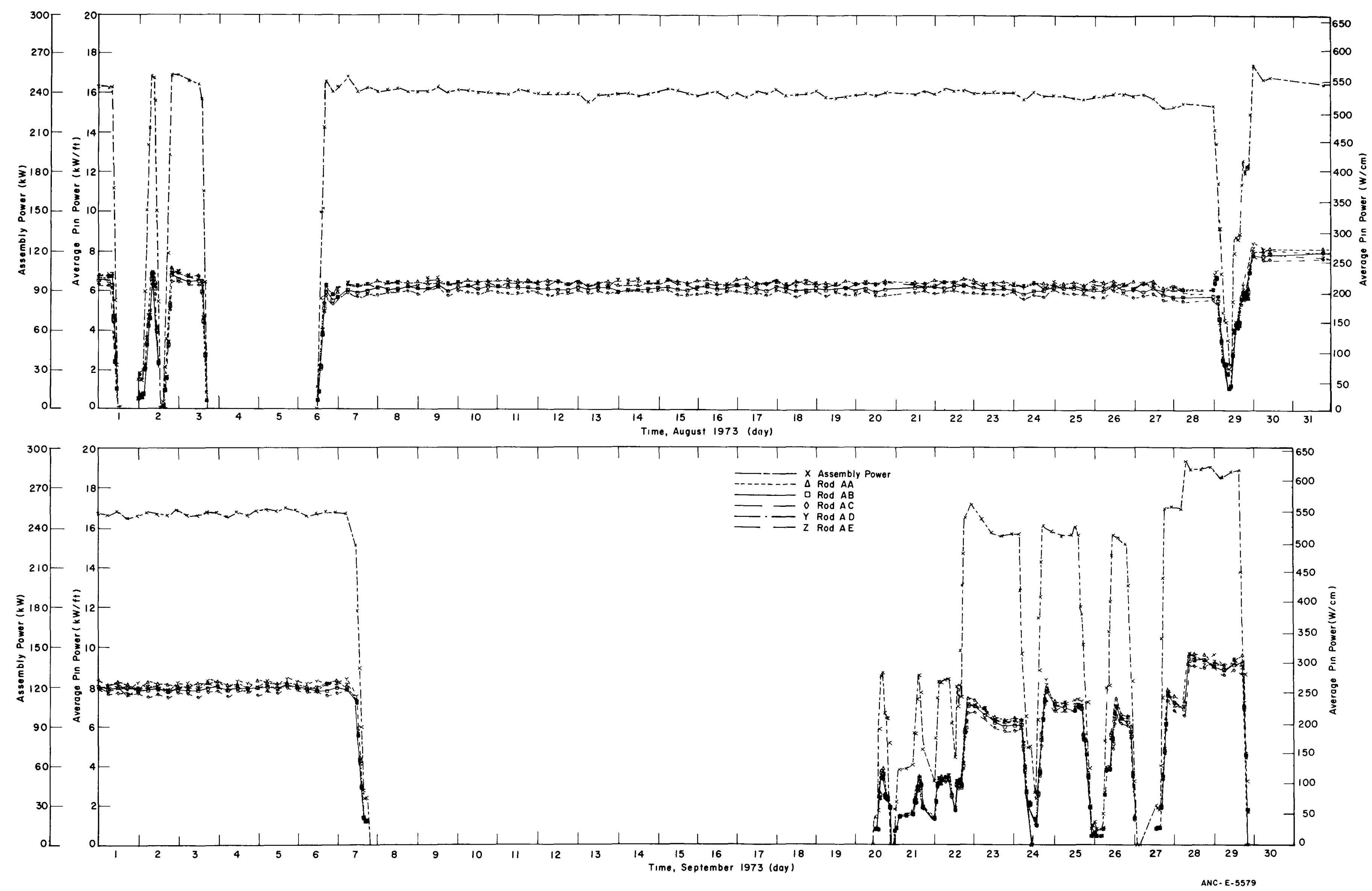

Fig. 51 Average power history of IFA-226 test rods from August 1973 through September 1973. 

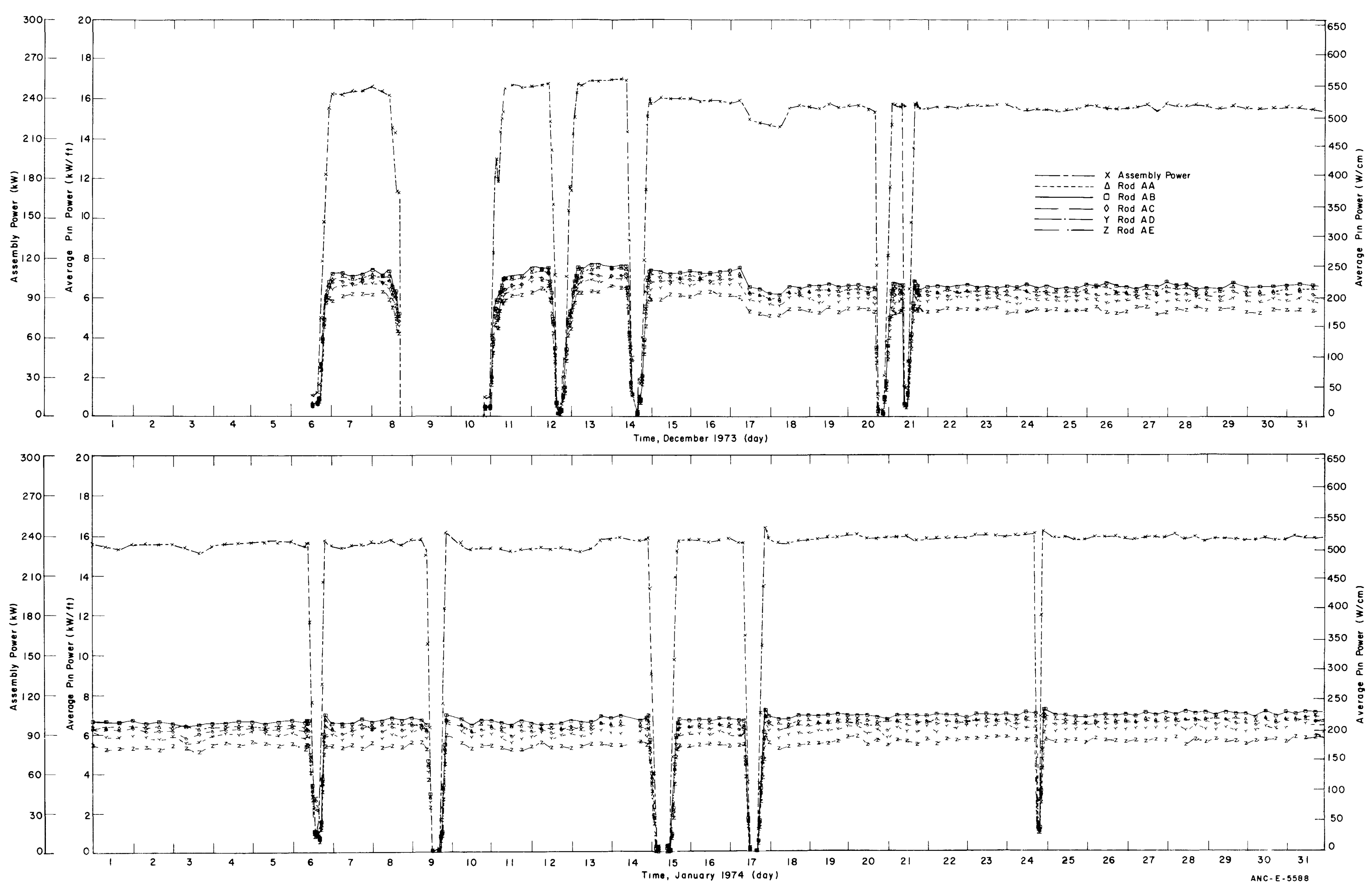

Fig. 52 Average power history of IFA-226 test rods from December 1973 through January 1974. 

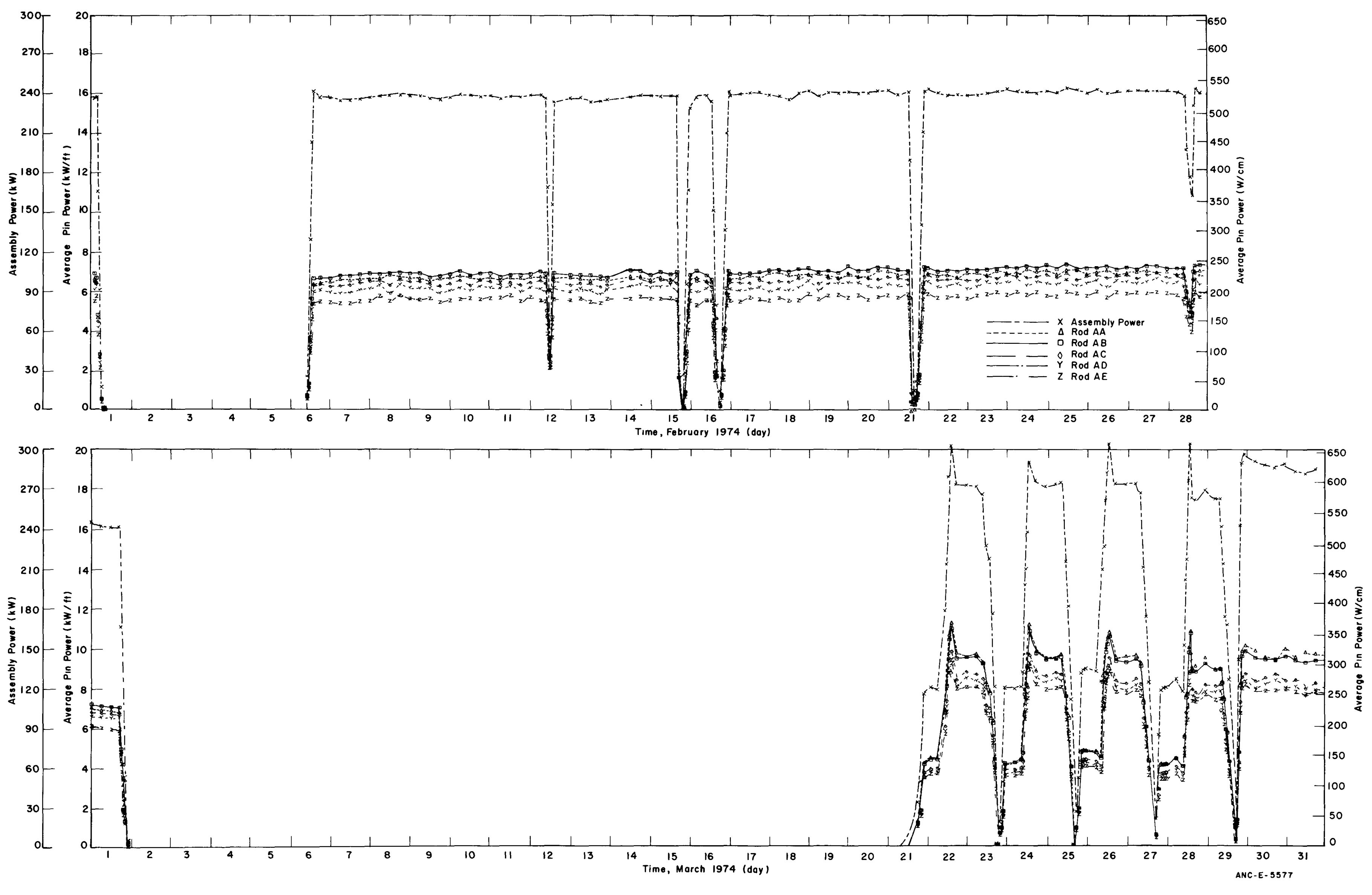

Fig. 53 Average power history of IFA-226 test rods from February 1974 through March 1974. 


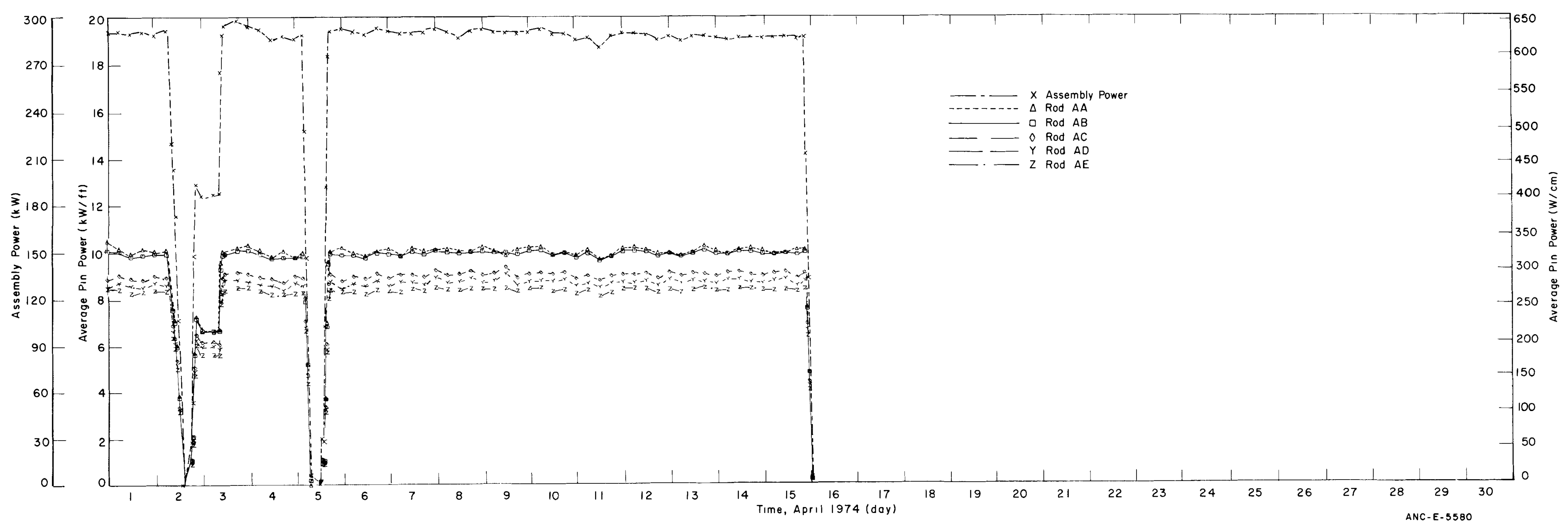

Fig. 54 Average power history of IFA-226 test rods for April 1974. 


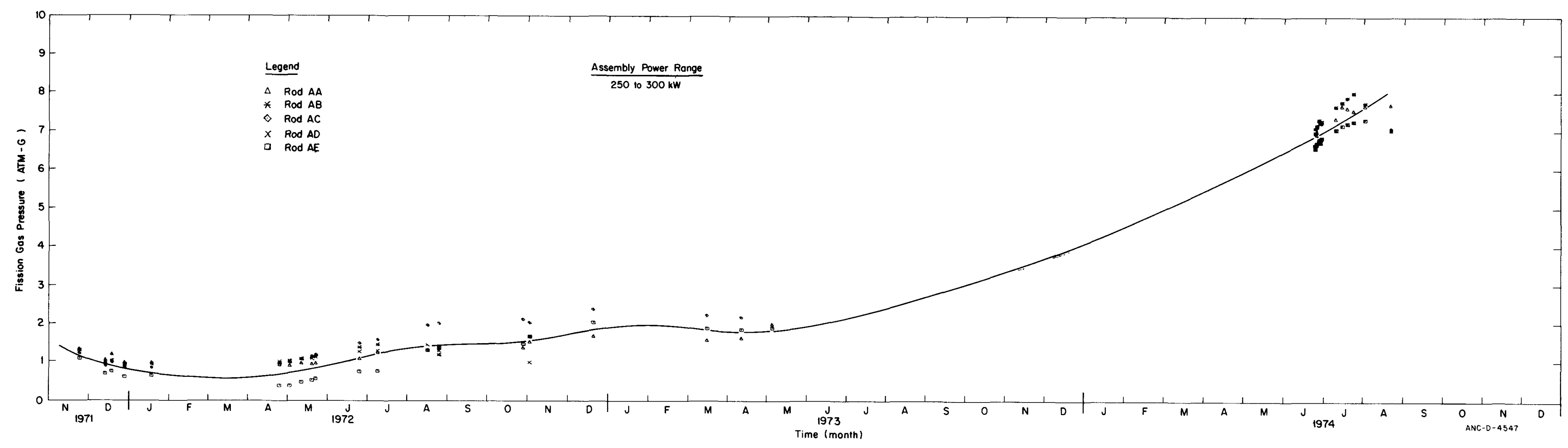

Fig. 55 Fission gas pressure history of IFA-226 test rods at high power levels. 

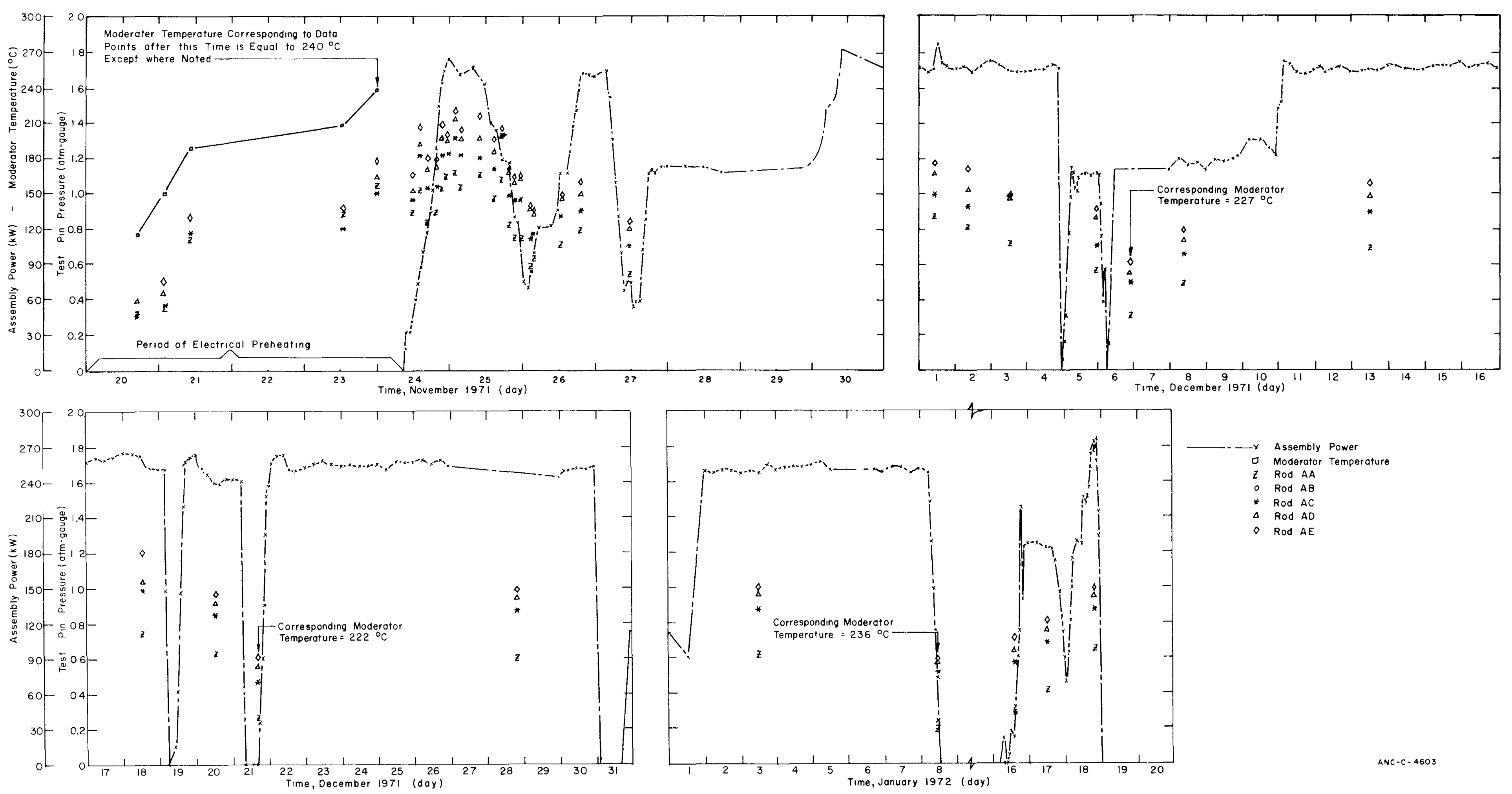

$\times$ Assembly Power

- Moderator Temperature

0 Rod $A B$

$*$ Rod $A C$
$\triangle$ Rod $A D$
0

Rod AE 

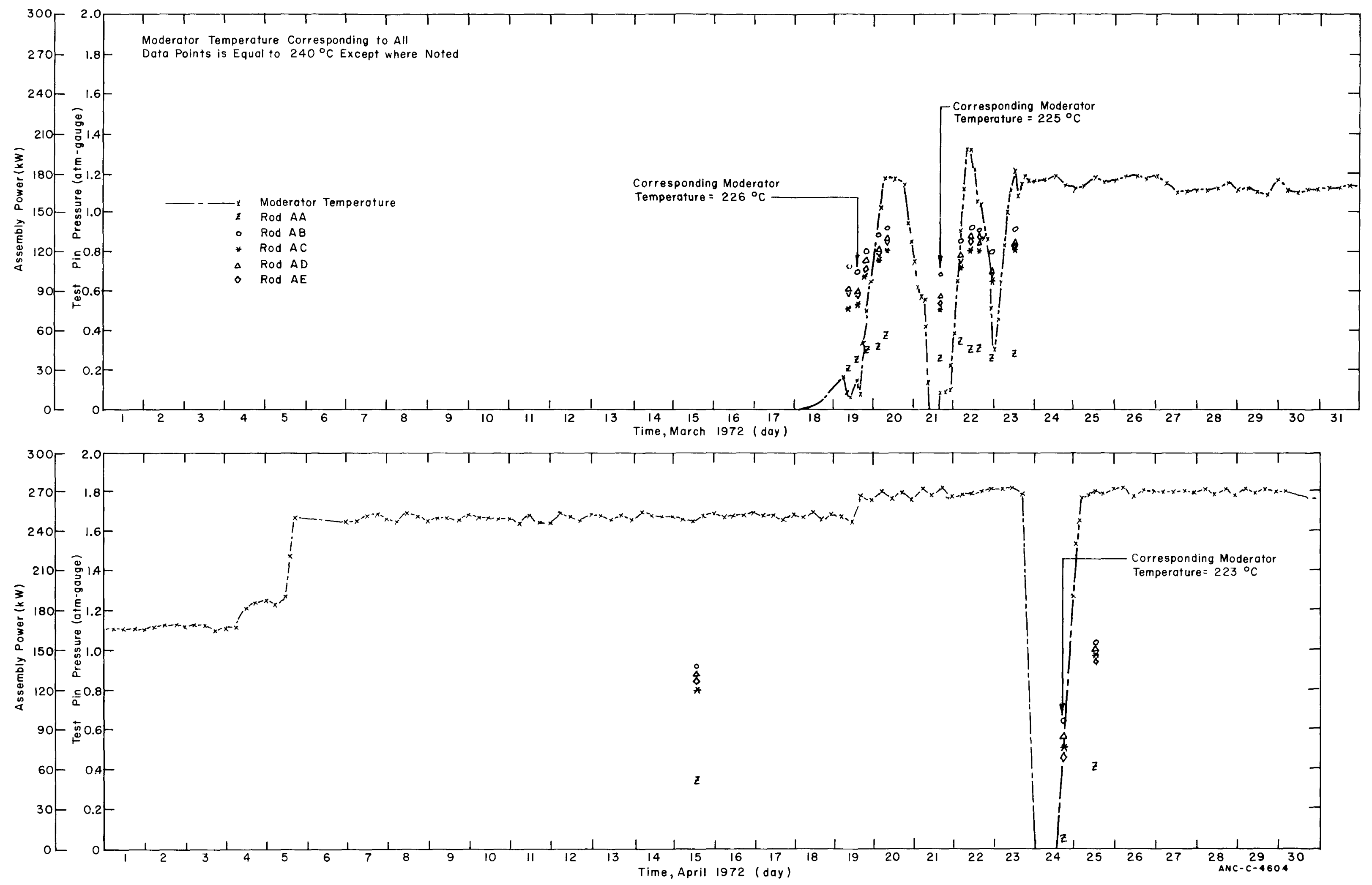

Fig. 57 Fission gas pressure history of IFA-226 test rods from March 1972 through April 1972. 

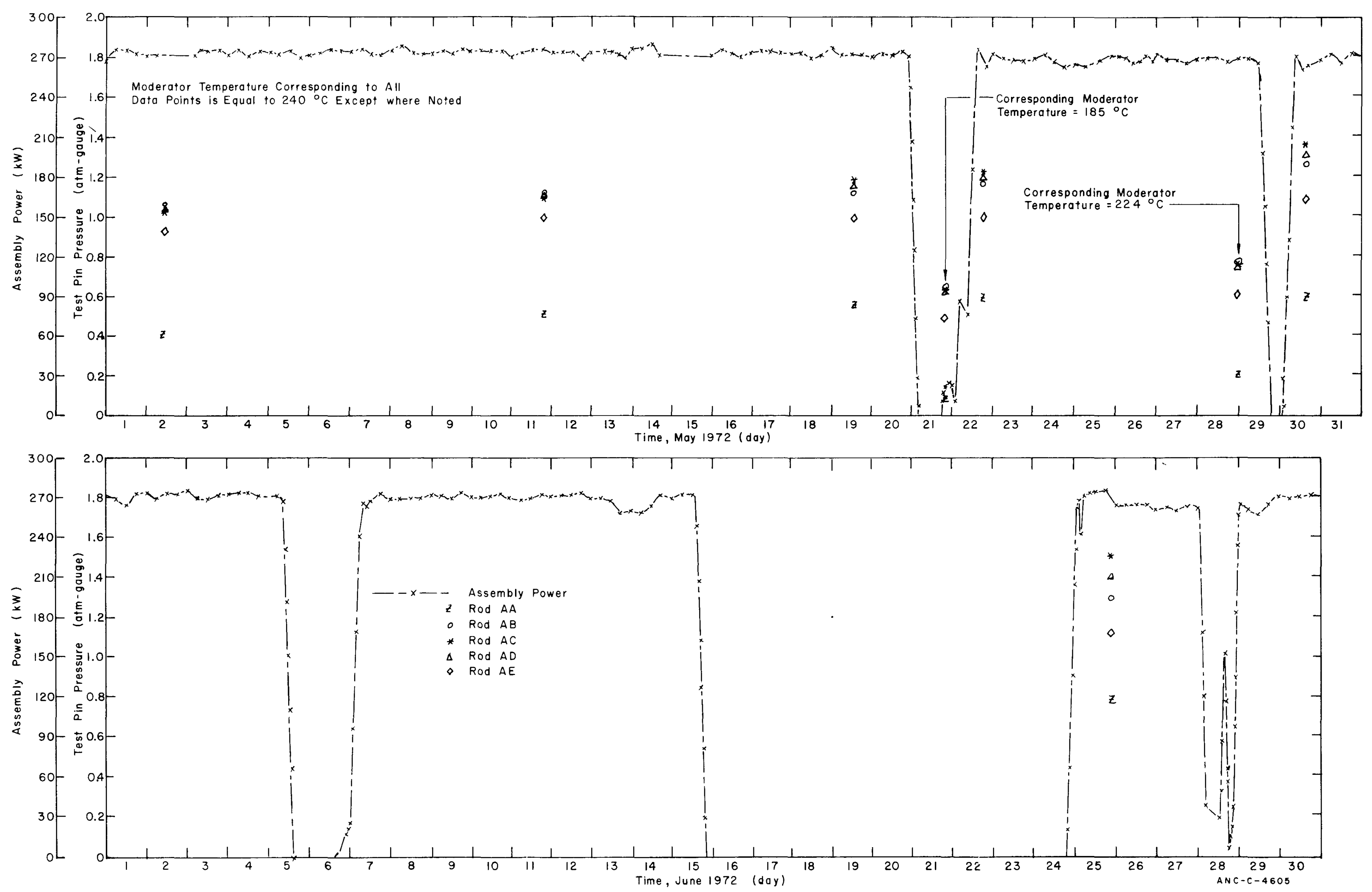

Fig. 58 Fission gas pressure history of IFA-226 test rods from May 1972 through June 1972 . 

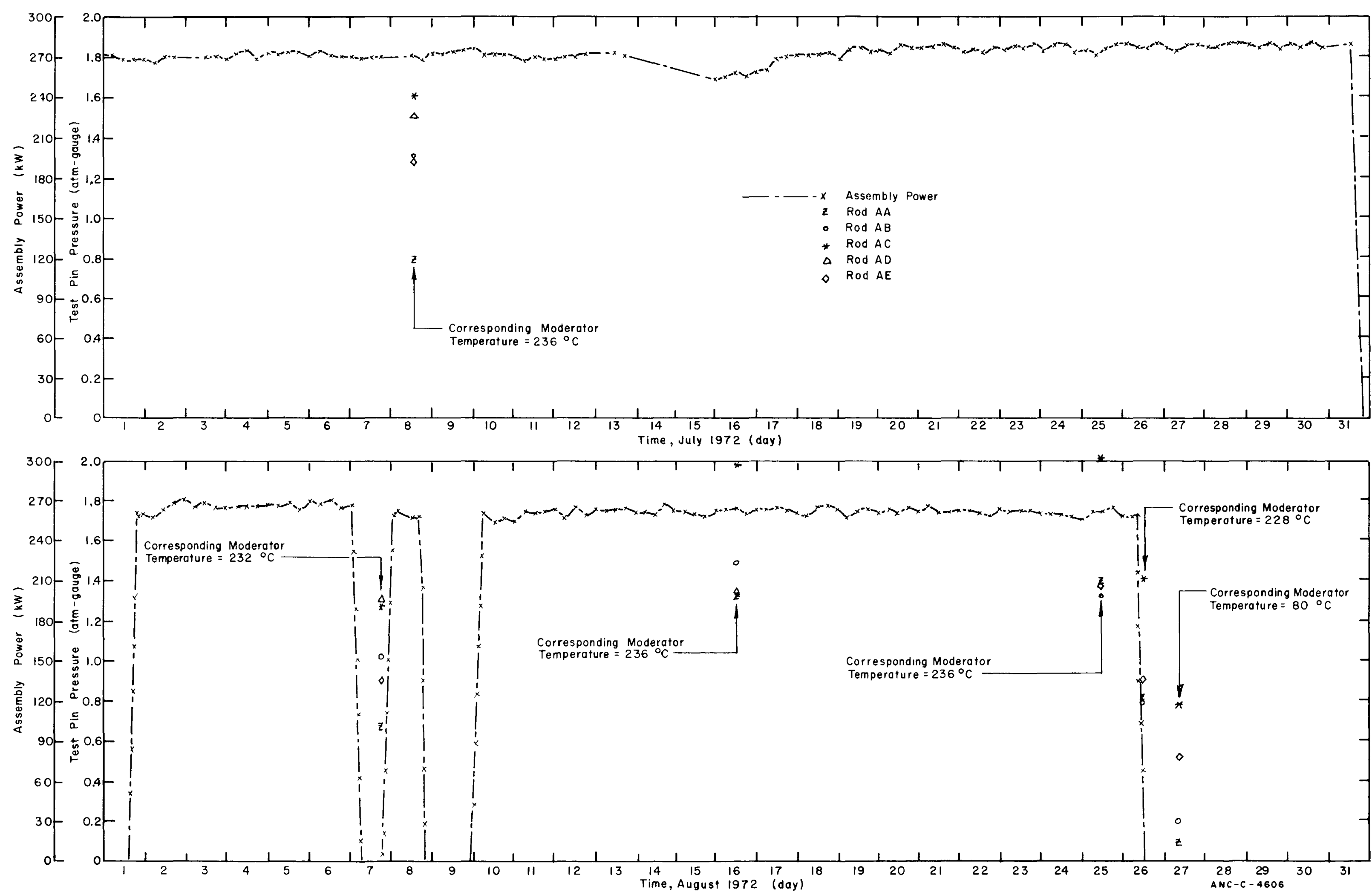

Fig. 59 Fission gas pressure history of IFA-226 test rods from July 1972 through August 1972. 


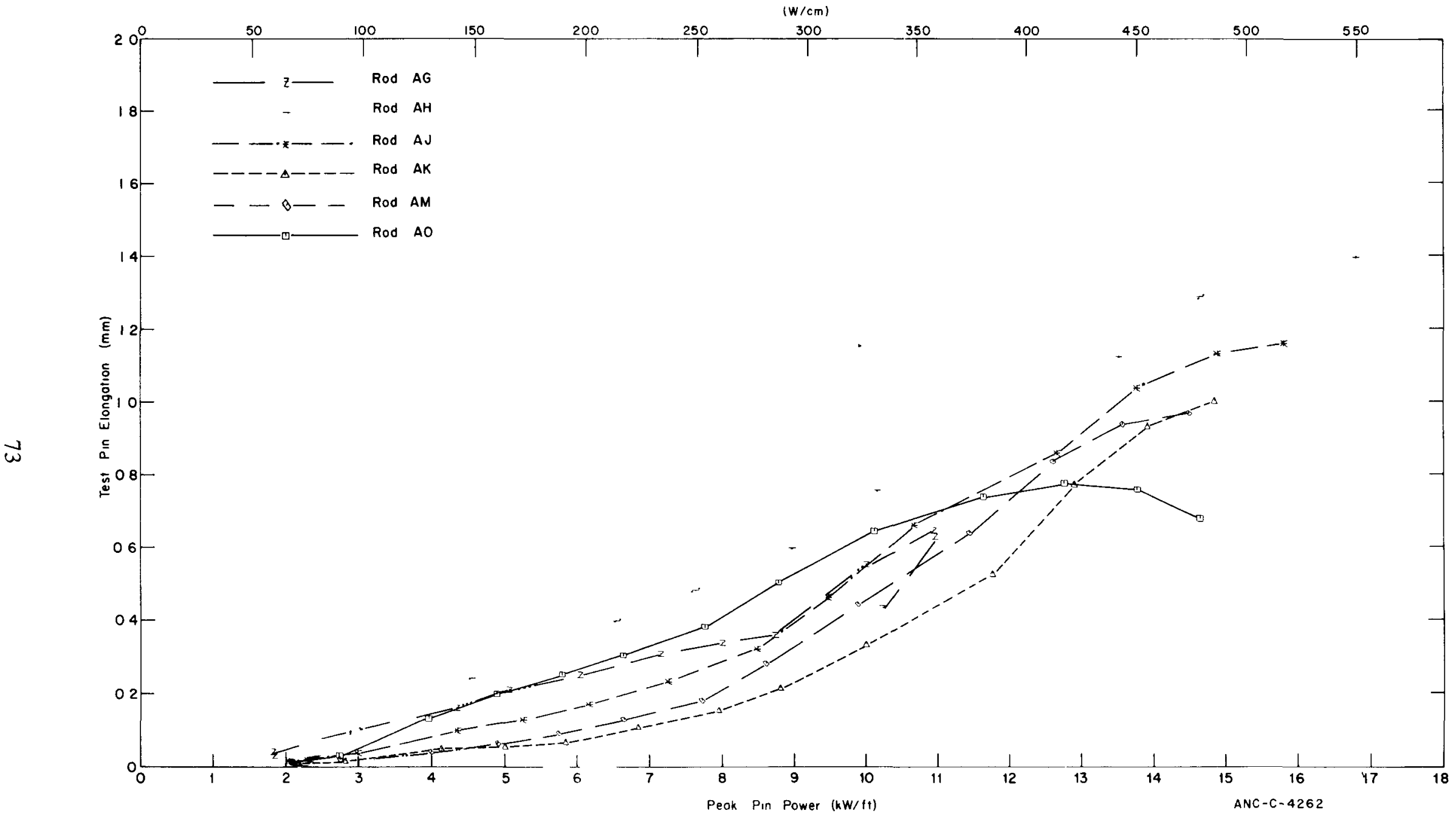

Fig. 60 IFA-226 test rod elongation versus peak rod power from November 24, 1971 at 1000 hours through November 24, 1971 at 2300 hours. 


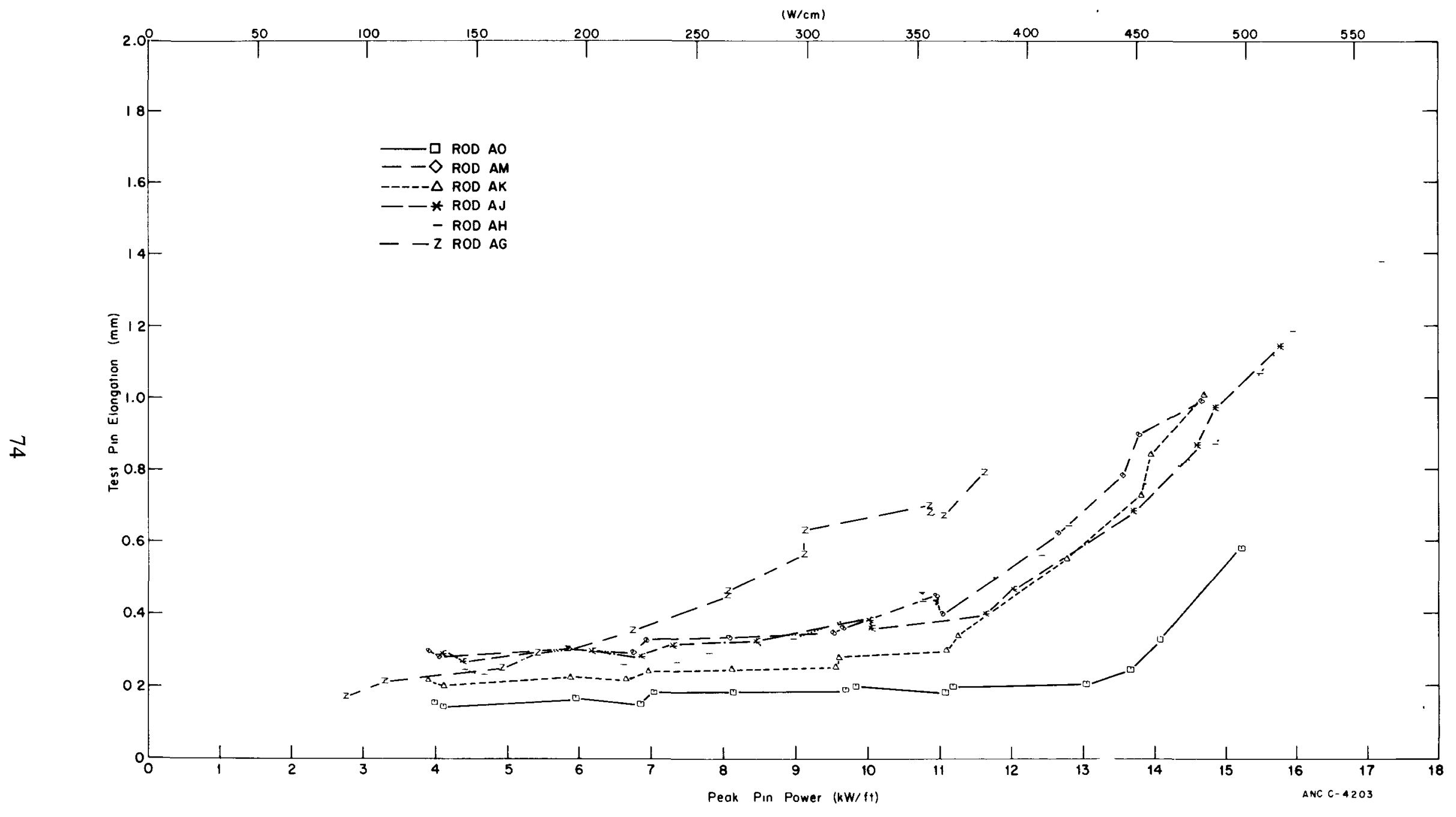

Fig. 61 IFA-226 test rod elongation versus peak rod power from November 25,1971 at 0000 hours through November 26, 1971 at 0200 hours. 


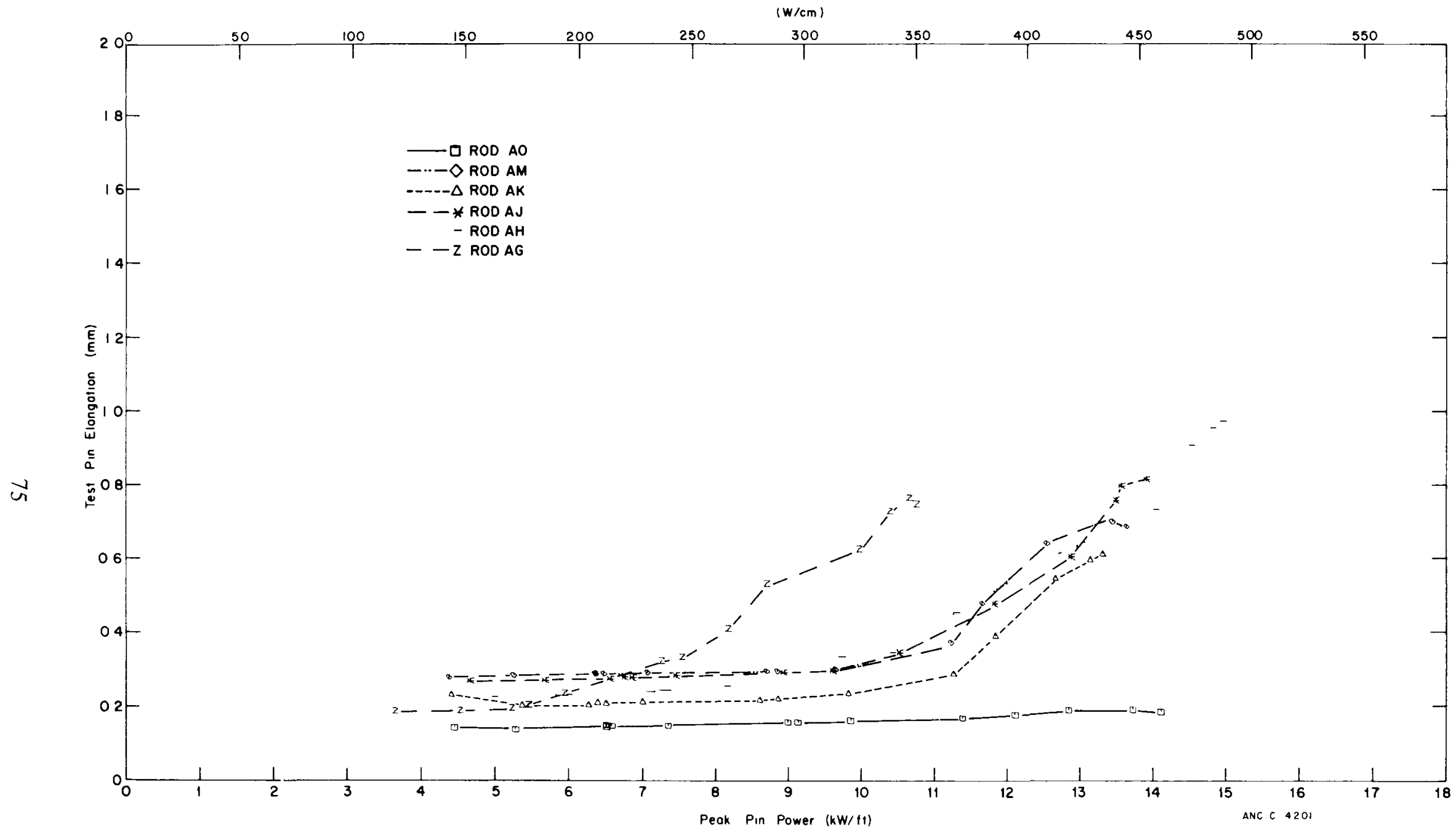

Fig. 62 IFA-226 test rod elongation versus peak rod power from November 26, 1971 at 0300 hours through November 26, 1971 at 2200 hours. 


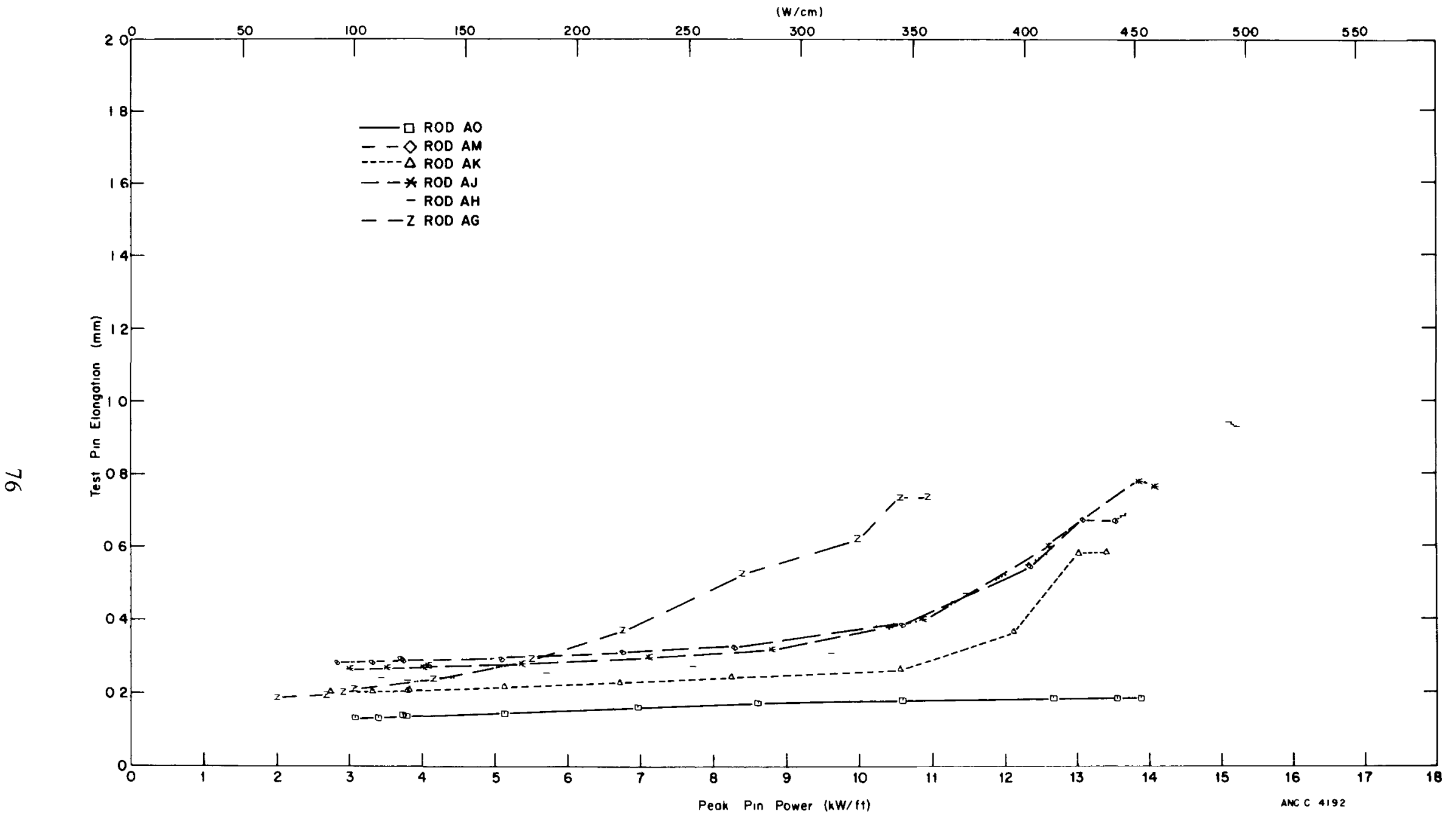

Fig. 63 IFA-226 test rod elongation versus peak rod power from November 27, 1971 at 0000 hours through November 27, 1971 at 1300 hours. 


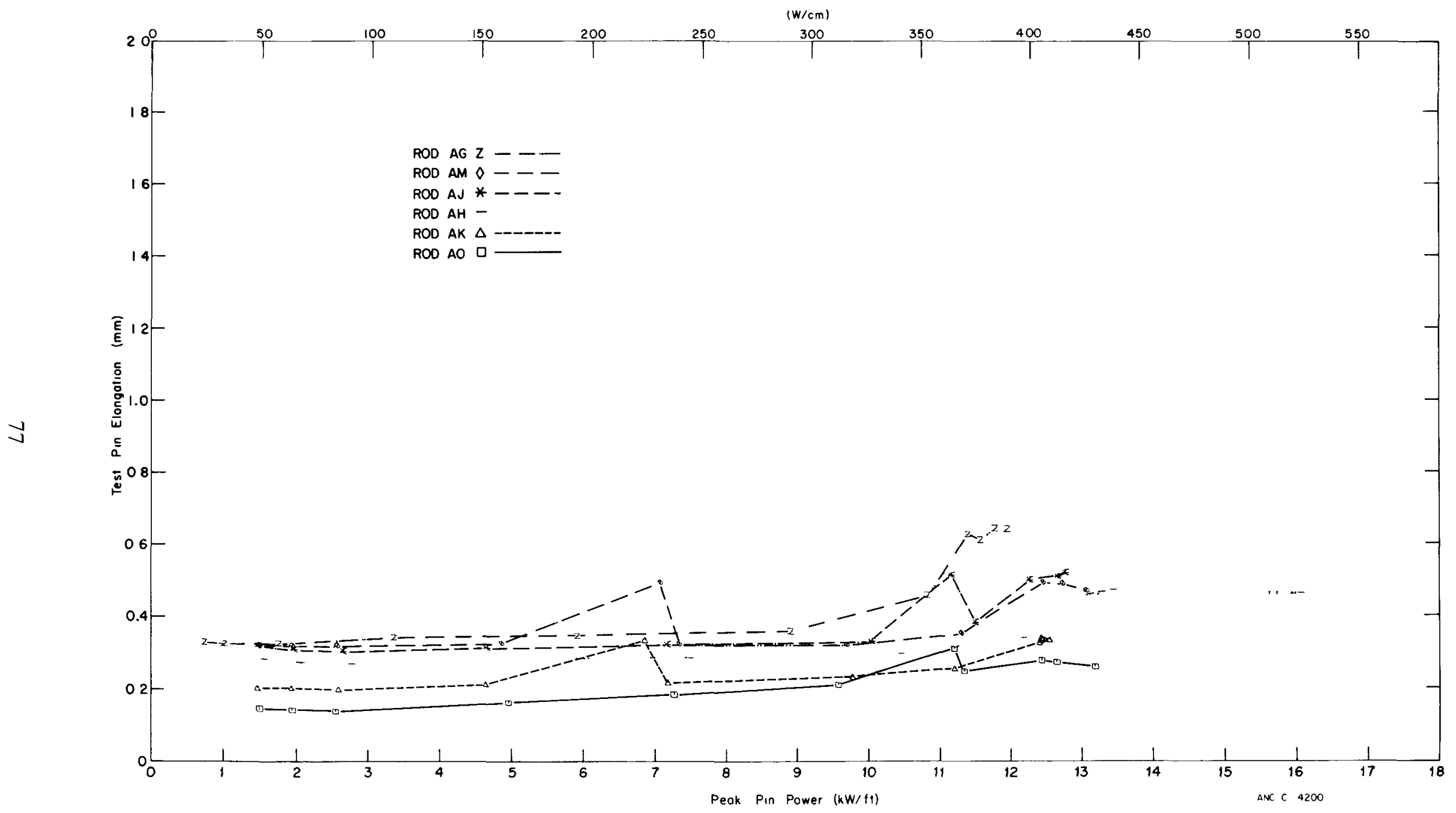

Fig. 64 IFA-226 test rod elongation versus peak rod power from December 21,1971 at 1700 hours through December 22, 1971 at 1000 hours. 


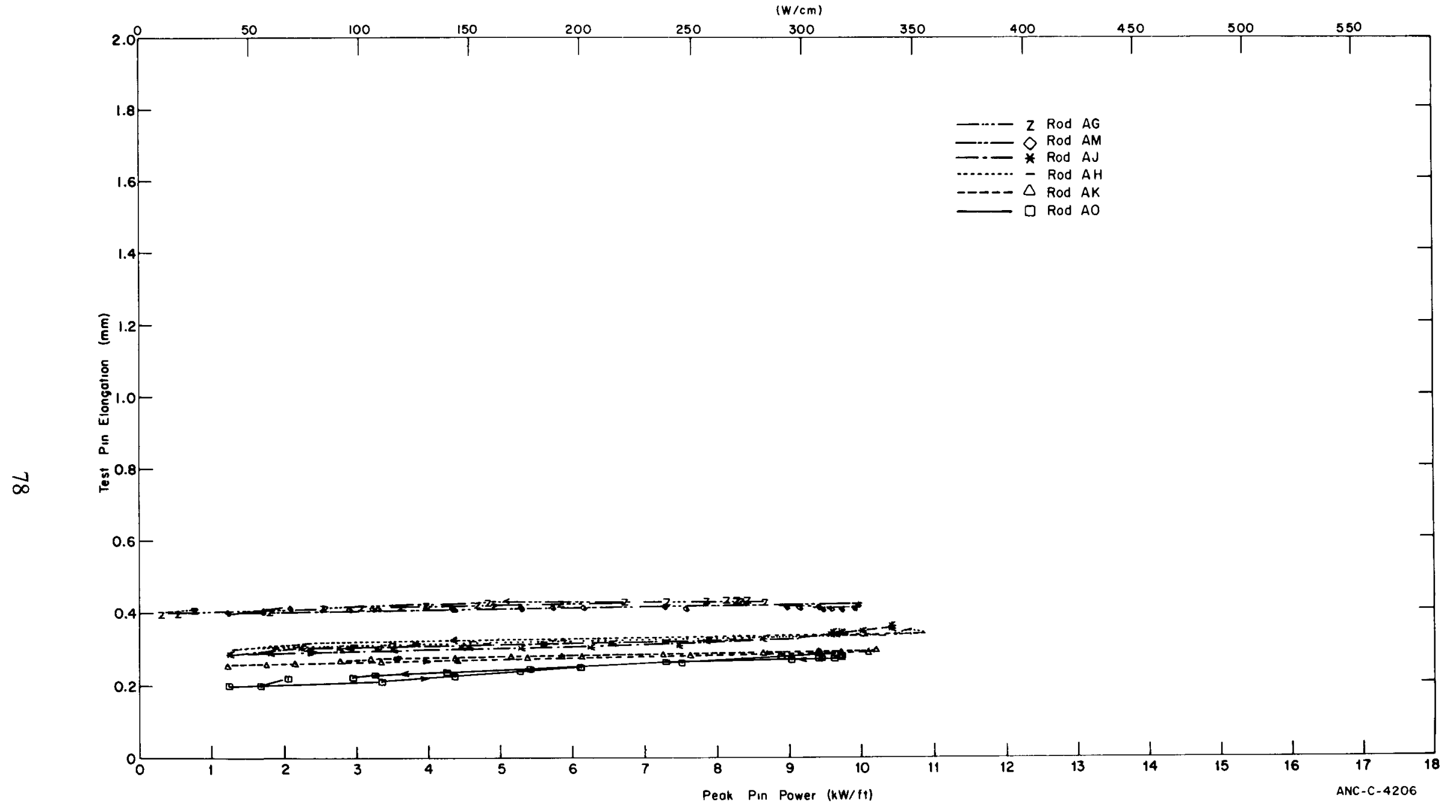

Fig. 65 IFA-226 test rod elongation versus peak rod power from January 16, 1972 at 1200 hours through January 18, 1972 at 0200 hours. 


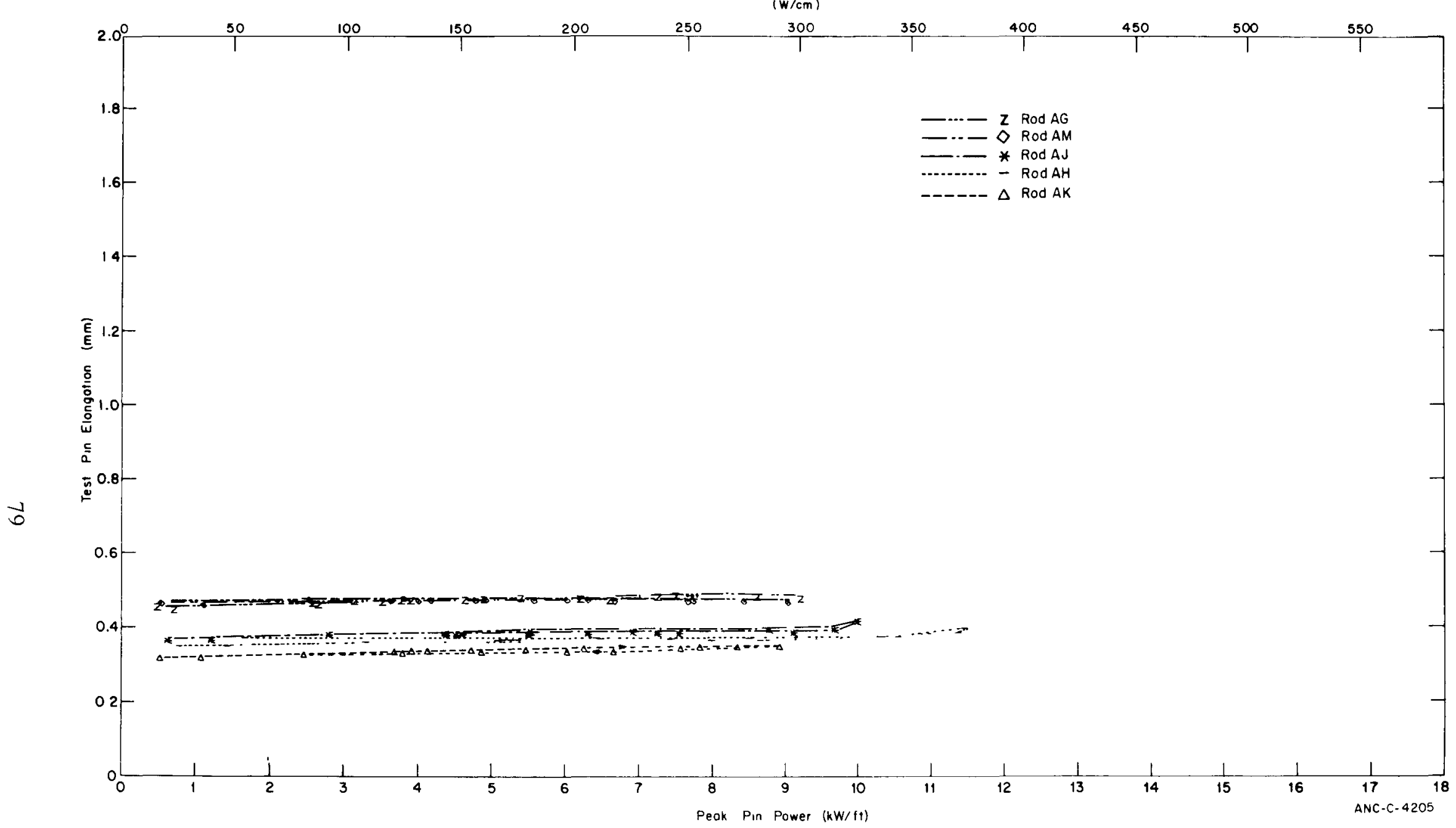

Fig. 66 IFA-226 test rod elongation versus peak rod power from March 19, 1972 at 1600 hours through March 21, 1972 at 1000 hours. 


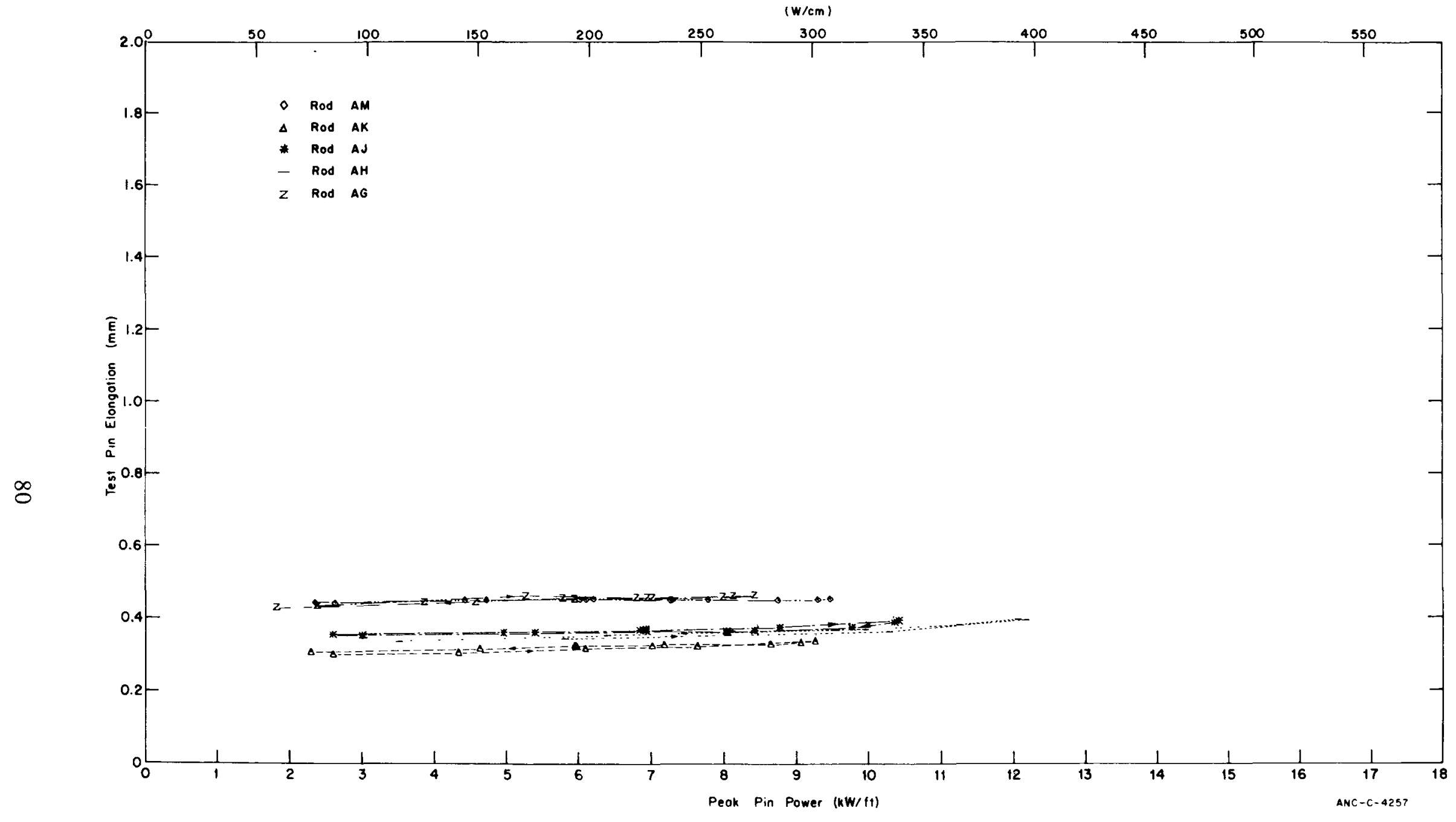

Fig. 67 IFA-226 test rod elongation versus peak rod power from March 21 , 1972 at 1500 hours through March 23, 1972 at 0000 hours. 


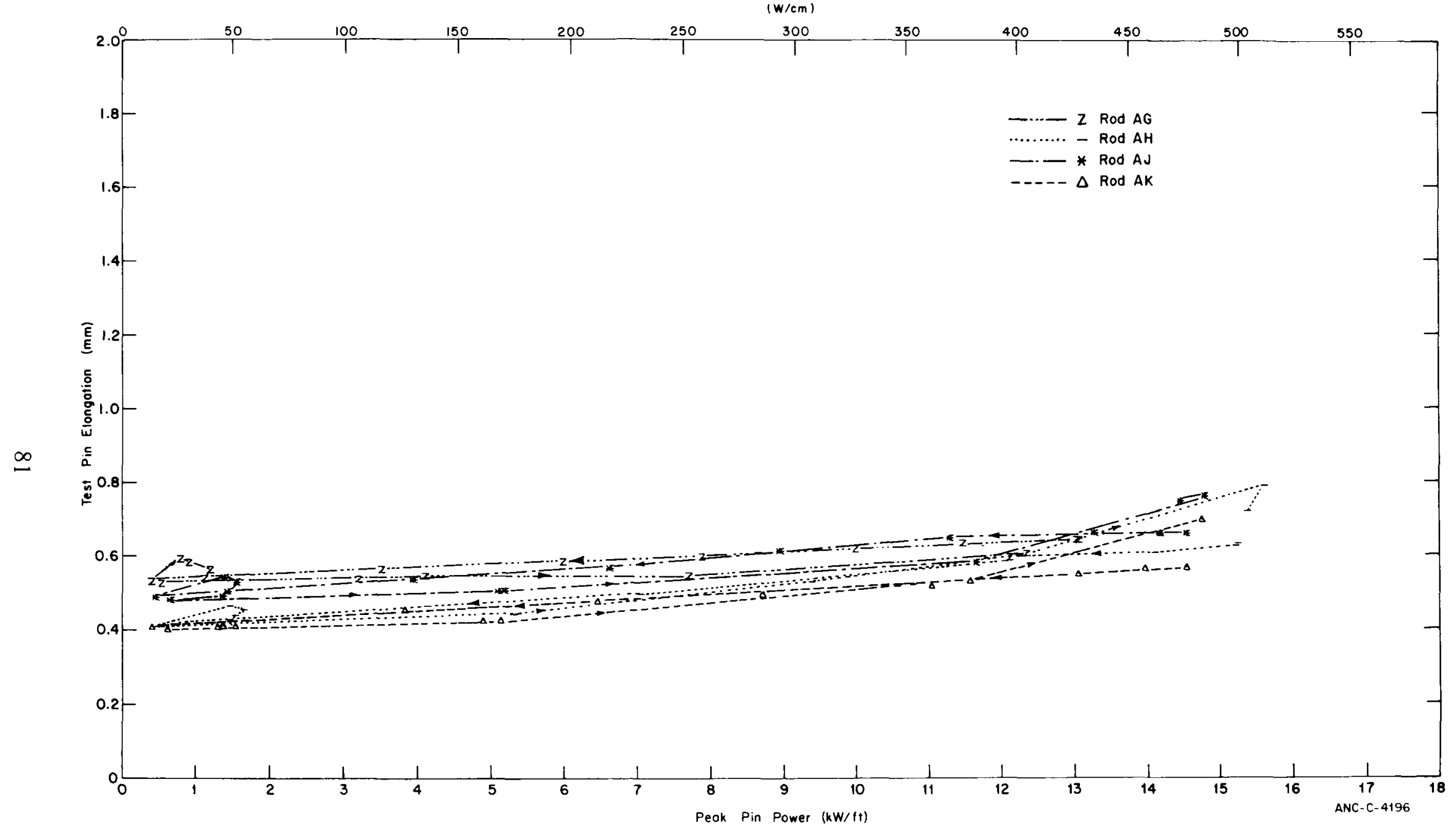

Fig. 68 IFA-226 test rod elongation versus peak rod power from May 20, 1972 at 1800 hours through May 22, 1972 at 2200 hours. 


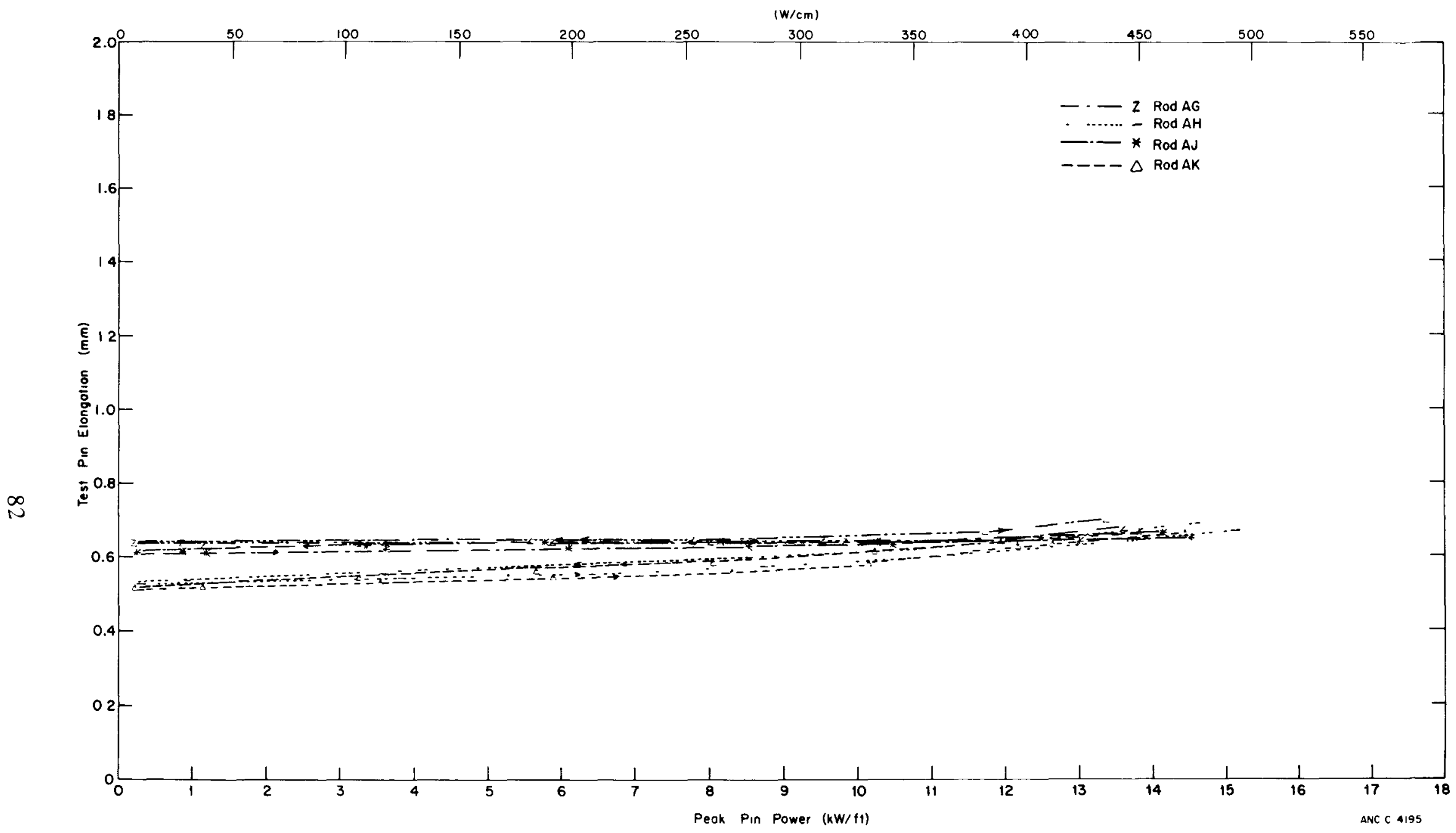

Fig. 69 IFA-226 test rod elongation versus peak rod power from August 7 , 1972 at 0000 hours through August 8, 1972 at 1000 hours. 


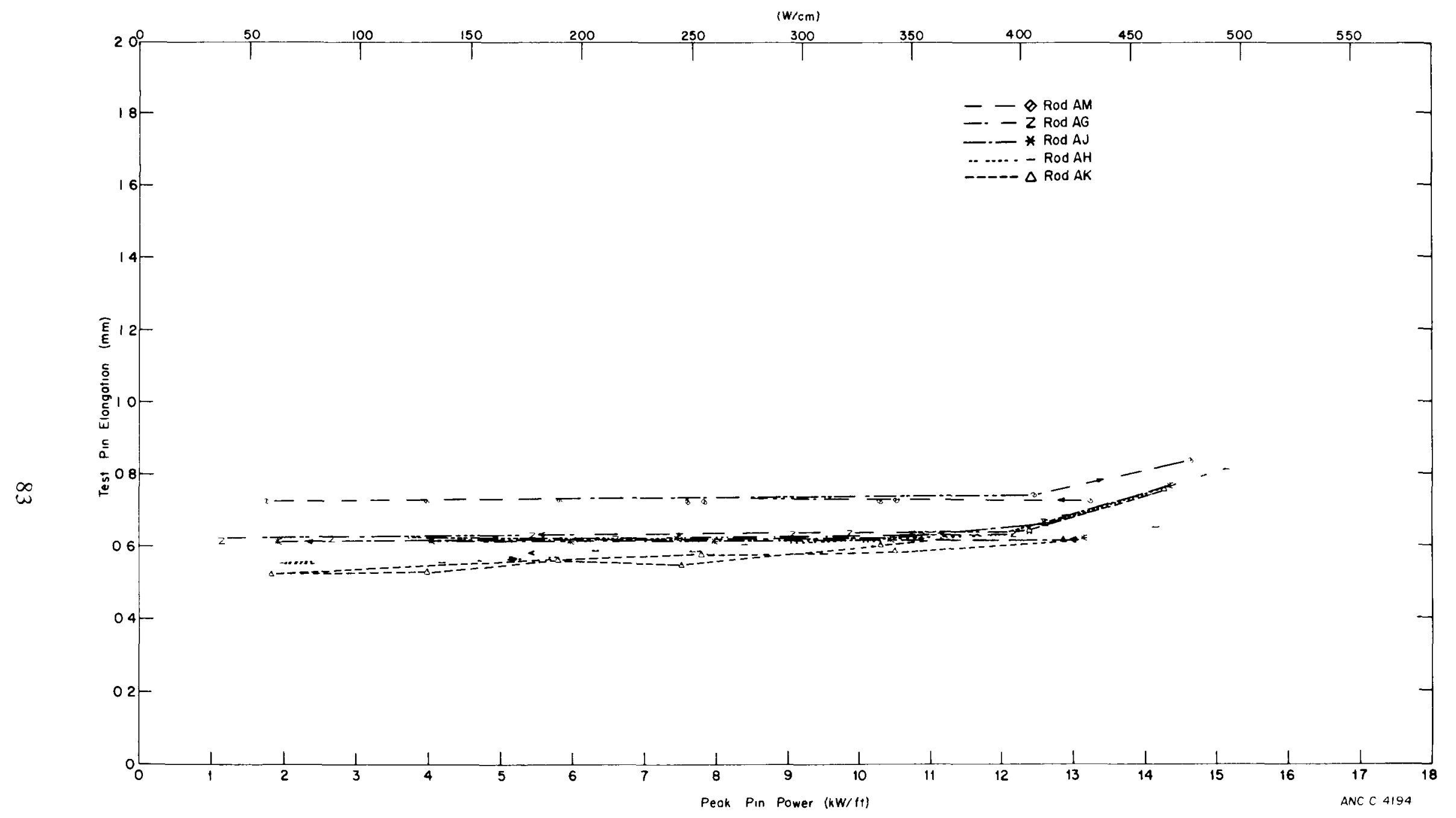

Fig. 70 IFA-226 test rod elongation versus peak rod power from December 14, 1972 at 0000 hours through December 15, 1972 at 1100 hours. 


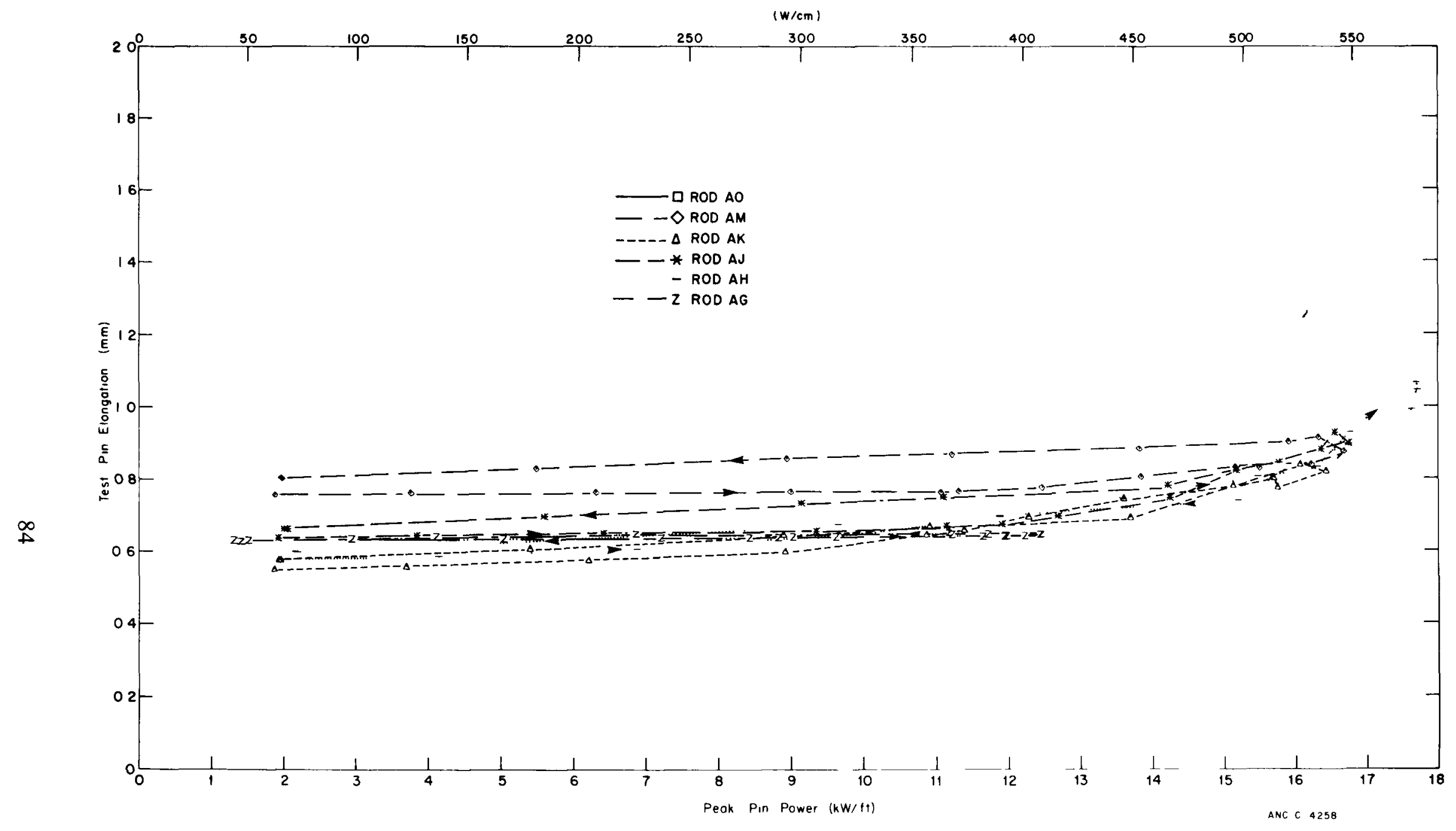

Fig. 71 IFA-226 test rod elongation versus peak rod power from March 14, 1973 at 1300 hours through March 16, 1973 at 0500 hours. 


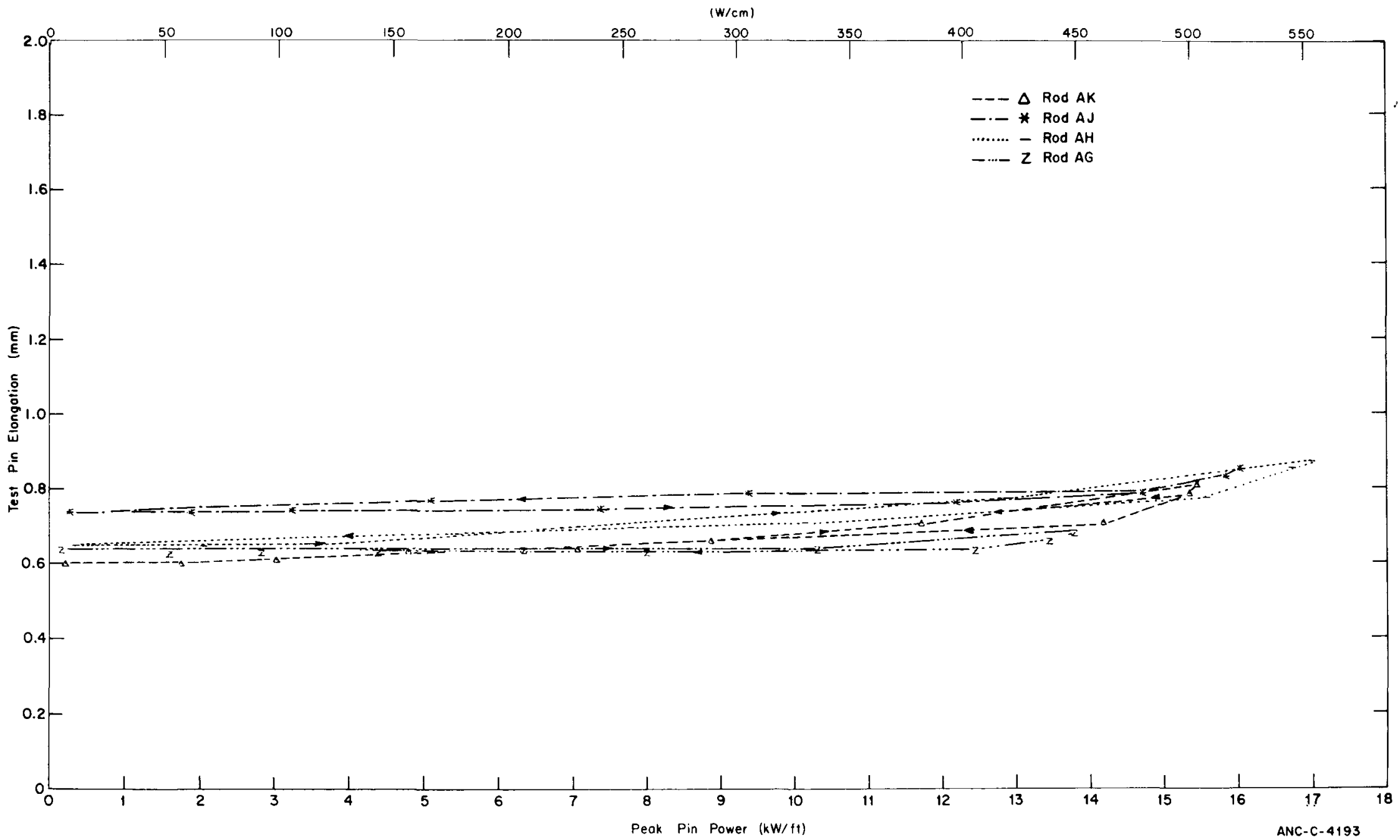

Fig. 72 IFA-226 test rod elongation versus peak rod power from August 2, 1973 at 0900 hours through August 2, 1973 at 2000 hours. 


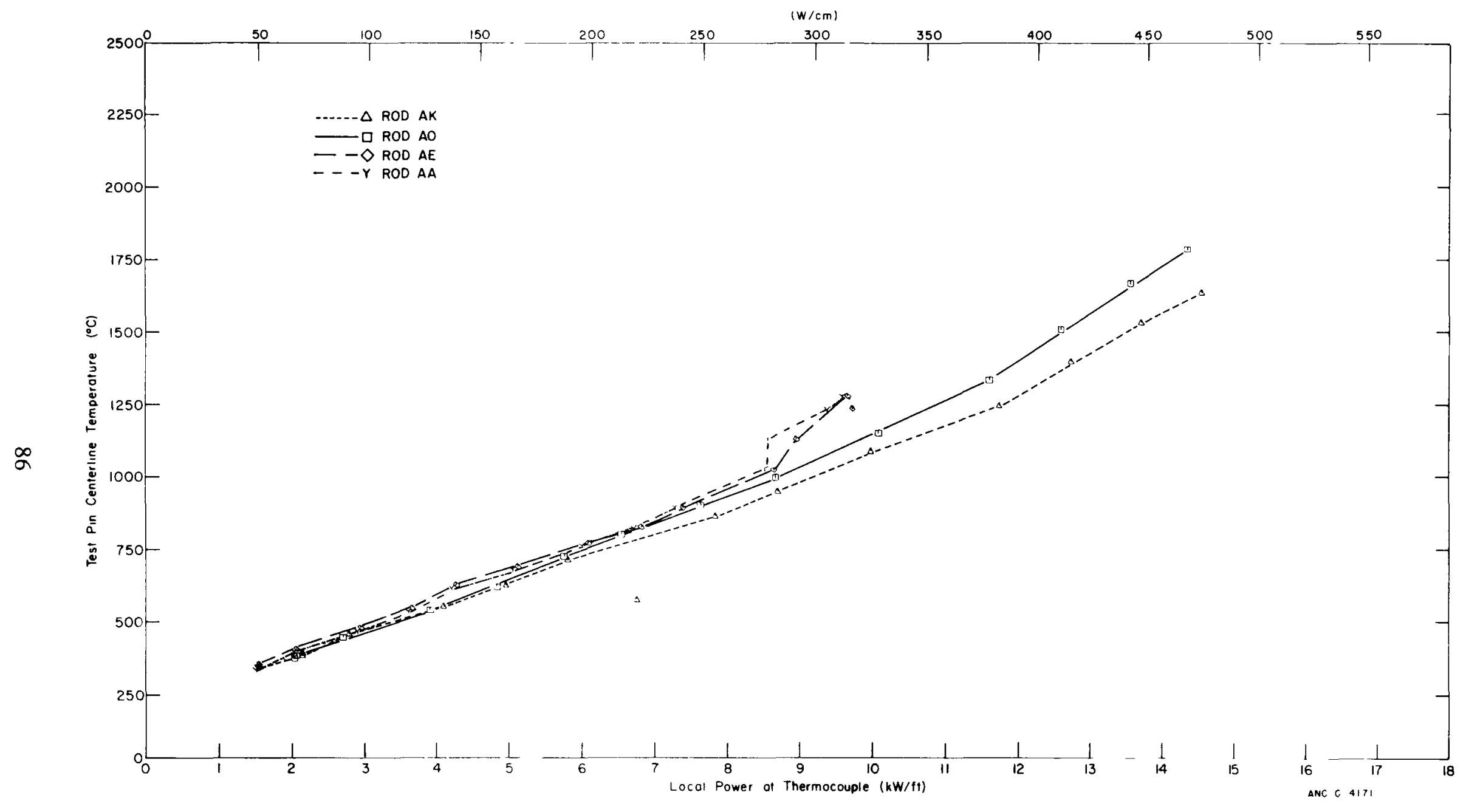

Fig. 73 IFA-226 test rod fuel centerline temperature versus local rod power at thermocouple location from November 24, 1971 at 1000 hours through November 24, 1971 at 2300 hours. 


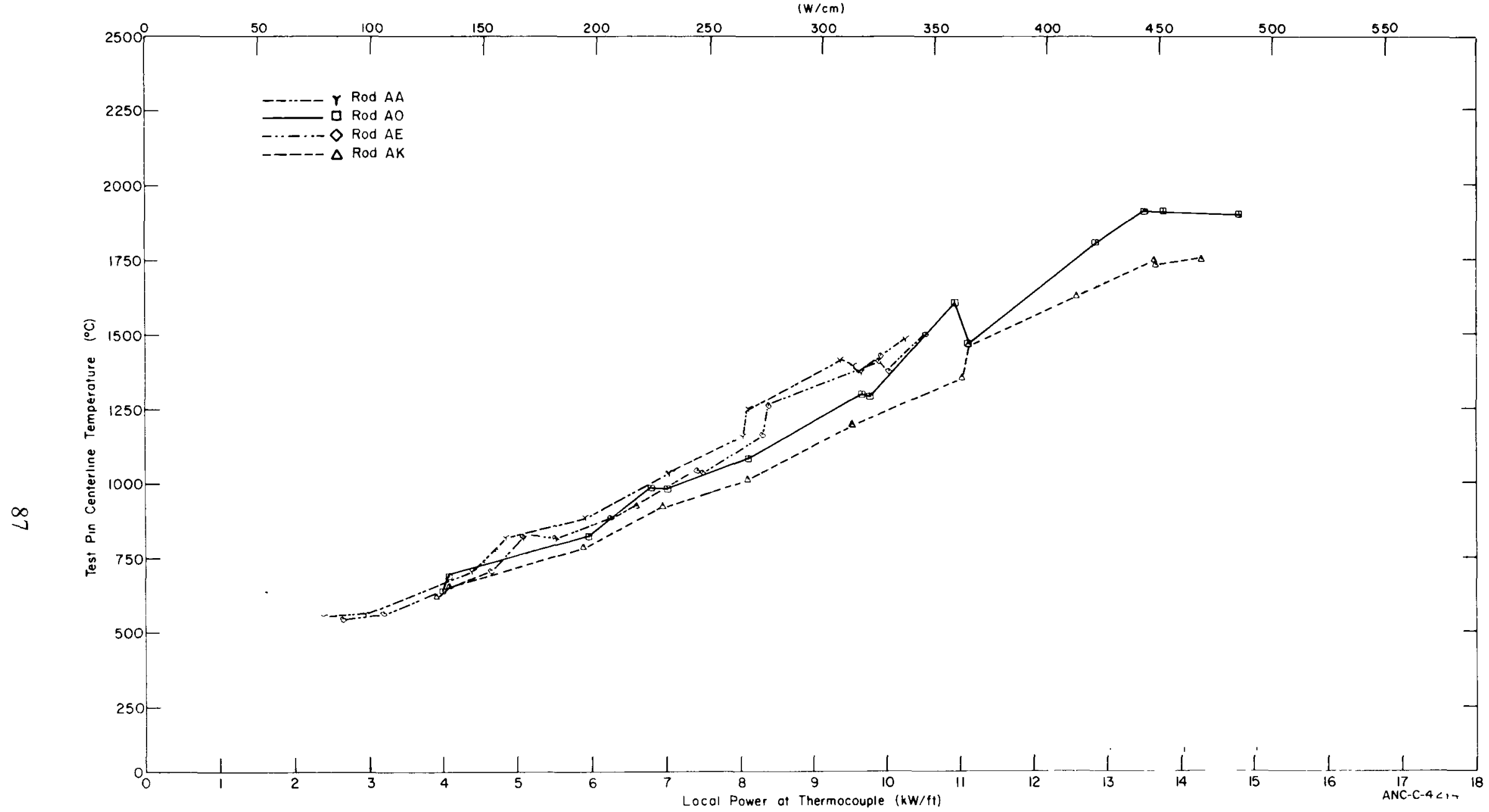

Fig. 74 IFA-226 test rod fuel centerline temperature versus local rod power at thermocouple location from November 25, 1971 at 0000 hours through November 26, 1971 at 0200 hours. 


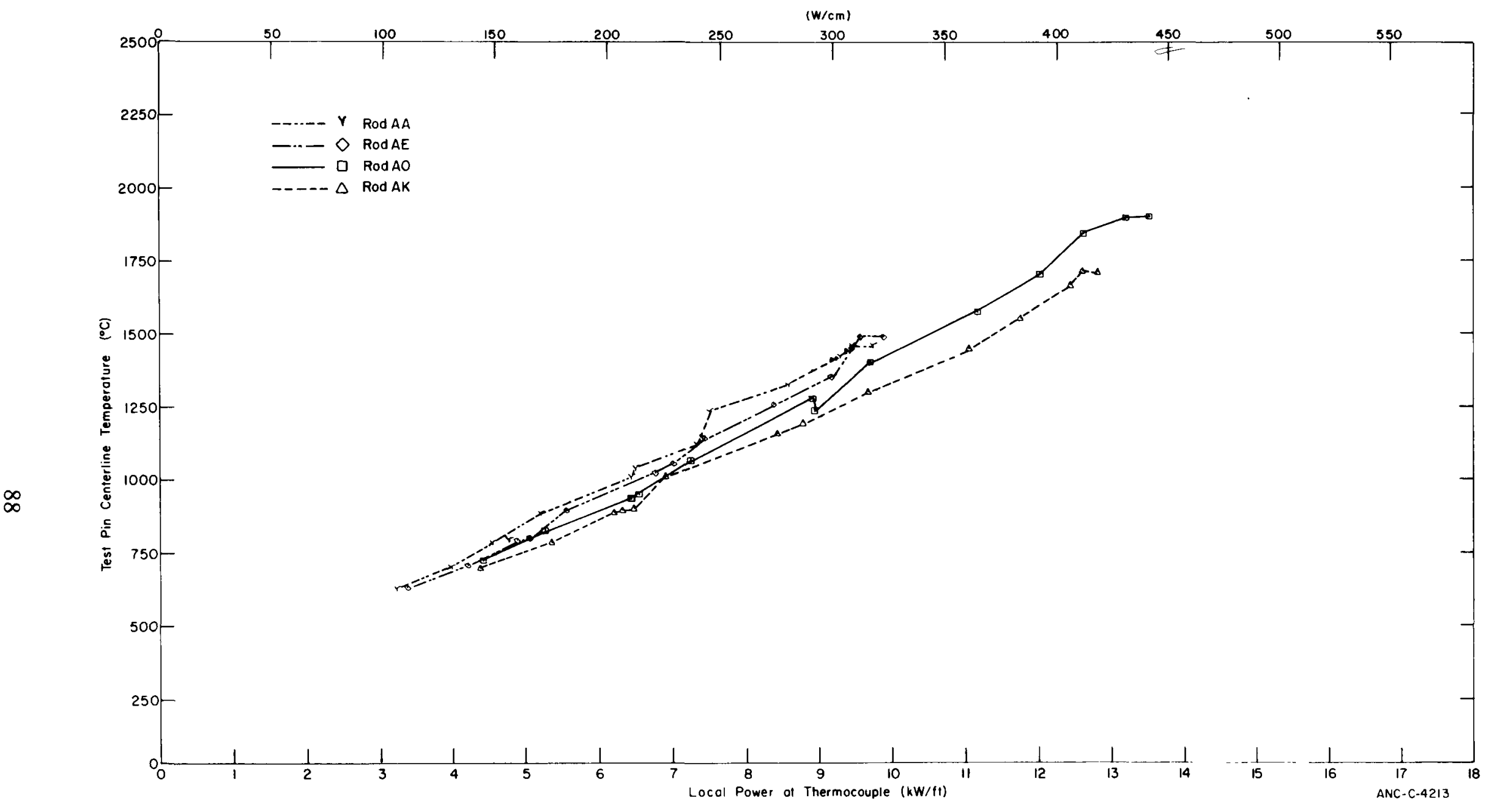

Fig. 75 IFA-226 test rod fuel centerline temperature versus local rod power at thermocouple location from November 26, 1971 at 0300 hours through November 26, 1971 at 2200 hours. 


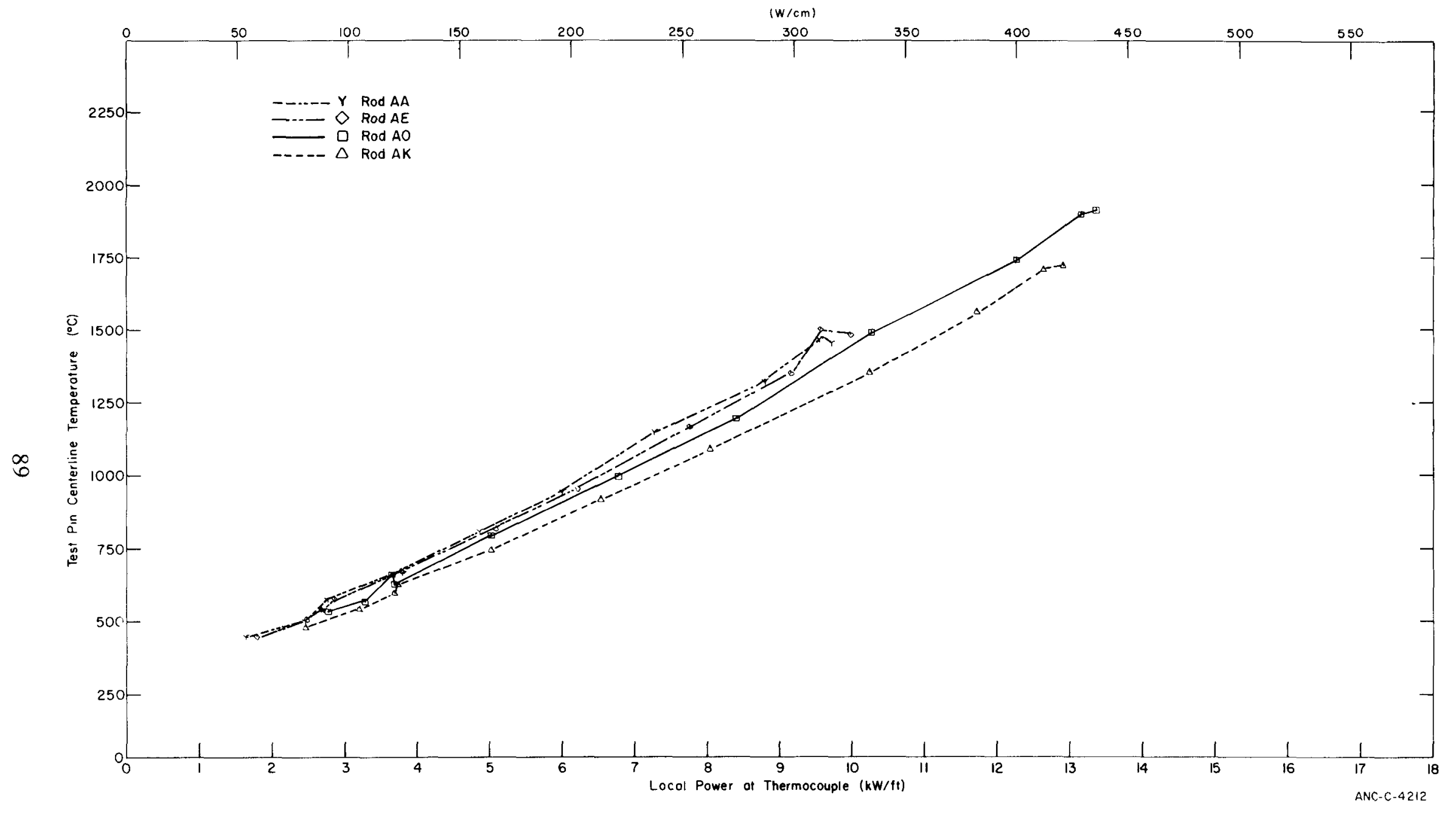

Fig. 76 IFA-226 test rod fuel centerline temperature versus local rod power at thermocouple location from November 27, 1971 at 0000 hours through November 27, 1971 at 1300 hours. 


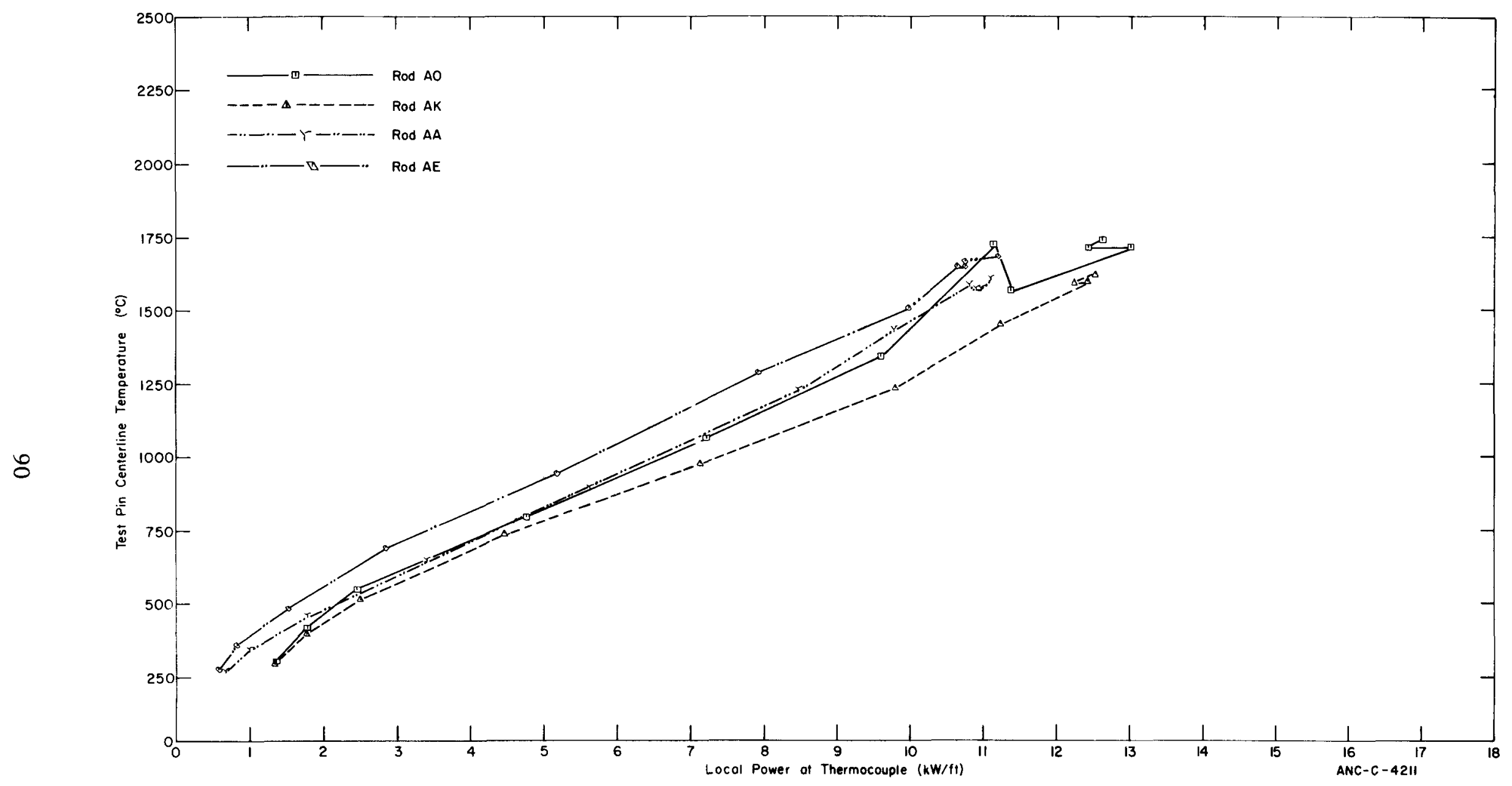

Fig. 77 IFA-226 test rod fuel centerline temperature versus local rod power at thermocouple location from December 21, 1971 at 1700 hours through December 22, 1971 at 1000 hours. 


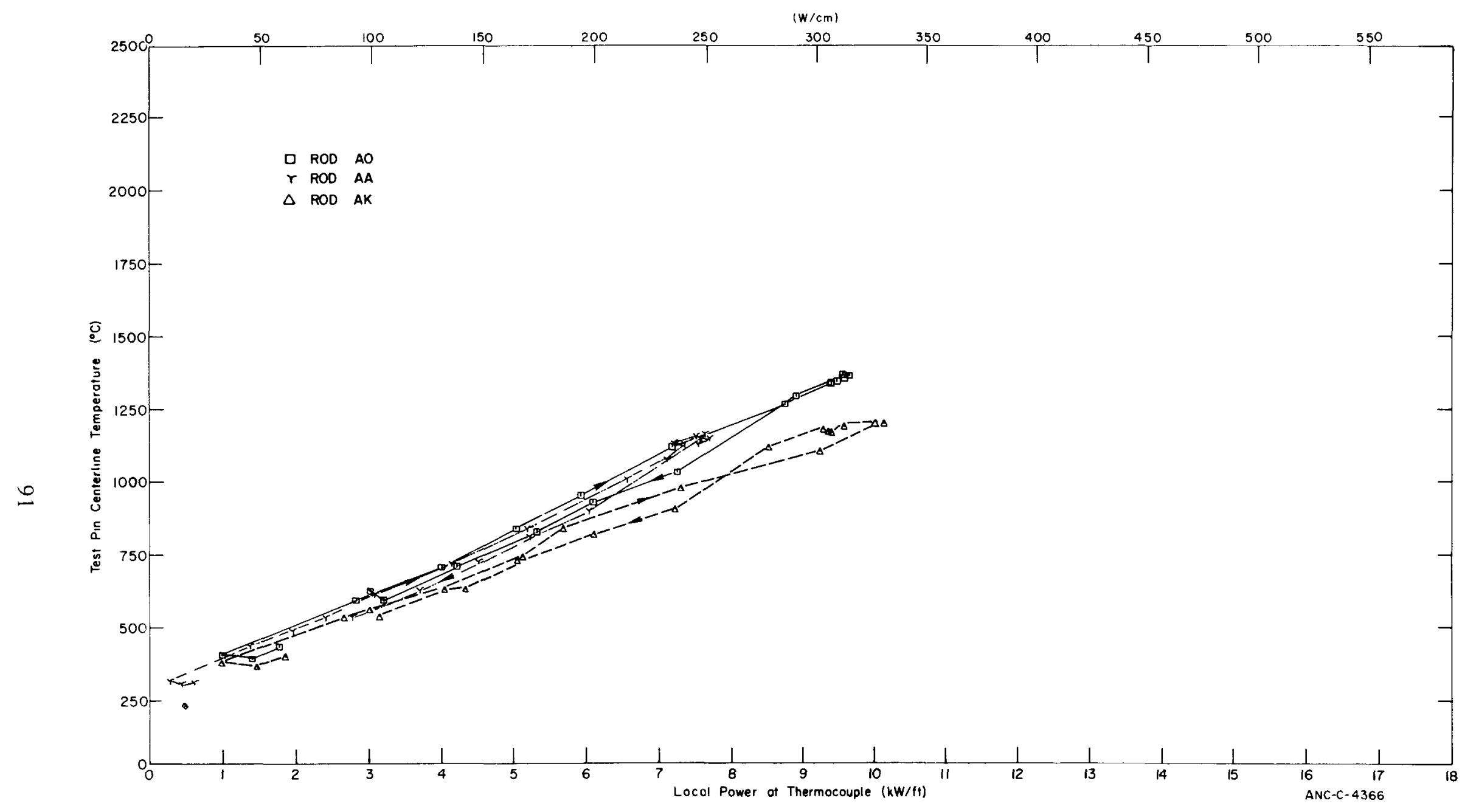

Fig. 78 IFA-226 test rod fuel centerline temperature versus local rod power at thermocouple location from January 16, 1972 at 1200 hours through January 18,1972 at 0200 hours. 


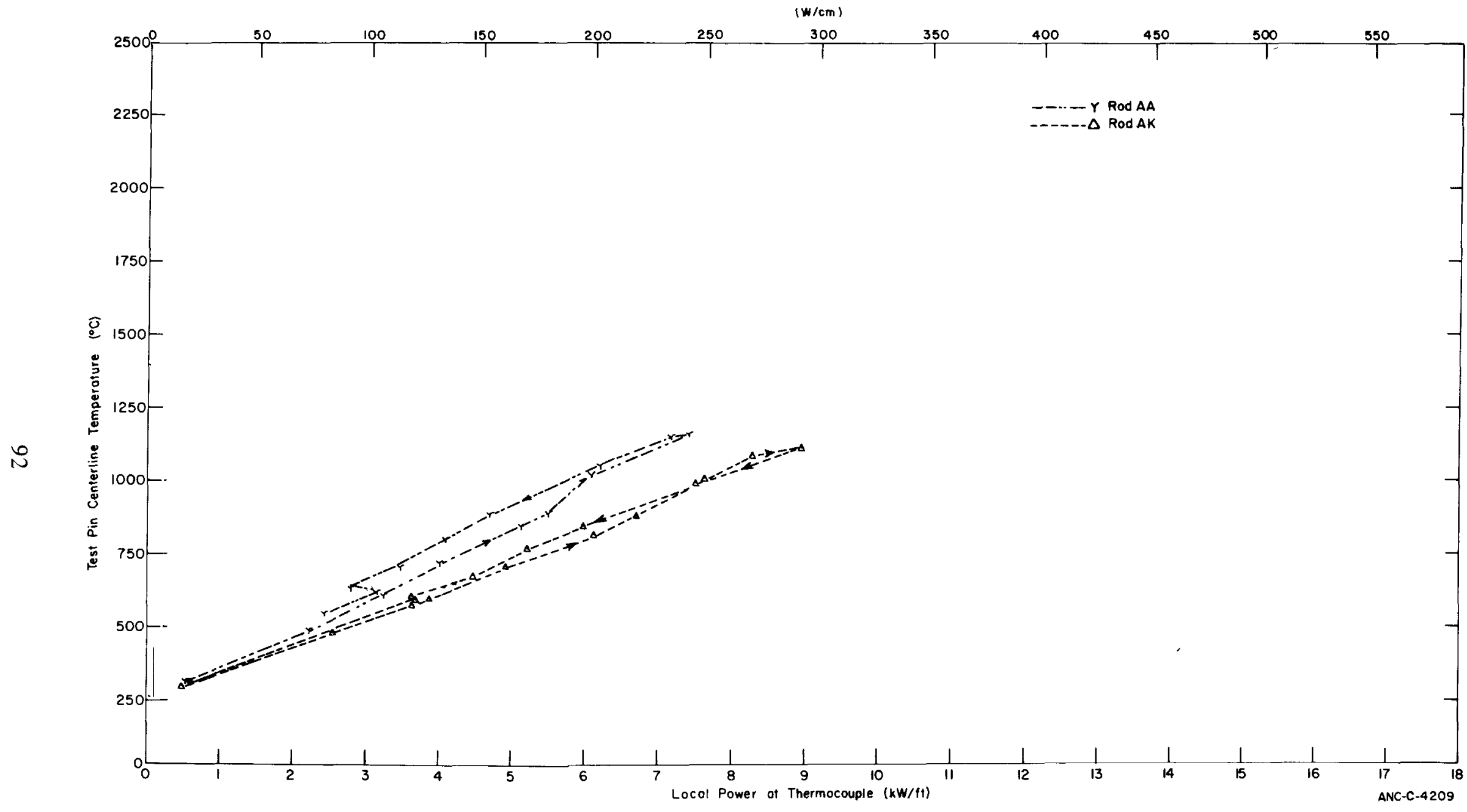

Fig. 79 IFA-226 test rod fuel centerline temperature versus local rod power at thermocouple location from March 19, 1972 at 1600 hours through March 21, 1971 at 1000 hours. 


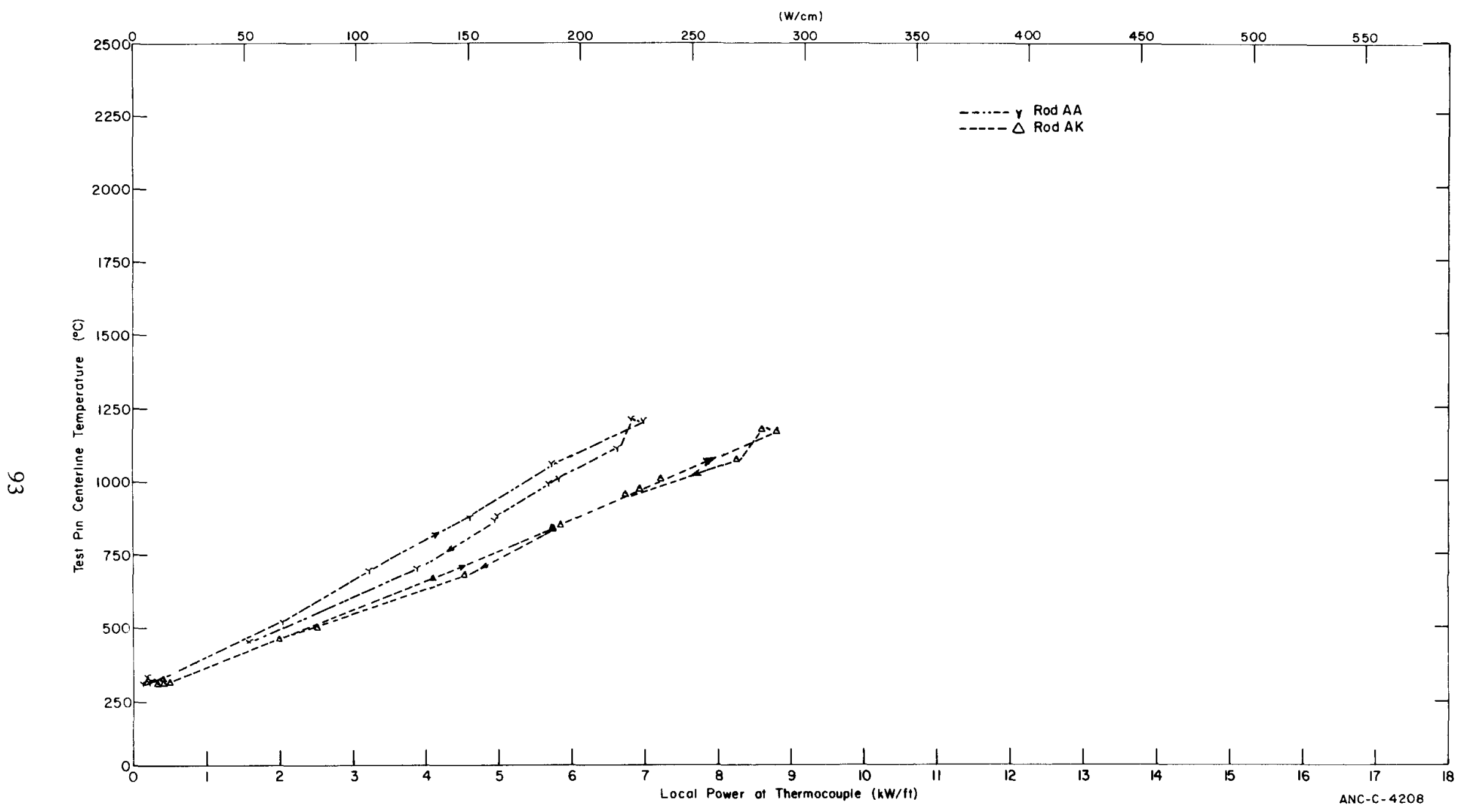

Fig. 80 IFA-226 test rod fuel center1ine temperature versus local rod power at thermocouple location from March 21, 1972 at 1500 hours through March 23, 1972 at 0000 hours. 


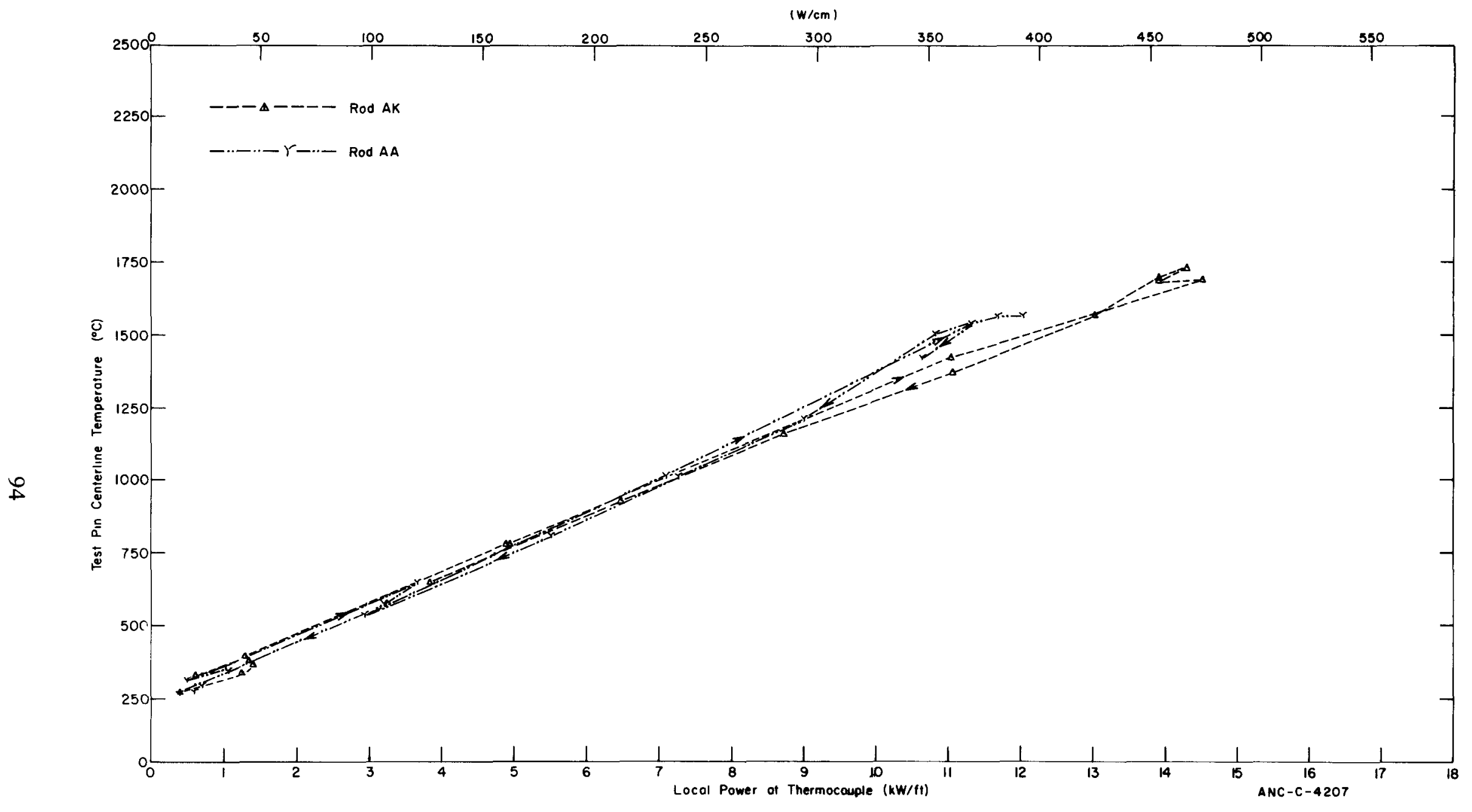

Fig. 81 IFA-226 test rod fuel centerline temperature versus local rod power at thermocouple location from May 20, 1972 at 1800 hours through May 22, 1972 at 2000 hours. 


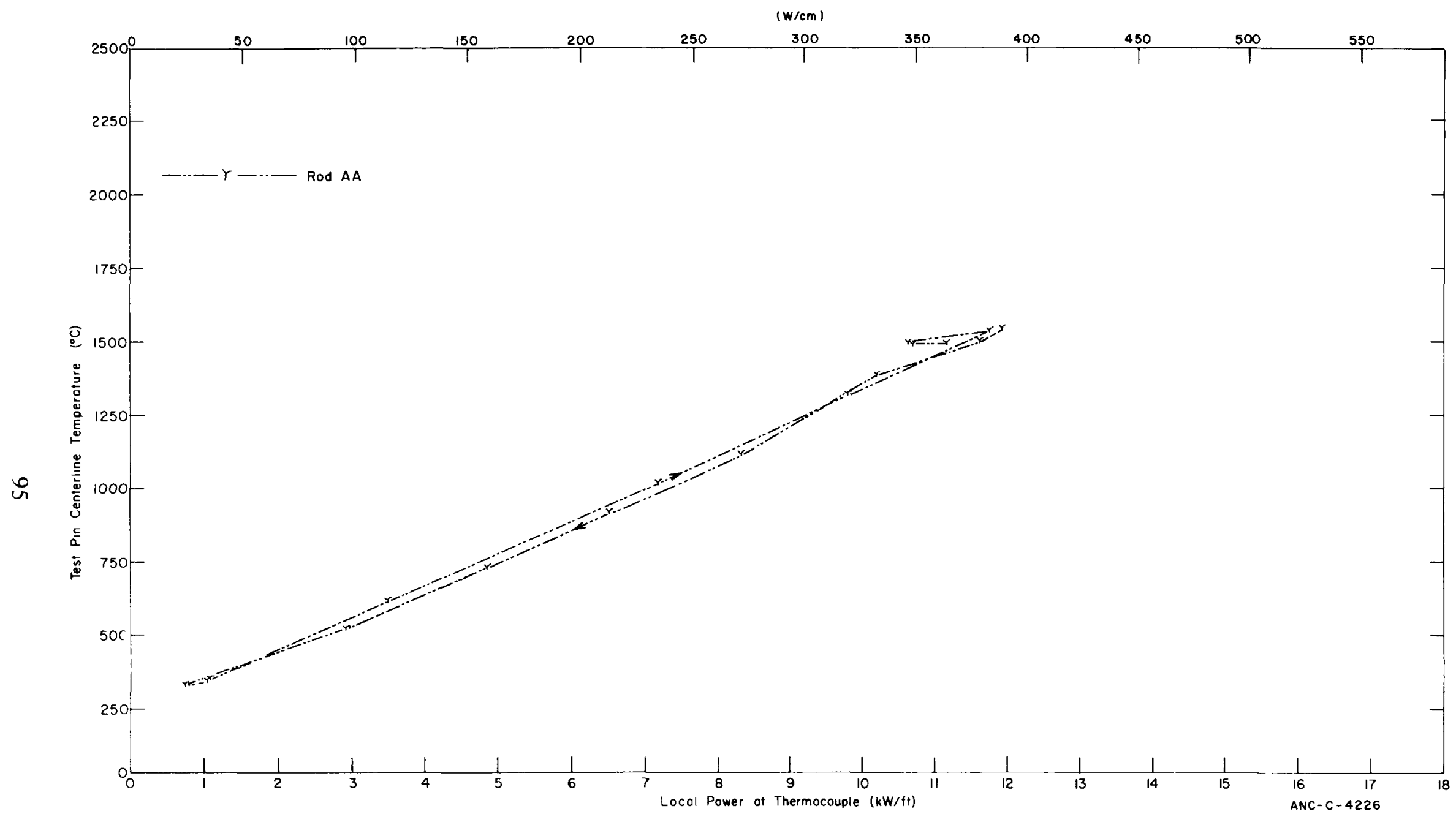

Fig. 82 IFA-226 test rod fuel centerline temperature versus local rod power at thermocouple location from June 5, 1972 at 0600 hours through June 7,1972 at 1800 hours. 


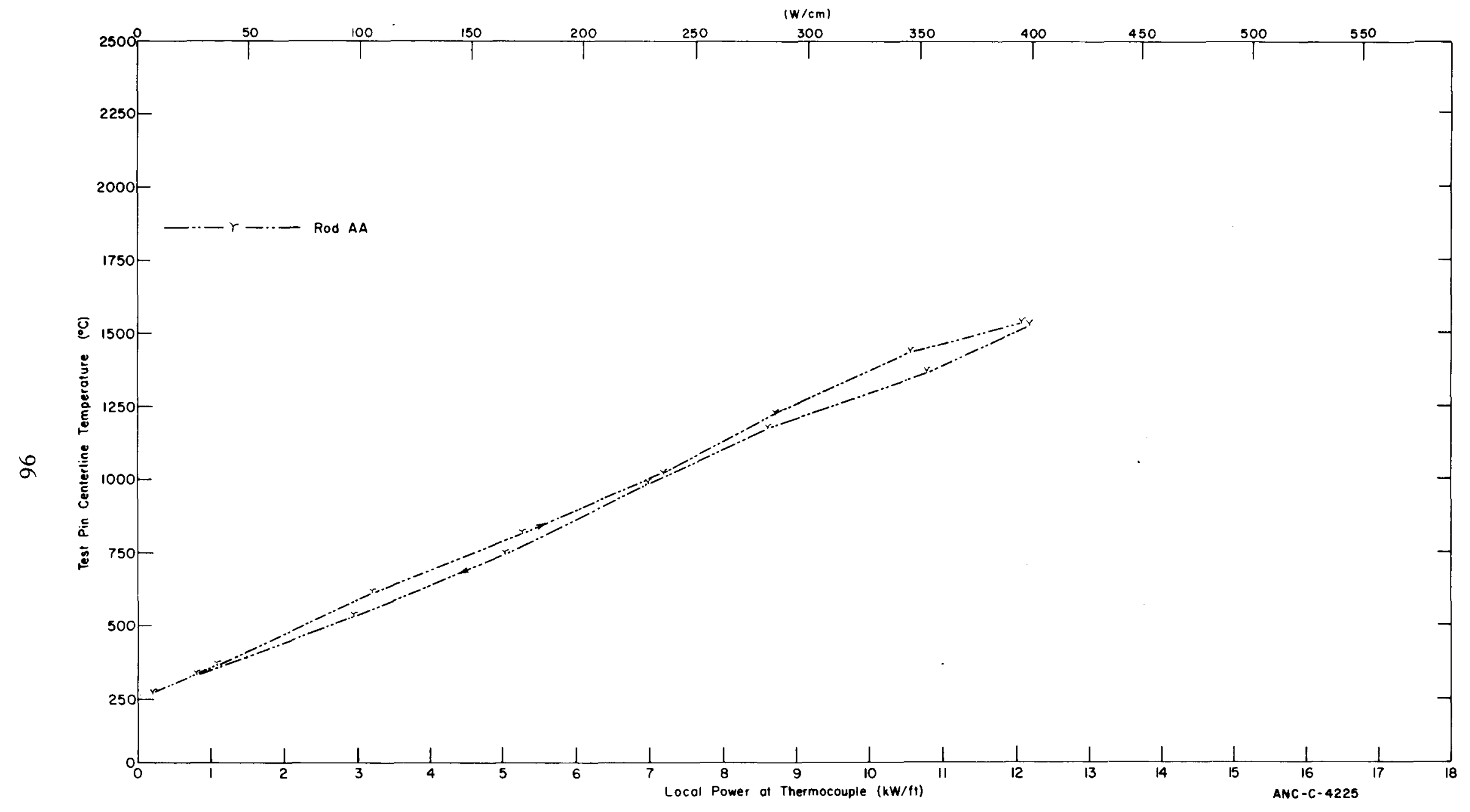

Fig. 83 IFA-226 test rod fuel centerline temperature versus local rod power at thermocouple location from August 7, 1972 at 0000 hours through August 8, 1972 at 1000 hours. 


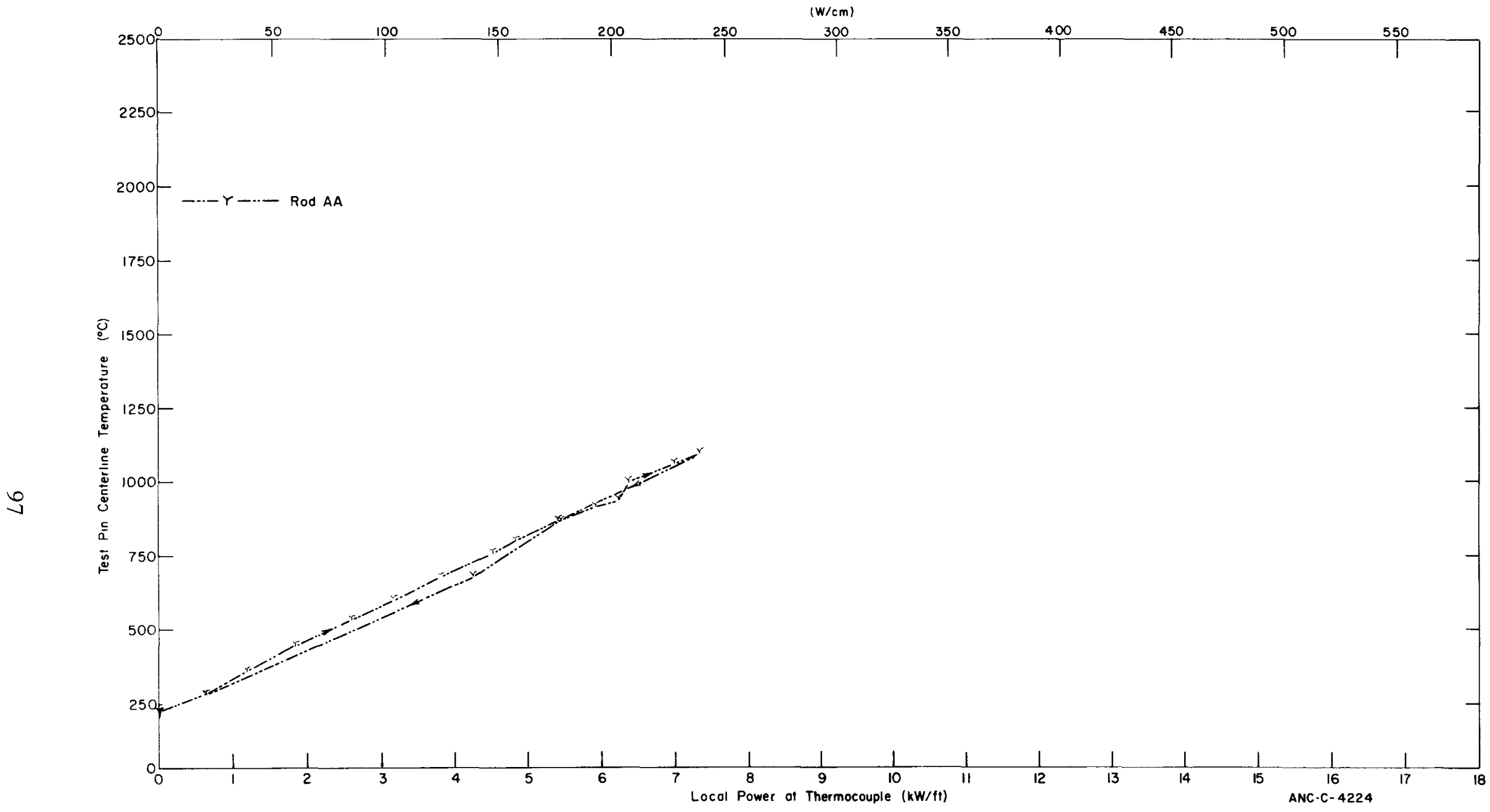

Fig. 84 IFA-226 test rod fuel centerline temperature versus local rod power at thermocouple location from October 26, 1972 at 1500 hours through October 27,1972 at 2250 hours. 


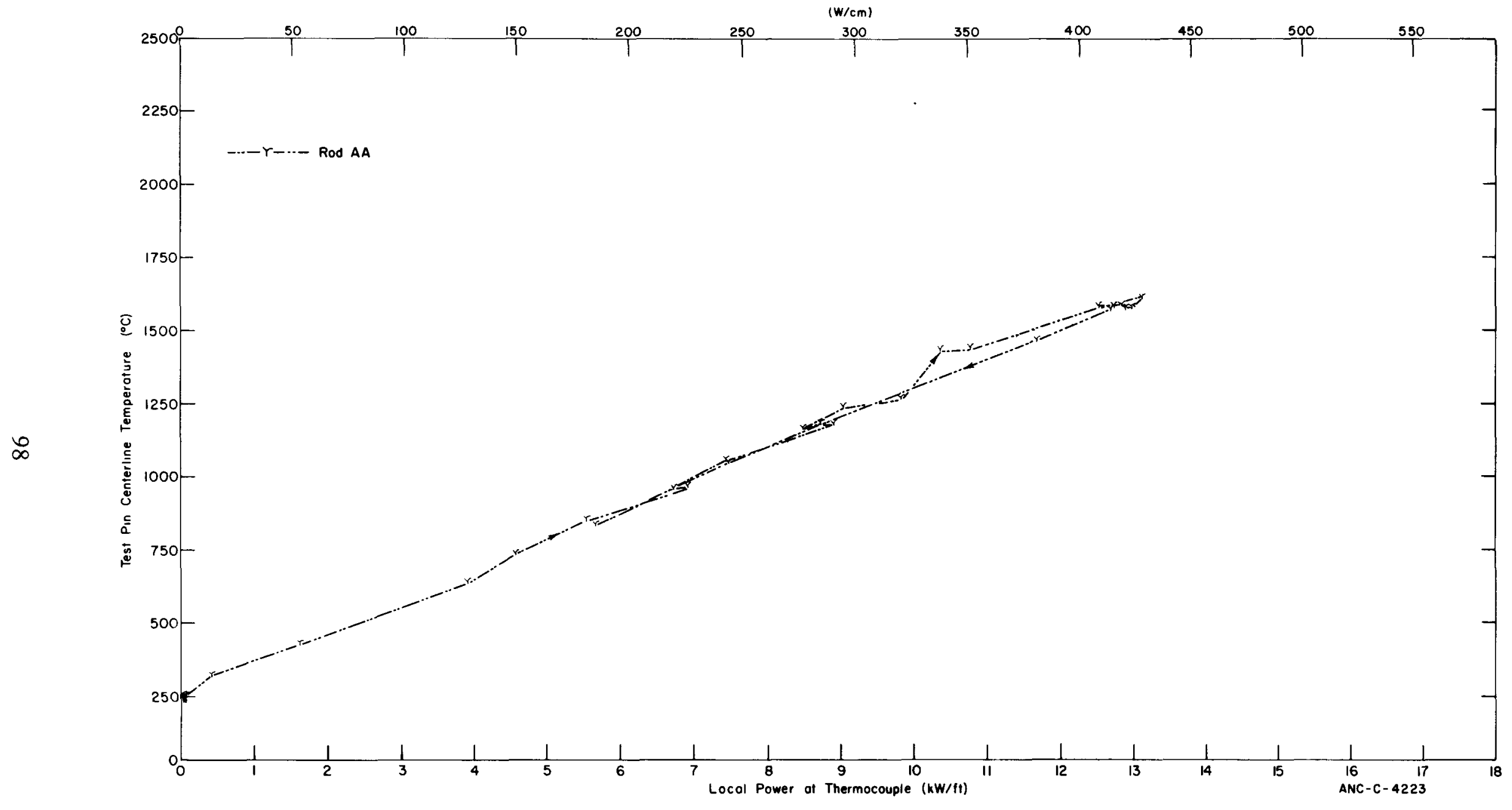

Fig. 85 IFA-226 test rod fuel centerline temperature versus local rod power at thermocouple location from October 27, 1972 at 2350 hours through October 29, 1972 at 1400 hours. 


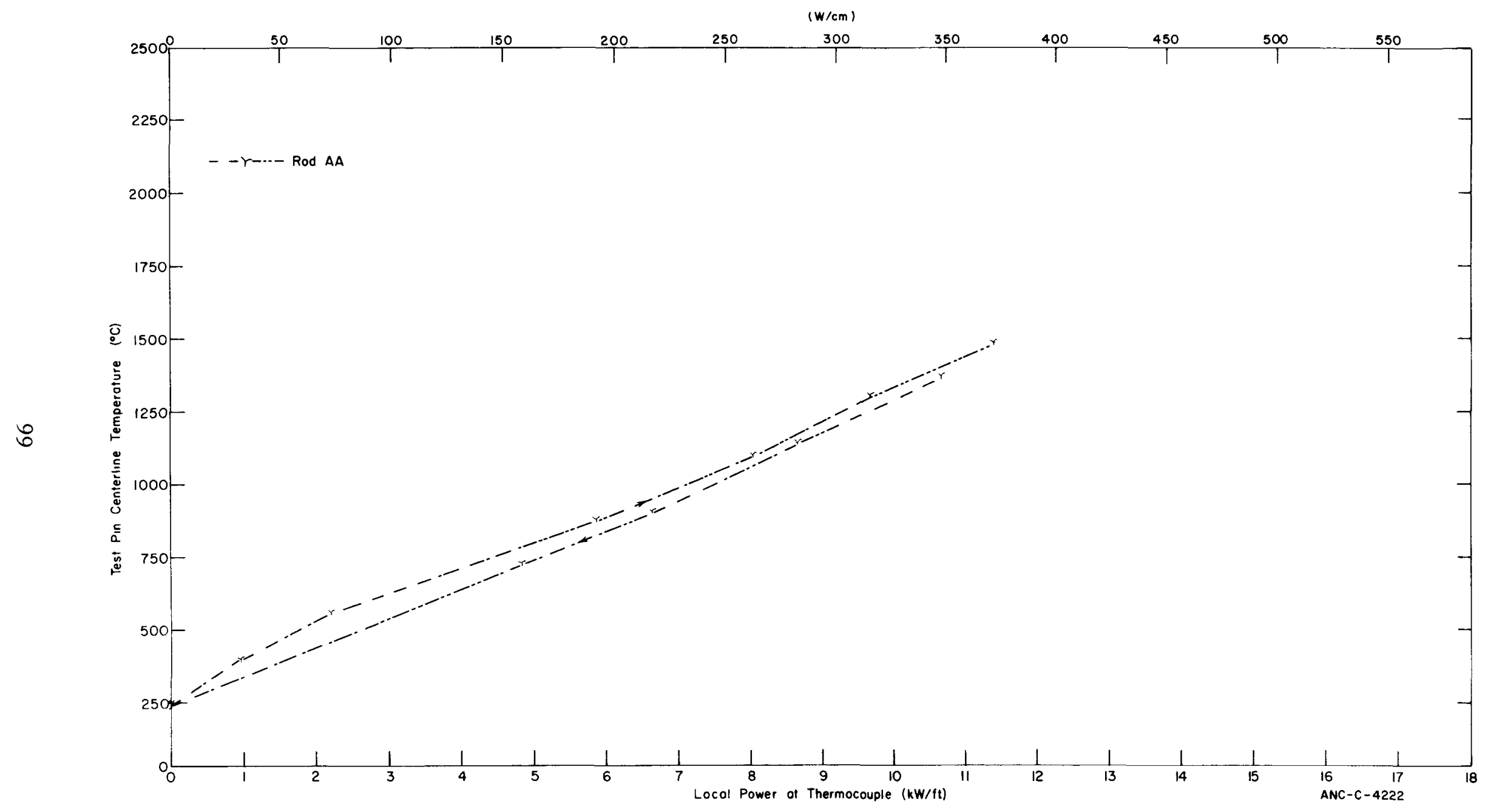

Fig. 86 IFA-226 test rod fuel centerline temperature versus local rod power at thermocouple location from December 14, 1972 at 0000 hours through December 15, 1972 at 1100 hours. 


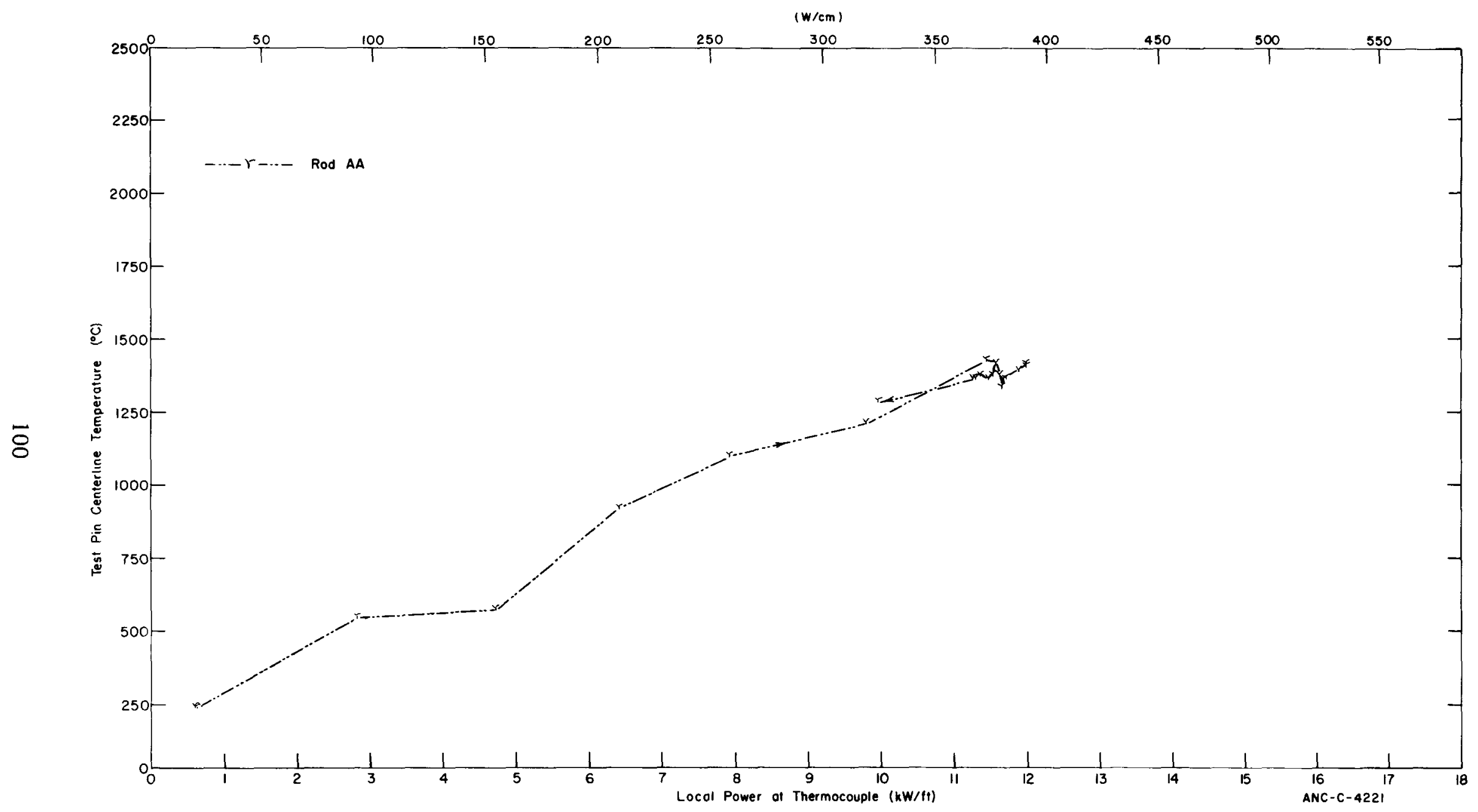

Fig. 87 IFA-226 test rod fuel centerline temperature versus local rod power at thermocouple location from January 15, 1972 at 2000 hours through January 19, 1973 at 0800 hours. 


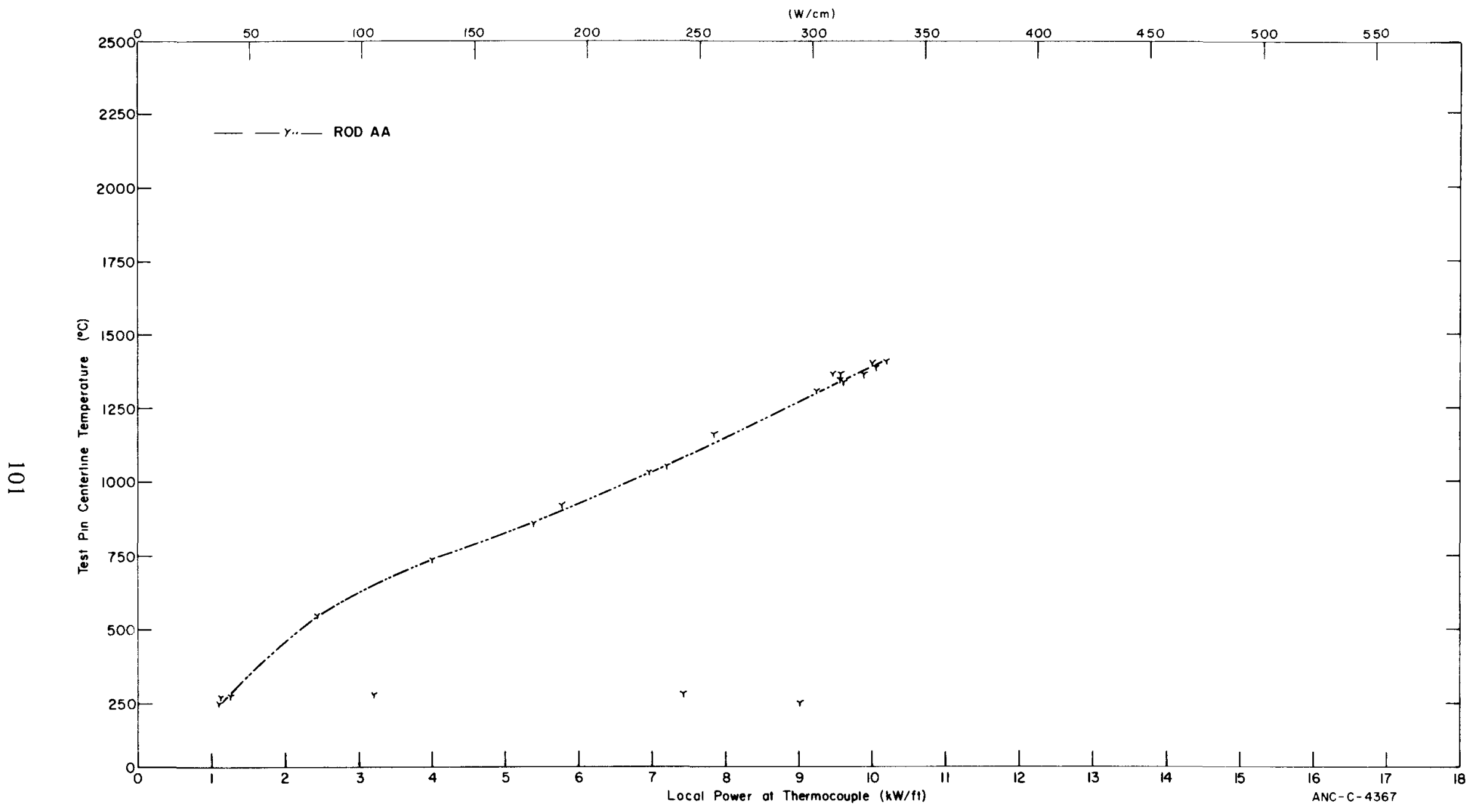

Fig. 88 IFA-226 test rod fuel centerline temperature versus local rod power at thermocouple location from March 14, 1973 at 1300 hours through March 16, 1973 at 0500 hours. 


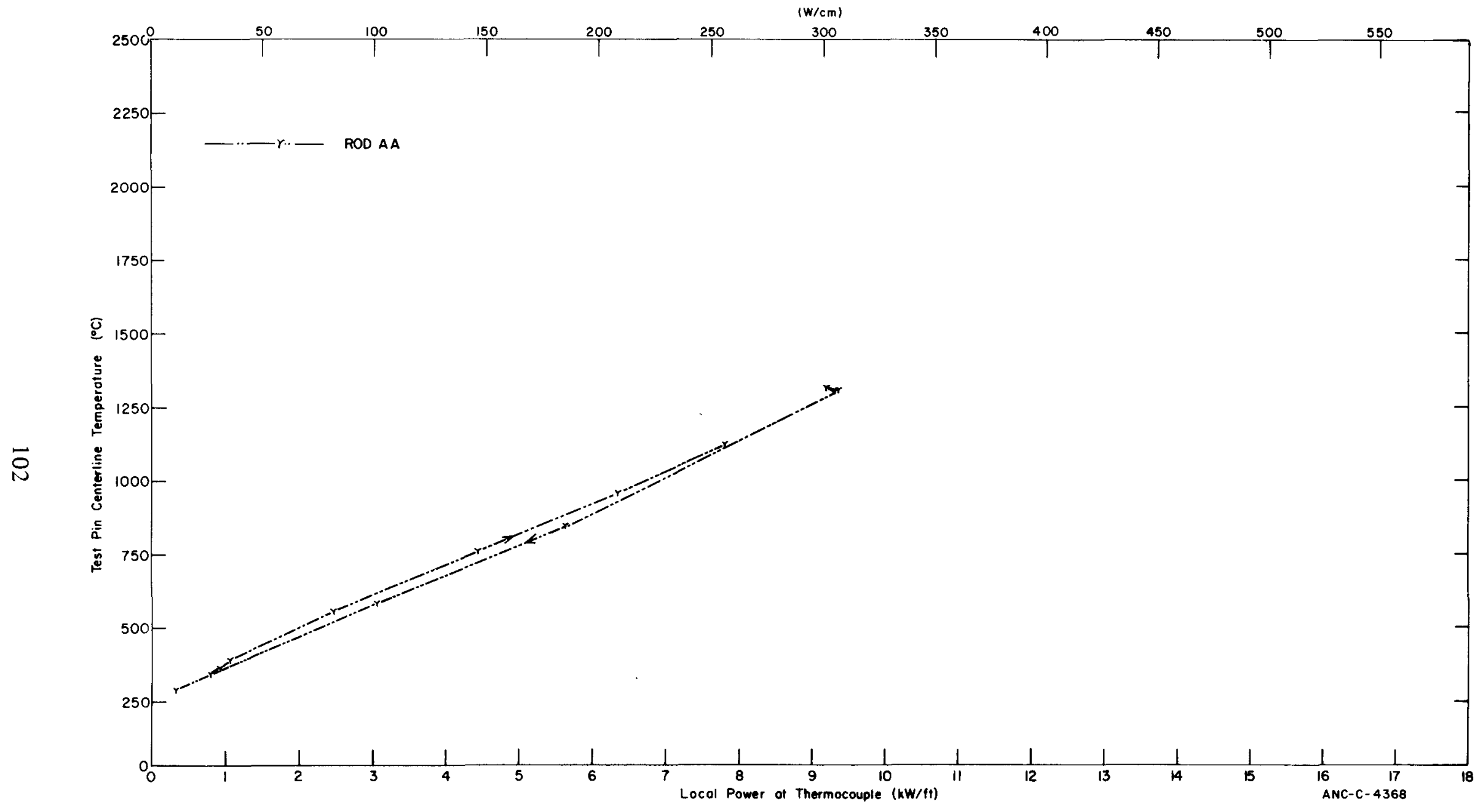

Fig. 89 IFA-226 test rod fuel centerline temperature versus local rod power at thermocouple location from July 7, 1973 at 0000 hours through July 8,1973 at 0600 hours. 


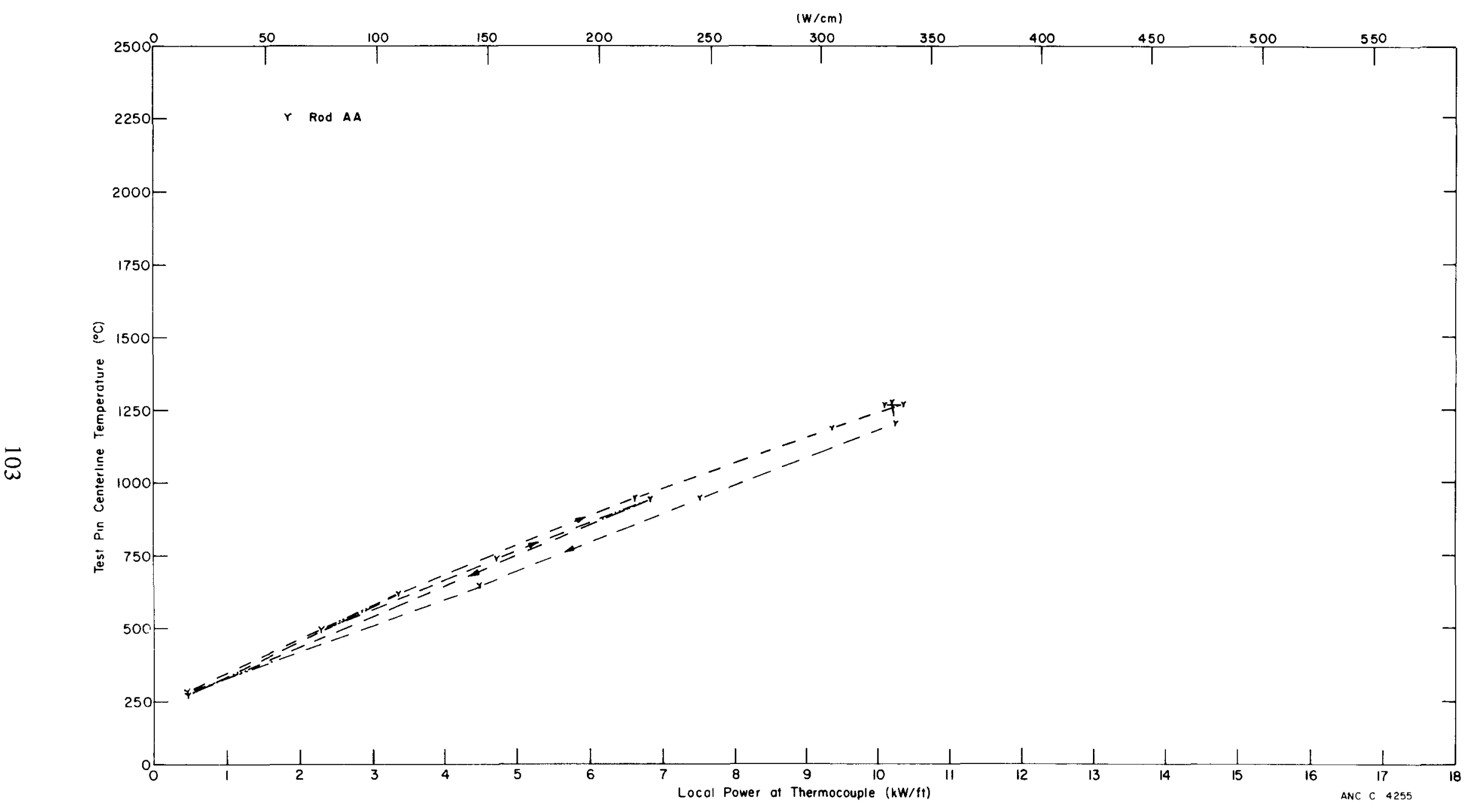

Fig. 90 IFA-226 test rod fuel centerline temperature versus local rod power at thermocouple location from July 12, 1973 at 0000 hours through July 13,1973 at 0800 hours. 


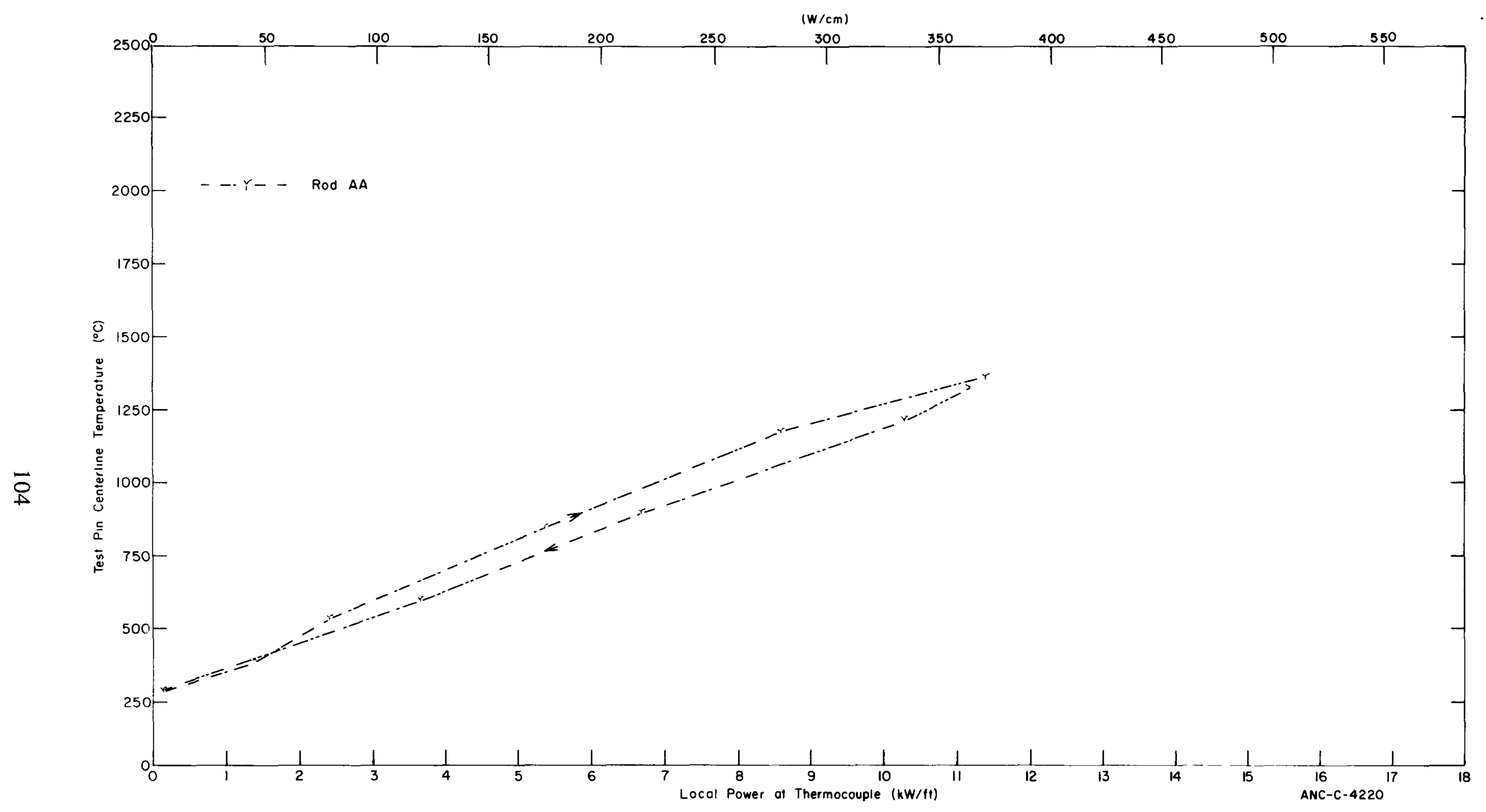

Fig. 91 IFA-226 test rod fuel centerline temperature versus local rod power at thermocouple location from August 2, 1973 at 0900 hours through August 2, 1973 at 2000 hours. 


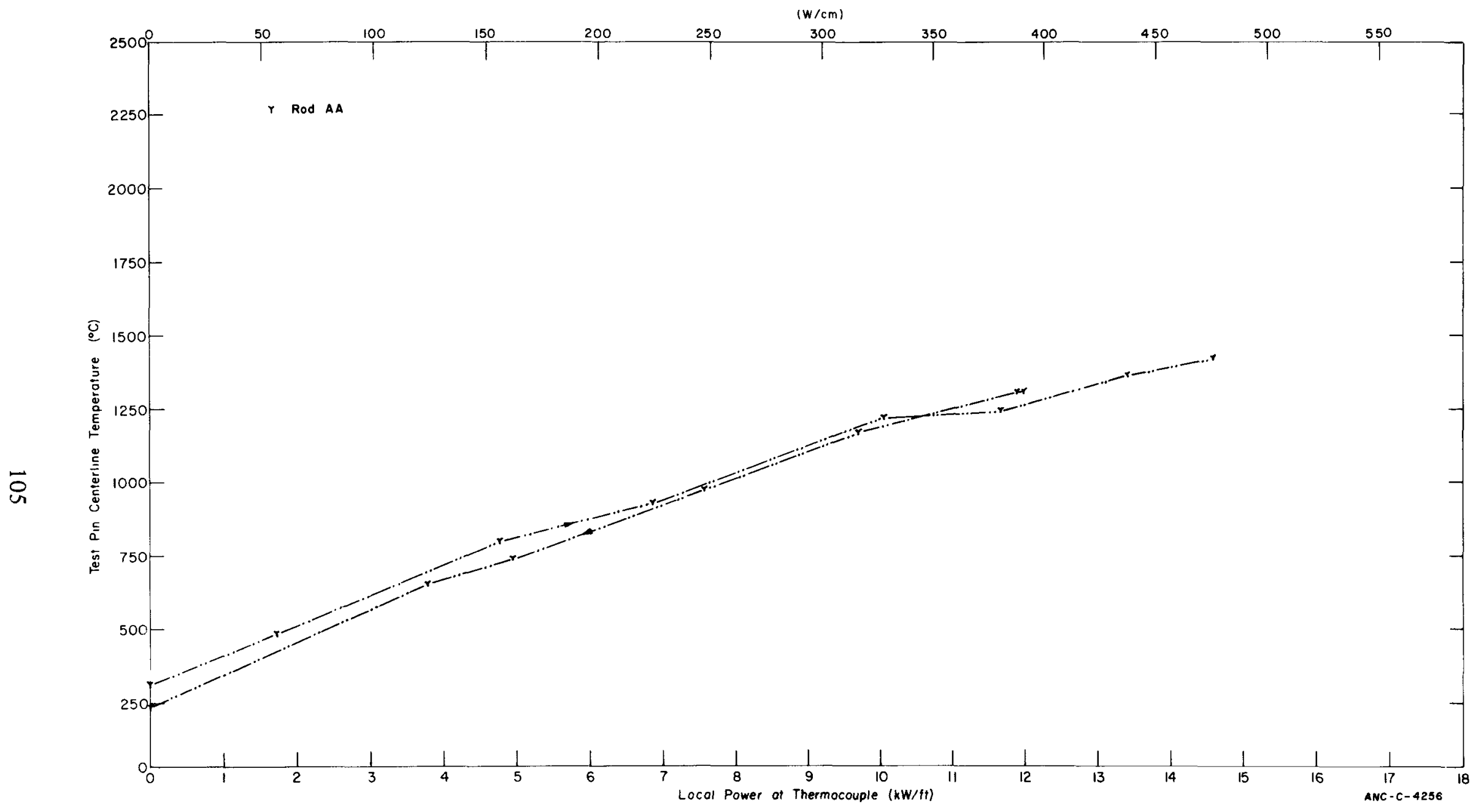

Fig. 92 IFA-226 test rod fuel centerline temperature versus local rod power at thermocouple location from September 24, 1973 at 0000 hours through September 24, 1973 at 1900 hours. 


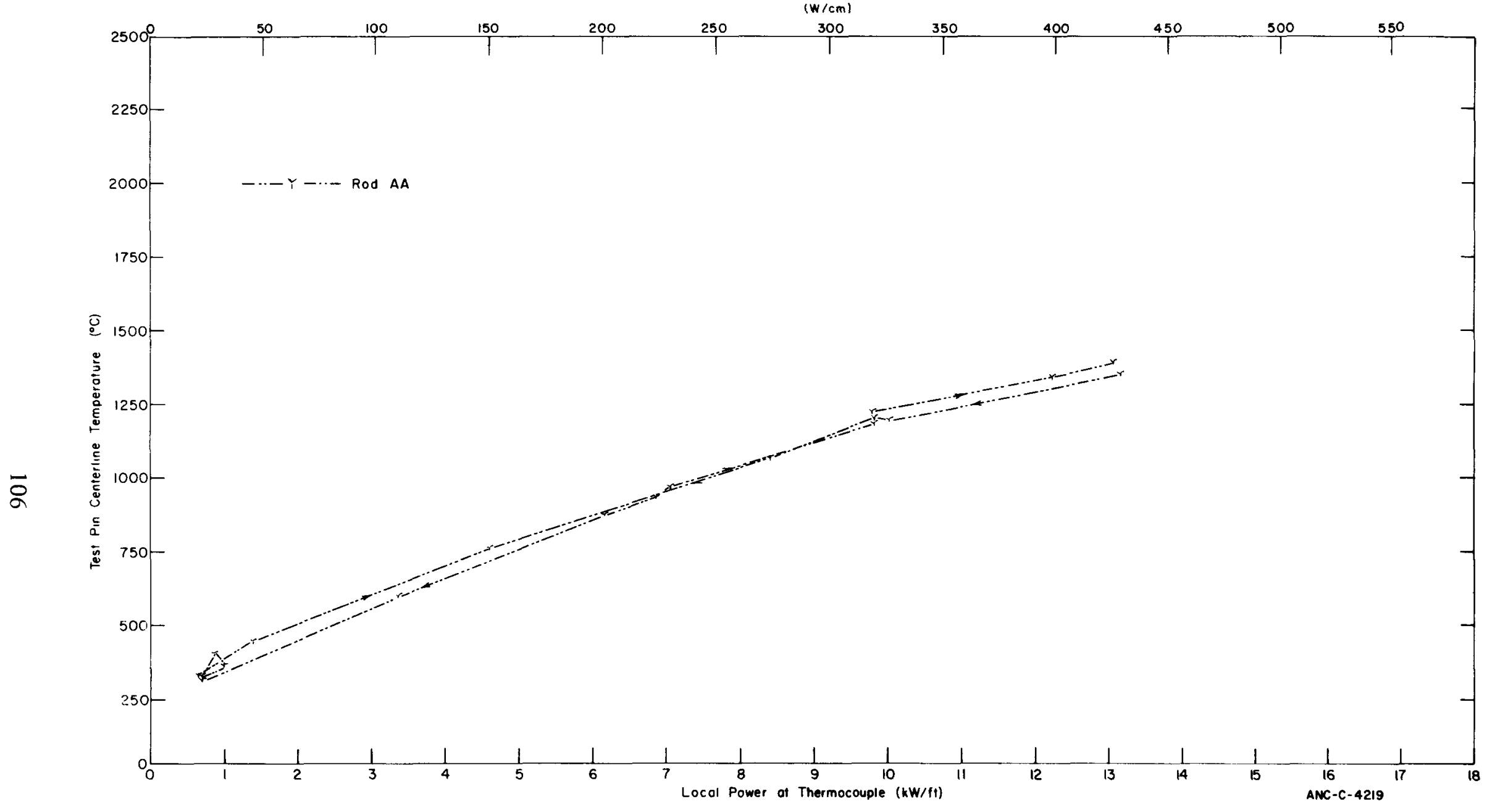

Fig. 93 IFA-226 test rod fuel centerline temperature versus local rod power at thermocouple location from September 25, 1973 at 1600 hours through September 26, 1973 at 1300 hours. 


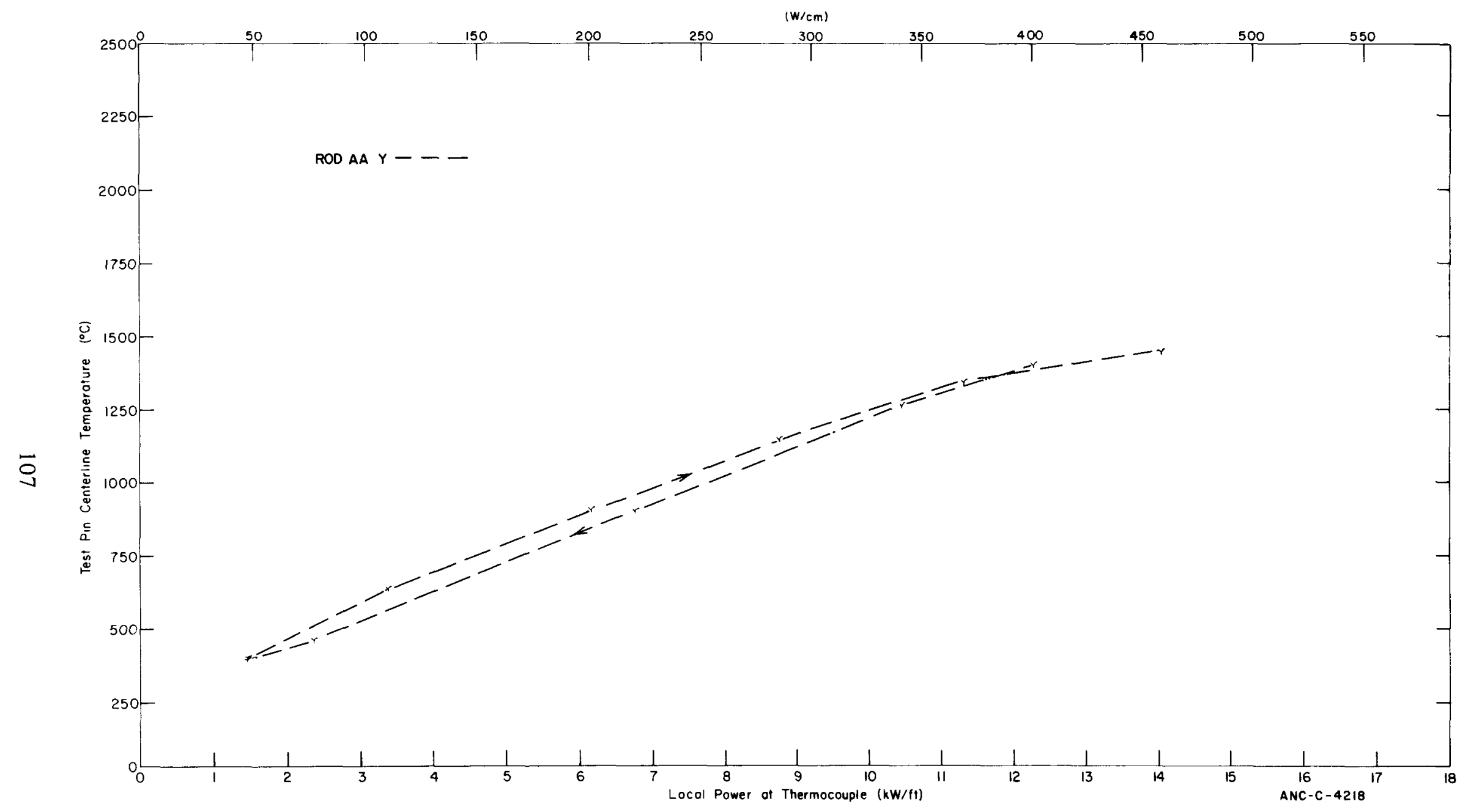

Fig. 94 IFA-226 test rod fuel centerline temperature versus local rod power at thermocouple location from October 26, 1973 at 2000 hours through October 27,1973 at 2000 hours. 


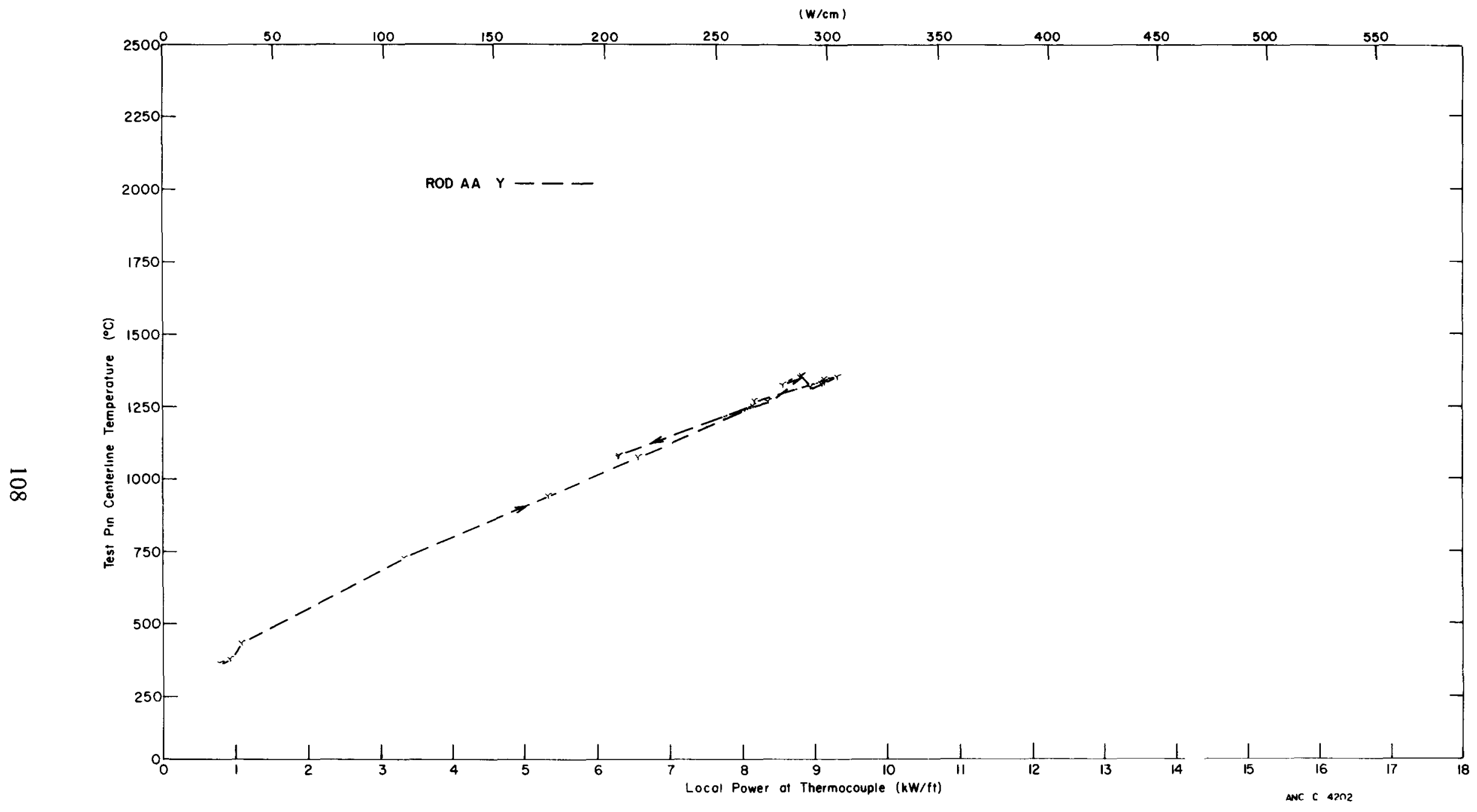

Fig. 95 IFA-226 test rod fuel centerline temperature versus local rod power at thermocouple location from December 6, 1973 at 1200 hours through December 8, 1973 at 1600 hours. 


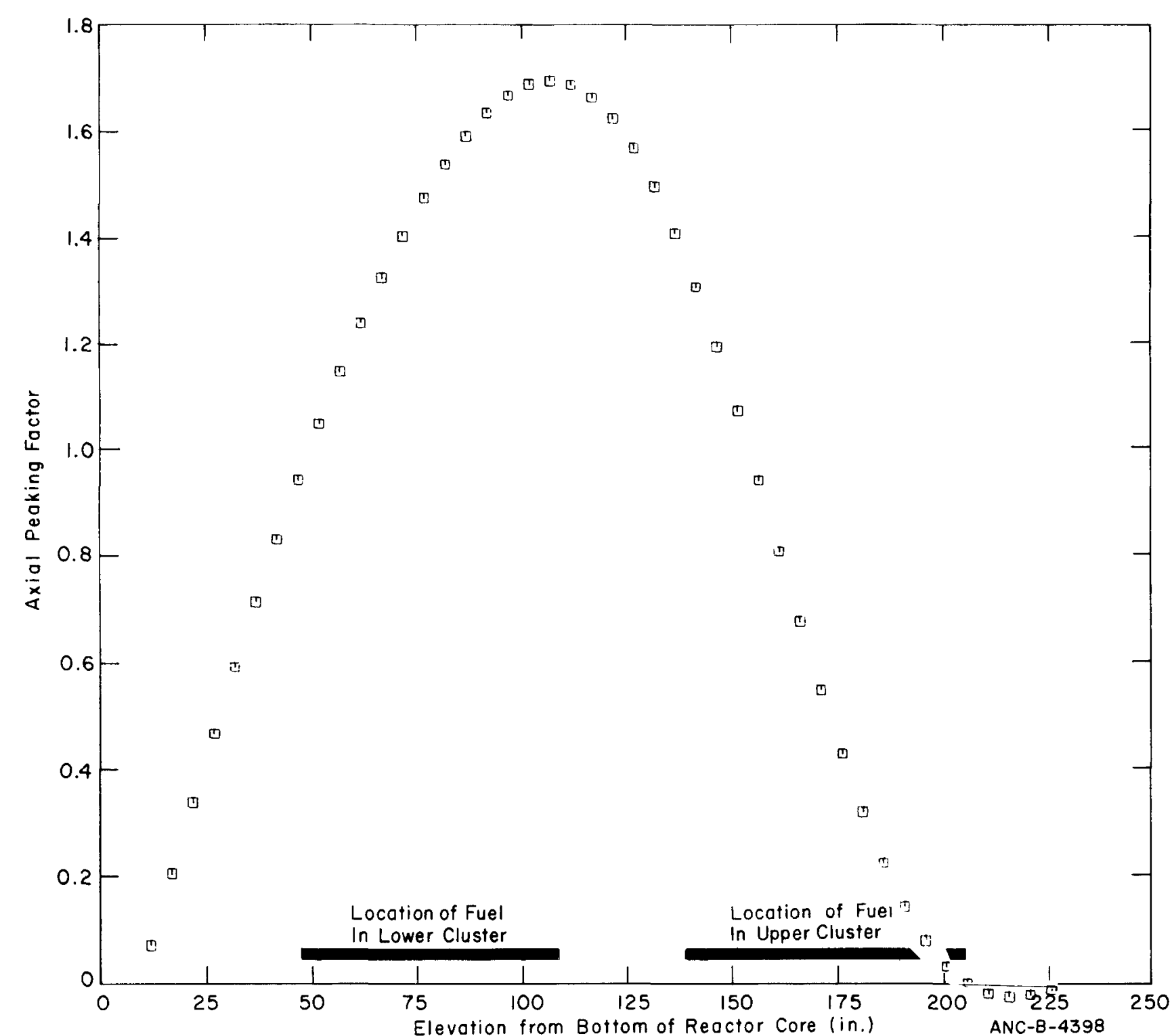

Fig. 96 IFA-226 assembly axial flux profile at 1200 hours on November 24 , 1971. 


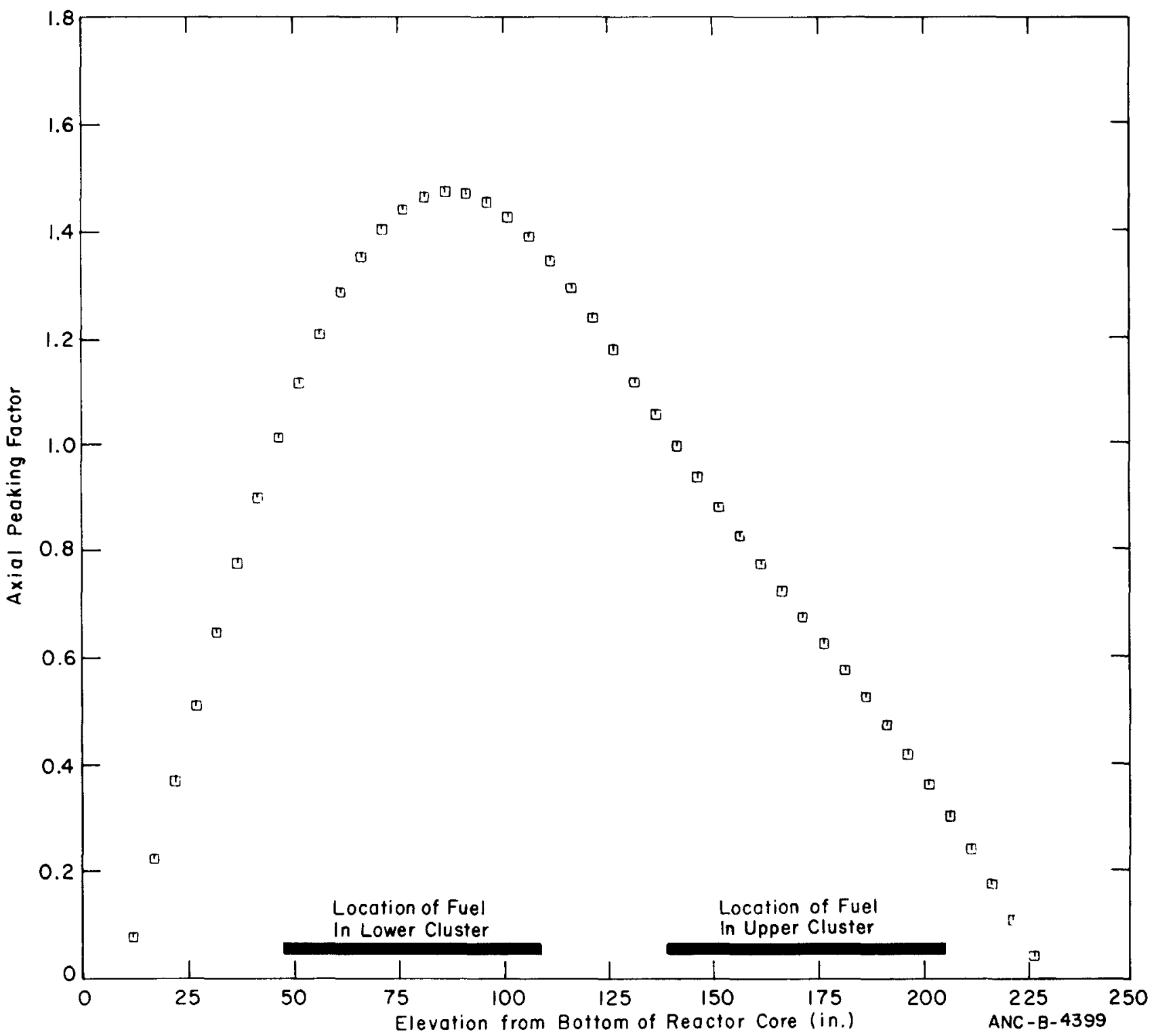

Fig. 97 IFA-226 assembly axial flux profile at 0000 hours on November 25, 1971. 


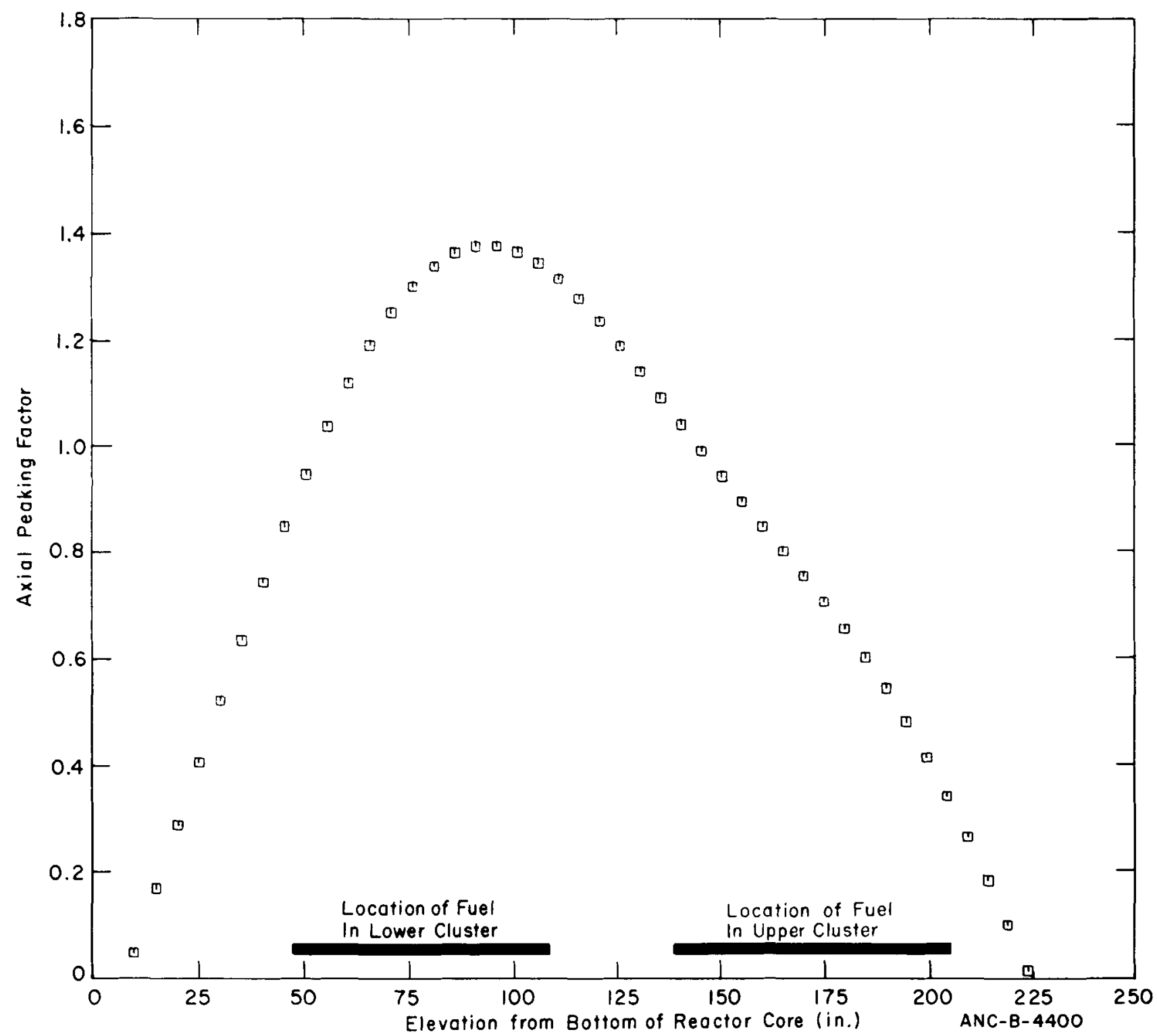

Fig. 98 IFA-226 assembly axial flux profile at 2100 hours on November 25 , 1971. 


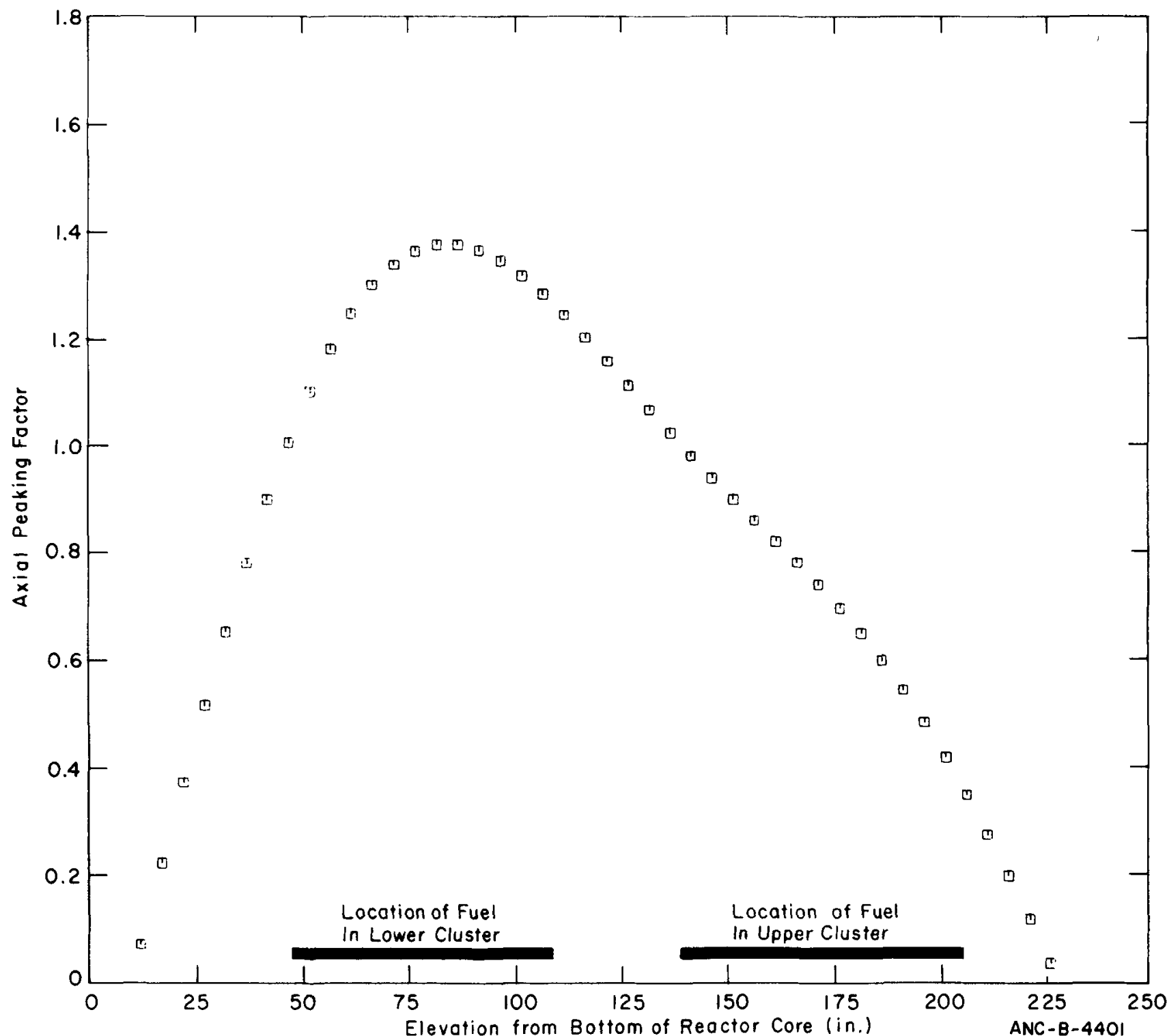

Fig. 99 IFA-226 assembly axial flux profile at 0400 hours on November 27 , 1971. 


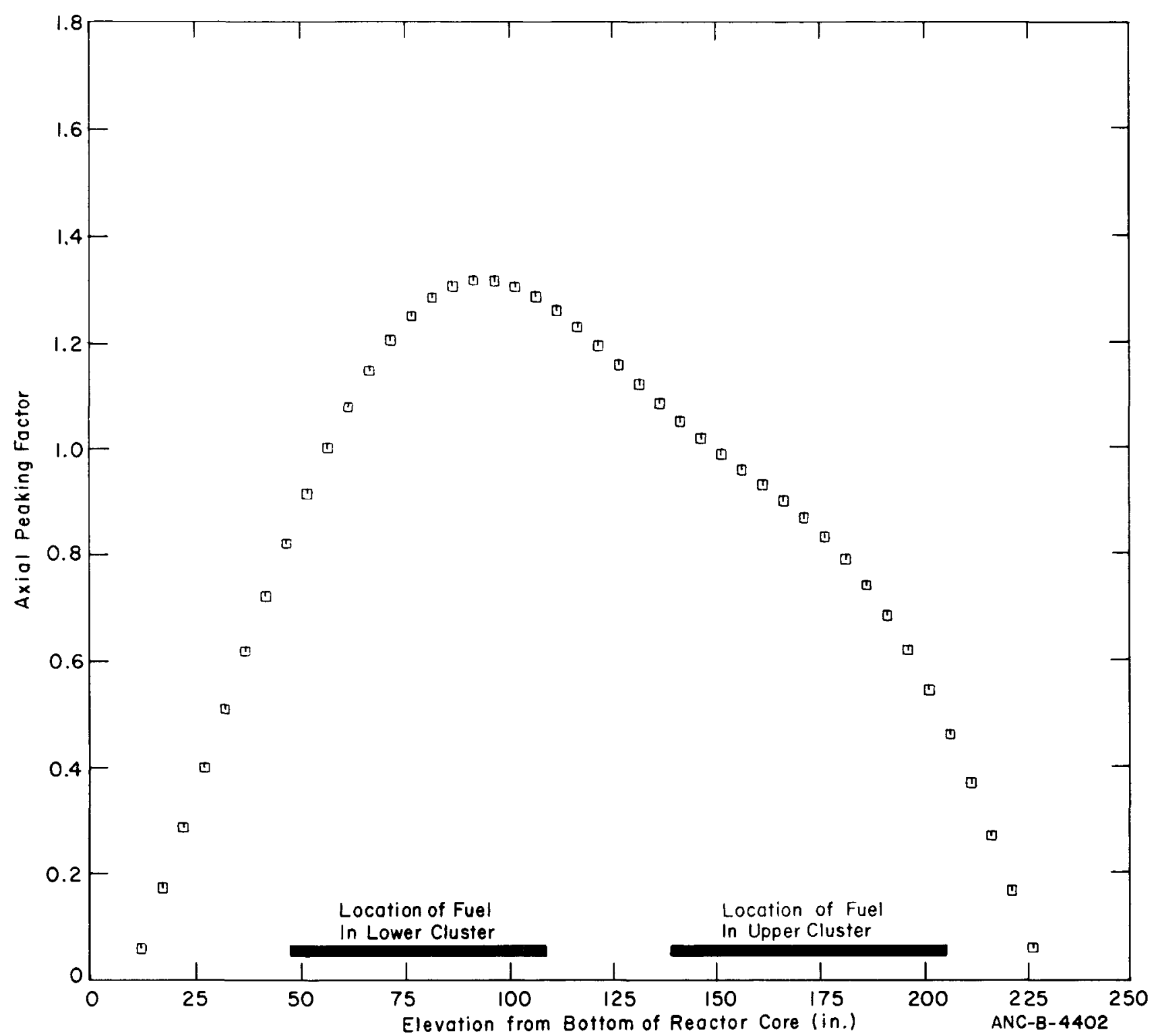

Fig. 100 IFA-226 assemb1y axial flux profile at 1800 hours on November 28 , 1971. 


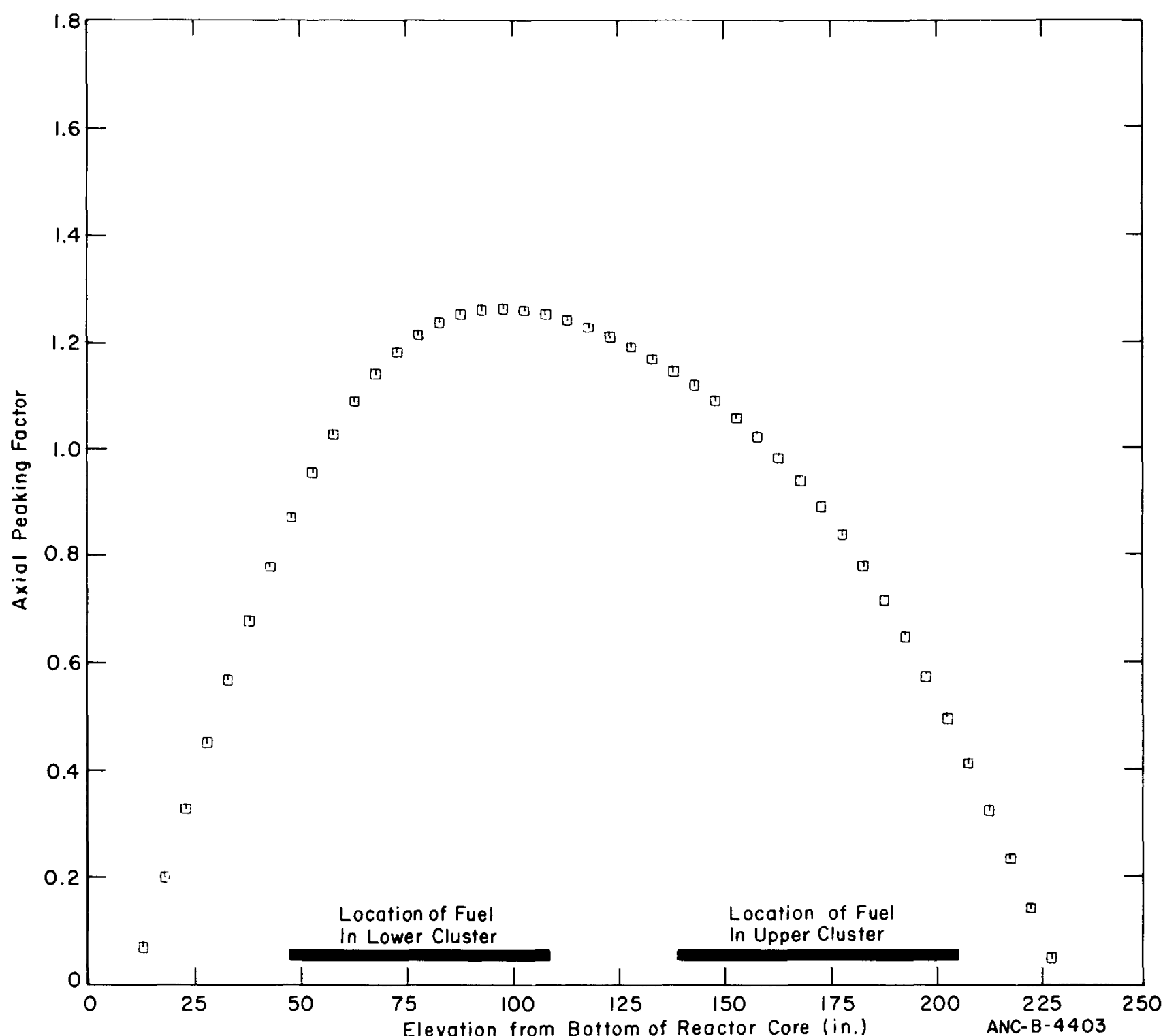

Fig. 101 IFA-226 assembly axial flux profile at 1800 hours on December 2, 1971. 


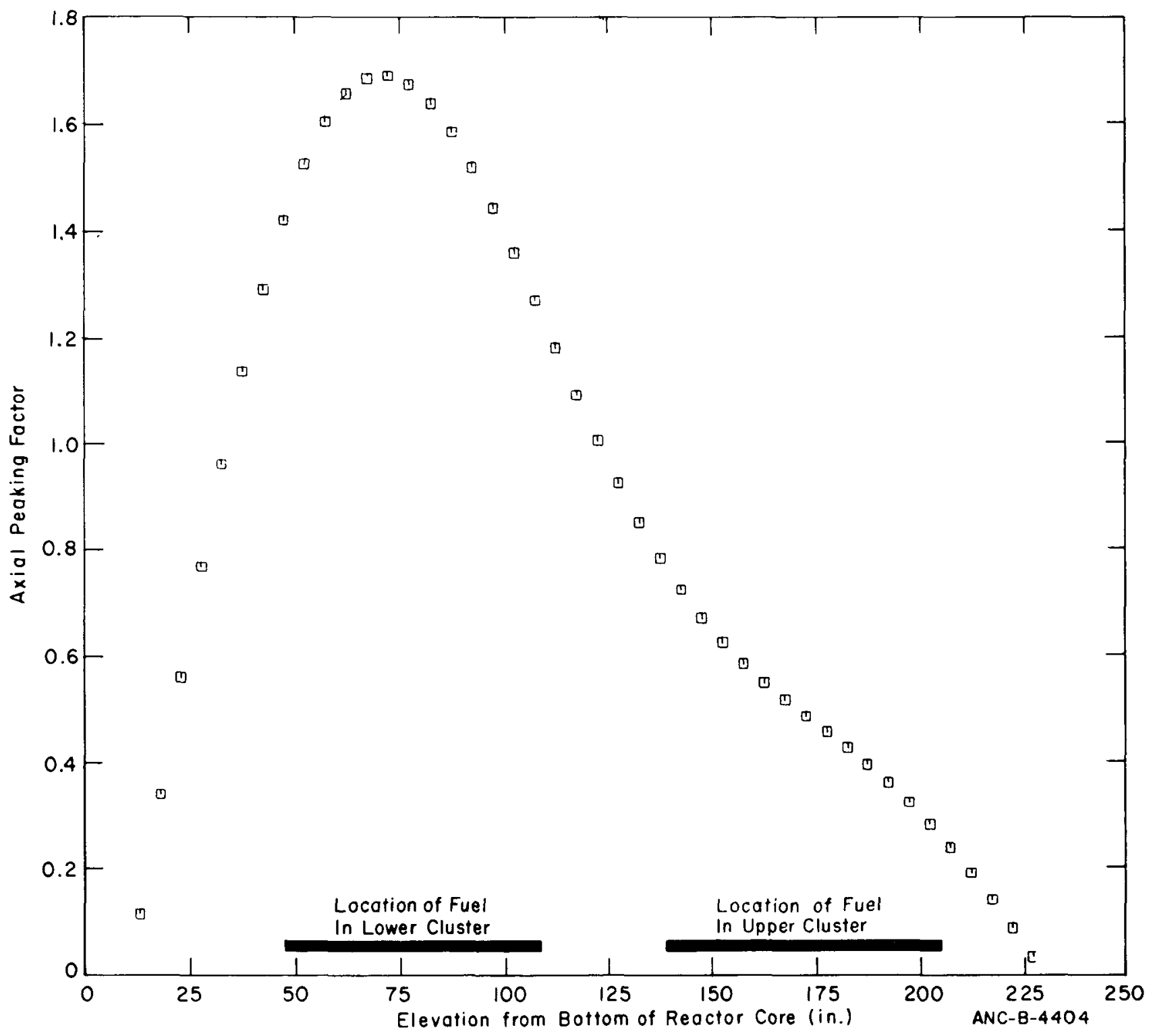

Fig. 102 IFA-226 assemb1y axial flux profile at 1800 hours on December 8 , 1971. 


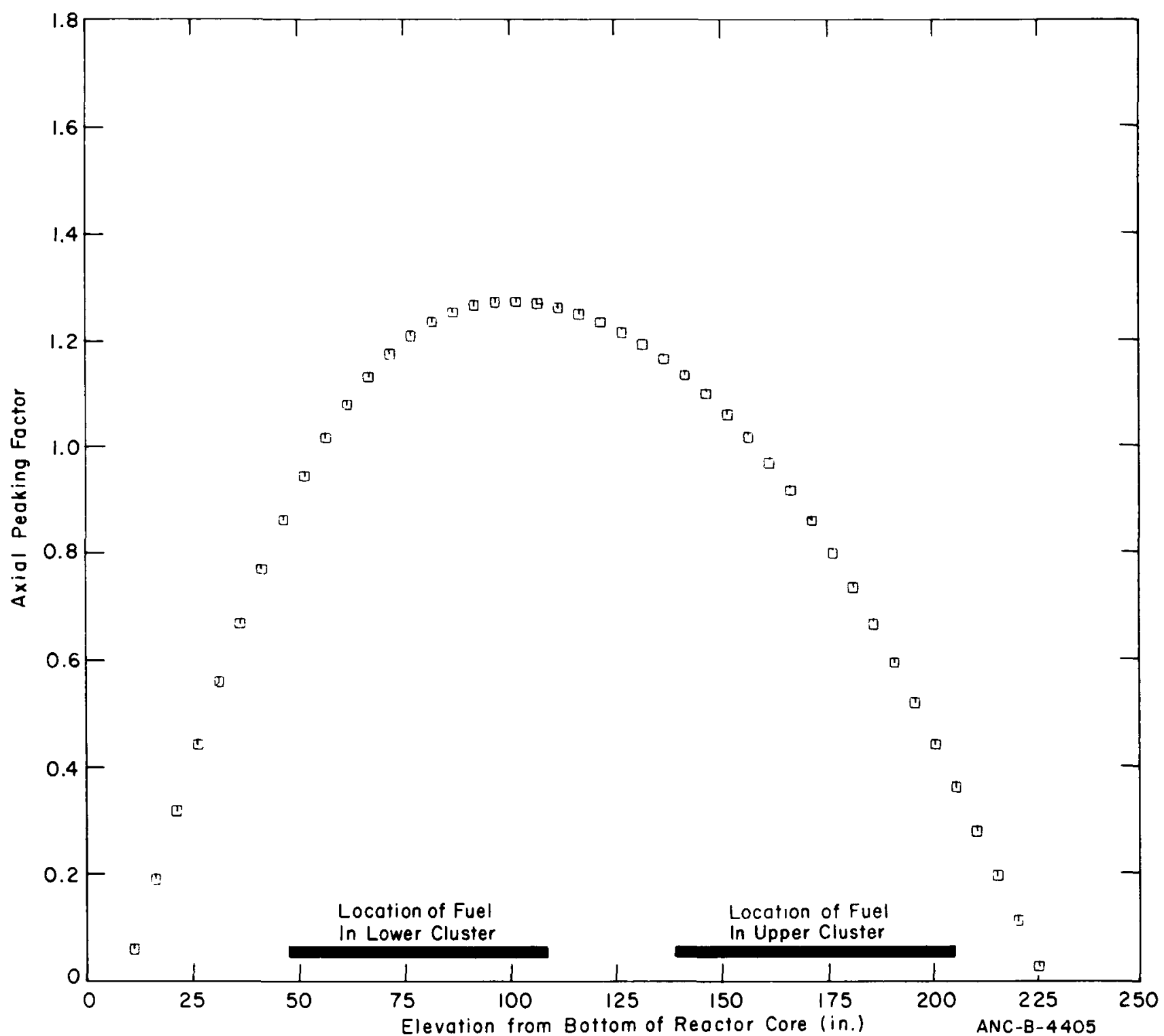

Fig. 103 IFA-226 assemb1y axial flux profile at 1800 hours on December 12 , 1971 . 


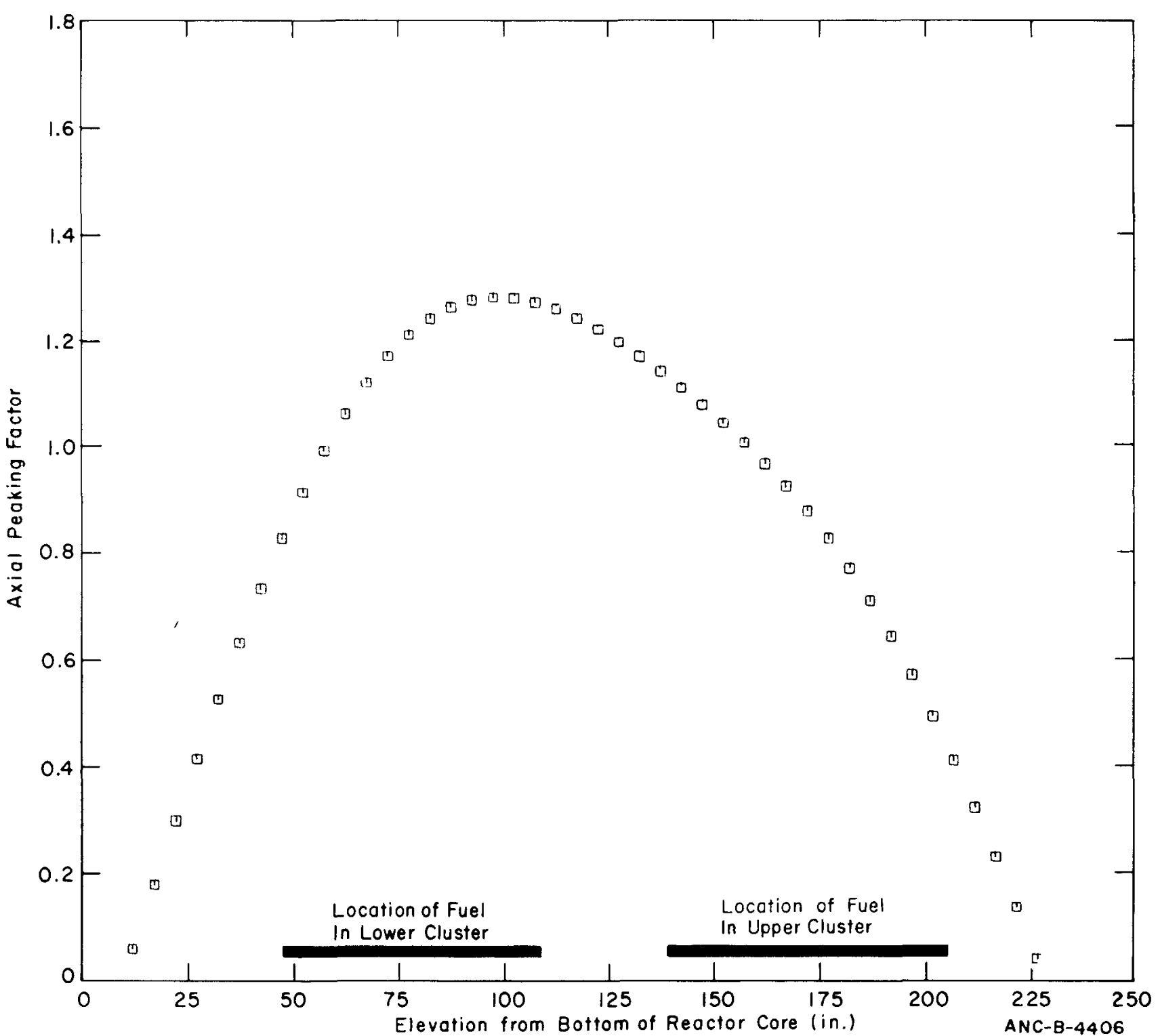

Fig. 104 IFA-226 assembly axial flux profile at 0000 hours on December 23, 1971. 


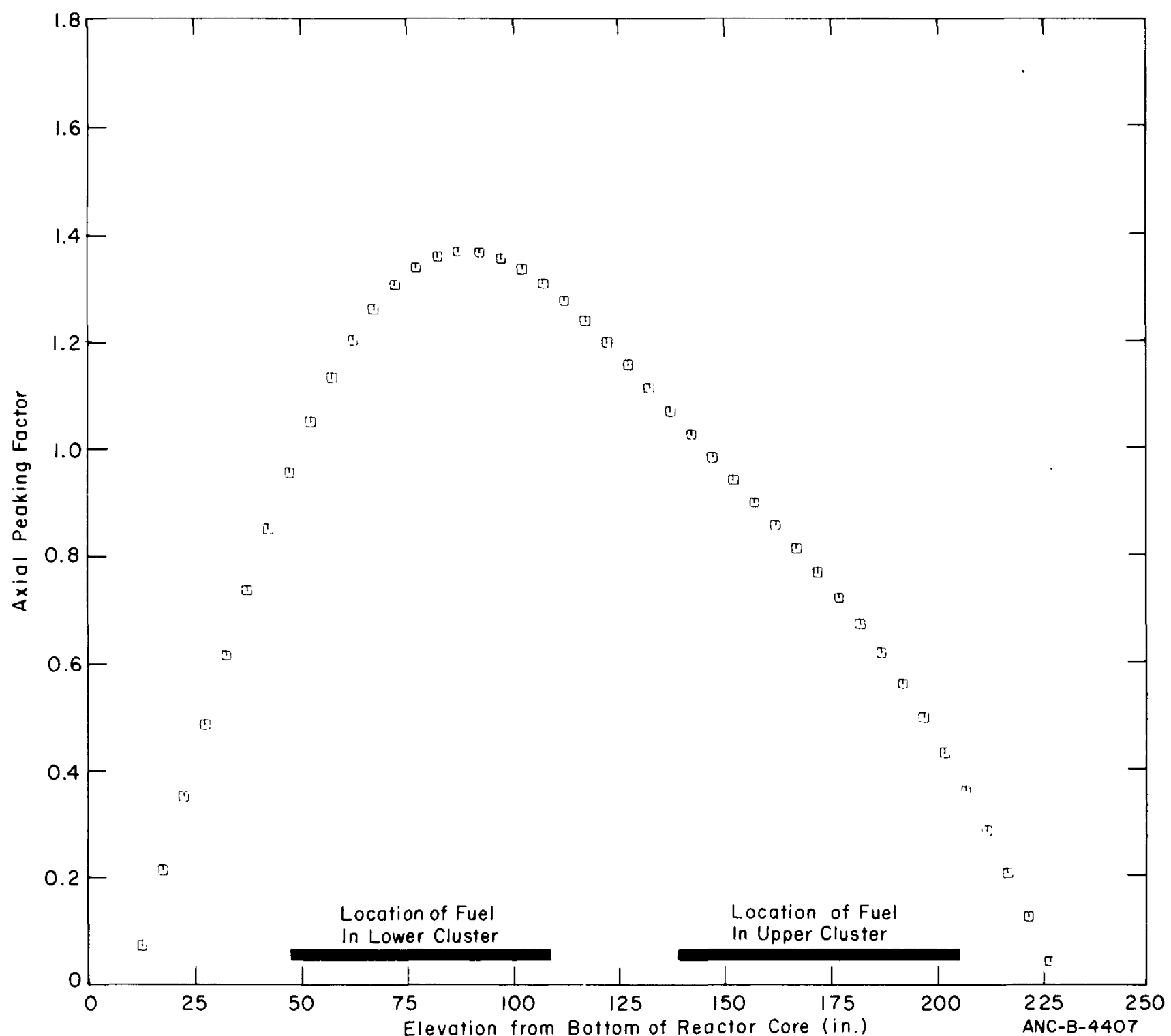

Fig. 105 IFA-226 assemb1y axia1 flux profile at 1200 hours on March 20, 1972 . 


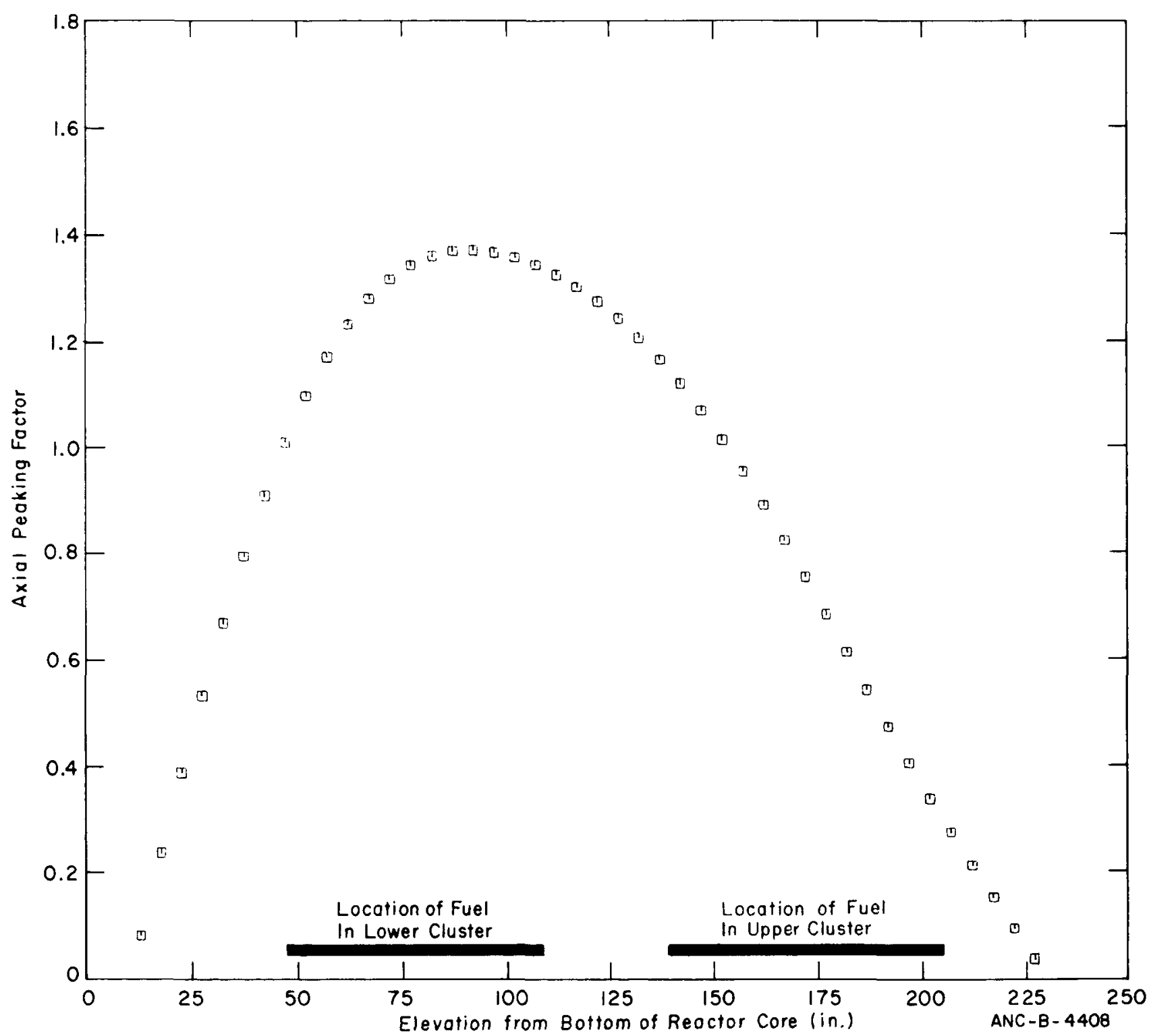

Fig. 106 IFA-226 assembly axial flux profile at 0000 hours on March 31 , 1972. 


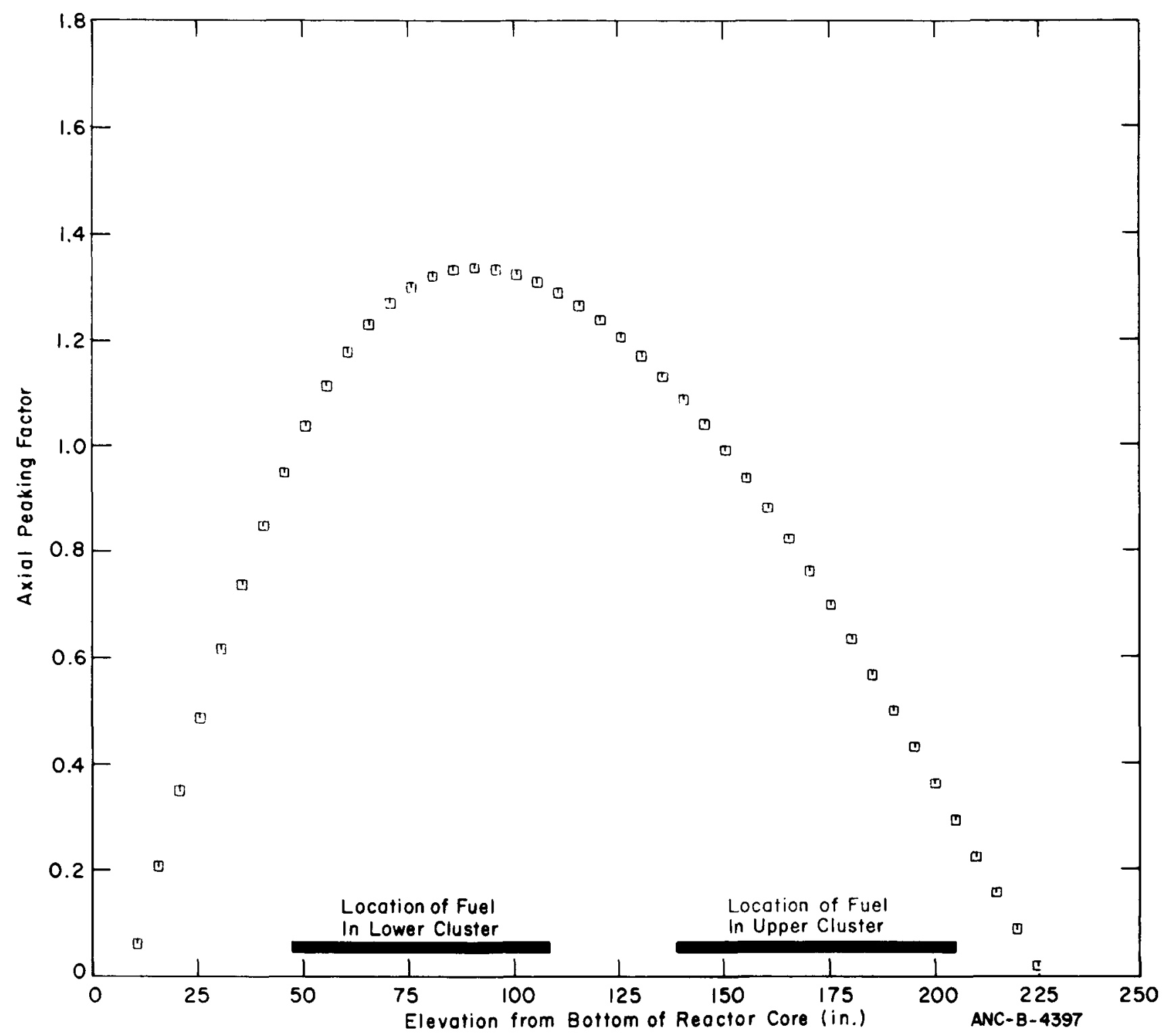

Fig. 107 IFA-226 assembly axial flux profile at 0000 hours on Apri1 12, 1972 . 


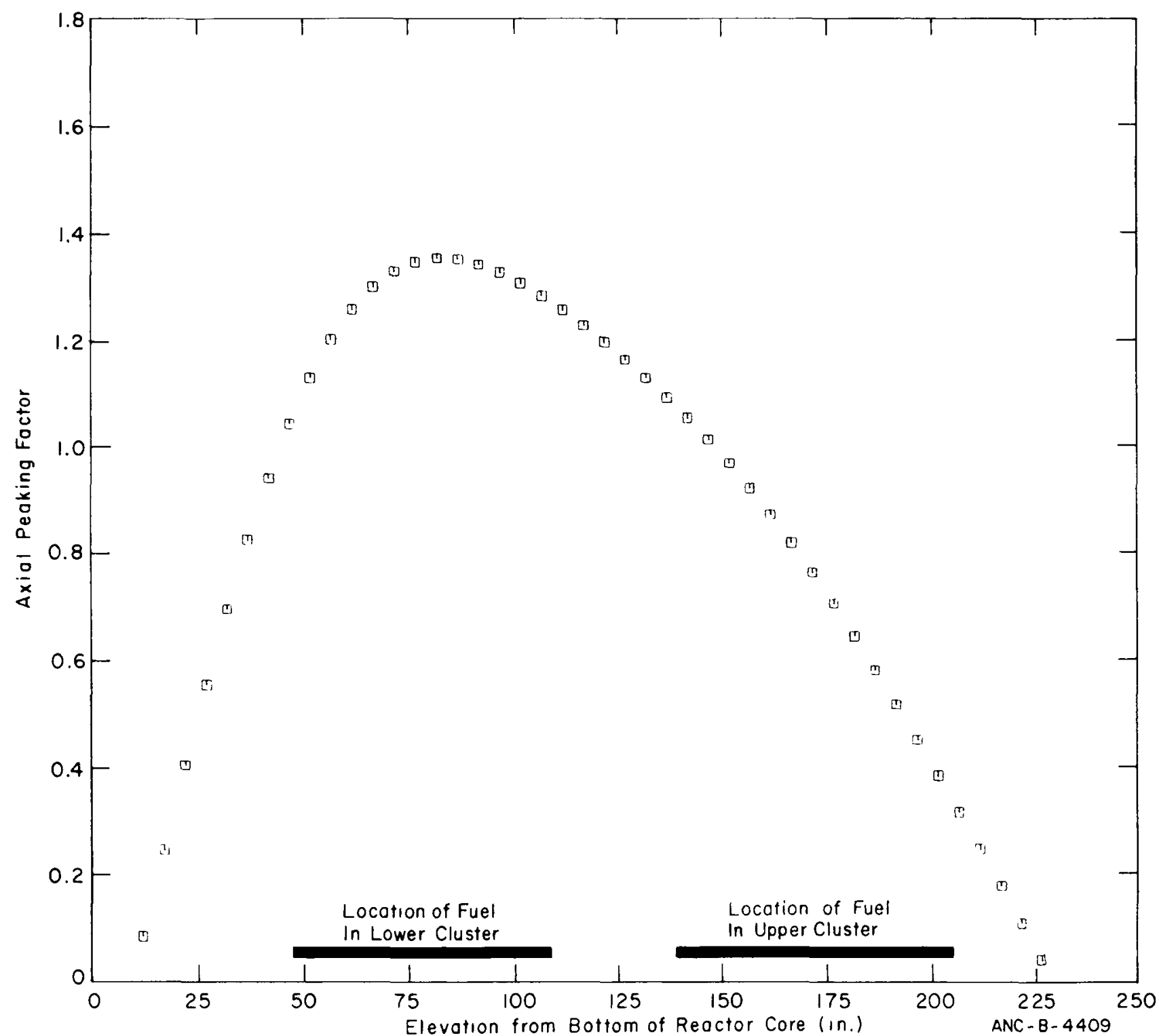

Fig. 108 IFA-226 assembly axial flux profile at 0000 hours on April 23, 1972. 


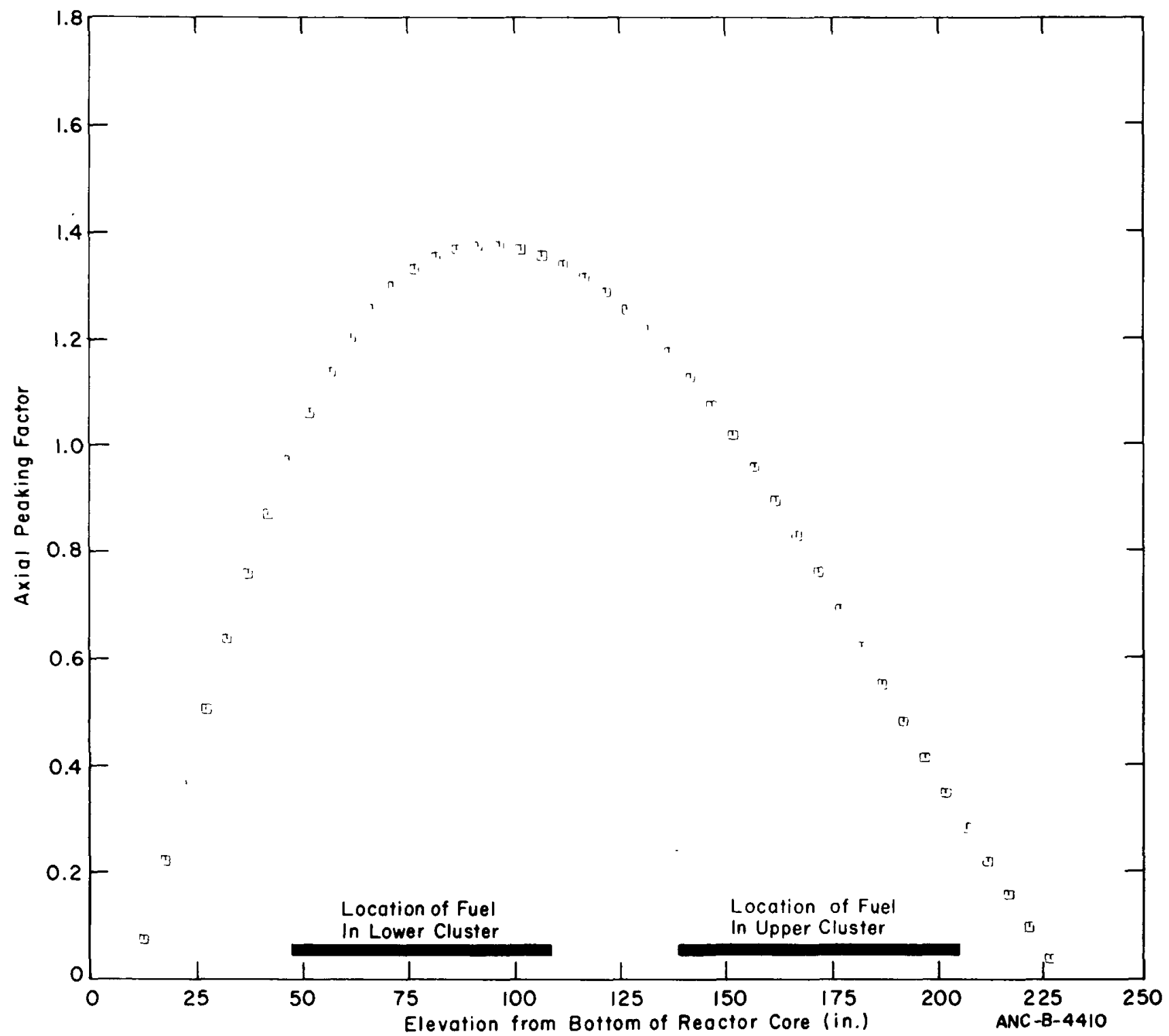

Fig. 109 IFA-226 assembly axial flux profile at 0000 hours on June 2, 1972. 


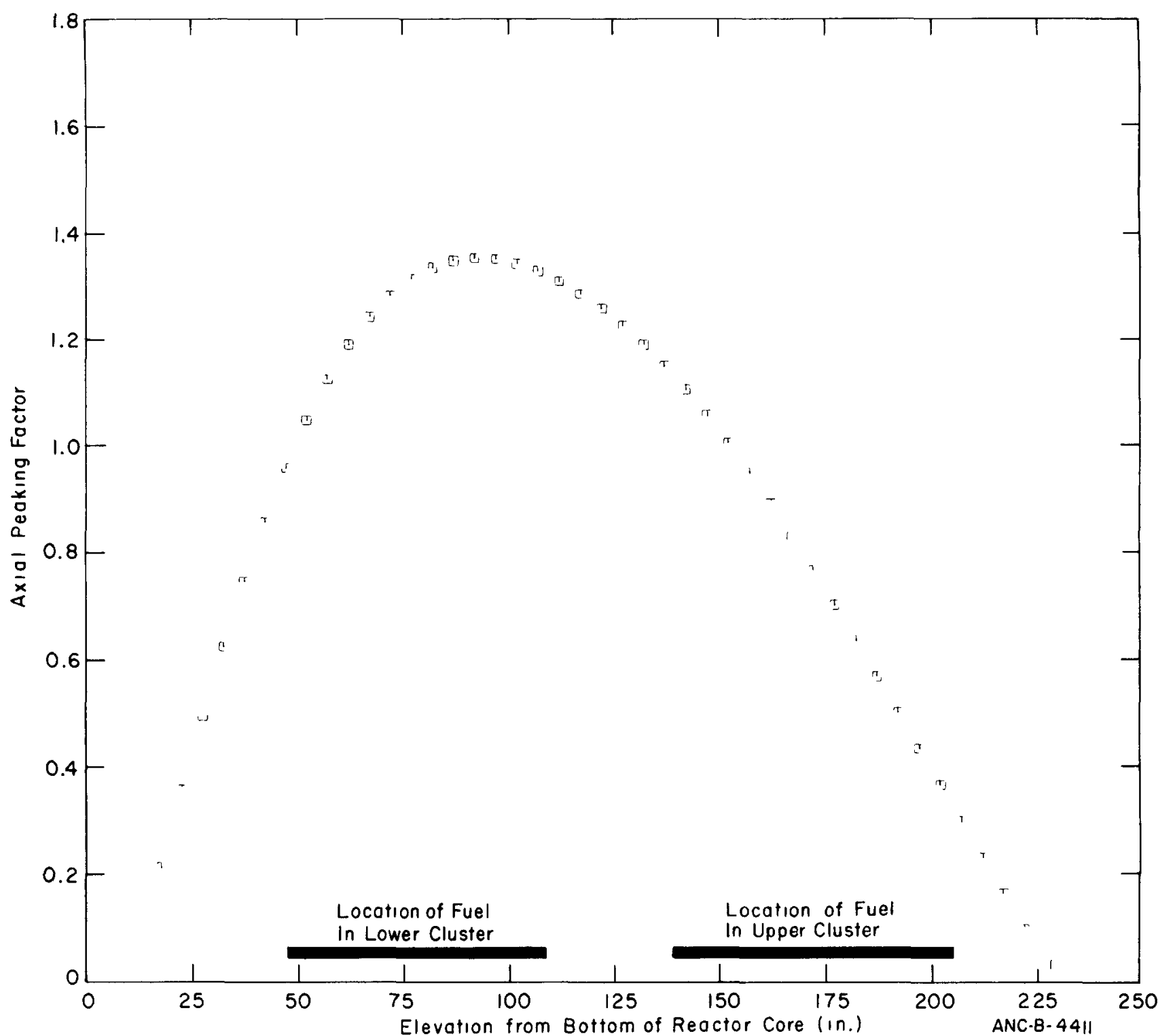

Fig. 110 IFA-226 assembly axial flux profile at 0000 hours on July $1,1972$. 


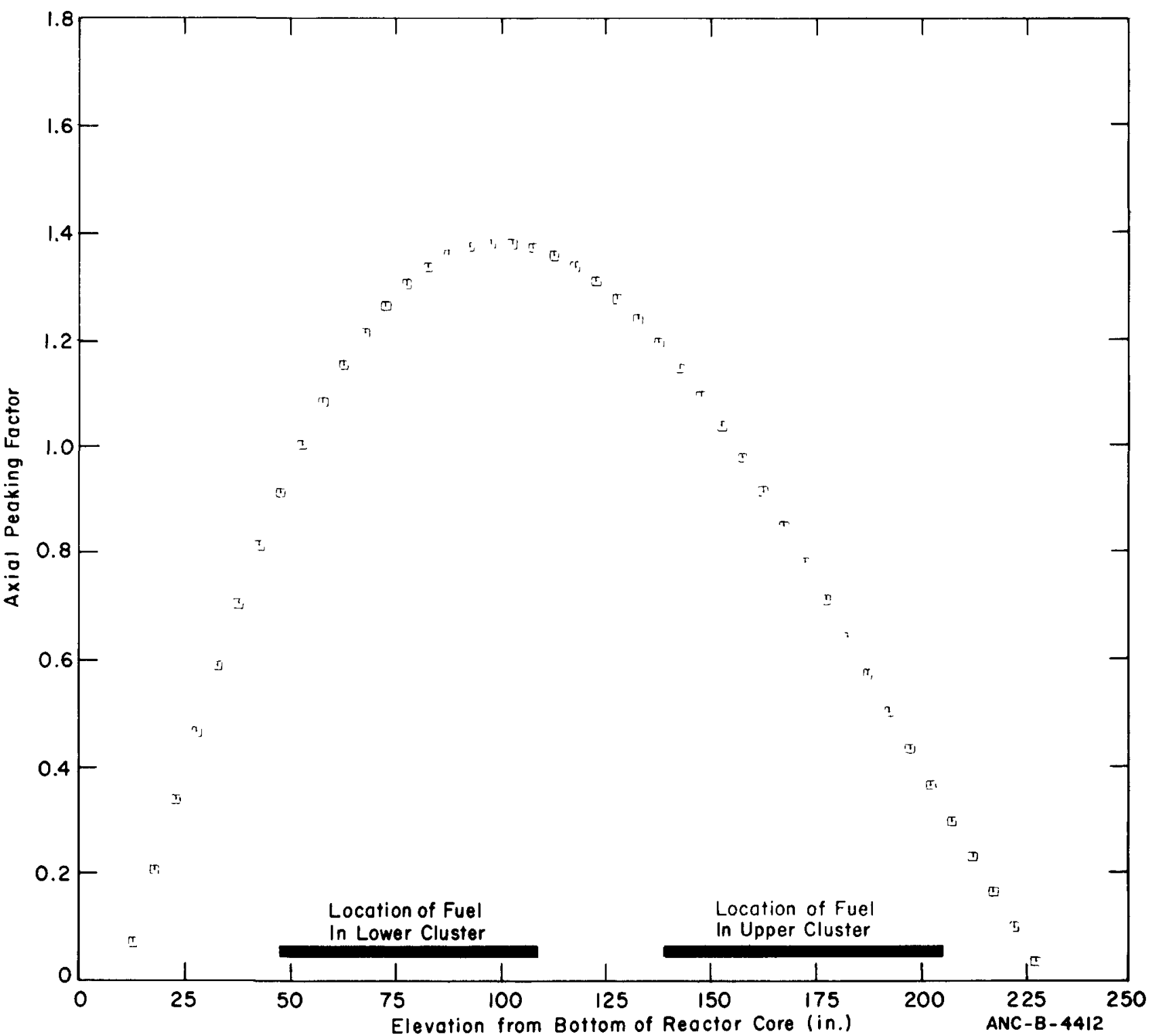

Fig. 111 IFA-226 assembly axial flux profile at 0000 hours on July 30, 1972 . 


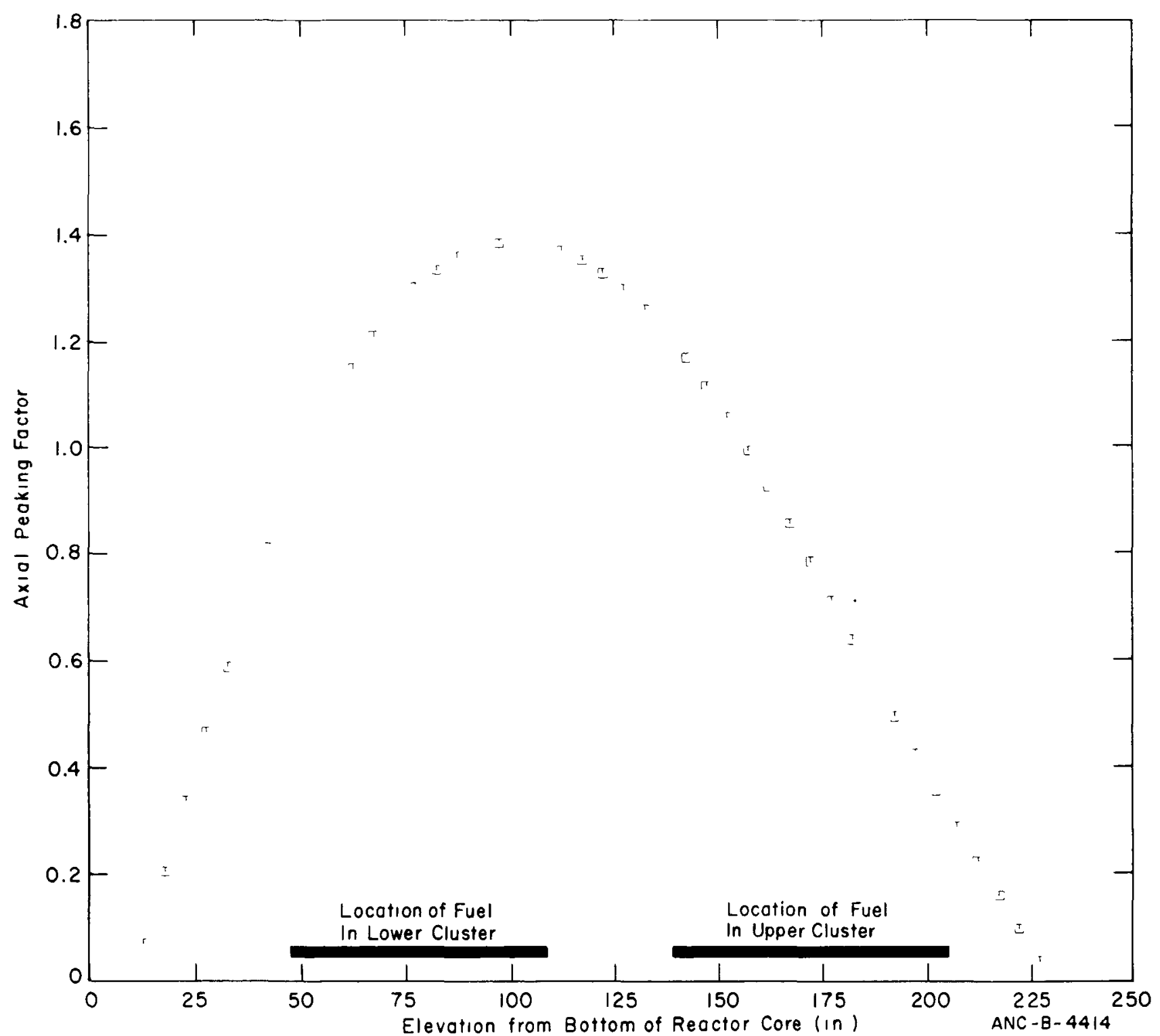

Fig. 112 IFA-226 assembly axial flux profile at 0000 hours on August 26, 1972. 


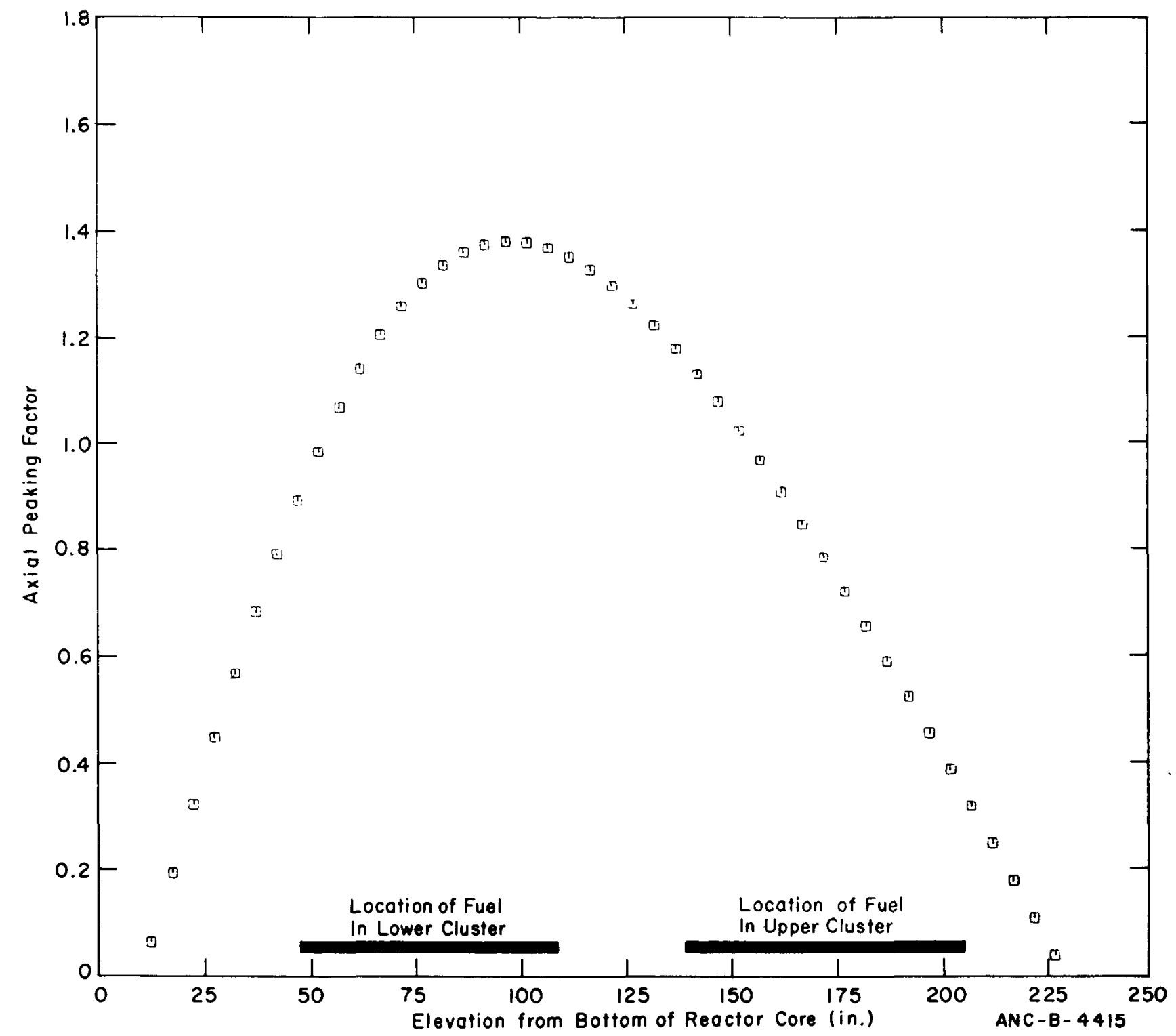

Fig. 113 IFA-226 assemb1y axial flux profile at 1800 hours on October 31, 1972. 


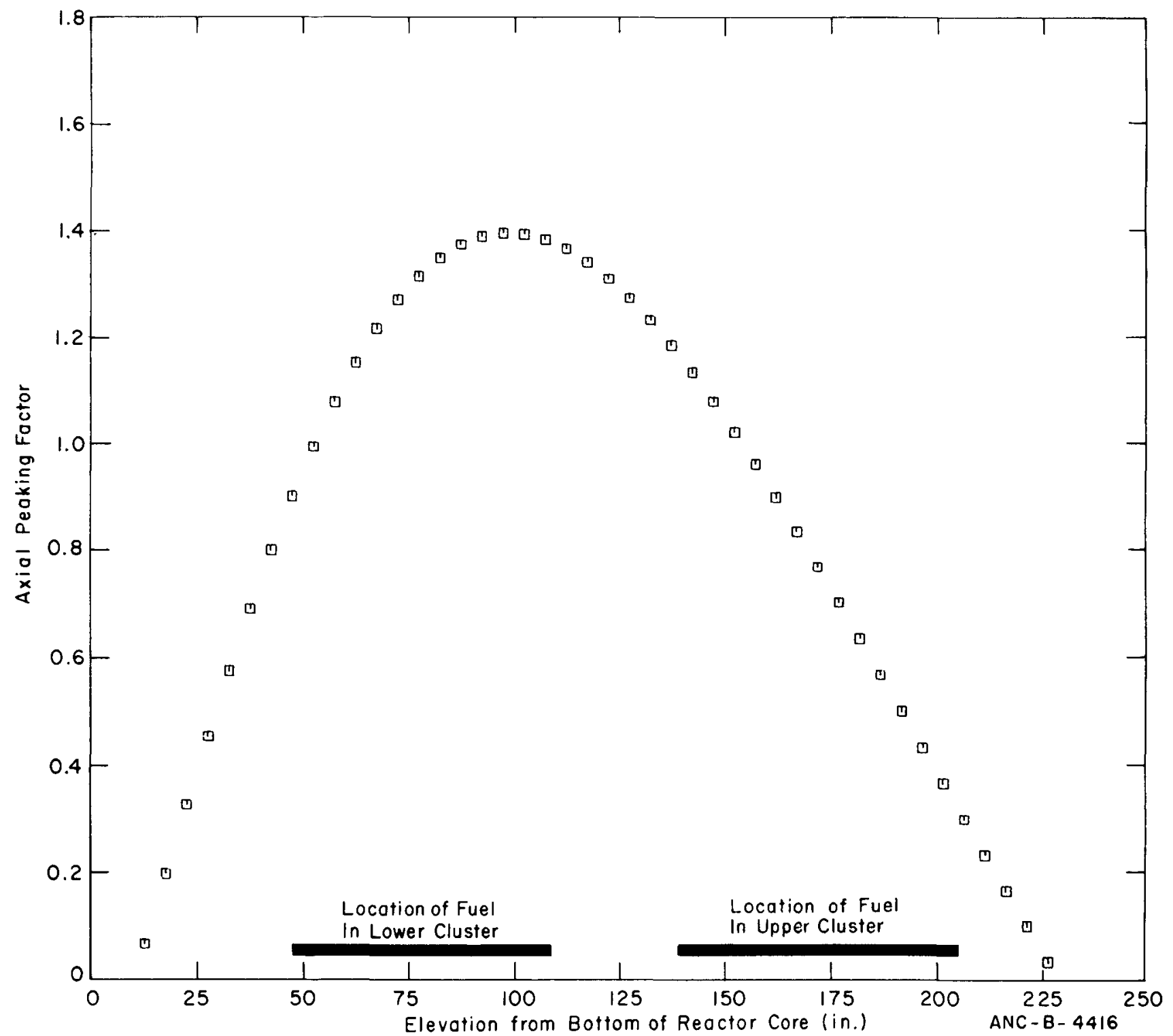

Fig. 114 IFA-226 assembly axial flux profile at 0000 hours on December 23,1972 . 


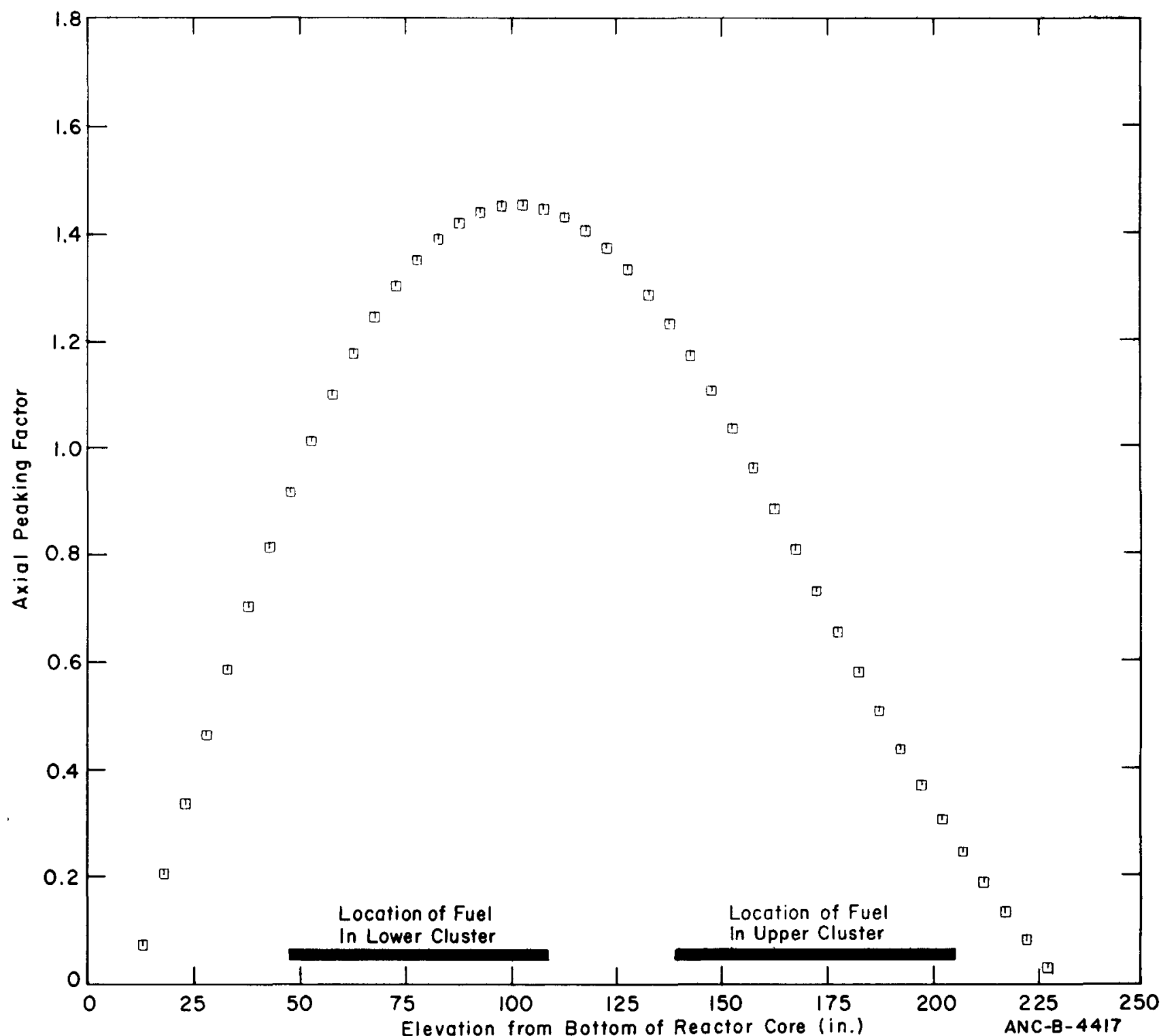

Fig. 115 IFA-226 assembly axial flux profile at 0000 hours on January 17, 1973. 


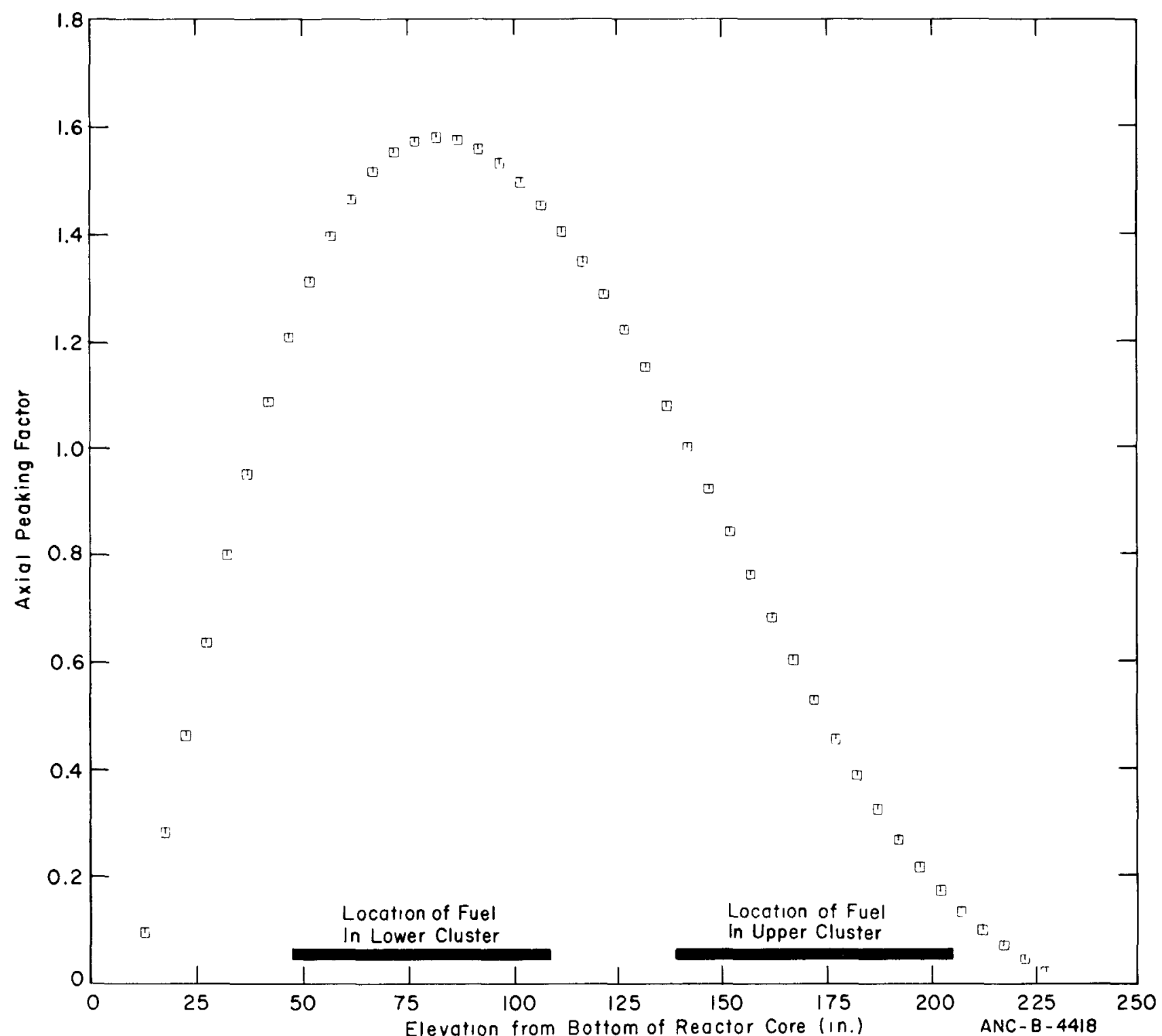

Fig. 116 IFA-226 assembly axial flux profile at 0000 hours on March 28, 1973. 


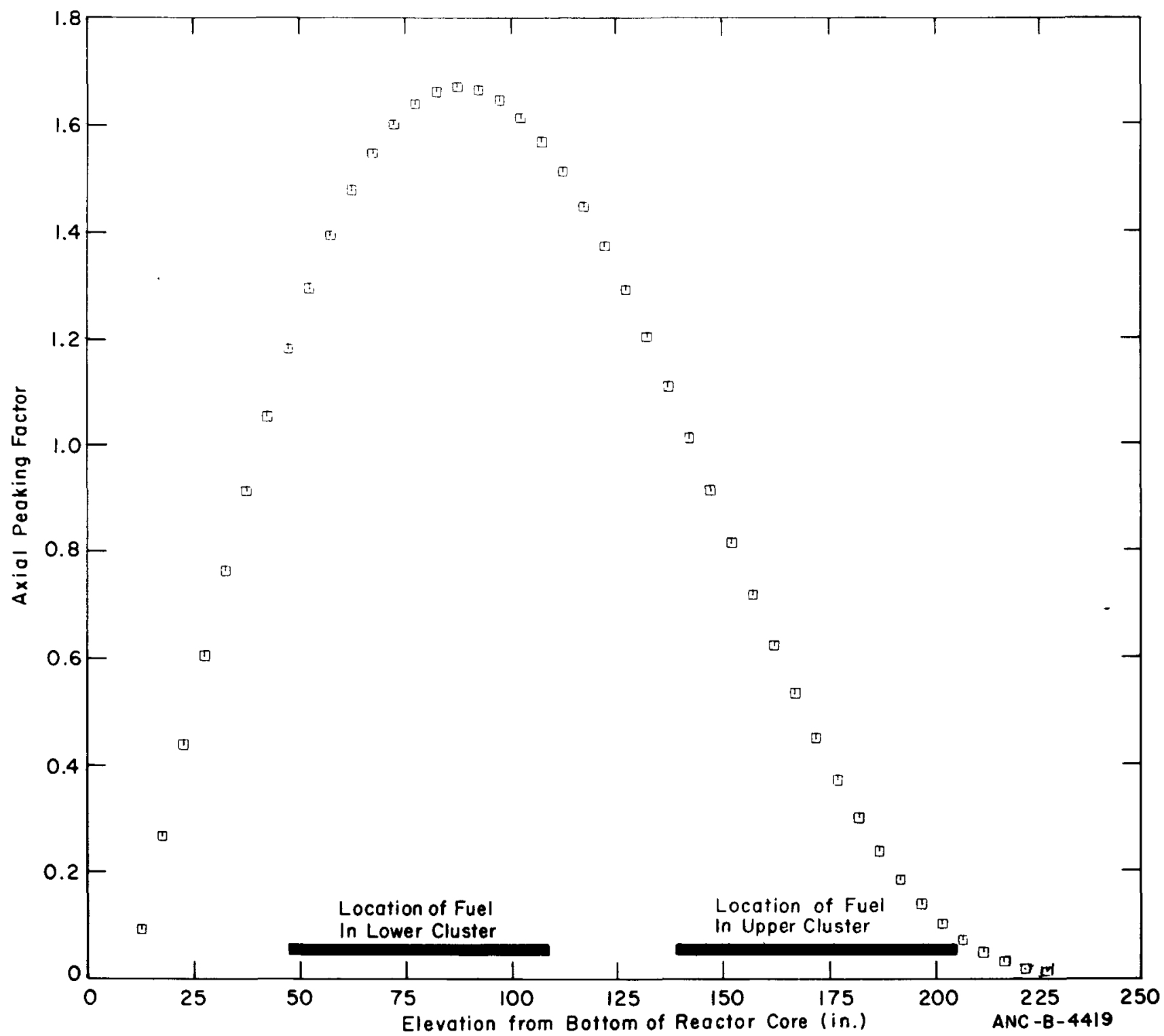

Fig. 117 IFA-226 assembly axial flux profile at 0000 hours on Apri1 3, 1973. 


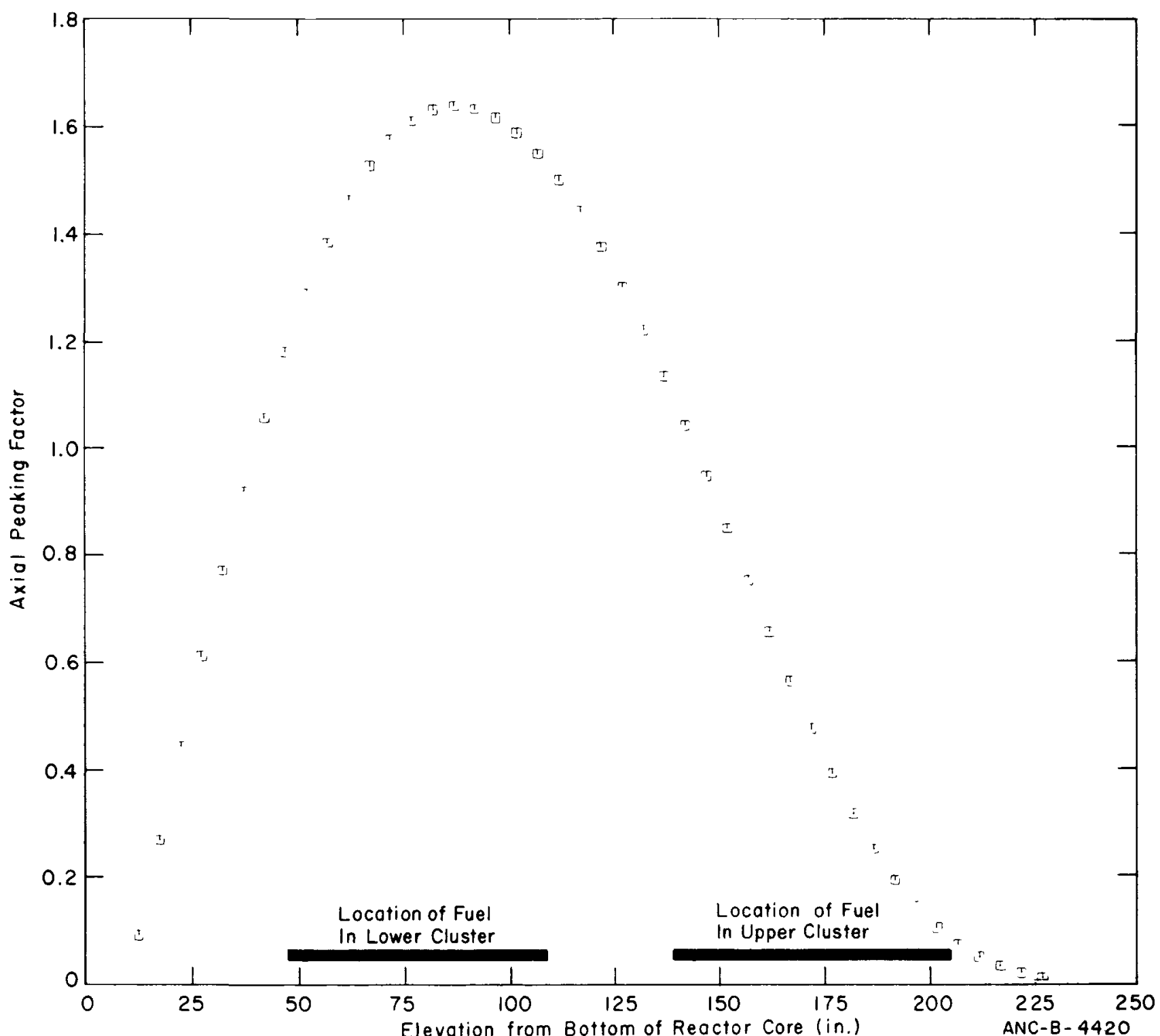

Fig. 118 IFA-226 assembly axial flux profile at 0000 hours on May 4, 1973. 


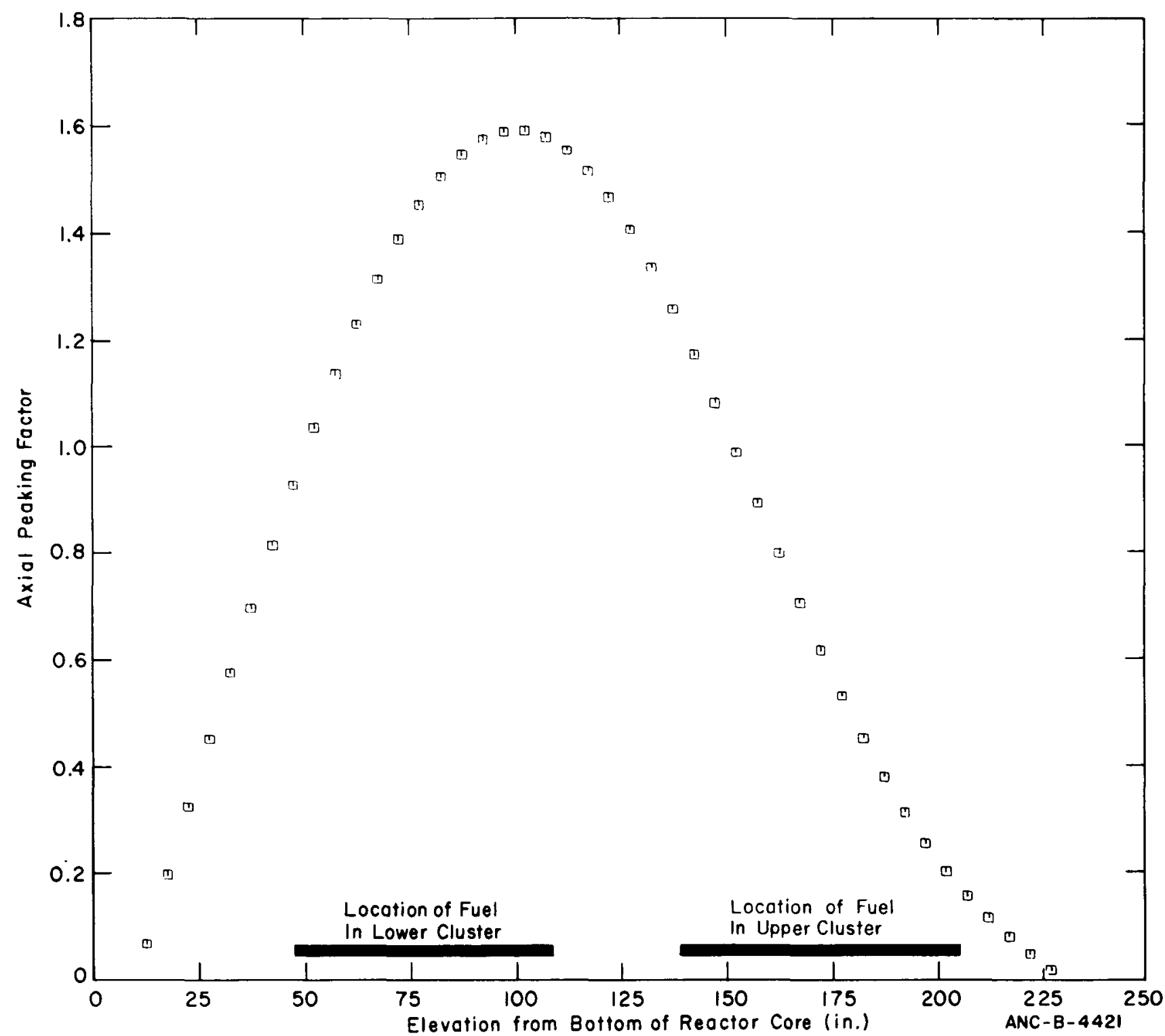

F1g. 119 IFA-226 assembly axial flux profile at 0000 hours on June 25, 1973. 


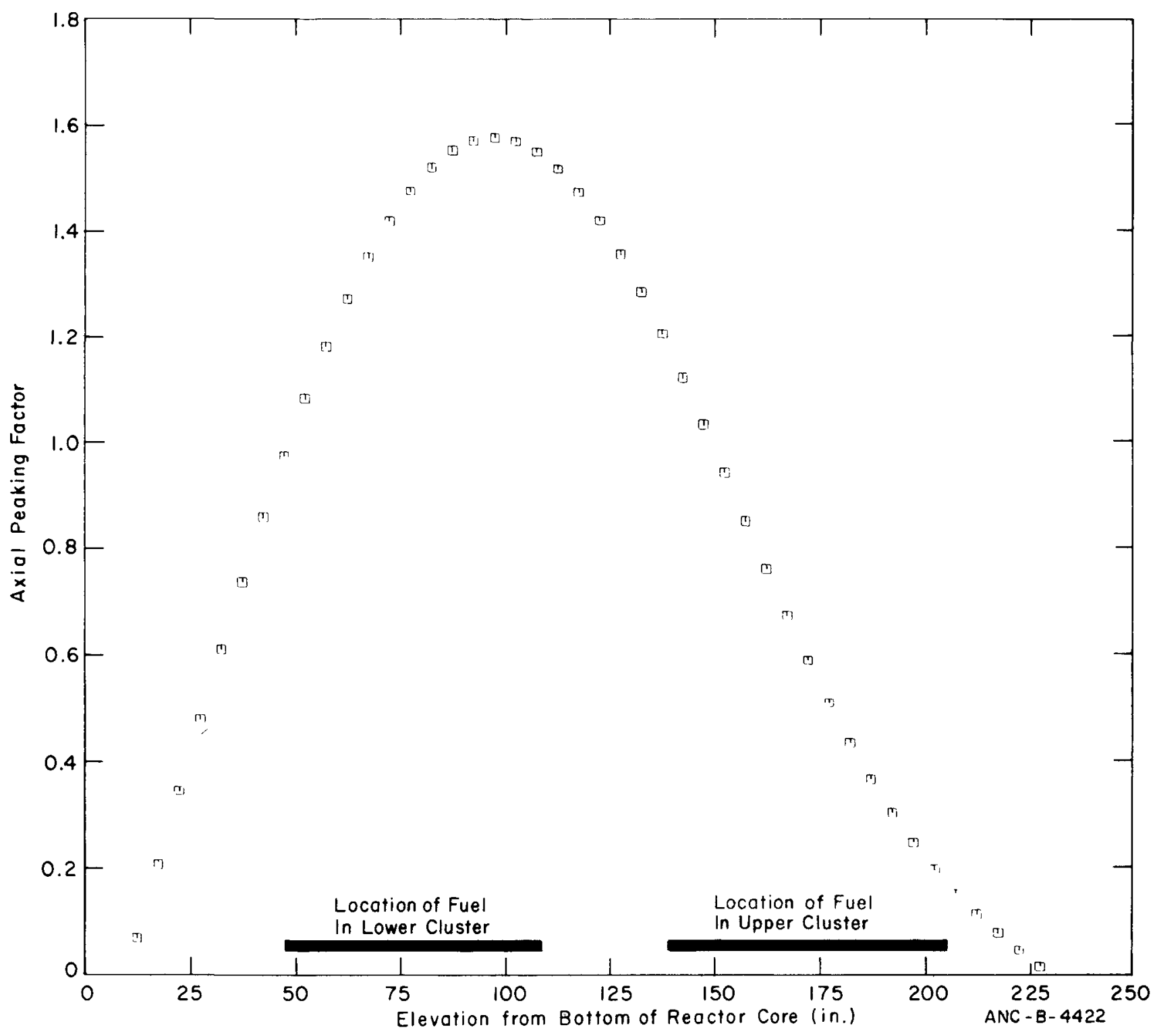

Fig. 120 IFA-226 assembly axial f1ux profile at 1800 hours on June 30 , 1973. 


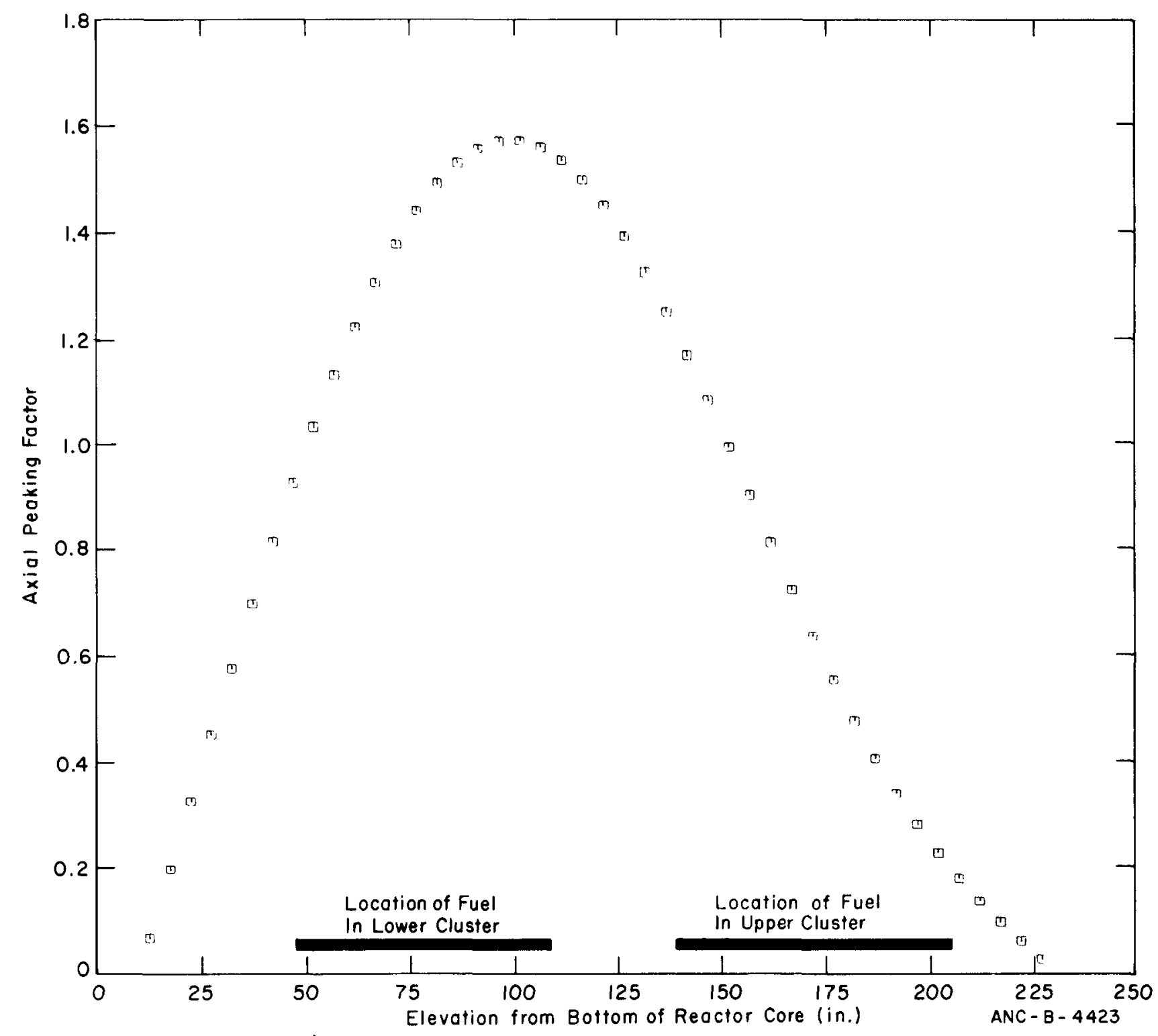

Fig. 121 IFA-226 assembly axial flux profile at 0000 hours on July 16, 1973. 


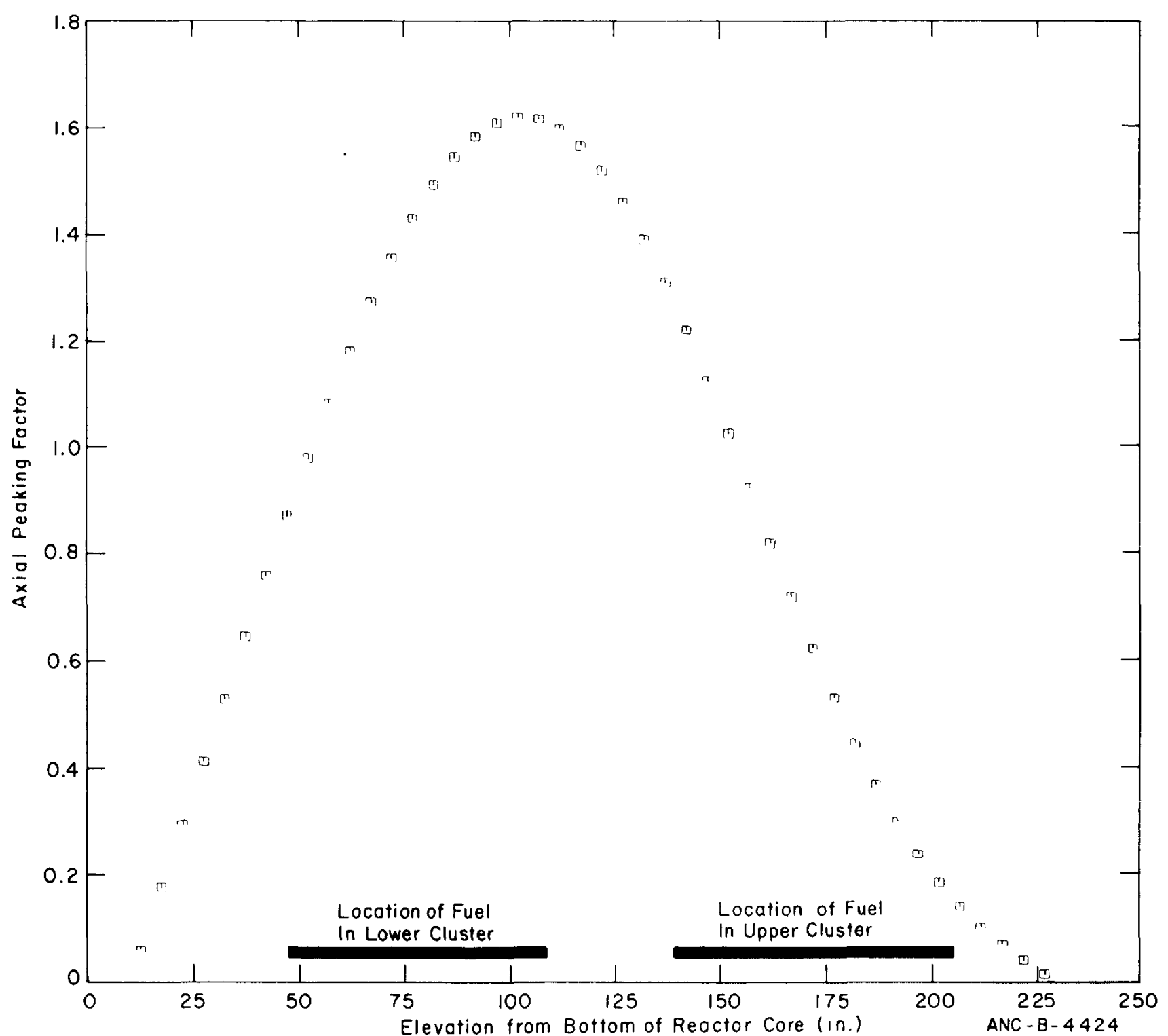

Fig. 122 IFA-226 assembly axial flux profile at 0000 hours on August 23, 1973. 


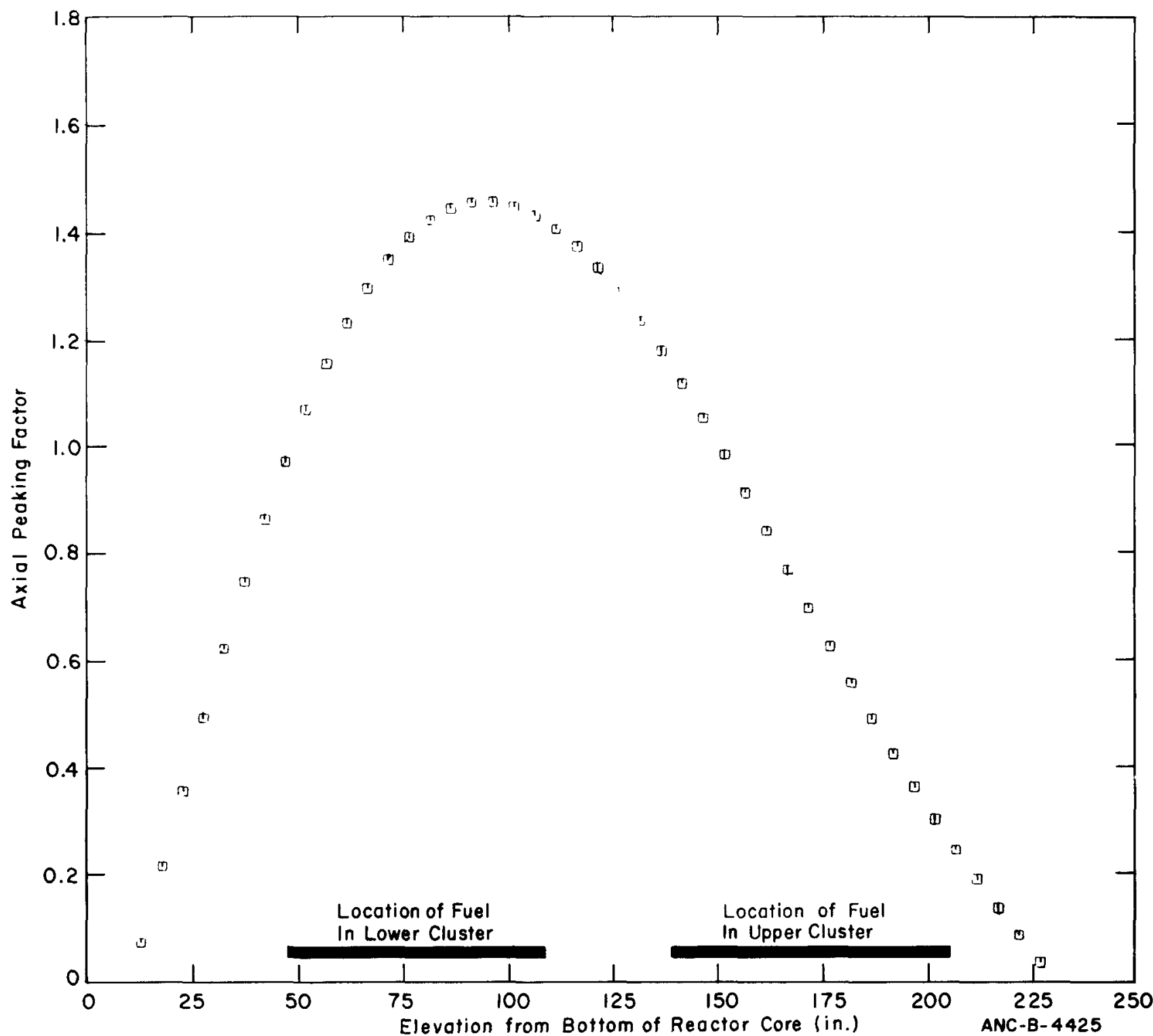

Fig. 123 IFA-226 assembly axial flux profile at 0000 hours on December $26,1973$. 


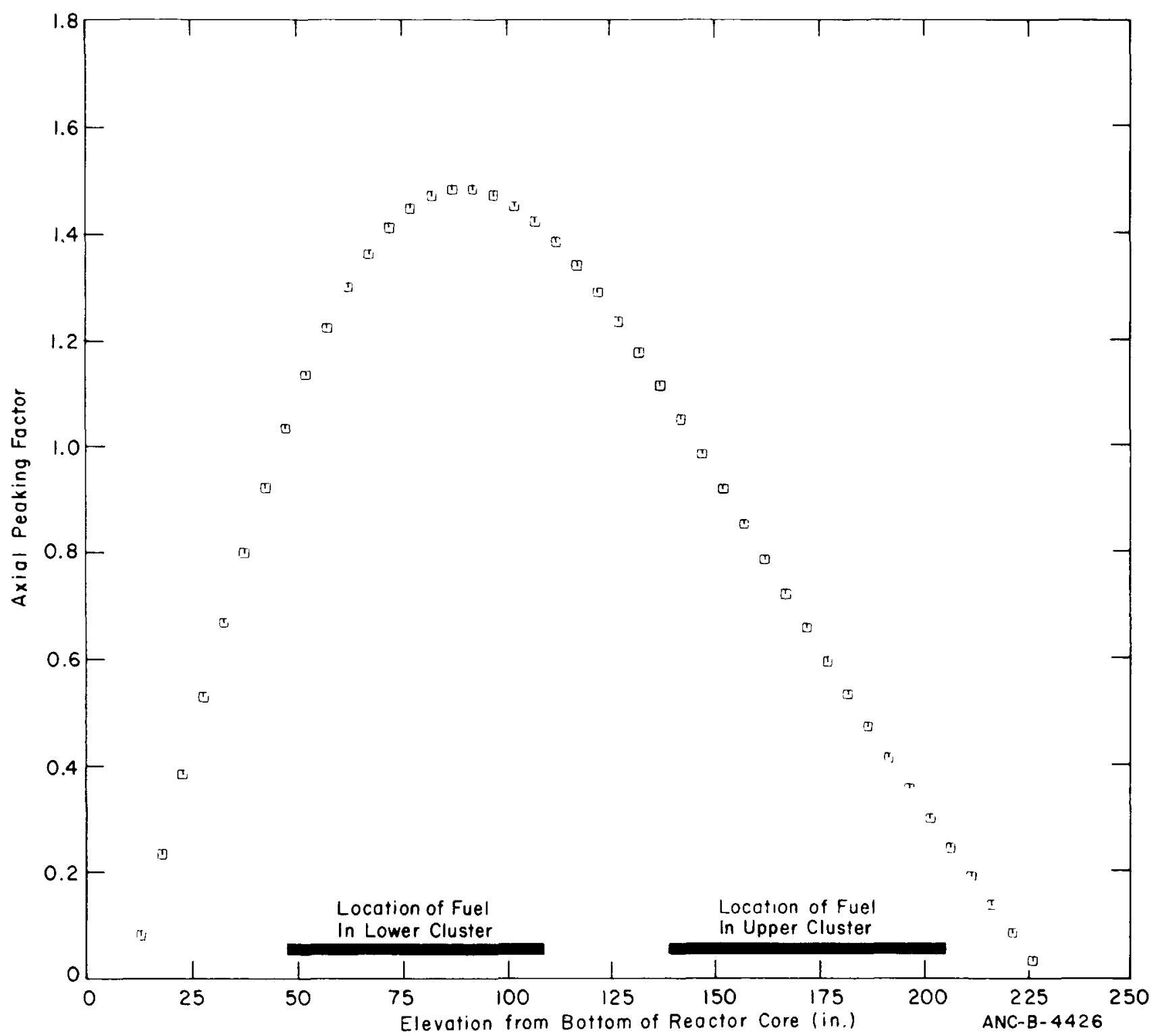

Fig. 124 IFA-226 assembly axial flux profile at 0000 hours on January 28 , 1974. 


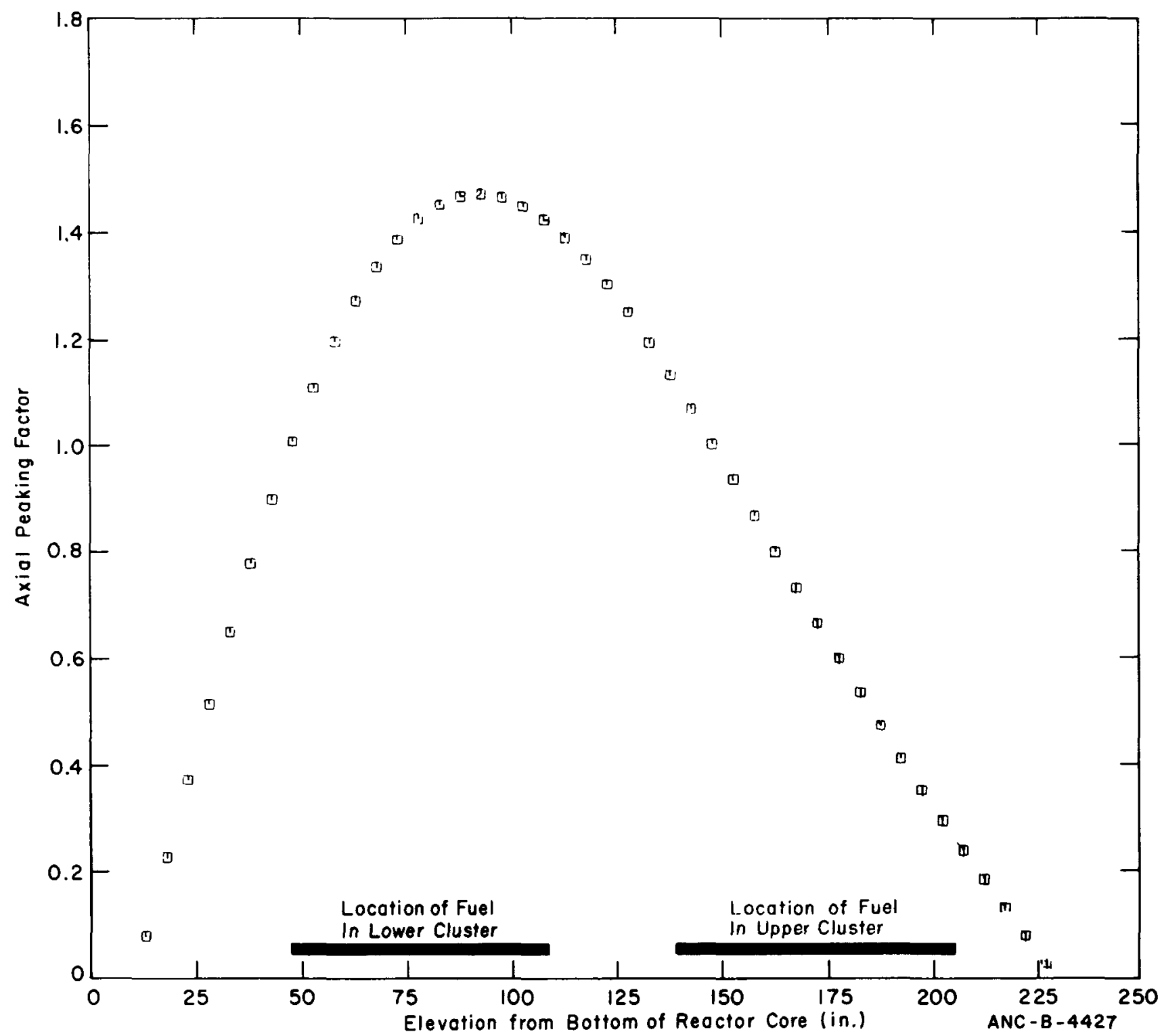

Fig. 125 IFA-226 assembly axial flux profile at 0000 hours on February 28, 1974. 


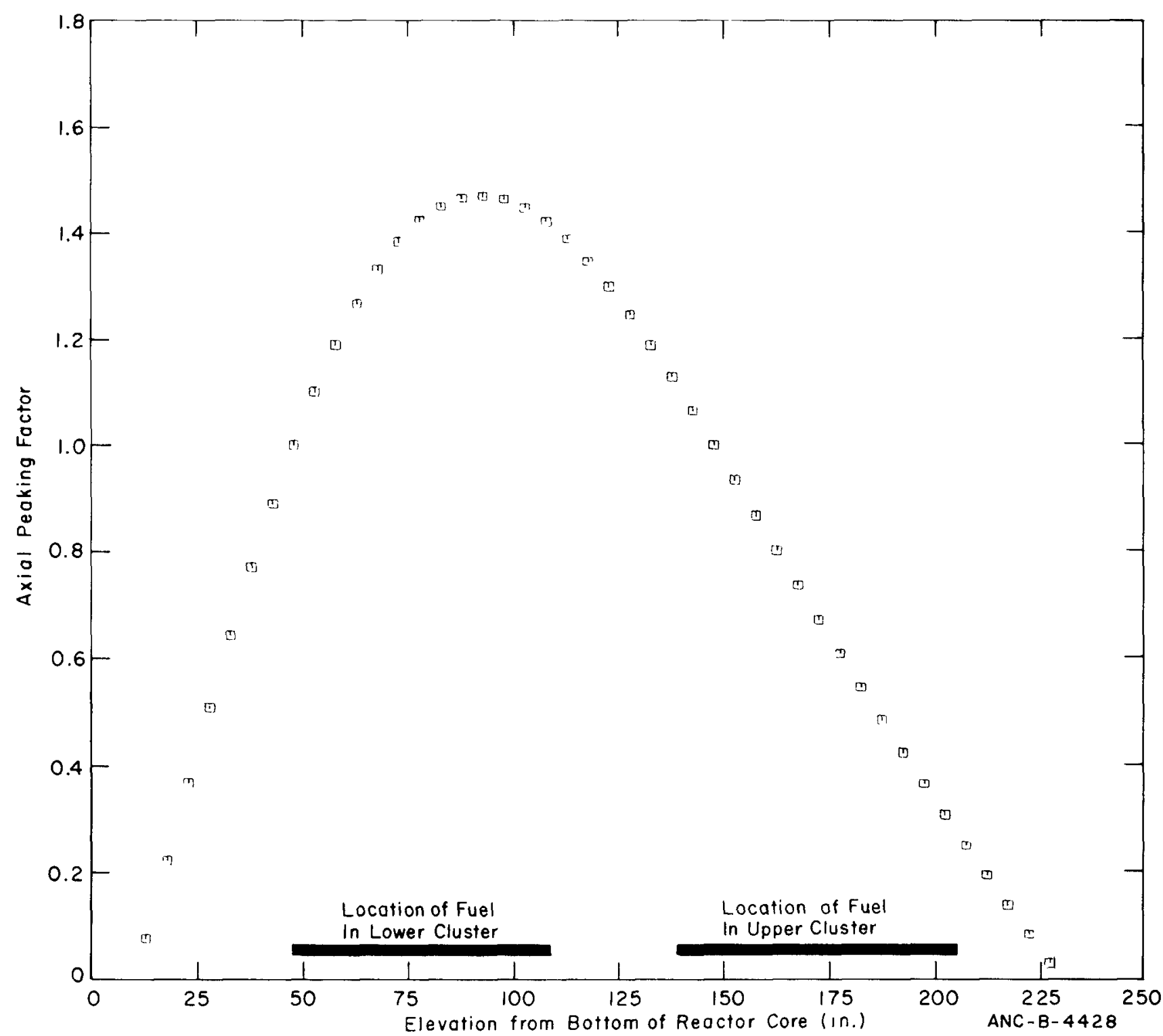

Fig. 126 IFA-226 assembly axial flux profile at 1200 hours an March 1, 1974. 


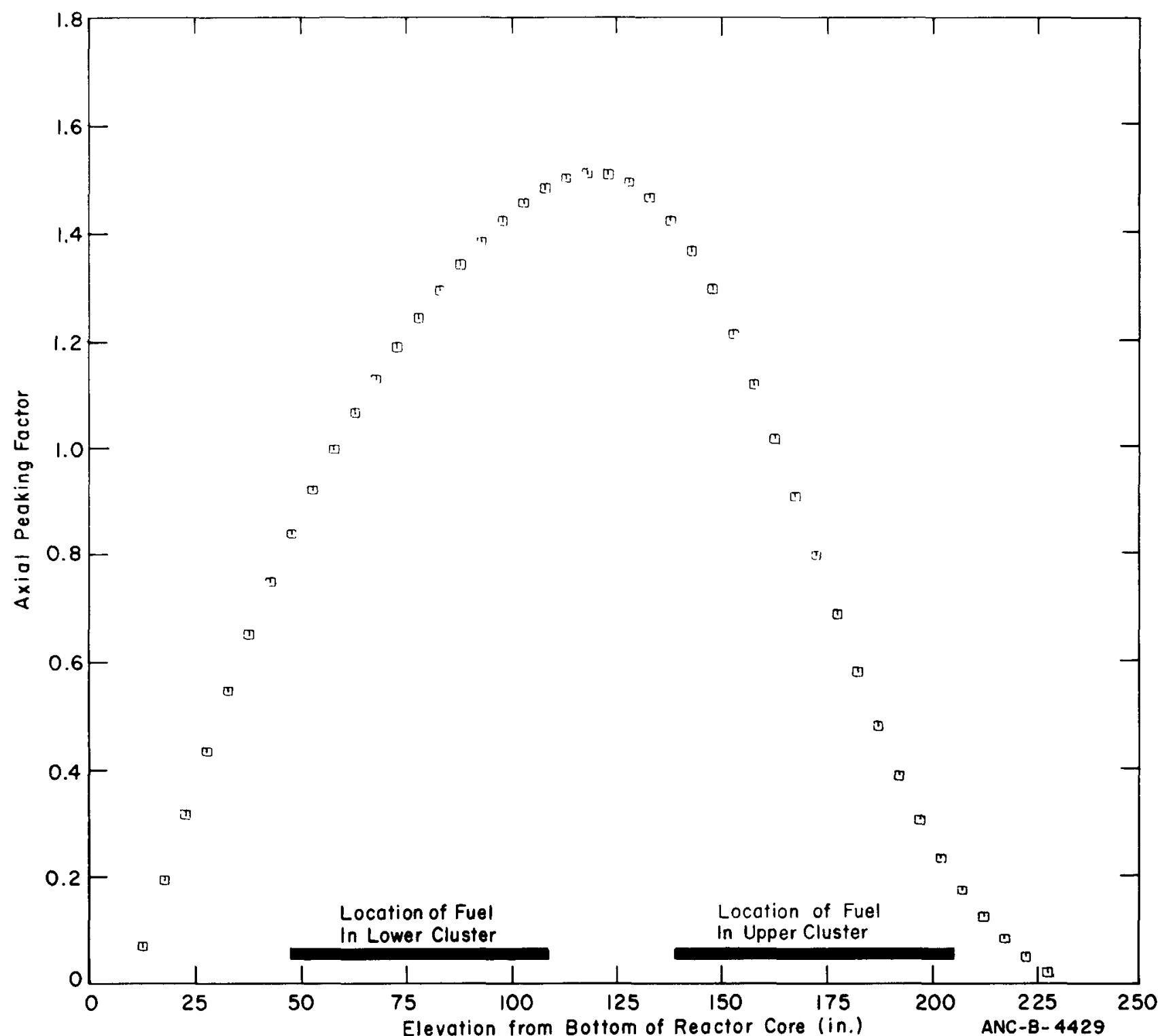

Fig. 127 IFA-226 assembly axial flux profile at 0600 hours on March 25, 1974. 


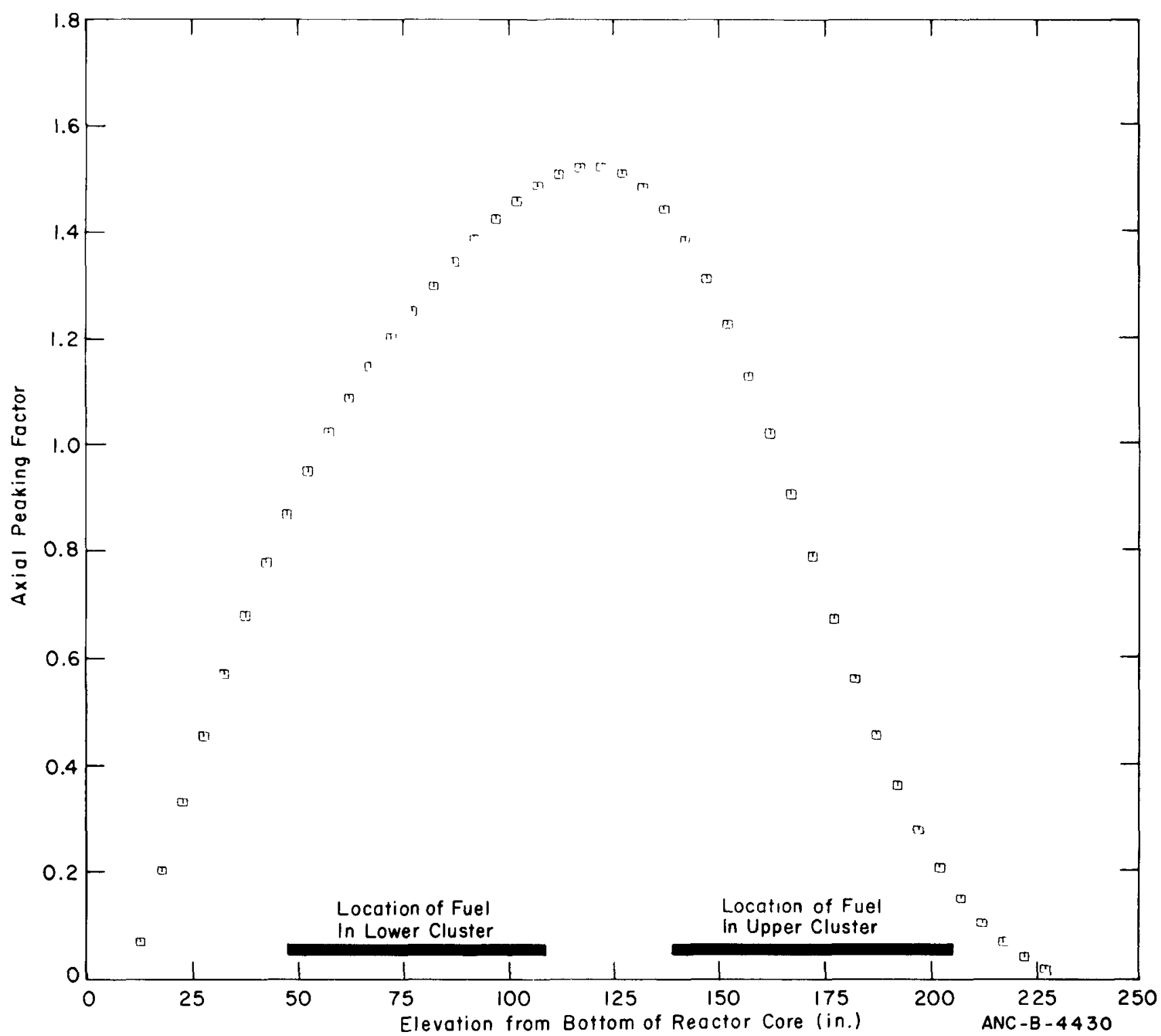

Fig. 128 IFA-226 assembly axial flux profile at 0000 hours on April 15, 1974. 


\section{PRESENTATION OF DATA FROM IFA-239}

Data for IFA-239 are shown in Table IV and Figures 129 through 158. Figure 129 shows the distance traveled by the diameter gauge. The results of the diametral profile measurements are shown in Figures 130 through 152. A sample of the results from the autoclave calibration measurements is presented in Figures 130 and 131; the results from the in-pile measurements are given in Figures 132 through 152. Also shown in Figures 134 through 150 is the axial flux profile present at essentially the same time as when the diametral profile data were obtained. Table IV summarizes the times when the in-pile measurements were made and gives their corresponding power level.

As can be seen from Table IV, a limited quantity of diametral profile data is currently available. The data which are available were obtained during the first few days of assembly operation. The elongation and assembly power histories, however, are available for the entire period from beginning-of-life through April 16, 1974. These data are presented in Figures 153 through 158.

The assembly power histories, which are shown in Figures 153 through 158, should be used with caution. During the first month of operation, all neutron detectors were operative. Thus, the power histories which were derived from these data are considered to be quite accurate. Shortly after this time, however, several neutron detectors failed, thus resulting in a less accurate and less reliable value for the assembly power. (The method that was used to reduce neutron detector data is described in Appendix C.)

The results from the diameter gauge used in IFA-239 must be interpreted with caution. During the out-of-pile autoclave testing, the data from the zircaloy calibration rod were significantly less noisy than the data from the in-pile experiments, as shown in Figures 130 and 131, respectively. Since the cladding of the calibration rod and the fuel rod were manufactured by the same vendor, the two rods are expected to have similar surface roughness characteristics. The only observed difference between the two rods was the degree of surface oxidation. The calibration rod became heavily oxidized (that is, it became shiny blue-black) during the autoclave testing due to relatively high oxygen levels in the autoclave. In comparison, the fuel rod was operated only in the environment of the reactor coolant where the oxygen content is much less. The only observed change of the surface finish after one year of operation was a slight dulling of the previously bright zircaloy surface. As a result, the two different oxidation states resulted in a different surface sliding coefficient between the fuel rod surface and the inconel pads of the diameter head.

The data shown in Figures 132 and 133 exhibit a sawtooth pattern in the direction of travel of the diameter gauge. The sawtooth shape points toward the top of the rod in Figure 132 and toward the bottom of the rod in Figure 133 as the diameter gauge was moved up and down the rod, respectively. Due to the design of the diameter gauge, excessive friction on the fuel rod restrained the movement of the LVDT core up to the point where the spring forces allowed abrupt release and thus produced the sawtooth pattern. 
TABLE IV

TIMES WHEN IN-PILE DIAMETRAL PROFILE DATA WERE OBTAINED

\begin{tabular}{|c|c|c|c|c|}
\hline Run & $\begin{array}{c}\text { Date } \\
(1973) \\
\end{array}$ & $\begin{array}{l}\text { Logging } \\
\text { Start Time } \\
\end{array}$ & $\begin{array}{c}\text { Diameter Gauge } \\
\text { Movement }\end{array}$ & $\begin{array}{c}\text { Assemb1y } \\
\text { Power (kW) }\end{array}$ \\
\hline 9 & March 12 & 1631 & UP & $\sim 2$ \\
\hline 10 & March 12 & 1645 & DOWN & $\sim 2$ \\
\hline 11 & March 12 & 2124 & UP & 8.6 \\
\hline 13 & March 13 & 0042 & UP & 16.8 \\
\hline 14 & March 13 & 0054 & DOWN & 17.1 \\
\hline 15 & March 13 & 0907 & UP & 16.5 \\
\hline 16 & March 13 & 0923 & DOWN & 16.4 \\
\hline 17 & March 13 & 1609 & UP & 15.7 \\
\hline 18 & March 13 & 1625 & DOWN & 15.7 \\
\hline 19 & March 14 & 1721 & UP & $\sim 17$ \\
\hline 20 & March 14 & 1734 & DOWN & $\sim 17$ \\
\hline 21 & March 14 & 2212 & UP & 22.3 \\
\hline 22 & March 14 & 2220 & DOWN & 22.1 \\
\hline 23 & March 15 & 0001 & UP & 25.8 \\
\hline 24 & March 15 & 0009 & DOWN & 25.7 \\
\hline 25 & March 15 & 0108 & UP & 25.5 \\
\hline 26 & March 15 & 0121 & DOWN & 25.4 \\
\hline 27 & March 15 & 1258 & UP & 25.5 \\
\hline 28 & March 15 & 1312 & DOWN & 25.5 \\
\hline 29 & March 16 & 0930 & UP & $\sim 0$ \\
\hline 30 & March 16 & 0942 & DOWN & $\sim 0$ \\
\hline
\end{tabular}

This sawtooth pattern was most pronounced at low power levels early in the rod irradiation period. At high power levels of about $400 \mathrm{~W} / \mathrm{cm}$, the same pattern was not present, and the few discrete ridges probably resulted from strong pellet-cladding contact. 


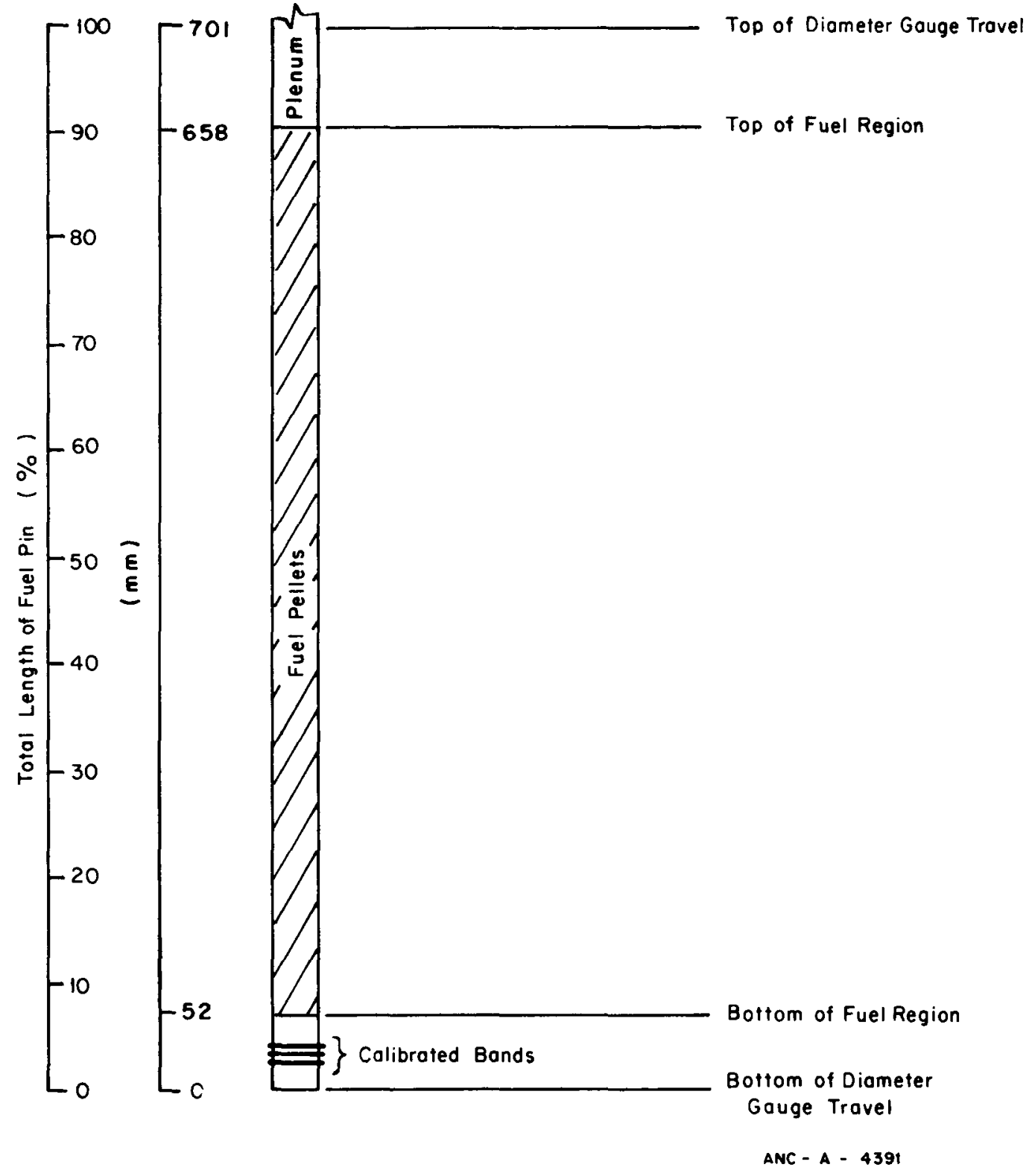

Fig. 129 Axial distance traveled by diameter gauge. 


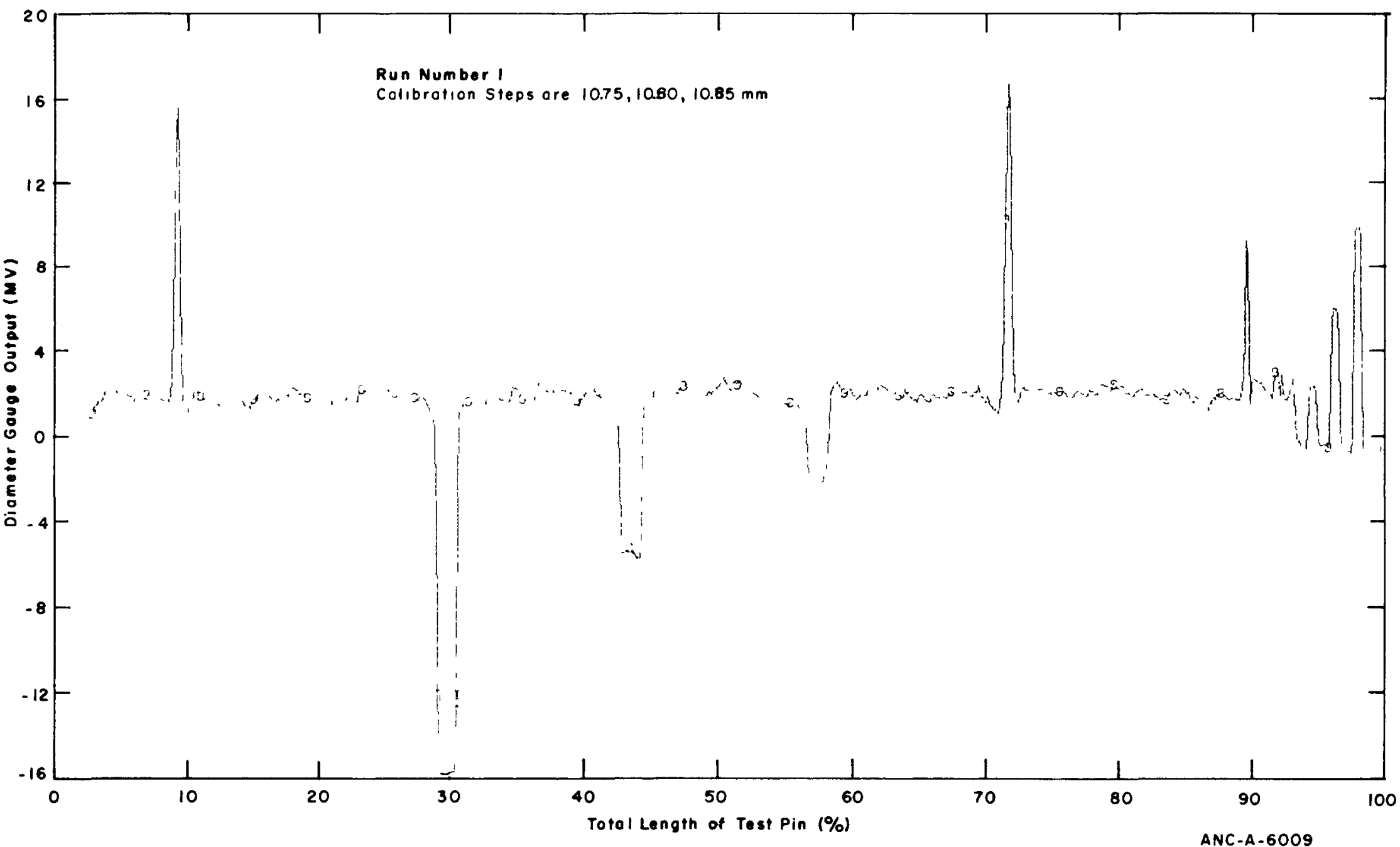

Fig. 130 Dlametral profile of IFA-239 calibration rod -- Run 1. 


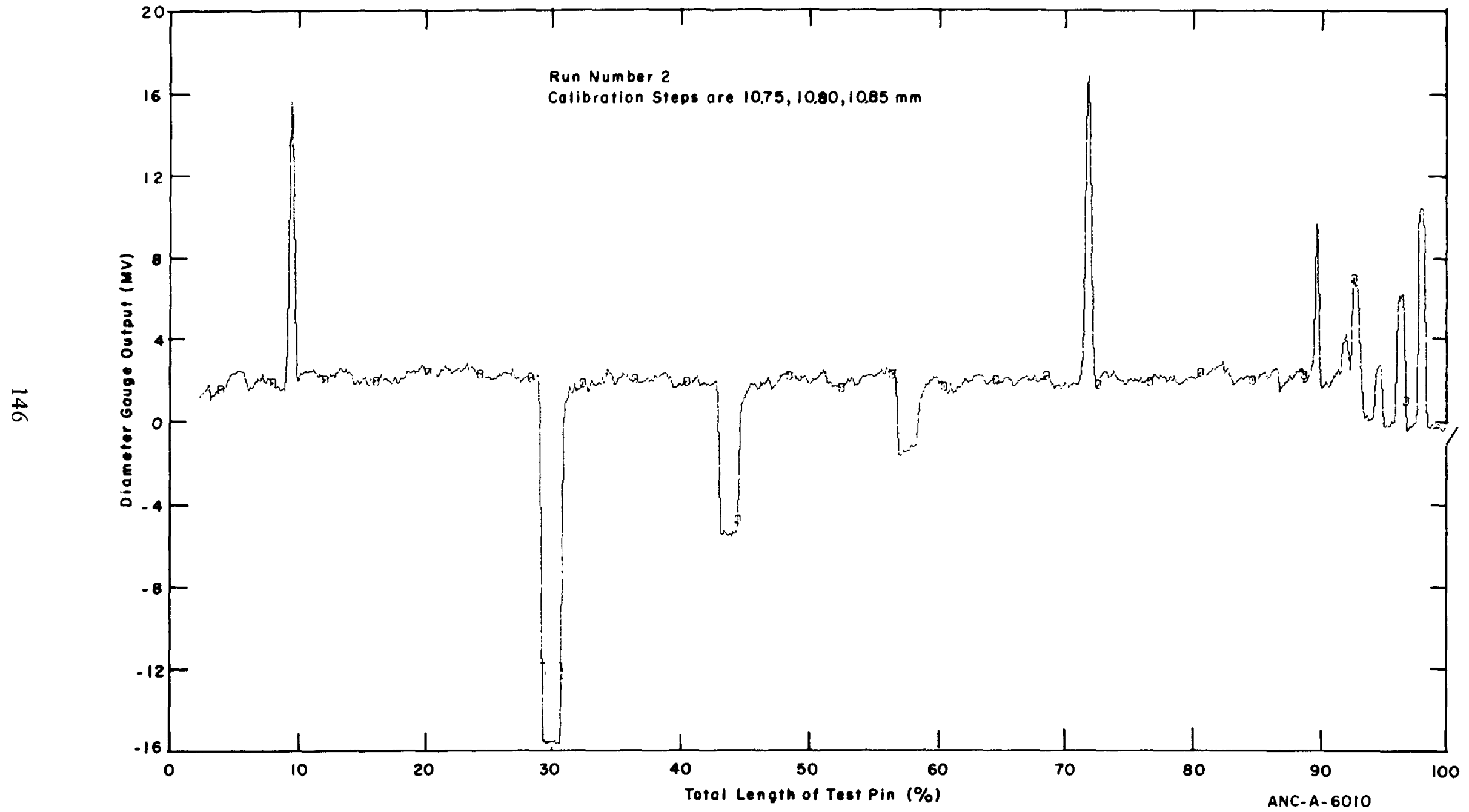

Fig. 131 Diametral profile of IFA-239 calibration rod -- Run 2. 


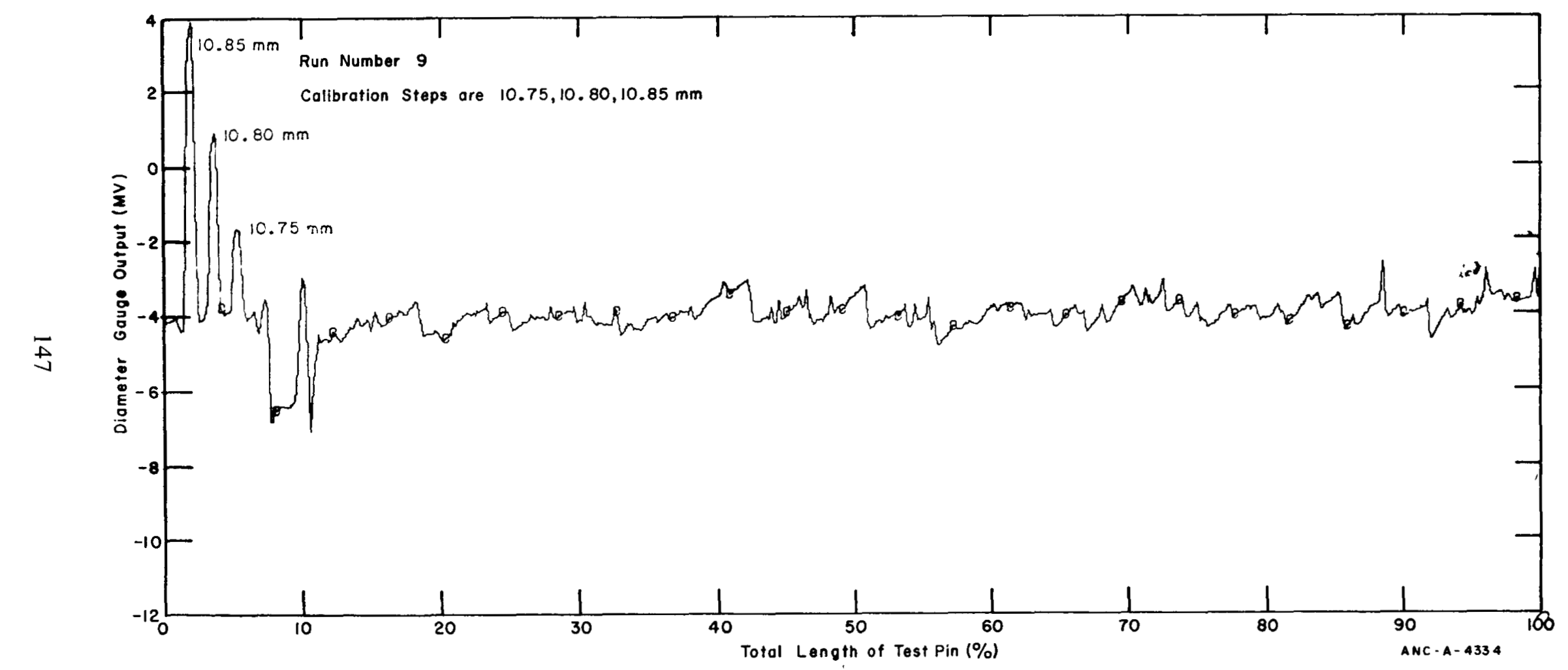

Fig. 132 IFA-239 diametral profile at 1631 hours on March 12, 1973. 


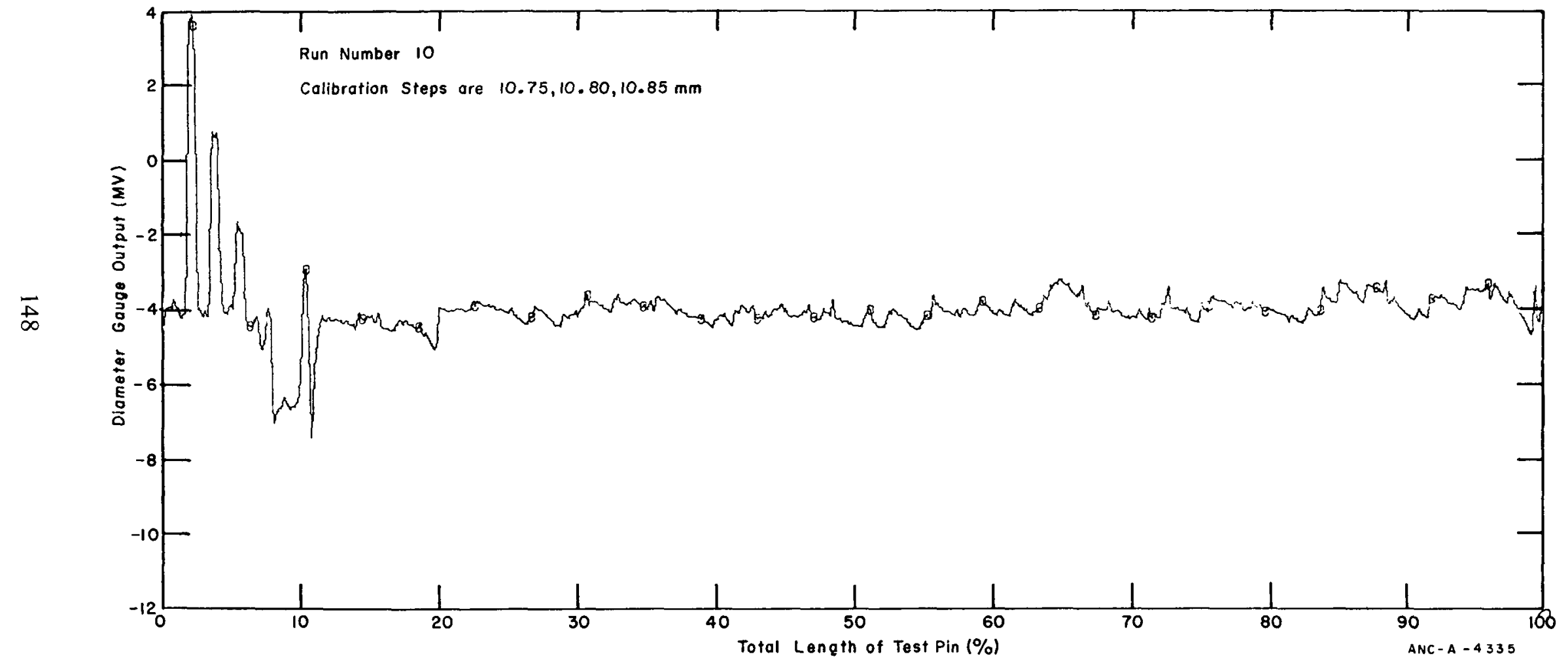

Fig. 133 IFA-239 diametral profile at 1645 hours on March 12, 1973. 


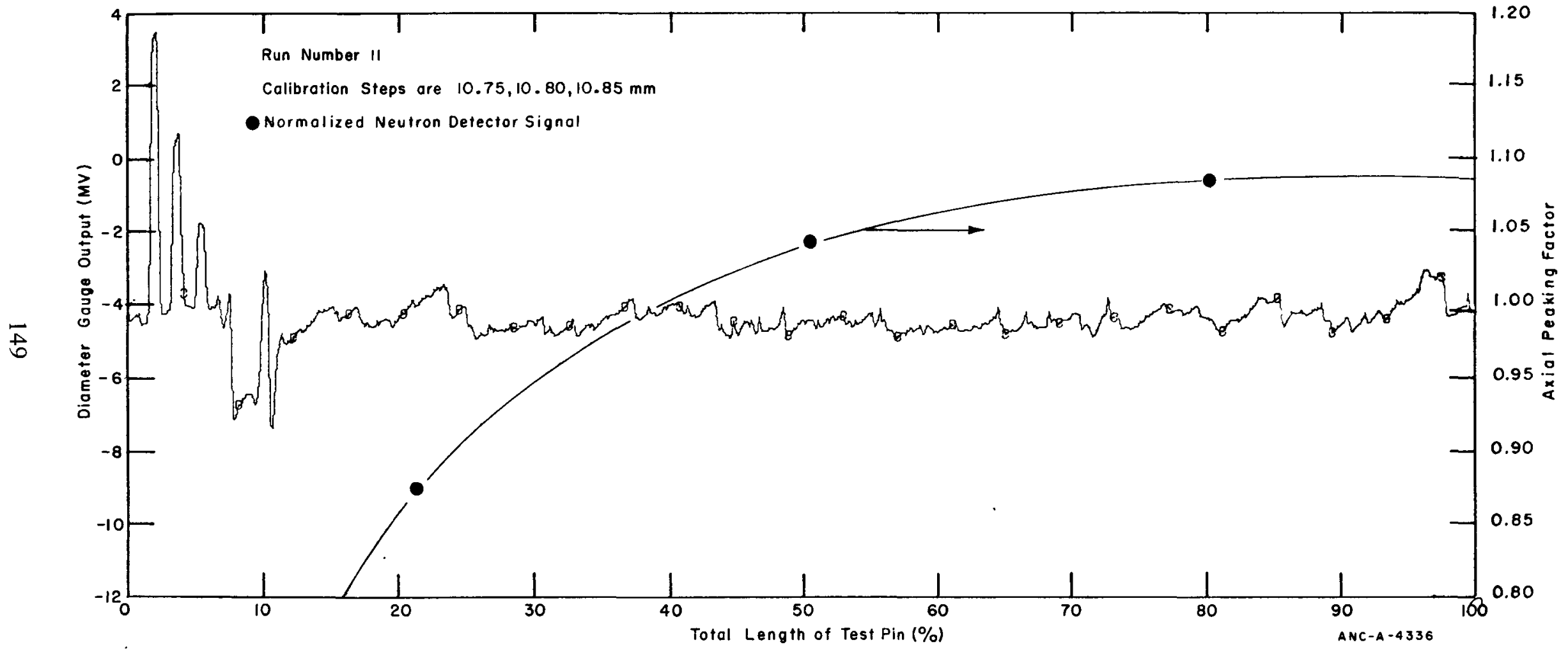

Fig. 134 IFA-239 diametral and axial flux profiles at 2124 hours on March $12,1973$. 


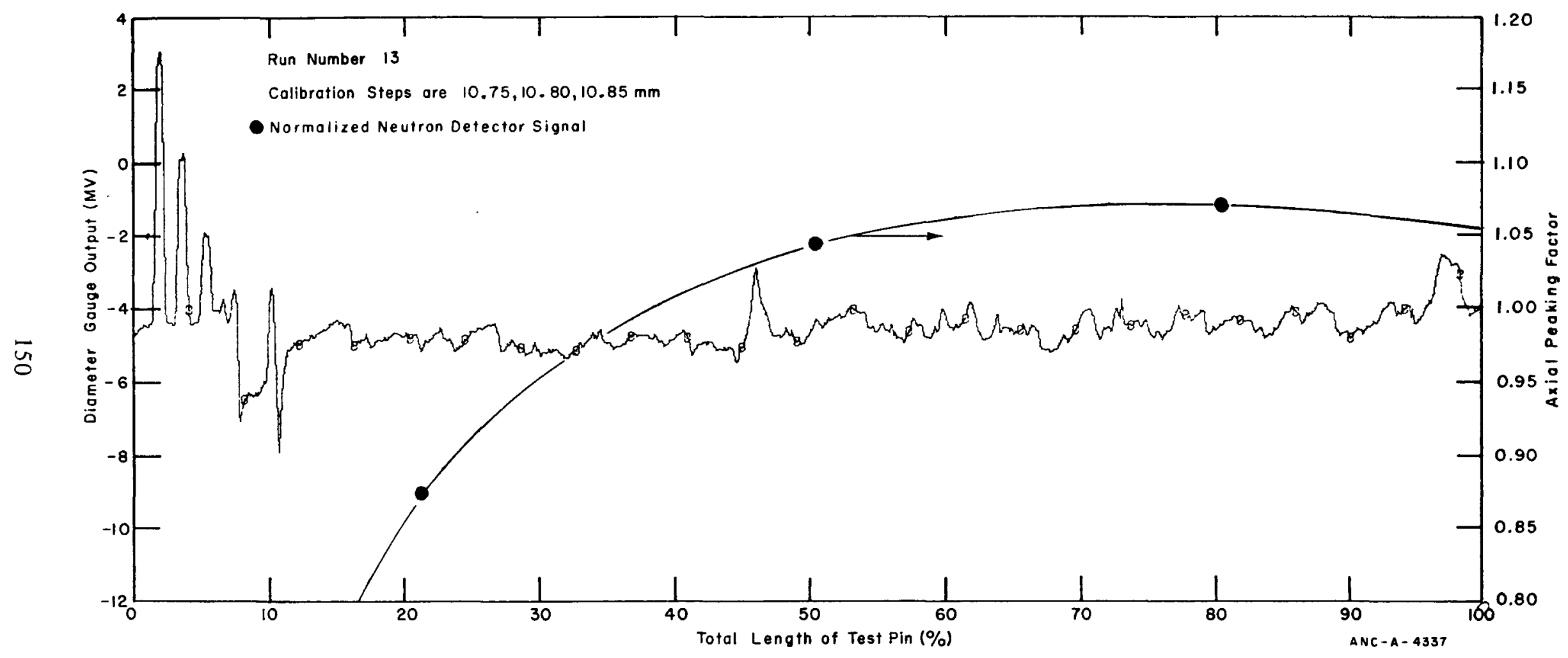

Fig. 135 IFA-239 diametral and axial flux profile at 0042 hours on March 13, 1973. 


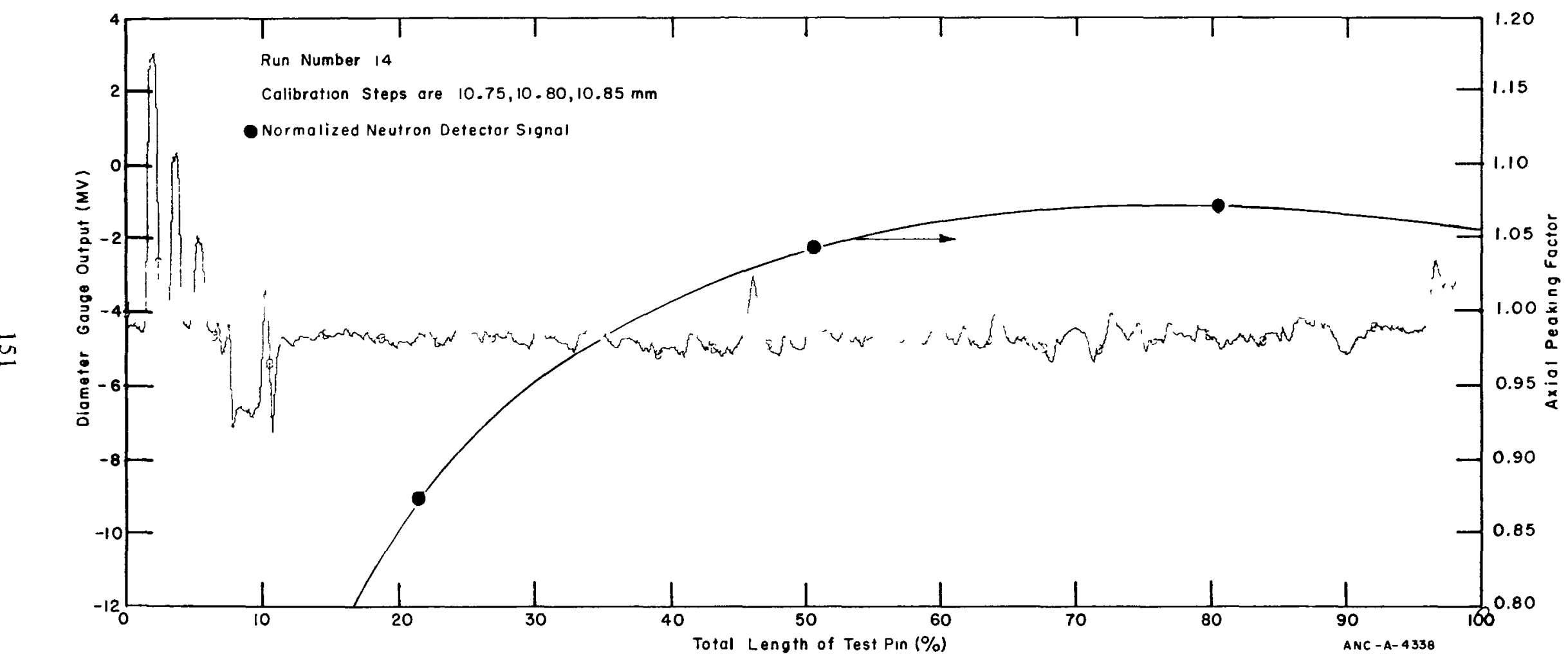

Fig. 136 IFA-239 diametral and axial flux profiles at 0054 hours on March 13, 1973. 


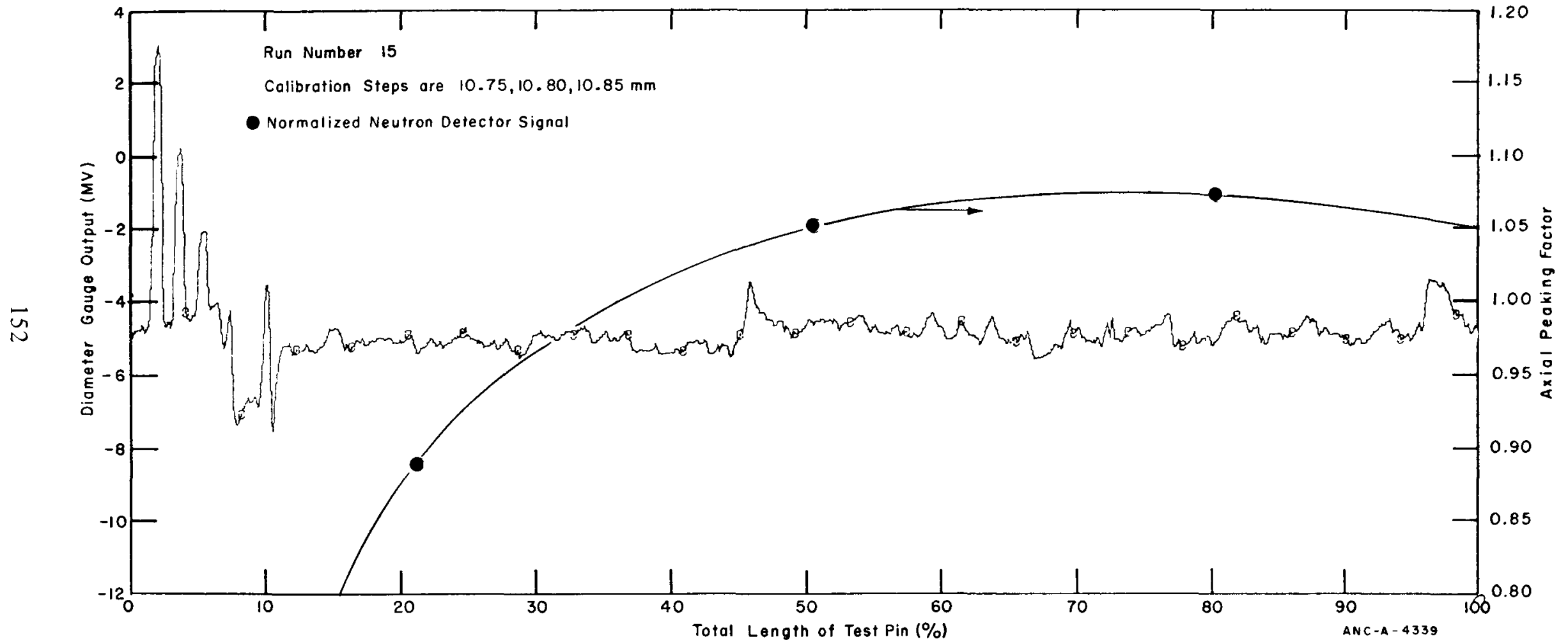

Fig. 137 IFA-239 diametral and axial flux profiles at 0907 hours on March 13, 1973. 


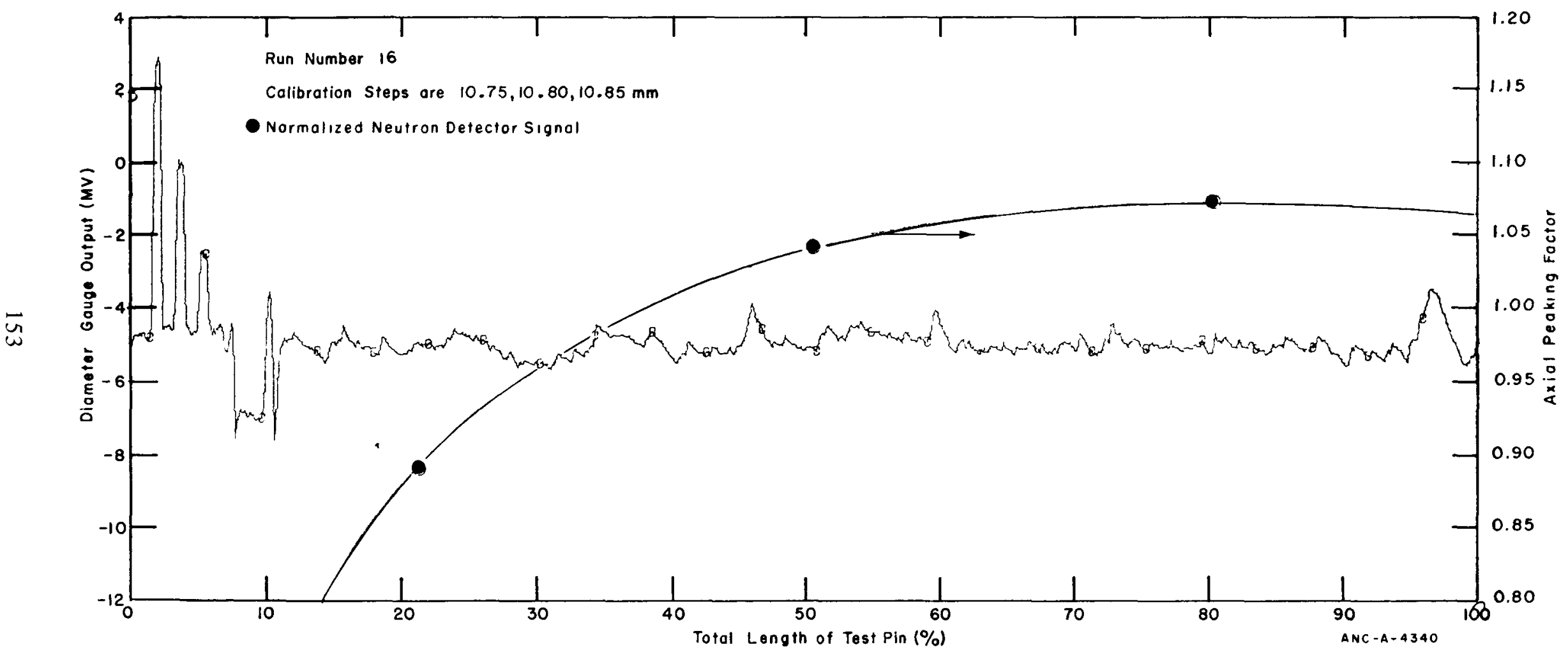

Fig. 138 IFA-239 diametral and axial flux profiles at 0923 hours on March 13, 1973. 


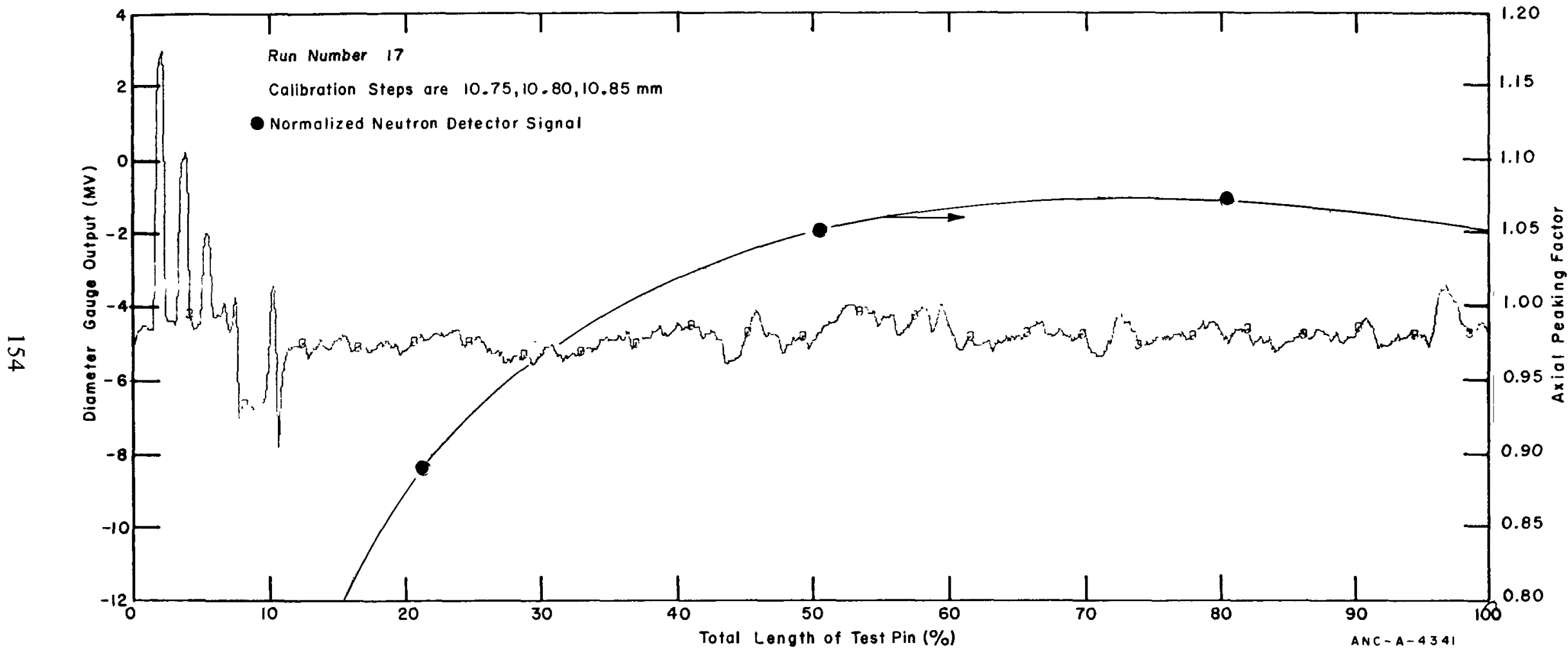

Fig. 139 IFA-239 diametral and axial flux profiles at 1609 hours on March 13, 1973. 


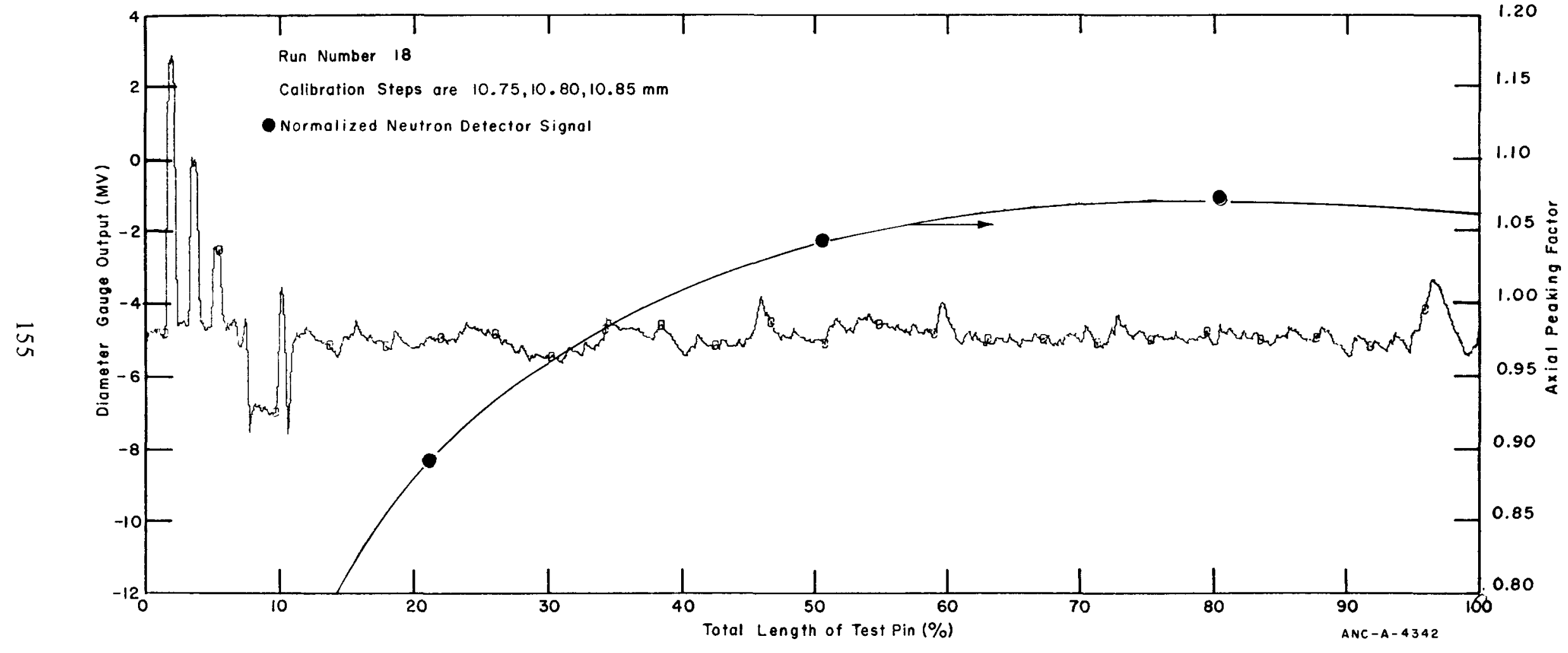

Fig. 140 IFA-239 diametral and axial flux profiles at 1625 hours on March 13, 1973. 


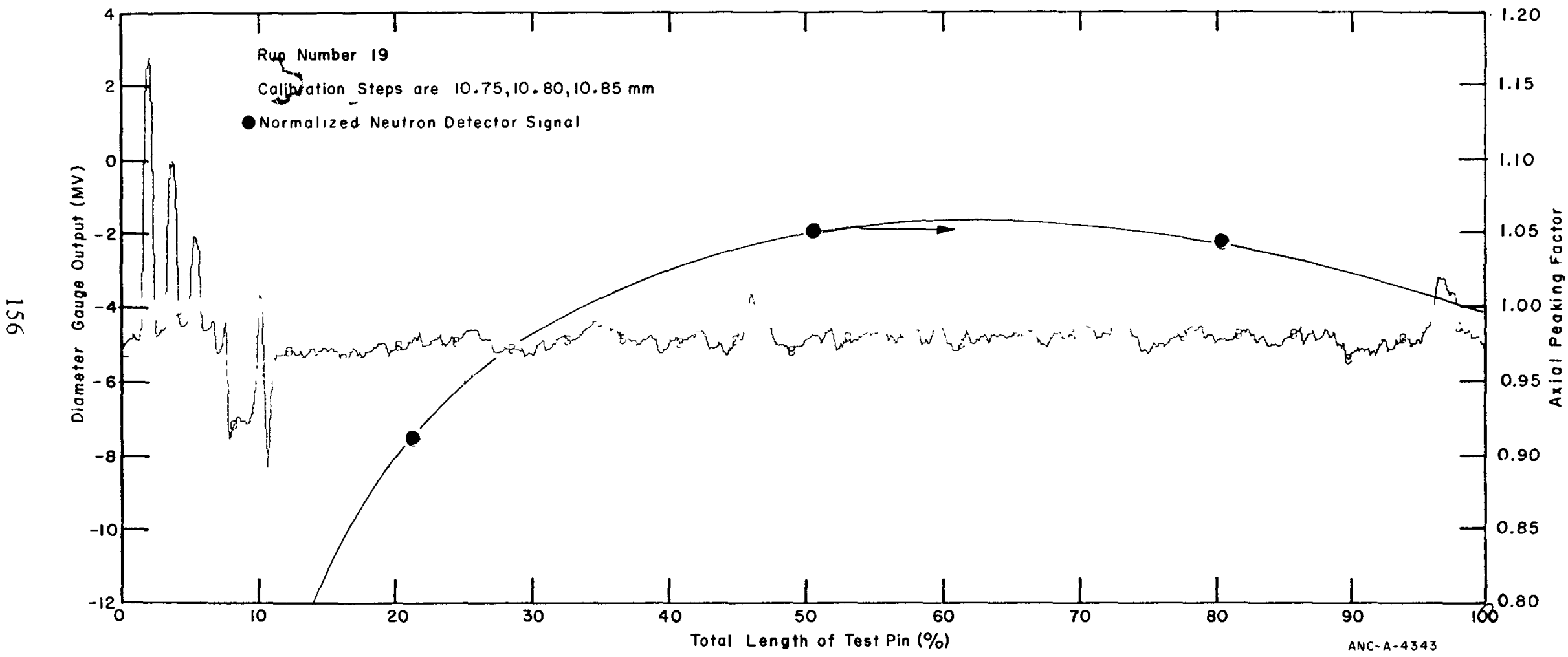

Fig. 141 IFA-239 diametral and axial flux profiles at 1721 hours on March 14, 1973. 


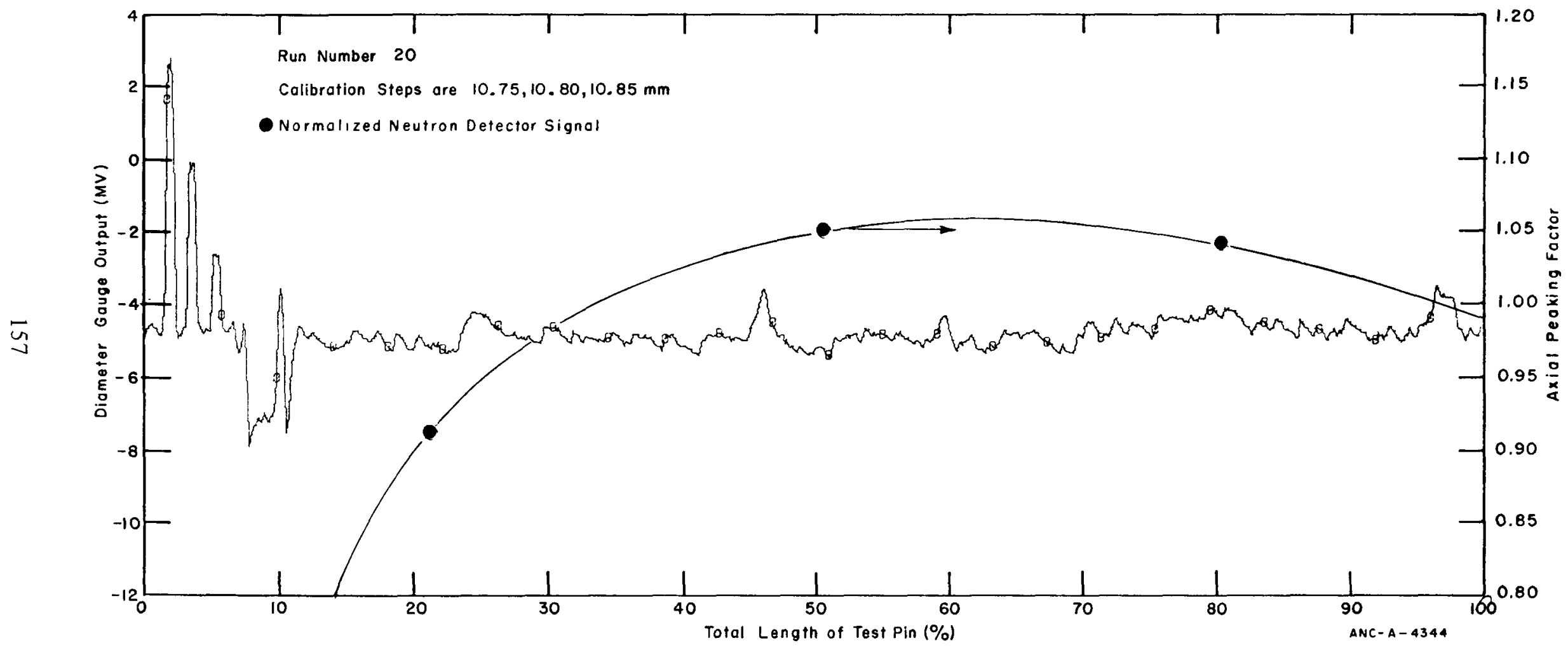

Fig. 142 IFA-239 diametral and axial flux profiles at 1734 hours on March 14, 1973. 


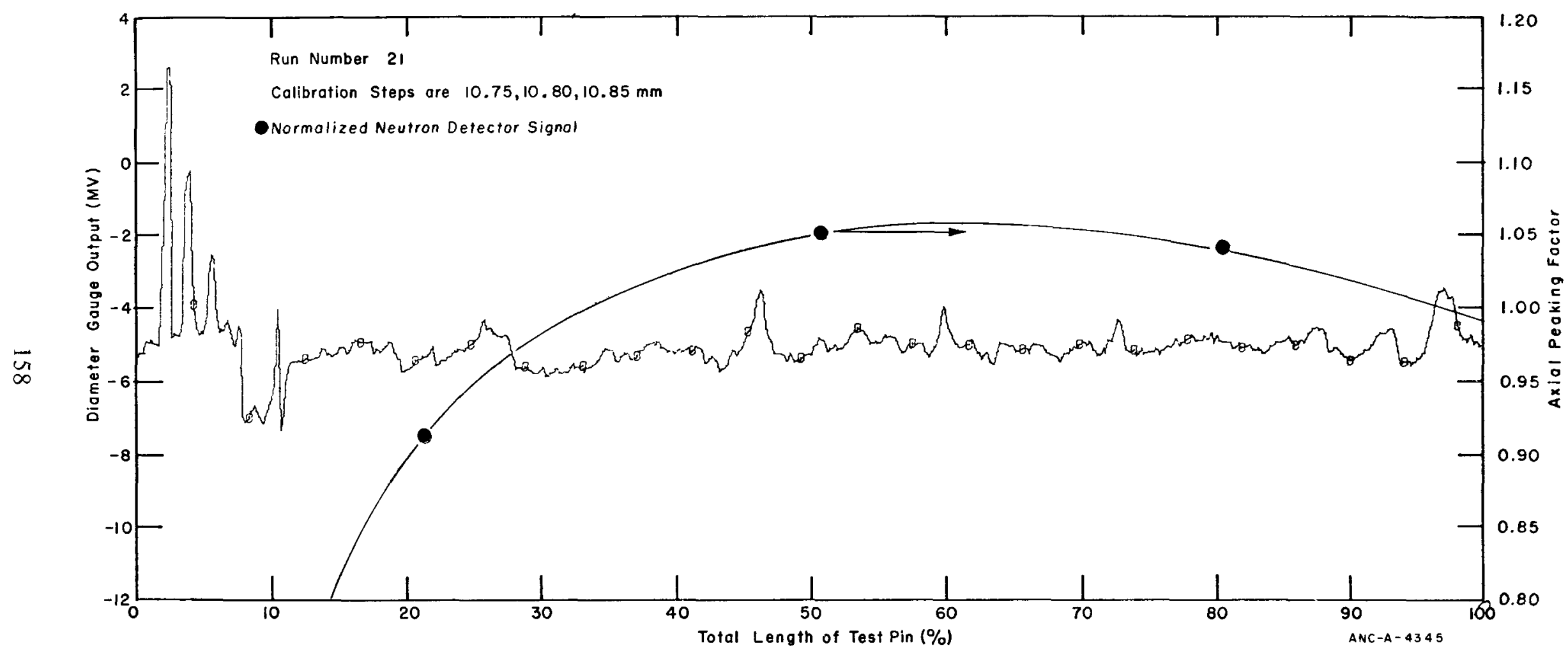

Fig. 143 IFA-239 diametral and axial flux profiles at 2212 hours on March 14, 1973. 


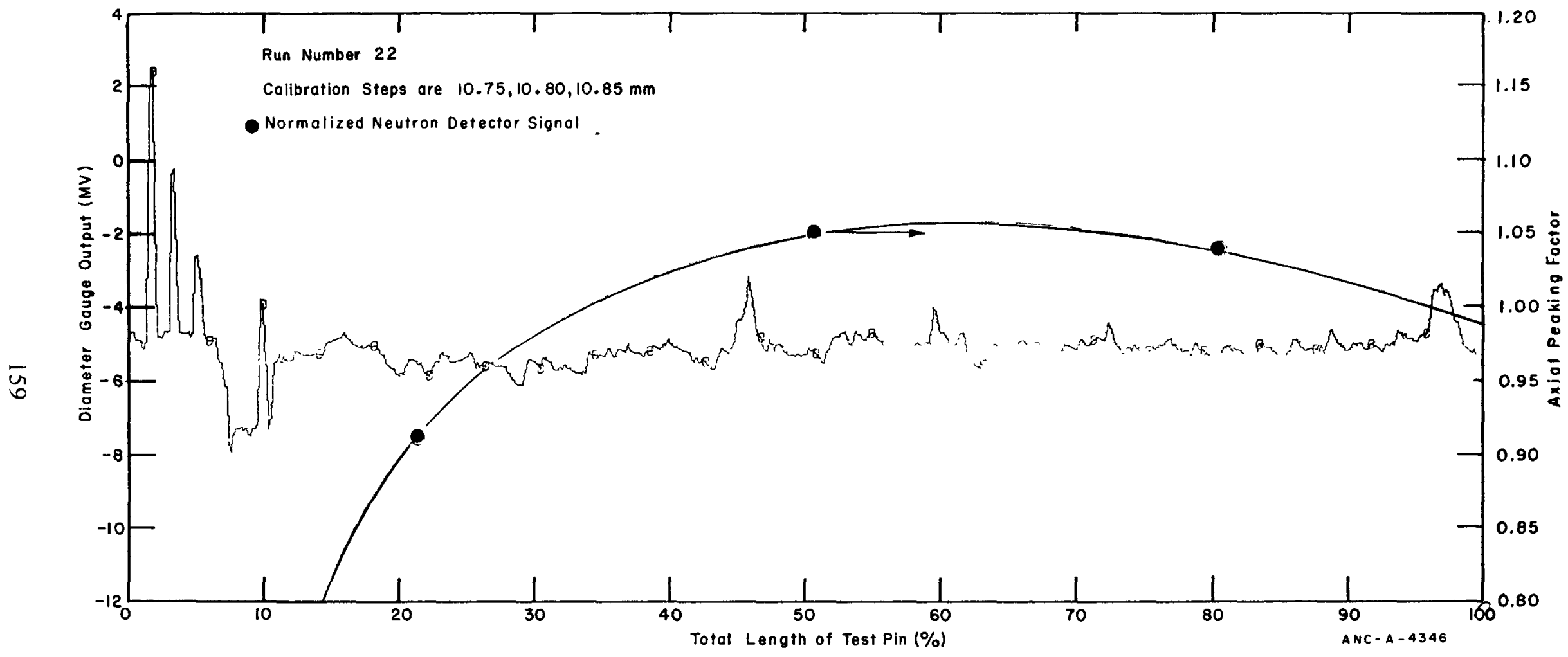

Fig. 144 IFA-239 diametral and axial flux profiles at 2220 hours on March 14, 1973. 


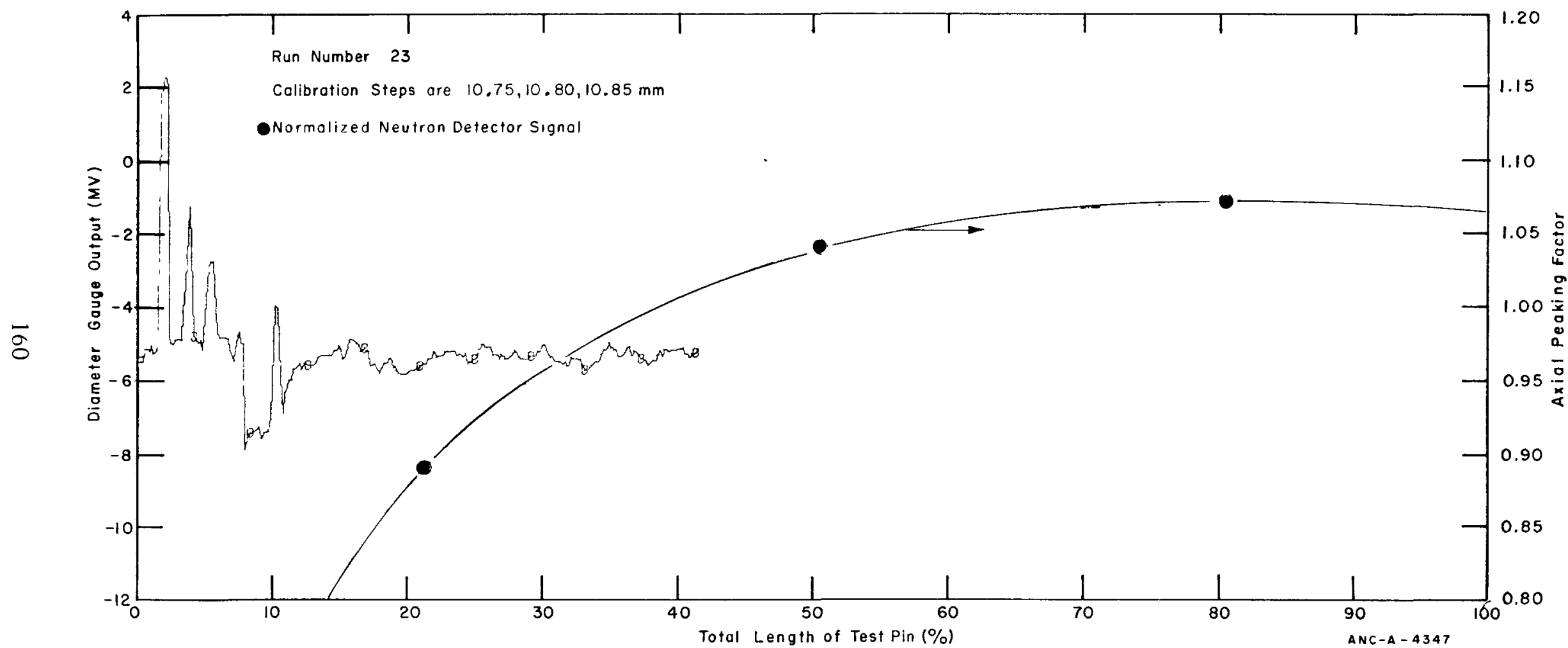

Fig. 145 IFA-239 diametral and axial flux profiles at 0001 hours on March 15, 1973. 


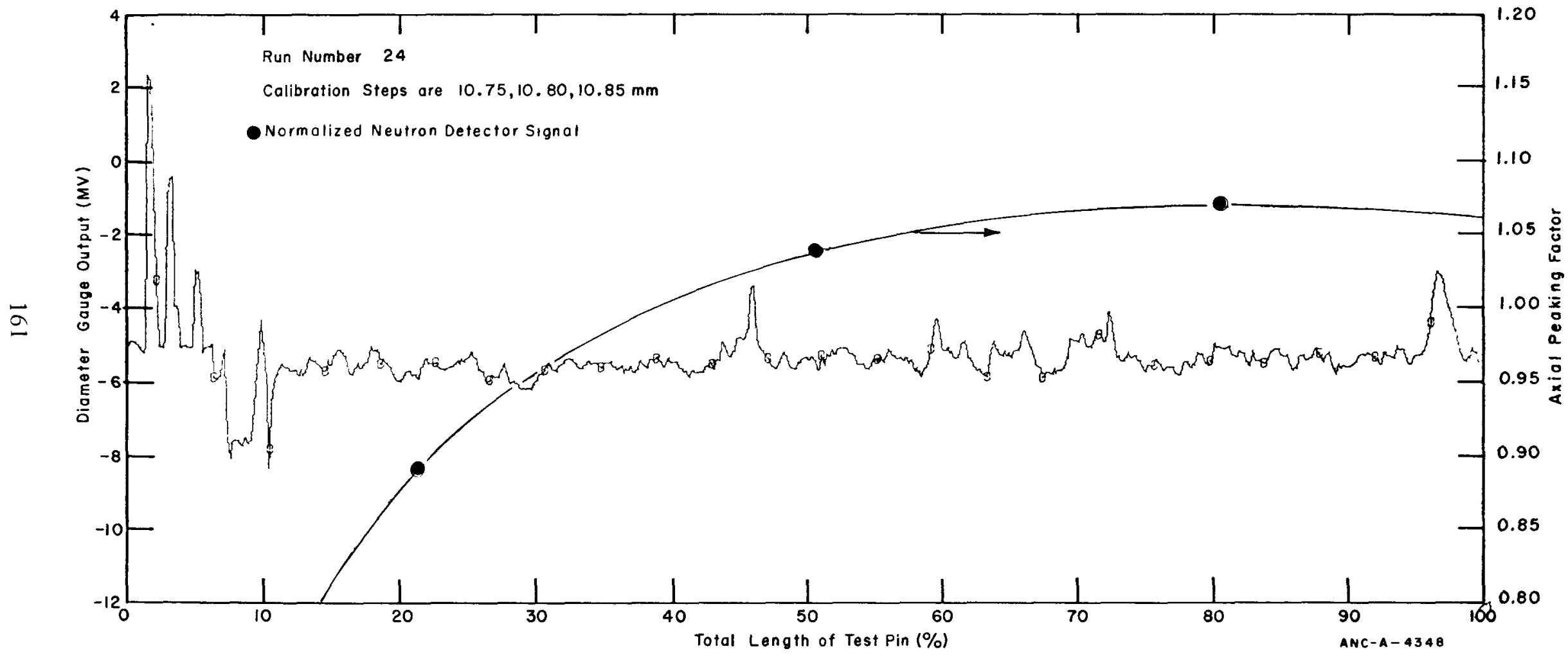

Fig. 146 IFA-239 diametral and axial flux profiles at 0009 hours on March 15, 1973. 


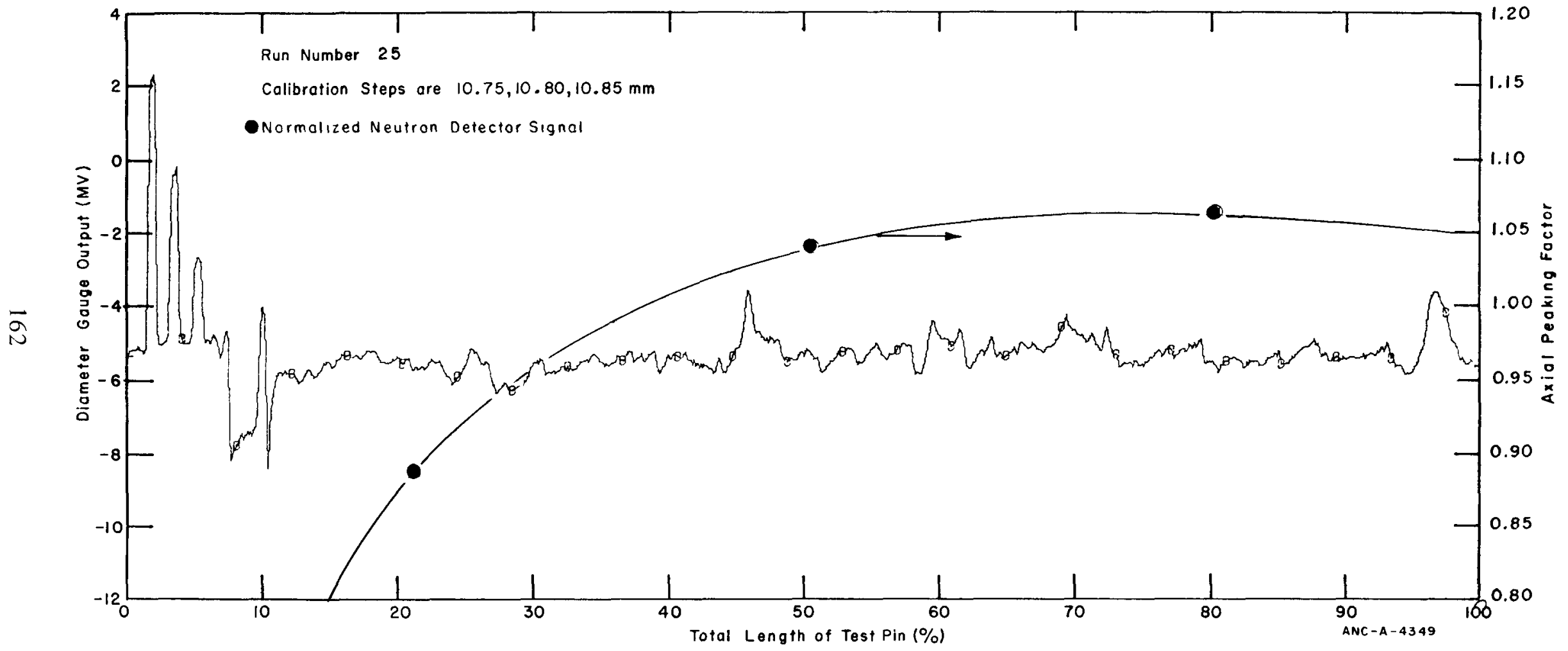

Fig. 147 IFA-239 diametral and axial flux profiles at 0108 hours on March 15, 1973. 


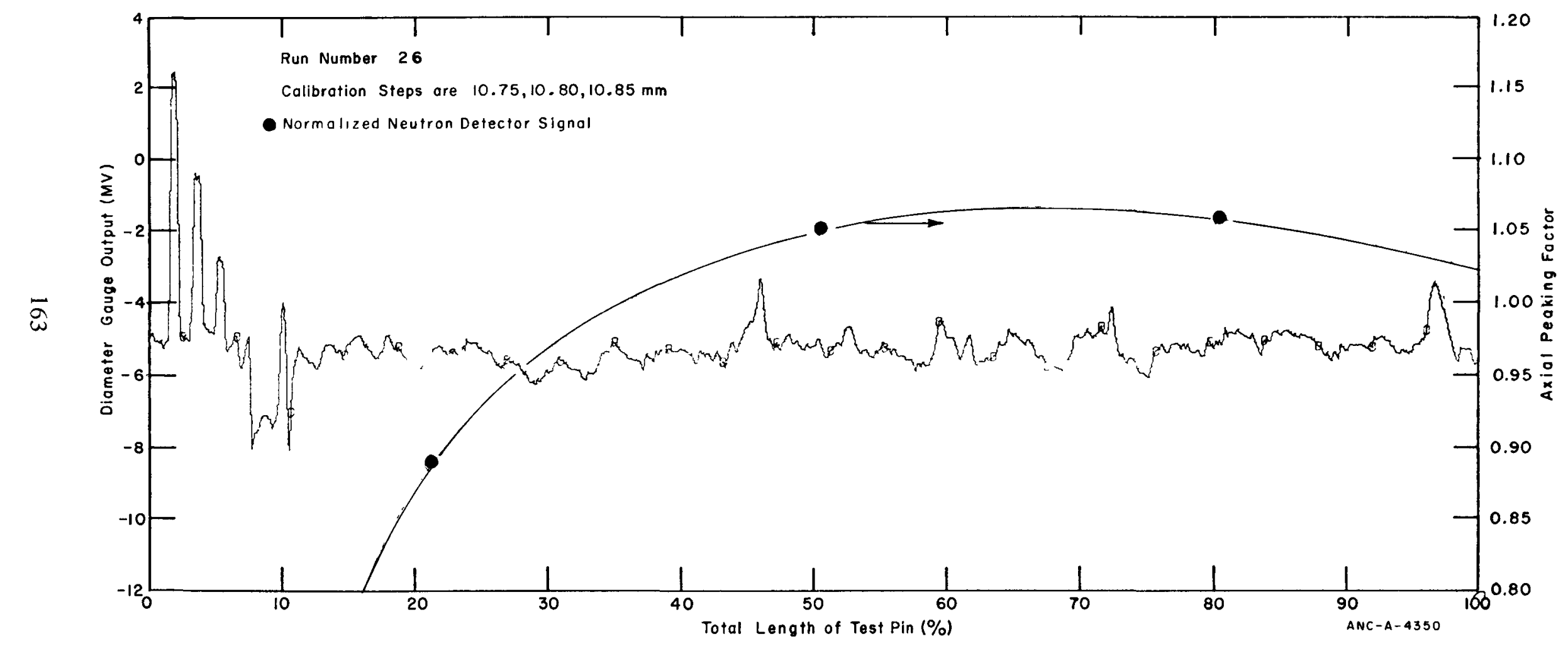

Fig. 148 IFA-239 diametral and axial flux profiles at 0121 hours on March 15, 1973. 


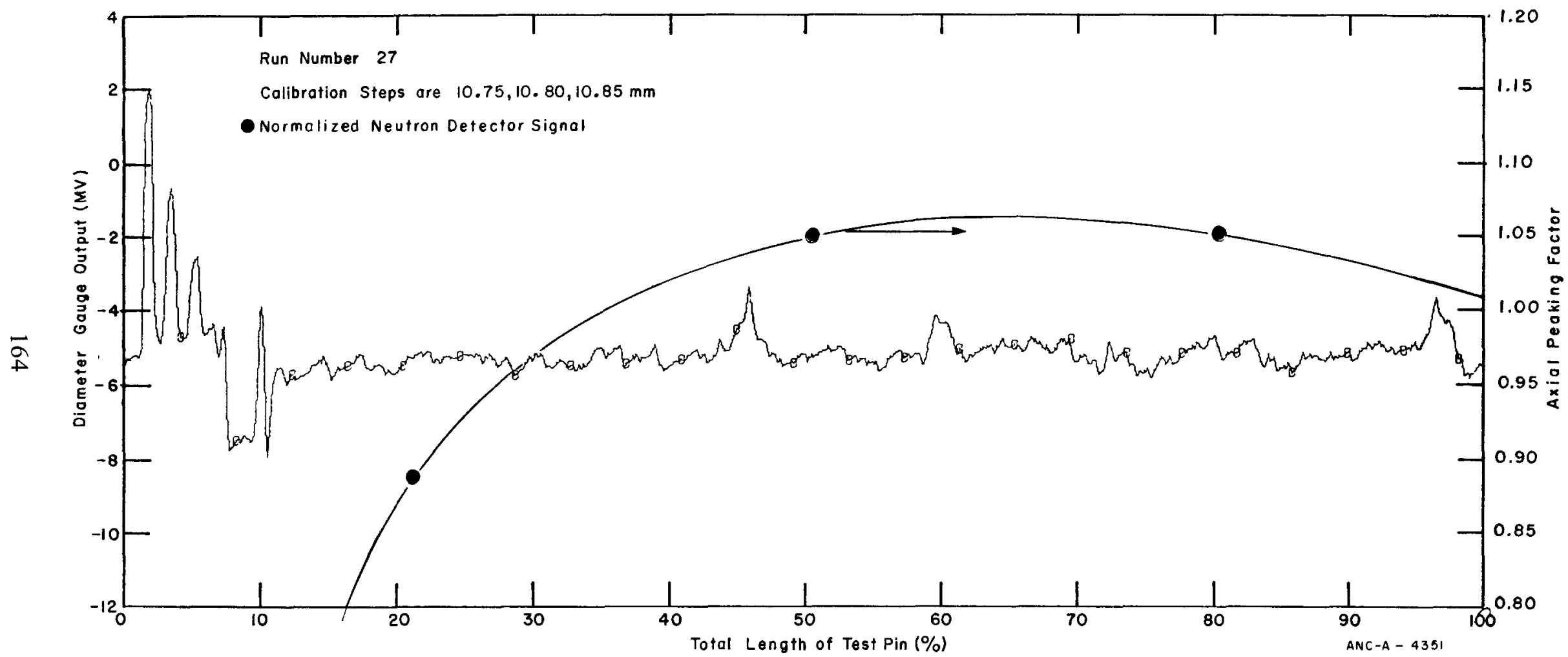

Fig. 149 IFA-239 diametral and axial flux profiles at 1258 hours on March 15, 1973. 


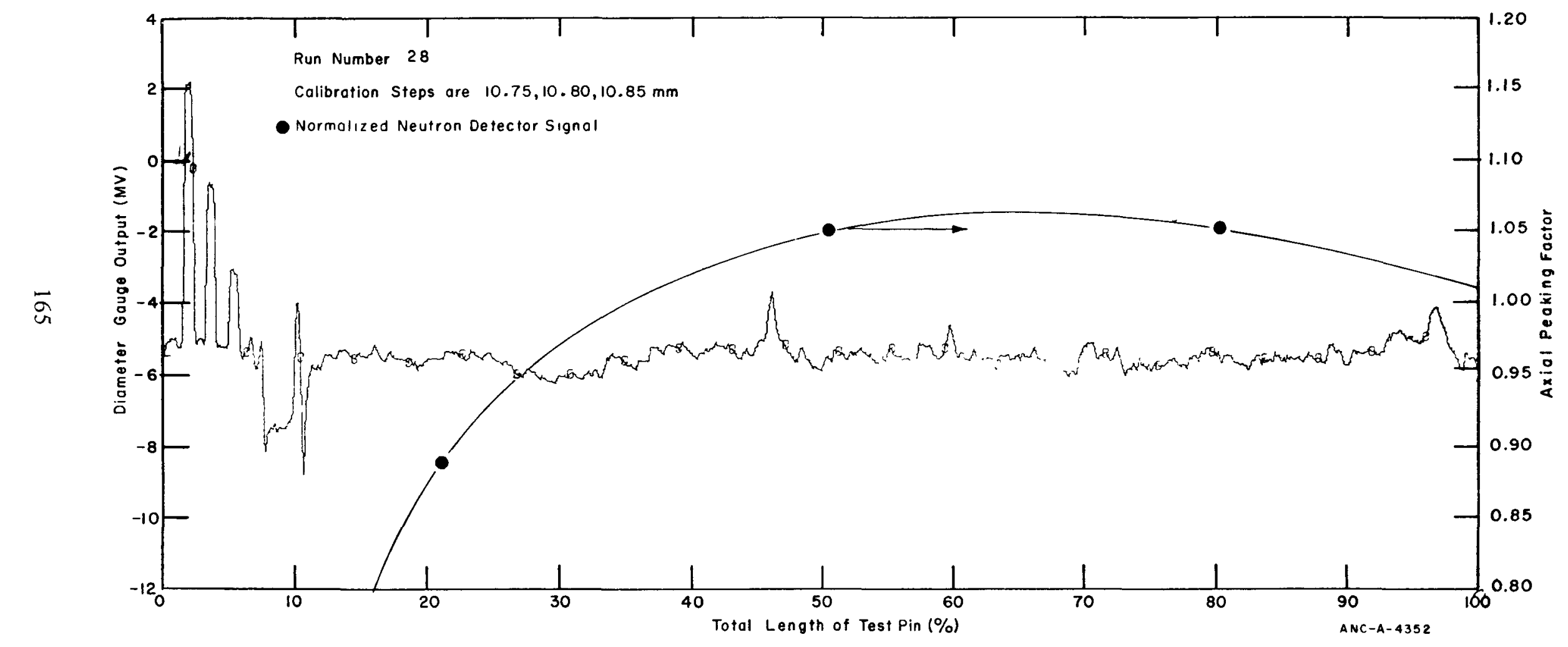

Fig. 150 IFA-239 diametral and axial flux profiles at 1312 hours on March 15, 1973. 


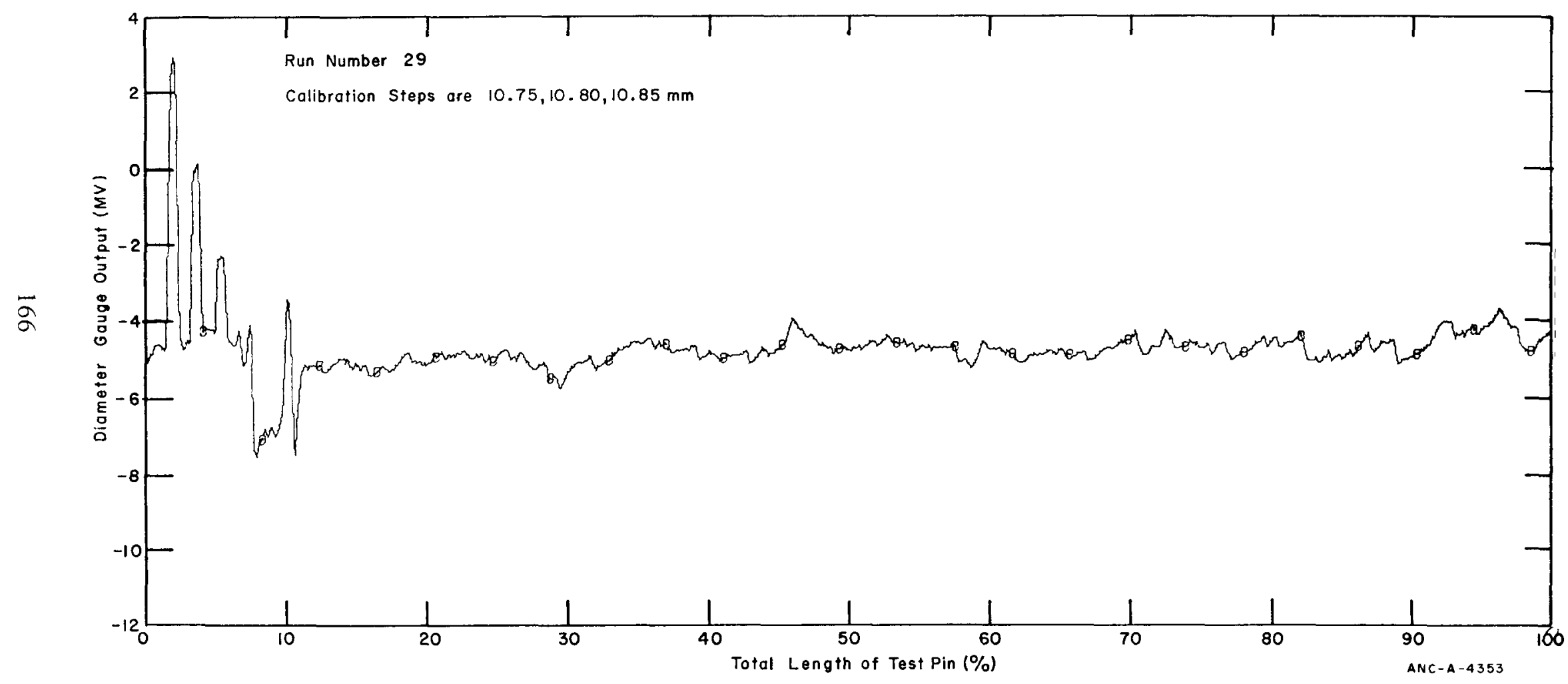

Fig. 151 IFA-239 diametral profile at 0930 hours on March 16, 1973. 


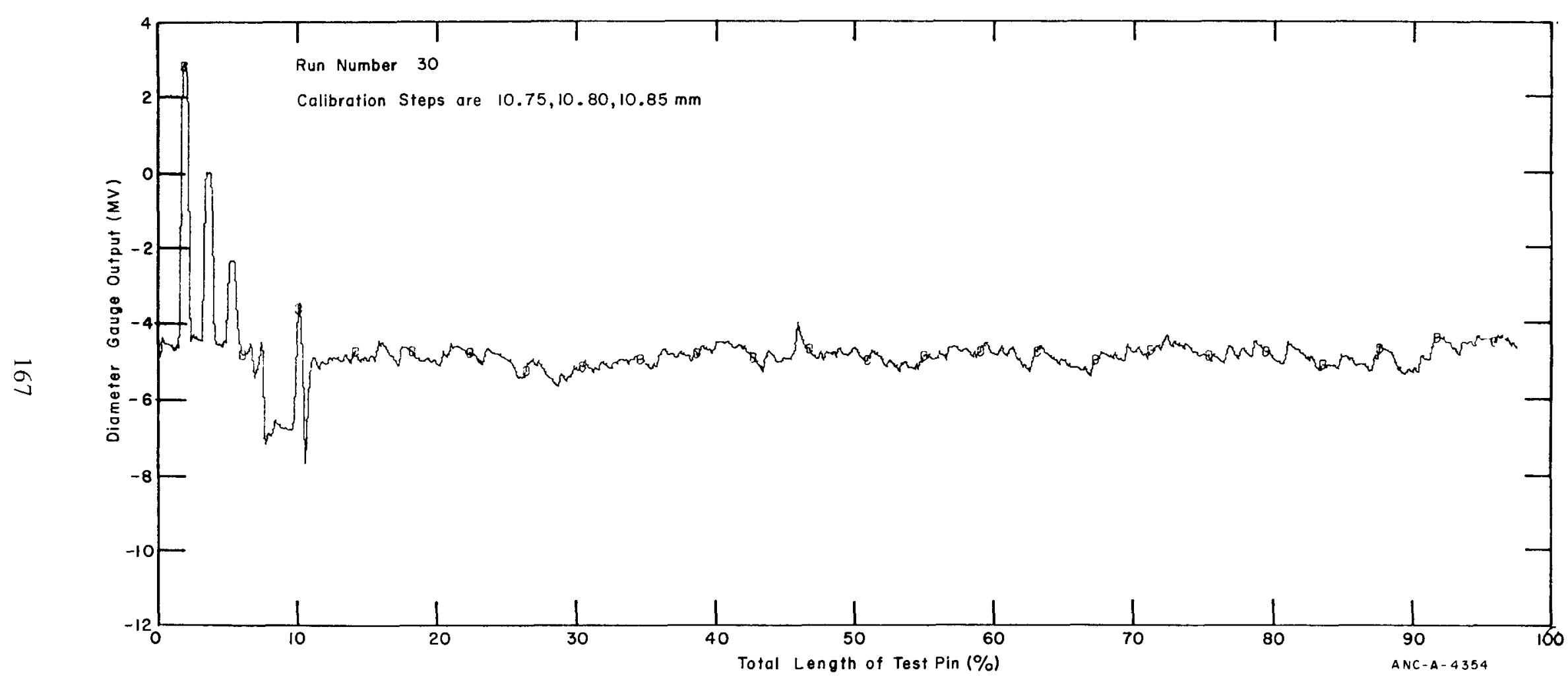

Fig. 152 IFA-239 diametral profile at 0942 hours on March 16, 1973. 

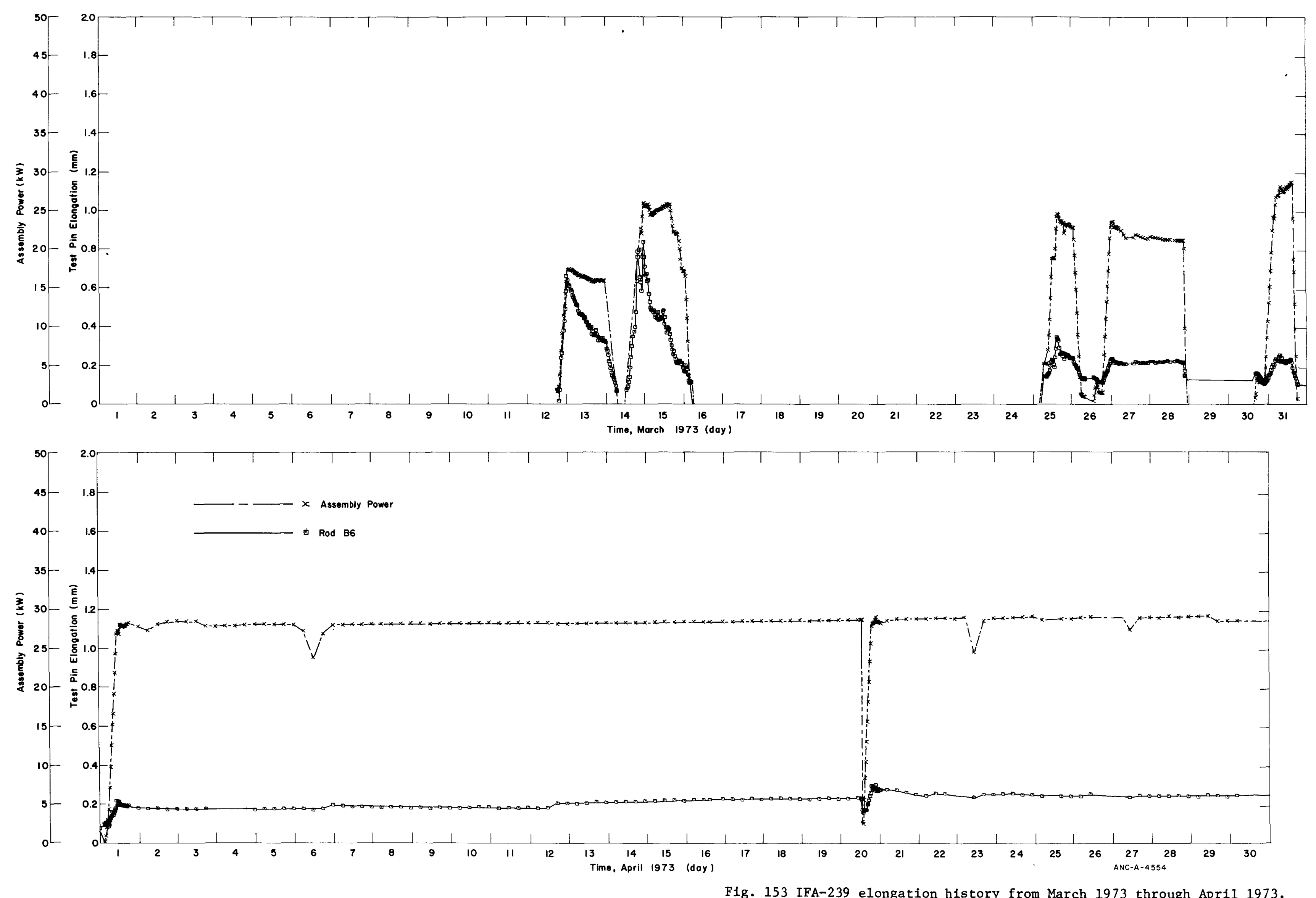

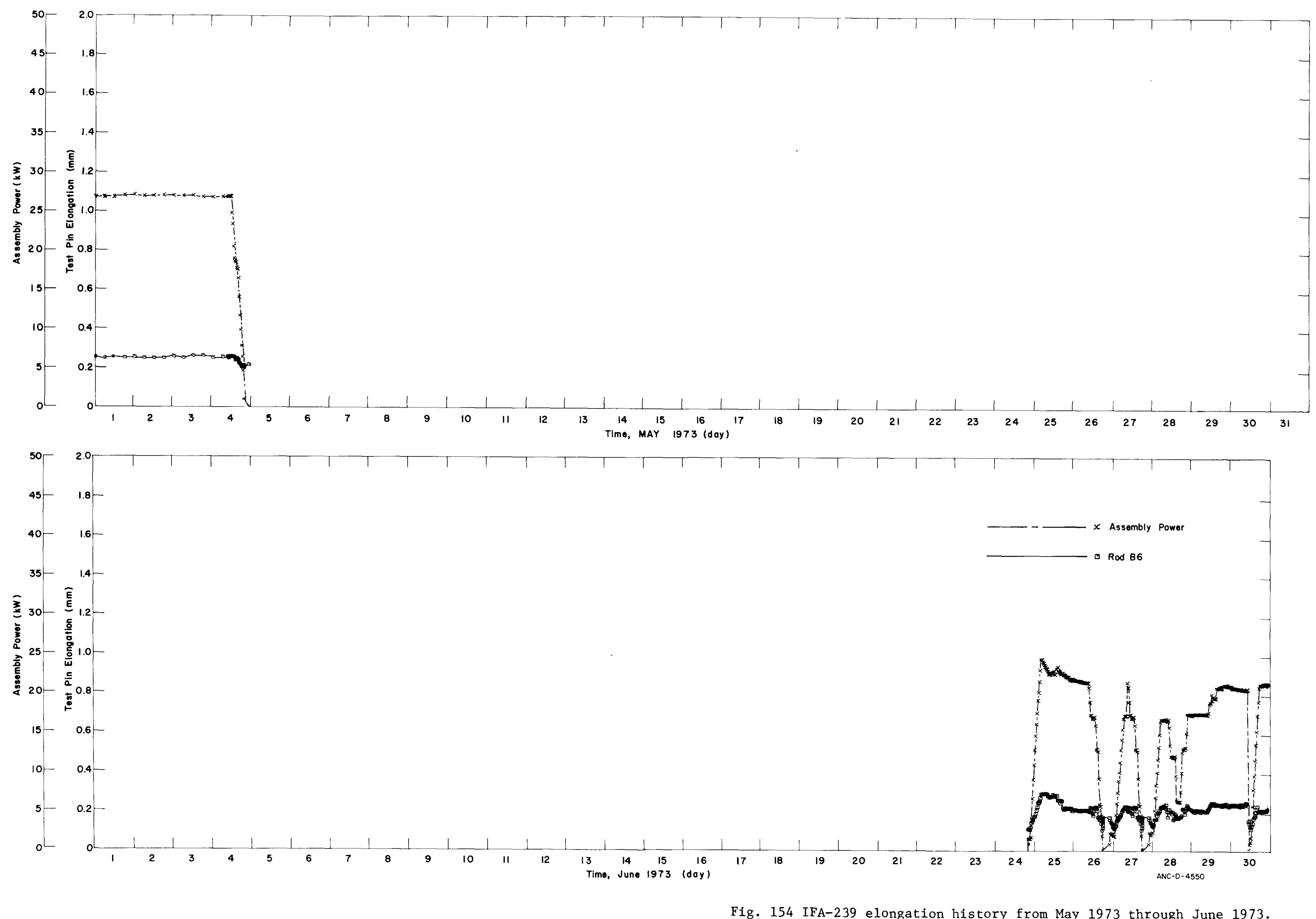

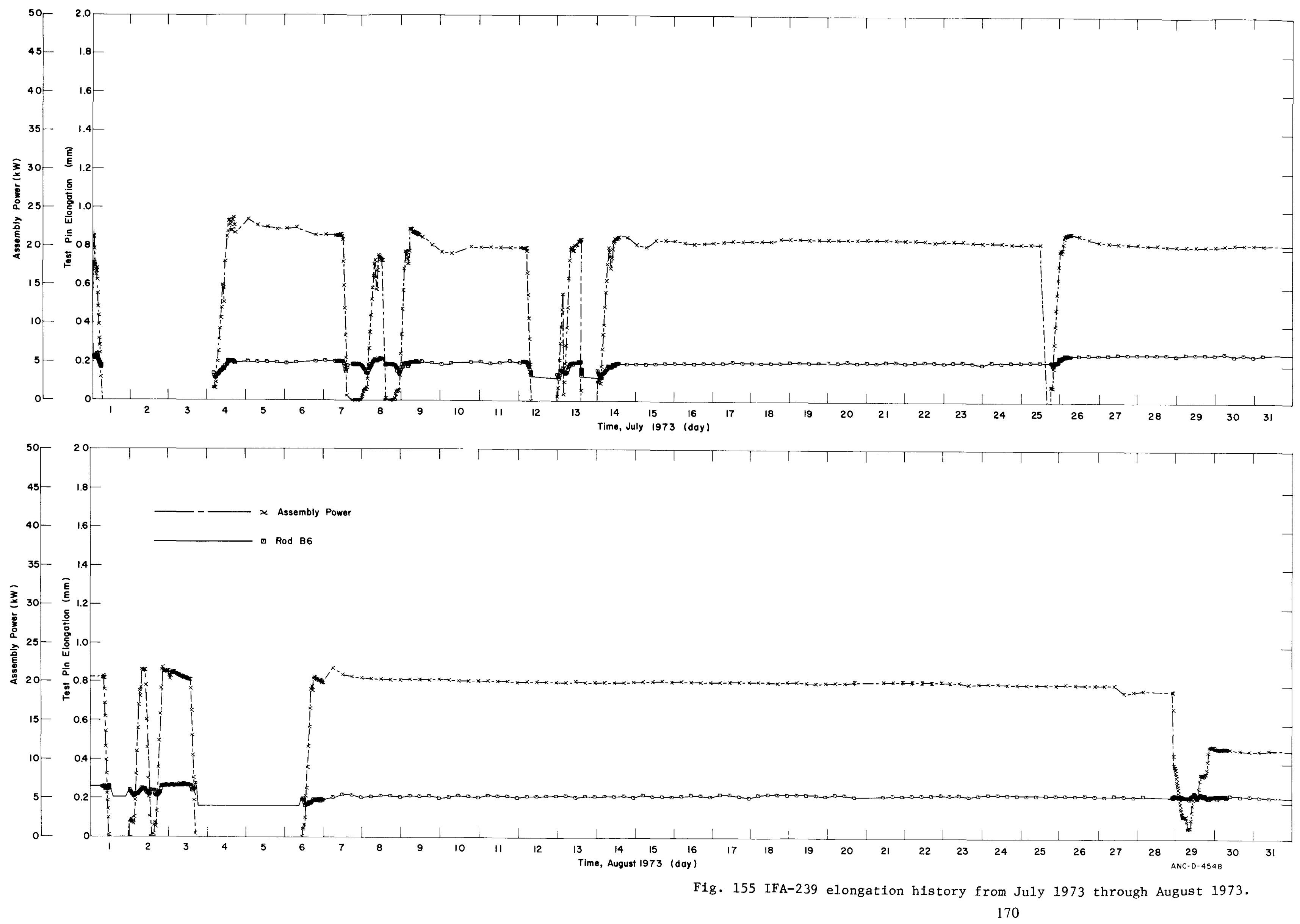

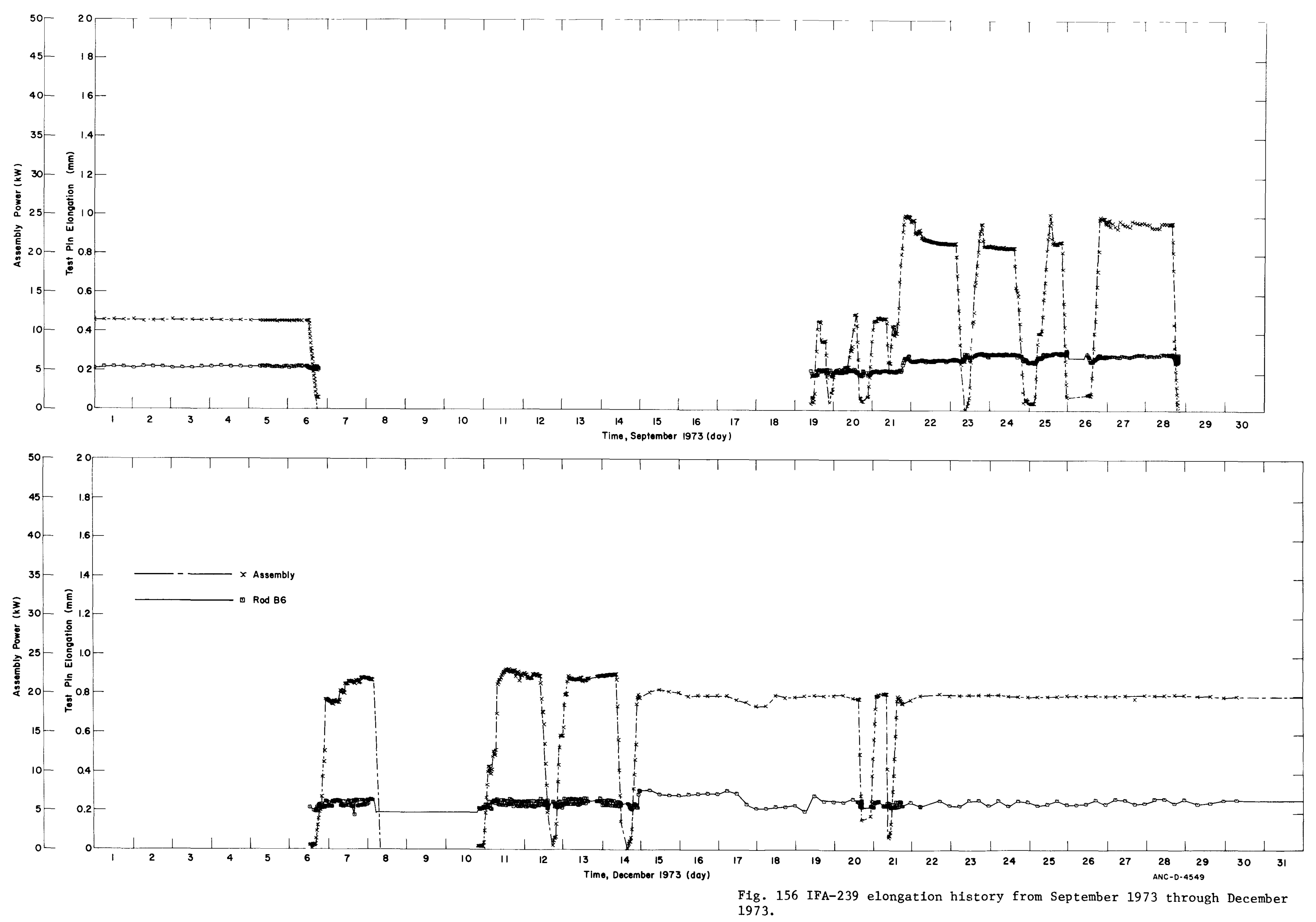

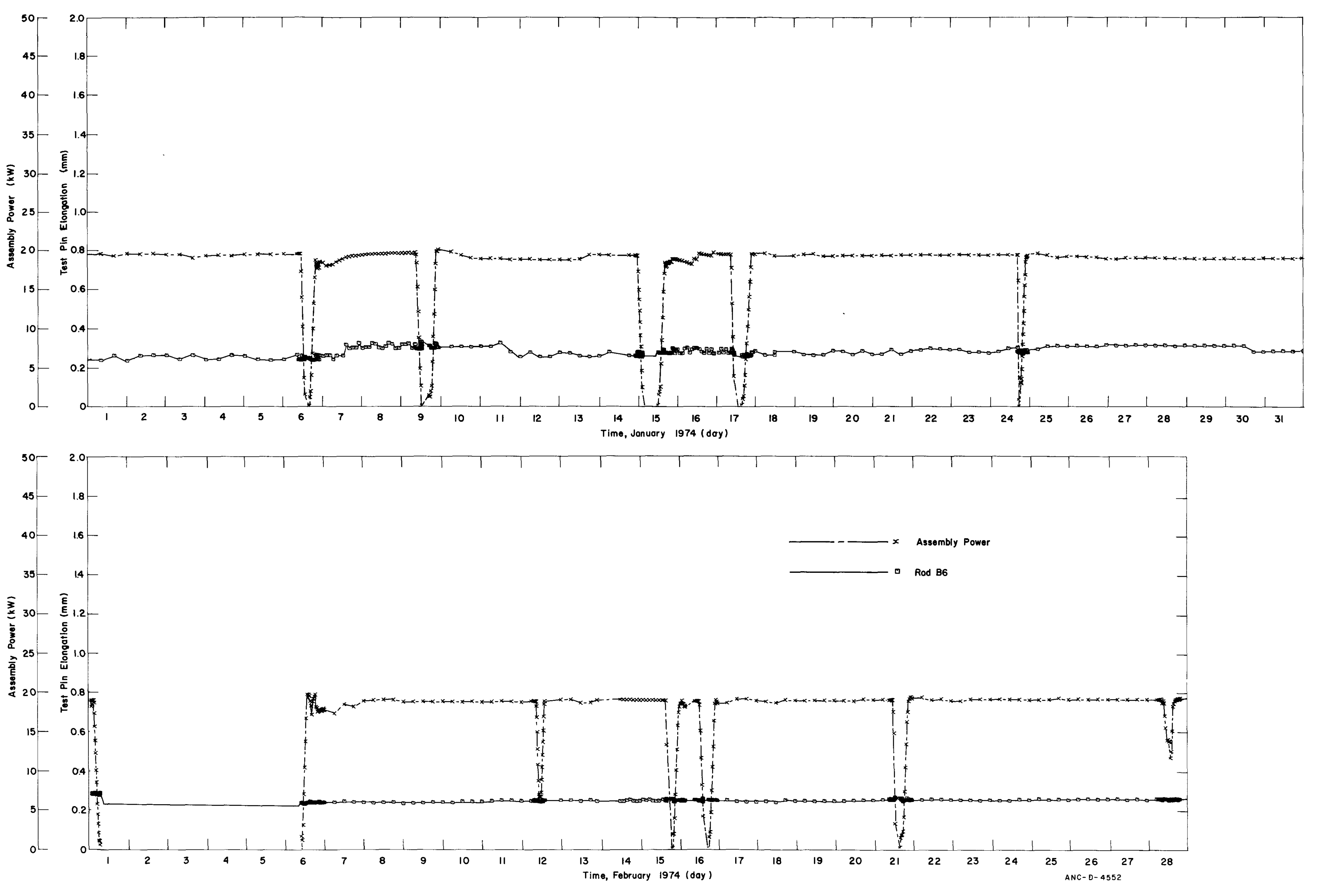

Fig. 157 IFA-239 elongation history from January 1974 through February 1974. 

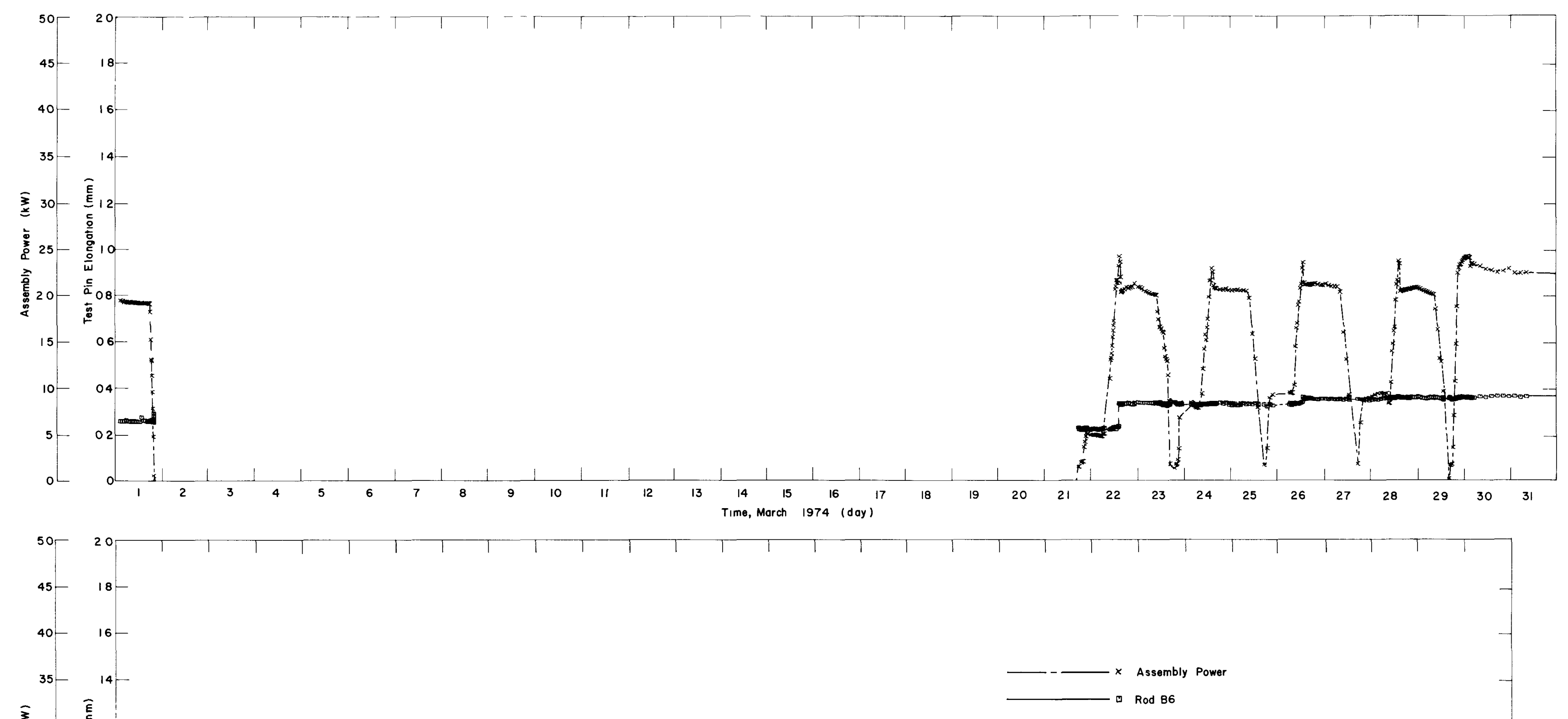

承 $30-\frac{\mathrm{E}_{\mathrm{E}}}{\mathrm{E}}$

言 25 - 毫

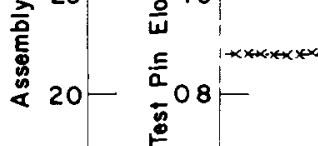

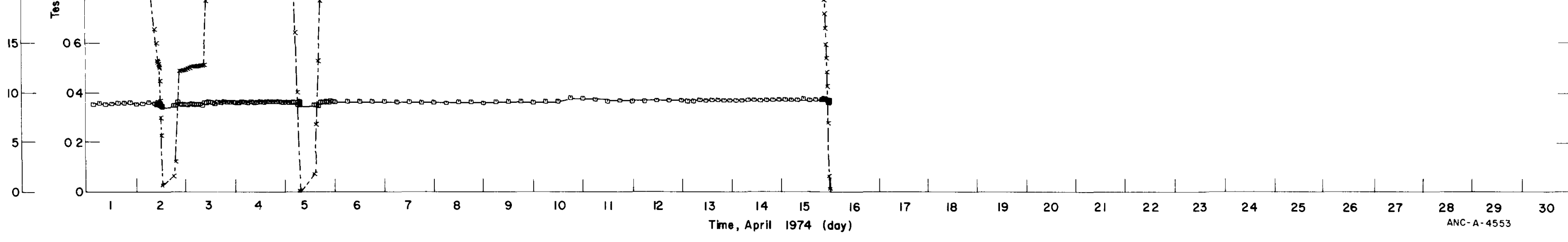

Fig. 158 IFA-239 elongation history from March 1974 through April 1974. 
3. OPERATIONAL STATUS OF THE INSTRUMENTATION

The operational status of the IFA-226 and IFA-239 instrumentation is summarized in Table V.

TABLE V

OPERATIONAL STATUS OF IFA-226 AND IFA-239 INSTRUMENTATION AS OF APRIL 16, 1974

\begin{tabular}{|c|c|c|c|}
\hline Assembly & Instrument & Number & Status \\
\hline \multirow[t]{4}{*}{ IFA-226 } & Neutron Detectors & $\begin{array}{l}\text { ND-1 } \\
\text { ND-2 } \\
\text { ND-3 } \\
\text { ND-4 } \\
\text { ND-5 } \\
\text { ND-6 } \\
\text { ND-7 } \\
\text { ND-8 }\end{array}$ & $\begin{array}{l}\{\text { Operational } \\
\text { Failed March 21, } 1974 \\
\text { Operationa1 }\end{array}$ \\
\hline & Fuel Center Thermocouples & $\begin{array}{l}\text { TF-1 } \\
\text { TF-2 } \\
\text { TF-3 } \\
\text { TF-4 }\end{array}$ & $\begin{array}{l}\text { Failed December 2, } 1972 \\
\text { Failed March 17, } 1972 \\
\text { Failed January 16, } 1972 \\
\text { Failed December 6, } 1973\end{array}$ \\
\hline & Elongation Sensors & $\begin{array}{l}\text { EC-1 } \\
\text { EC-2 } \\
\text { EC-3 } \\
\text { EC-4 } \\
\text { EC-5 } \\
\text { EC-6 }\end{array}$ & $\begin{array}{l}\text { Failed March } 17,1972 \\
\text { Failed May 4,1972 } \\
\text { Operationa1 }\end{array}$ \\
\hline & Fission Gas Sensors & $\begin{array}{l}\text { PF-1 } \\
\text { PF-2 } \\
\text { PF-3 } \\
\text { PF-4 } \\
\text { PF-5 }\end{array}$ & Operational \\
\hline \multirow[t]{3}{*}{ IFA-239 } & Neutron Detectors & $\begin{array}{l}\text { ND-1 } \\
\text { ND-2 } \\
\text { ND-3 } \\
\text { ND-4 } \\
\text { ND-5 } \\
\text { ND-6 }\end{array}$ & $\begin{array}{l}\text { Operational } \\
\text { Failed April 4, } 1973 \\
\text { Failed April 11, } 1973 \\
\text { Operational } \\
\text { Failed March 27, } 1973\end{array}$ \\
\hline & Diametral Profile Sensor & & Failed Fall 1973 \\
\hline & Elongation Sensor & EC-1 & Operational \\
\hline
\end{tabular}


APPENDIX A

FABRICATION REPORT 


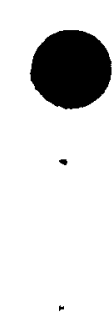

• 


\section{APPENDIX A}

\section{FABRICATION REPORT}

This appendix describes the materials and the fabrication process used for the test rods in the Halden Boiling Water Reactor assemblies IFA-226 and IFA-239.

\section{PELLET FABRICATION}

The IFA-226 and IFA-239 fuel pellets contain approximately $90.5 \%$ depleted uranium dioxide with an initial enrichment of $0.2 \% \mathrm{U}^{235}$ and $9.5 \%$ recycled plutonium dioxide. The recycled plutonium dioxide powder contained approximately $84.3 \%$ fissile material.

\subsection{Pellet Starting Materials}

A description of the nuclear fuel materials used for fabricating the test rod fuel pellets is presented.

1.1.1 Plutonium Dioxide. The plutonium dioxide powder was obtained from two lots of plutonium nitrate solution: one 11.60-gram lot was generated in the New Plutonium Reactor (NPR) at Hanford, and the second 18.92-gram lot was generated in the Consumer's Power Company (CPC) Big Rock Point Reactor in Michigan. The isotopic content of each lot is shown in Table A-I. The burnup of the reprocessed fuel was estimated to be 9,000 and $7,000 \mathrm{MWd} / \mathrm{tU}$ for the $\mathrm{CPC}$ and NPR materials, respectively. The calculated isotopic contents associated with the estimated burnup are shown in Table A-I. The impurities which were present in each plutonium nitrate solution are listed in Table A-II.

The plutonium nitrate was chemically converted to plutonium oxide by utilizing a precipitation process. This process was applied to each lot of plutonium nitrate separately. Upon completion, the two lots were mechanically blended together.

1.1.2 Uranium Dioxide. The $\mathrm{UO}_{2}$ powder was prepared from depleted $\mathrm{UF}_{6}$ material using an ammonium diuranate process. (Basically, the uranyl fluoride was mixed with ammonium hydroxide, precipitated, and then heated in the presence of steam.) The chemical impurities which were found in the $\mathrm{UO}_{2}$ powder are listed in Table A-III. The powder particle size was about $0.55 \mu \mathrm{m}$ and the oxygen-to-metal ratio was 2.01 .

\subsection{Final Pellet Fabrication}

After the oxide powders were screened and mechanically mixed in the desired proportion and then ball-milled, the fuel pellets were fabricated by using a pressing and 
CPC PLUTONIUM LOT:

\begin{tabular}{ccc} 
Isotope & $\begin{array}{c}\text { Weight Percent } \\
\text { Measured }\end{array}$ & $\begin{array}{c}\text { Weight Percent } \\
\text { Estimated for } \\
9,000 \mathrm{MWd} / \mathrm{tU}\end{array}$ \\
$\begin{array}{c}\mathrm{Pu} 238 \\
239^{[\mathrm{a}]}\end{array}$ & $\begin{array}{c}0.43 \\
26.24\end{array}$ & 76 \\
240 & 16.34 & 17.7 \\
$241^{[\mathrm{a}]}$ & 5.82 & 5.2 \\
& 1.18 & 0.5 \\
\hline
\end{tabular}

NPR PLUTONIUM LOT:

\begin{tabular}{|c|c|c|}
\hline Isotope & $\begin{array}{c}\text { Weight Percent } \\
\text { Measured }\end{array}$ & $\begin{array}{l}\text { Weight Percent } \\
\text { Estimated for } \\
7,000 \mathrm{MWd} / \mathrm{tU} \\
\end{array}$ \\
\hline $\mathrm{Pu} 238$ & 1.08 & \\
\hline $239^{[\mathrm{b}]}$ & 85.83 & 86 \\
\hline 240 & 11.53 & 11 \\
\hline $241^{[b]}$ & 2.31 & 2.6 \\
\hline 242 & 0.25 & $\sim 0.2$ \\
\hline
\end{tabular}

sintering technique. Rather high press pressure was used, based upon results which were obtained from prefabrication tests. Specifically, the pellets were pressed at about 100,000 psi and sintered for four hours at $2,800^{\circ} \mathrm{F}$, six hours at $3,050^{\circ} \mathrm{F}$, or sixteen hours at $3,070^{\circ} \mathrm{F}$, depending on desired pellet density. The pellets were then ground to the desired dimensions and outgassed using a 10 to $20 \mu$ vacuum at $1,000^{\circ} \mathrm{F}$ for one hour.

\subsection{Chemical Analysis}

The finished fuel pellets were subjected to chemical analyses in order to determine the isotopic content, the enrichment, and the chemical impurities. These results are presented in Tables A-IV, A-V, and A-VI, respectively. 
TABLE A-II

PLUTONIUM NITRATE IMPURITIES

\begin{tabular}{|c|c|c|c|c|}
\hline \multirow[t]{2}{*}{ Impurity } & \multicolumn{2}{|c|}{$\mathrm{NPR} \mathrm{Pu}\left(\mathrm{NO}_{3}\right)$} & \multicolumn{2}{|c|}{$\mathrm{CPC} \mathrm{Pu}\left(\mathrm{NO}_{3}\right)$} \\
\hline & $\begin{array}{c}\text { Sample } 1 \\
\text { (ppm) }\end{array}$ & $\begin{array}{c}\text { Sample } 2 \\
(\mathrm{ppm})\end{array}$ & $\begin{array}{c}\text { Sample } 1 \\
(\mathrm{ppm})\end{array}$ & $\begin{array}{c}\text { Sample } 2 \\
\text { (ppm) }\end{array}$ \\
\hline $\mathrm{Ag}$ & 0.1 & 0.1 & 0.9 & 0.7 \\
\hline $\mathrm{Al}$ & 10 & 10 & 25.9 & 22.5 \\
\hline As & 10 & 10 & 10 & 10 \\
\hline B & 0.5 & 0.5 & 1.1 & 0.7 \\
\hline $\mathrm{Ba}$ & 10 & 10 & 5 & 5 \\
\hline $\mathrm{Be}$ & 2 & 2 & 6 & 6 \\
\hline $\mathrm{Bi}$ & 2 & 2 & 2 & 2 \\
\hline $\mathrm{Ca}$ & 10 & 10 & 125 & 150 \\
\hline $\mathrm{Cd}$ & 0.5 & 0.5 & 5 & 5 \\
\hline Co & 1 & 1 & 1 & 1 \\
\hline $\mathrm{Cr}$ & 1,667 & 1,667 & 763.7 & 764.6 \\
\hline $\mathrm{Cu}$ & 7.2 & 7.2 & 4.9 & 6.1 \\
\hline $\mathrm{Fe}$ & 4,900 & 4,900 & $1,778.2$ & $1,234.8$ \\
\hline $\mathrm{Ge}$ & 2 & 2 & 10 & 10 \\
\hline $\mathrm{K}$ & 4 & 4 & 10 & 8 \\
\hline L1 & 5 & 5 & 5 & 10 \\
\hline $\mathrm{Mg}$ & 28 & 31 & 14 & 15 \\
\hline Mn & 140 & 140 & 58.3 & 73.4 \\
\hline Mo & 5.8 & 6 & 4.1 & 3.7 \\
\hline $\mathrm{Na}$ & 120 & 120 & 99.8 & 94.1 \\
\hline $\mathrm{Ni}$ & 1,034 & 1,034 & 935.6 & $1,026.1$ \\
\hline $\mathrm{P}$ & 450 & 550 & 358.2 & 472.8 \\
\hline $\mathrm{Pb}$ & 2 & 2 & 15 & 12.4 \\
\hline $\mathrm{Sc}$ & 31 & 35 & 31 & 31 \\
\hline Sn & 2 & 2 & 17.8 & 19.9 \\
\hline St & 50 & 50 & 50 & 50 \\
\hline $\mathrm{Te}$ & 10 & 10 & 10 & 10 \\
\hline $\mathrm{Ti}$ & 5 & 5 & & \\
\hline $\mathrm{T} 1$ & 10 & 10 & 10 & 10 \\
\hline $\mathrm{V}$ & 5 & 5 & 5 & 5 \\
\hline $\mathrm{Sb}$ & & & 3 & 3 \\
\hline $\mathrm{Zn}$ & 10 & 10 & & \\
\hline $\mathrm{C}$ & 0.2 & 0.2 & & \\
\hline$S$ & 200 & & 1,000 & \\
\hline Halide & 200 & & 150 & \\
\hline Dy & & & 2 & 2 \\
\hline $\mathrm{Eu}$ & & & 1 & 1 \\
\hline $\mathrm{Gd}$ & & & 2 & 2 \\
\hline $\mathrm{Sm}$ & & & 5 & 5 \\
\hline Total & & & & \\
\hline
\end{tabular}


TABLE A-III

DEPLETED $\mathrm{UO}_{2}$ POWDER IMPURITIES

\begin{tabular}{|c|c|}
\hline Impurity & Sample (ppm) \\
\hline $\mathrm{Ag}$ & 0.1 \\
\hline Al & 14 \\
\hline As & 10 \\
\hline \multicolumn{2}{|l|}{$\mathrm{Au}$} \\
\hline $\mathrm{B}$ & 0.2 \\
\hline $\mathrm{Ba}$ & 5 \\
\hline $\mathrm{Be}$ & 0.1 \\
\hline $\mathrm{Bi}$ & 1 \\
\hline $\mathrm{Ca}$ & 25 \\
\hline $\mathrm{Cd}$ & 0.85 \\
\hline Co & 5 \\
\hline $\mathrm{Cr}$ & 15 \\
\hline $\mathrm{Cu}$ & 3 \\
\hline $\mathrm{Fe}$ & 115 \\
\hline $\mathrm{Ge}$ & 1 \\
\hline $\mathrm{Hg}$ & 10 \\
\hline $\mathrm{Li}$ & 50 \\
\hline $\mathrm{Mg}$ & 12 \\
\hline $\mathrm{Mn}$ & 5 \\
\hline Mo & 1 \\
\hline $\mathrm{Na}$ & 40 \\
\hline $\mathrm{Ni}$ & 36 \\
\hline $\mathrm{P}$ & 10 \\
\hline $\mathrm{Pb}$ & 1 \\
\hline $\mathrm{Sb}$ & 1 \\
\hline Si & $13 \overline{5}$ \\
\hline $\mathrm{Sn}$ & 1 \\
\hline $\mathrm{Sr}$ & 100 \\
\hline $\mathrm{Te}$ & 1 \\
\hline Th & 100 \\
\hline $\mathrm{Ti}$ & 1 \\
\hline $\mathrm{T} 1$ & 1 \\
\hline $\mathrm{V}$ & 2.5 \\
\hline $\mathrm{W}$ & 50 \\
\hline $\mathrm{Zn}$ & 3 \\
\hline $\mathrm{C}$ & 123 \\
\hline $\mathrm{N}$ & 23 \\
\hline $\mathrm{F}$ & 12 \\
\hline $\mathrm{Cl}$ & 15 \\
\hline Dy & 0.02 \\
\hline $\mathrm{Eu}$ & 0.02 \\
\hline $\mathrm{Gd}$ & 0.01 \\
\hline $\mathrm{Sm}$ & 0.2 \\
\hline
\end{tabular}


$\underline{\text { TABLE A-IV }}$

ISOTOPE CONTENT OF FUEL PELLETS

\begin{tabular}{cccc}
\hline Plutonium Isotope & Content (wt $\%)$ & Uranium Isotope & Content (wt \%) \\
\cline { 1 - 2 } $\mathrm{Pu}^{238}$ & 0.31 & $\mathrm{U}^{234}$ & $\sim 0.00$ \\
$\mathrm{Pu}^{239}$ & 79.98 & $\mathrm{U}^{235}$ & 0.20 \\
$\mathrm{Pu}^{240}$ & 14.52 & $\mathrm{U}^{236}$ & $\sim 0.00$ \\
$\mathrm{Pu}^{241}$ & 4.36 & $\mathrm{U}^{238}$ & 99.79 \\
$\mathrm{Pu}^{242}$ & 0.83 & &
\end{tabular}

TABLE A-V

PLUTONIUM CONTENT

\begin{tabular}{|c|c|c|c|}
\hline Blend & Enrichment & $\begin{array}{l}\text { Oxygen-to- } \\
\text { Metal Ratio }\end{array}$ & Test Rods \\
\hline 1 & 9.27 & 1.970 to 1.974 & $\begin{array}{l}A A, A B, A C, A D, A E, \\
A G, A J[a], A M[a], A O \\
B 5[a]\end{array}$ \\
\hline 4 & 9.21 & 1.972 to 1.987 & $\mathrm{AK}, \mathrm{AM}[\mathrm{a}], \mathrm{B} 6$ \\
\hline 5 & 9.45 & 1.972 to 1.981 & $\mathrm{AH}, \mathrm{AJ}[\mathrm{a}], \operatorname{AM}[a], \mathrm{B}^{[a}$ \\
\hline
\end{tabular}

[a] Rods which contain pellets from more than one blend.

A fuel oxygen-to-metal ratio ranging from 1.970 to 1.987 was also measured ( 8 samples, 2 measurements each).

\section{$1.4 \quad$ Pellet Autoradiography and Metallography}

Fuel pellet samples from each of three enrichment blends were autoradiographed using Kodak NTA film plates. Figure A-1 illustrates the plutonium particle size (actually particle agglomerate size) and dispersion for samples from Blends 1 and 4. The largest plutonium particle is noted on each autoradiograph. (Table A-V lists which test rods contain which enrichment blend.) All three blends were screened and then ball-milled for 16 hours; however, the delay time between screening and ball-milling varied somewhat from blend to blend and is noted on Figure A-1. Increased particle reagglomeration seemed to be associated with increased screening to ball-milling delay time. 
FUEL PELLET IMPURITIES

\begin{tabular}{lccc}
\hline Element & Impurities (ppm) & Element & Impurities (ppm) \\
\cline { 2 - 3 } $\mathrm{Al}$ & 170 & $\mathrm{Mg}$ & 30 \\
$\mathrm{~B}$ & $>1$ & $\mathrm{Mn}$ & 2 \\
$\mathrm{Bi}$ & 2 & $\mathrm{Mo}$ & 19 \\
$\mathrm{C}$ & 104 & $\mathrm{~N}$ & 12 \\
$\mathrm{Ca}$ & 5 & $\mathrm{Ni}$ & 114 \\
$\mathrm{Cd}$ & $>1$ & $\mathrm{~Pb}$ & 2 \\
$\mathrm{Co}$ & 2 & $\mathrm{Si}$ & 208 \\
$\mathrm{Cr}$ & 38 & $\mathrm{Sn}$ & 12 \\
$\mathrm{Cu}$ & 22 & $\mathrm{Ti}$ & 250 \\
$\mathrm{~F}$ & 5 & $\mathrm{~V}$ & 5 \\
$\mathrm{Fe}$ & 60 & $\mathrm{Zn}$ & 102 \\
$\mathrm{H}$ & $2.2^{[\mathrm{a}]}$ & Total gas & $0.025 \mathrm{~g} / \mathrm{cm}^{3}[\mathrm{a}]$ \\
$\mathrm{H}{ }^{0}$ & $1.6^{[\mathrm{a}]}$ & 5 &
\end{tabular}

[a] Measured after hot vacuum outgassing of the pellets.

Photomicrographs were also obtained from samples from each blend. Figures A-2 and A-3 illustrate the pore size and distribution at the pellet center and near the surface of Blend 5 radial and axial sections, respectively. The large porosity average diameter and the average number of large pores per square inch are noted on the figures.

\section{CLADDING MATERIALS}

The IFA-226 and IFA-239 test rod tubing was supplied by Sandvik Special Metals, Inc. Two lots of tubing were purchased. The chemical and physical data supplied by Sandvik with the first batch of material (Lot 84001) are presented in Table A-VII. The data for the second batch (Lot 74001) are presented in Table A-VIII. Photomicrographs showing the zirconium hydride orientations of Lot 84003 are shown in Figure A-4. Figure A-5 presents the photomicrographs for Lot 74001 .

To check the Sandvik strength and ductility measurements, random samples from each batch were sent to Battelle Memorial Institute (BMI), Columbus, Ohio, for elevated temperature testing. The BMI tensile test results were consistently several thousand psi lower, and the elongation was several percent higher, than those reported by Sandvik Special Metals, Inc., for this same material. These results suggest a variation between the BMI and the Sandvik tubing material or in their testing temperatures. The test temperatures which were used by BMI were checked and found to be correct. 


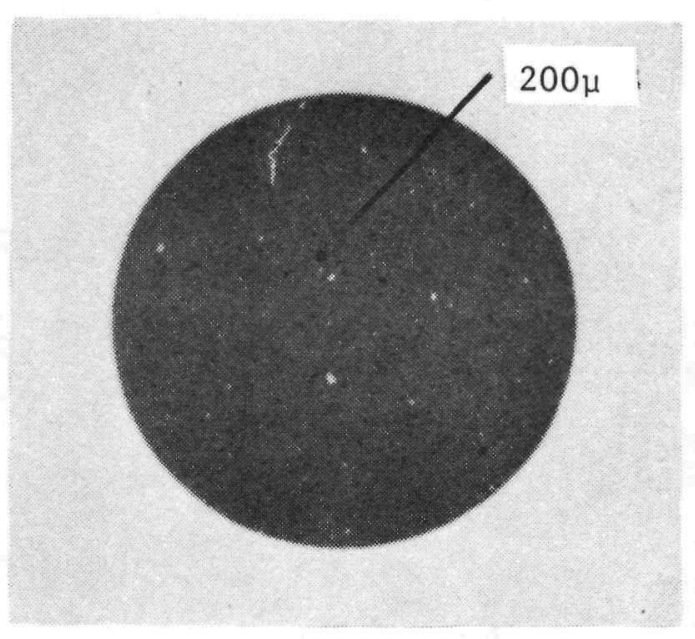

RADIAL

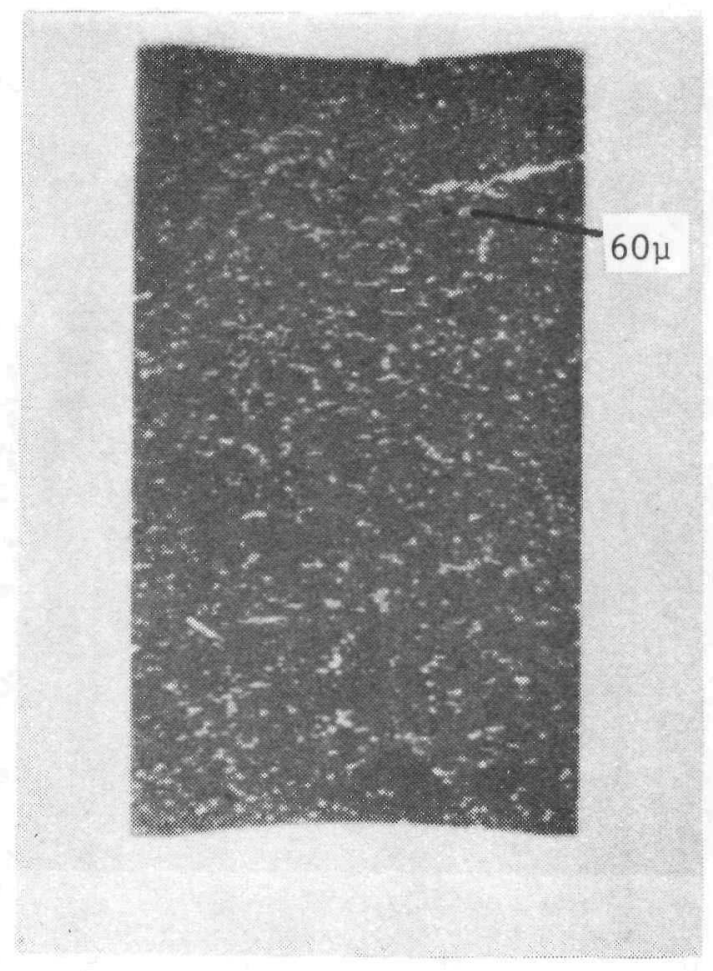

AXIAL

Blend 1 (9.5wt \%)

$\Delta t-7$ days

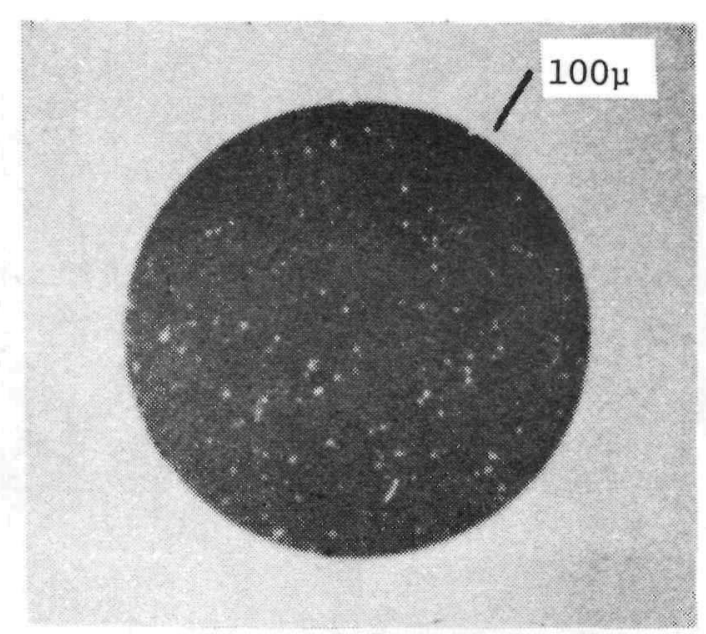

RADIAL

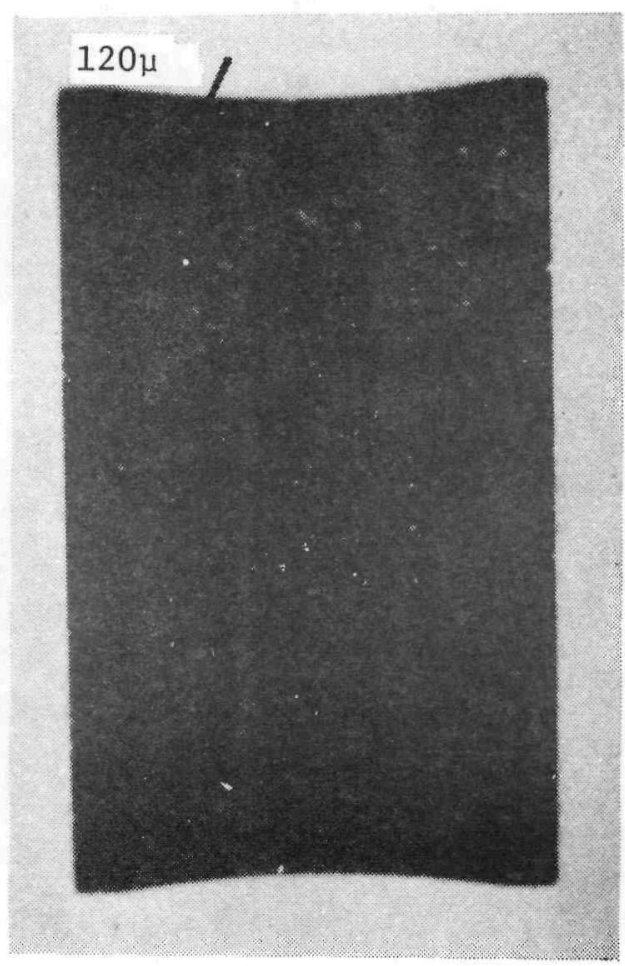

AXIAL

Blend 4 ( $9.5 w t \%)$

$\Delta t-10$ days

Fig. A-1 Fuel pellet autoradiography. 

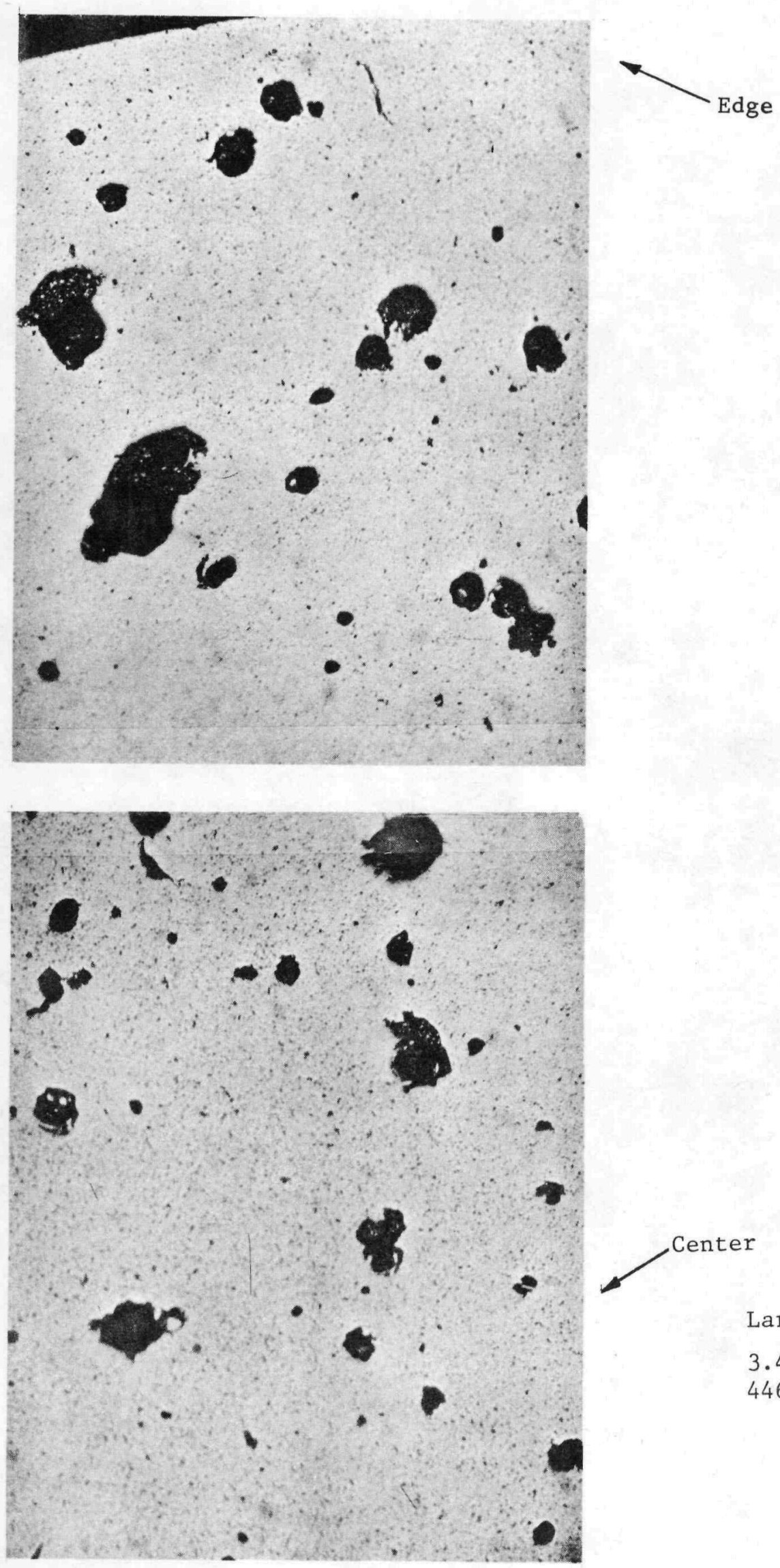

$$
\begin{aligned}
& \text { Large Porosity } \\
& 3.48 \mathrm{mils} \text { average diameter } \\
& 446 \text { average pores per } 0.1 \mathrm{in.}^{2}
\end{aligned}
$$$$
\text { 9.5 wt\% Fuel (Blend 5) }
$$

Fig. A-2 Fuel pellet metallography -- radial section. 

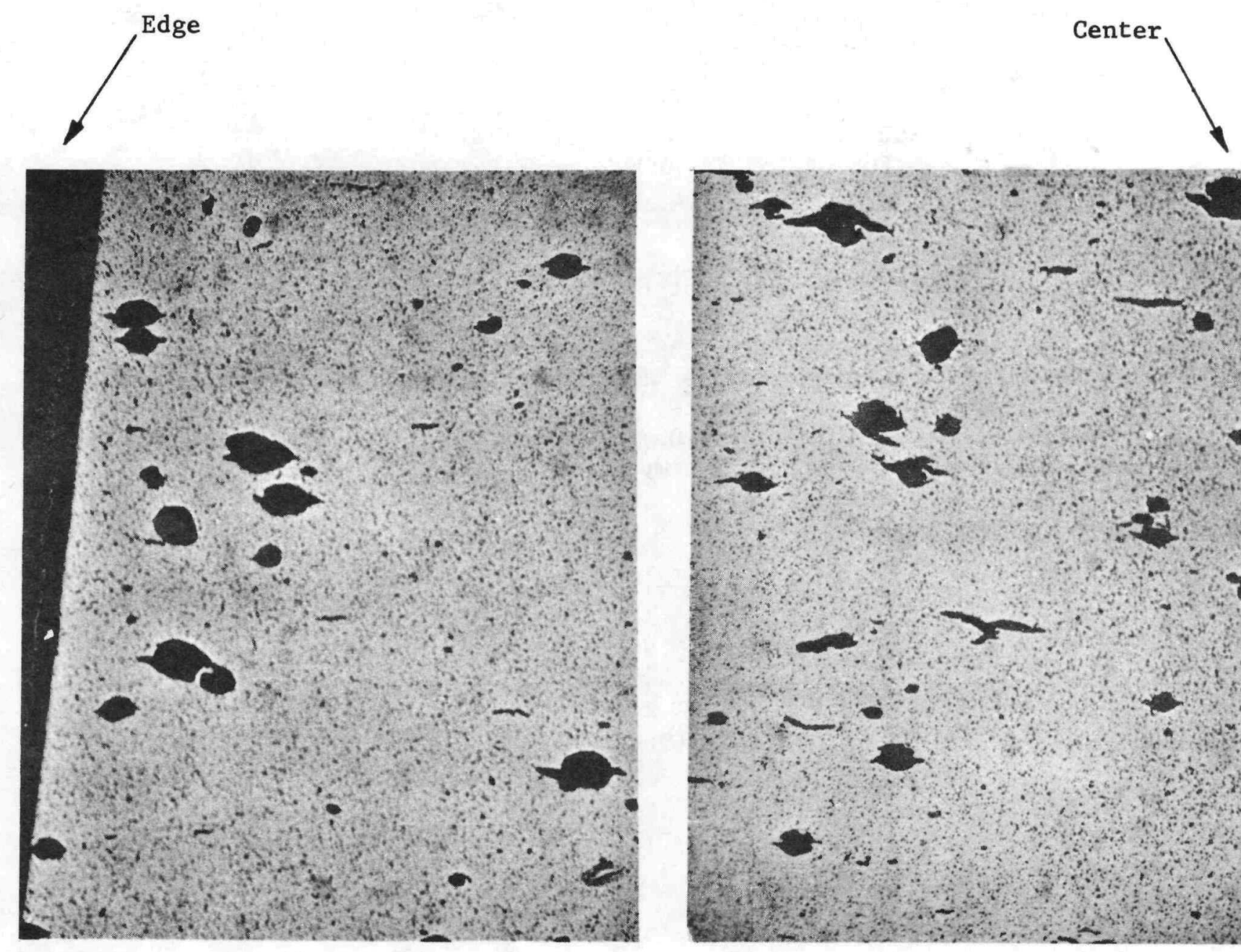

$01^{\text {Edge }}$

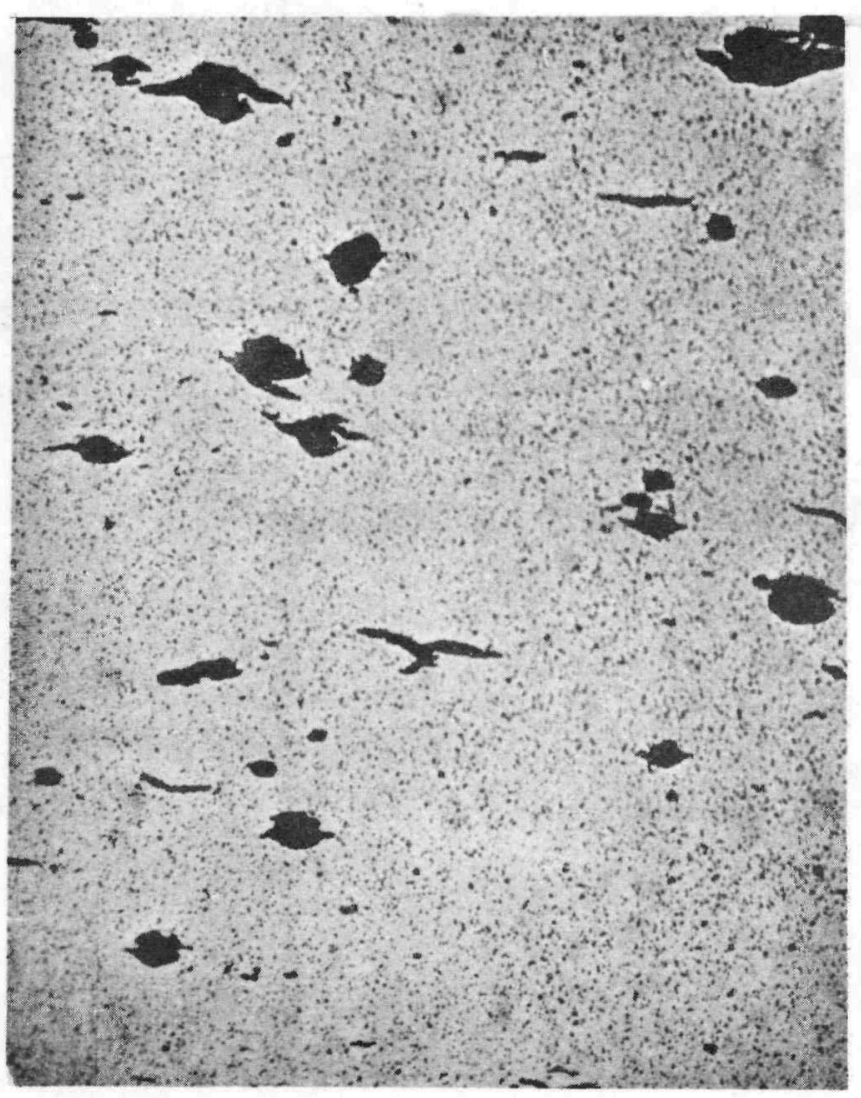

Large Porosity

3.08 mils average diameter
396 average pores per 0.1 in.

9.5 wt\% Fuel (Blend 5)

Fig. A-3 Fuel pellet metallography -- axial section.

The end plug bar stock was supplied by Wah Chang Corporation and was machined in the NFS Rockville Model Shop. The chemical and physical data for the material used for the smooth end plugs and for the Halden instrument fabrication are presented in Tables A-IX and A-X, respectively. The data for the grooved end plugs are presented in Table A-XI. 
DESCRIPTION, PROPERTIES, AND TEST RESULTS

FOR SANDVIK CLADDING -- FIRST LOT

\section{MATERIAL}

Sandvik zircaloy-4 tubing, Lot 84003 (Rods AG, AH, AJ, AM, B5, B6)

Inside Diameter $=9.487 \pm 0.038 \mathrm{~mm}$

Final Annealing Temperature $=488^{\circ} \mathrm{C}$ for $4 \mathrm{hr}$

Length $=838+1.5 \mathrm{~mm}$ Diameter

Outside Diamēerer $=10.74 \pm 0.05 \mathrm{~mm}$

wa11 Thickness $=0.533 \mathrm{mrn}$ minimum

FINISHED TUBE ANALYSIS (ppm)

Element

$$
\begin{aligned}
& \mathrm{H} \\
& \mathrm{N} \\
& \mathrm{O}
\end{aligned}
$$

Sample 1

12

34

1,100
Sample 2

11

29

1,140

TENSILE PROPERTIES (test temperature of $380^{\circ} \mathrm{C}$ )

Ultimate Tensile Strength $\left(\mathrm{N} / \mathrm{m}^{2}\right)$

$0.2 \%$ Yield Strength $\left(\mathrm{N} / \mathrm{m}^{2}\right)$

Elongation for $51 \mathrm{~mm}$ specimen (\%)
Sample 1

$4.68 \times 10^{8}$

$3.54 \times 10^{8}$

23.4
Sample 2

$4.66 \times 10^{8}$

$3.47 \times 10^{8}$

23.4

\section{CORROSION TEST}

Sample 1 Samp1e 2 Sample 3

Weight Gain after Three Days

Color:

$$
\left(\mathrm{mg} / \mathrm{dm}^{2}\right)
$$

17.6

16.2

16.6

GRAIN SIZE (recrystallization data $-667^{\circ} \mathrm{C}$ for 45 minutes)

Longitudina1, ASTM Number

Transverse, ASTM Number

$$
\begin{array}{cc}
\frac{\text { Sample } 1}{\text { Not Applicable }} & \frac{\text { Sample 2 }}{11.5} \\
11.5
\end{array}
$$

HYDRIDE ORIENTATION (exposed to 1 mular LiOH at $316^{\circ} \mathrm{C}$ for 18 hours)

$\mathrm{F}_{\mathbf{n}}$ Number

Sample 1

Sample 2

$$
0.03
$$

0.04

SURFACE ROUGHNESS

OD (mm)

ID $(\mathrm{mm})$
Sample 1

0.25

0.36
Sample 2

0.25

0.41 
DIMENSIONS, STRAIGHTNESS, ULTRASONIC FLAW AND FREE PATH TEST

Al1 Tubes Approved

INGOT ANALYSIS

COMPOSITION (wt\%)

\begin{tabular}{llrr}
\hline & Top & Center & Bottom \\
$\mathrm{Sn}$ & 1.54 & 1.48 & 1.37 \\
$\mathrm{Fe}$ & 0.22 & 0.22 & 0.20 \\
$\mathrm{Cr}$ & 0.11 & 0.12 & 0.11
\end{tabular}

Impurities (ppm)

$\begin{array}{lrrr}\mathrm{A} 1 & <25 & 31 & 33 \\ \mathrm{~B} & 0.2 & <0.2 & <0.2 \\ \mathrm{C} & 120 & 180 & 170 \\ \mathrm{Ca} & <10 & <10 & <10 \\ \mathrm{Cd} & <0.2 & <0.2 & <0.2 \\ \mathrm{C} 1 & <15 & <15 & <15 \\ \mathrm{Co} & <5 & <5 & <5 \\ \mathrm{Cu} & 16 & <10 & 17 \\ \mathrm{H} & 5 & 4.8 & 6 \\ \mathrm{Hf} & 55 & 51 & 51 \\ \mathrm{Hg} & <5 & <5 & <5 \\ \mathrm{Mn} & <10 & <10 & <10 \\ \mathrm{~N} & 27 & 26 & 26 \\ \mathrm{Ni} & 24 & 19 & 16 \\ \mathrm{O} & 1,050 & 1,120 & 1,140 \\ \mathrm{~Pb} & <20 & <20 & <20 \\ \mathrm{Si} & 47 & 41 & 43 \\ \mathrm{Ti} & <20 & <20 & <20 \\ \mathrm{U} & <0.5 & <0.5 & <0.5 \\ \mathrm{~W} & <25 & <25 & <25\end{array}$

FORGING ULTRASONIC TEST RESULTS

Acceptable

CORROSION TEST RESULTS, RUNS $301-10$ (14 days at $399^{\circ} \mathrm{C}, 1.03 \times 10^{7} \mathrm{~N} / \mathrm{m}^{2}$ )

\begin{tabular}{|c|c|c|}
\hline Sample & $\begin{array}{l}\text { Weight Gain } \\
\left(\mathrm{mg} / \mathrm{dm}^{2}\right) \\
\end{array}$ & Appearance \\
\hline 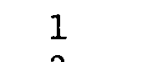 & 26 & Acceptable, No Visible \\
\hline 2 & 25 & Corrosion Defects \\
\hline
\end{tabular}

PRODUCT CHEMISTRY (ppm)

$\begin{array}{cc} & \text { Sample } 1 \\ \mathrm{~N} & 42 \\ \mathrm{H} & 15\end{array}$

Sample 2

47

18

HARDNESS (BHN)

$\begin{array}{ll}\text { Range } & 163 \text { to } 170 \\ \text { Average } & 167\end{array}$




\section{MATERIAL}

Sandvik zircaloy-4 tubing, Lot 74001 (Rods $\mathrm{AA}, \mathrm{AB}, \mathrm{AC}, \mathrm{AD}, \mathrm{AE}, \mathrm{AK}, \mathrm{AO}$ )

Inside Diameter $=9.49 \pm 0.038 \mathrm{~mm}$

Final Annealing Temperature $=496^{\circ} \mathrm{C}$ for $4 \mathrm{hr}$

Length $=368.1+3.0-0.0 \mathrm{~mm}$

Outside Diameter $=10.72+0.05 \mathrm{~mm}$

Wal1 Thickness $=0.533$ minimum

FINISHED TUBE ANALYSIS (ppm)

Element

$\mathrm{H}$

$\mathrm{N}$

0
Samp1e 1

14

34

1,060
Sample 2

14

36

1,050

TENSILE PROPERTIES (test temperature $371^{\circ} \mathrm{C}$ )

Ultimate Tensile Strength $\left(\mathrm{N} / \mathrm{m}^{2}\right)$

$0.2 \%$ Yield Strength $\left(\mathrm{N} / \mathrm{m}^{2}\right)$

Elongation for $51 \mathrm{~mm}$ Specimen (\%)

\section{Sample 1}

$4.29 \times 10^{8}$

$3.20 \times 10^{8}$

23.4
Sample 2

$4.34 \times 10^{8}$

$3.28 \times 10^{8}$

21.9

CORROSION TEST

Weight Gain after Three Days

Color:

$$
\left(\mathrm{mg} / \mathrm{dm}^{2}\right)
$$

\section{Sample 1 Sample $2 \quad$ Sample 3}

14.9

13.1

15.0

Lustrous Black

GRAIN SIZE (recrystallization data $-677^{\circ} \mathrm{C}$ for 45 minutes)

Longitudinal, ASTM Number

Sample $1 \quad$ Sample 2

Transverse, ASTM Number

Not App1icable

11.5

11.5

HYDRIDE ORIENTATION (exposed to 1 molar LiOH at $316^{\circ} \mathrm{C}$ for 18 hours)

$\mathrm{F}_{\mathrm{n}}$ Number $\quad \frac{\text { Sample 1 }}{0.04} \quad \frac{\text { Samp1e 2 }}{0.03} \quad \frac{\text { Samp1e 3 }}{0.04}$

SURFACE ROUGHNESS

Range of Values

OD (mm)

0.46 to 0.51

ID $(\mathrm{mm})$

0.43 to 0.46 
TABLE A-VIII (contd.)

DIMENSIONS, STRAIGHTNESS, ULTRASONIC FLAW AND FREE PATH TEST

All Tubes Approved

INGOT ANALYSIS

COMPOSITION (wt\%)

\begin{tabular}{|c|c|c|c|}
\hline & Top & Center & Bottom \\
\hline $\mathrm{Sn}$ & 1.44 & 1.41 & 1.37 \\
\hline $\mathrm{Fe}$ & 0.21 & 0.21 & 0.21 \\
\hline $\mathrm{Cr}$ & 0.11 & 0.11 & 0.11 \\
\hline \multirow[t]{2}{*}{$\mathrm{Fe}+\mathrm{Cr}$} & 0.32 & 0.32 & 0.32 \\
\hline & \multicolumn{3}{|c|}{ Impurities (ppm) } \\
\hline Al & 27 & 32 & 33 \\
\hline B & 0.3 & 0.4 & 0.5 \\
\hline C & 180 & 150 & 110 \\
\hline $\mathrm{Cd}$ & $<0.2$ & $<0.2$ & $<0.2$ \\
\hline Co & $<5$ & $<5$ & $<5$ \\
\hline $\mathrm{Cu}$ & 19 & 22 & 33 \\
\hline $\mathrm{Ca}$ & $<10$ & $<10$ & $<10$ \\
\hline $\mathrm{Cl}$ & $<15$ & $<15$ & $<15$ \\
\hline $\mathrm{H}$ & 3.5 & 3.7 & 6 \\
\hline $\mathrm{Hf}$ & 41 & 41 & 40 \\
\hline $\mathrm{Mn}$ & 18 & 18 & 16 \\
\hline $\mathrm{Mg}$ & $<5$ & $<5$ & $<5$ \\
\hline $\mathrm{N}$ & 31 & 31 & 39 \\
\hline $\mathrm{Ni}$ & 25 & 25 & 23 \\
\hline 0 & 1,170 & 1,170 & 1,220 \\
\hline $\mathrm{Pb}$ & $<20$ & $<20$ & $<20$ \\
\hline $\mathrm{Si}$ & 55 & 55 & 77 \\
\hline $\mathrm{T} \mathbf{1}$ & $<30$ & $<20$ & $<20$ \\
\hline $\mathrm{W}$ & $<25$ & $<25$ & $<25$ \\
\hline $\mathrm{U}$ & $<0.5$ & $<0.5$ & $<0.5$ \\
\hline
\end{tabular}

\section{BILLET ULTRASONIC RESULTS}

Acceptable

PRODUCT CHEMISTRY (ppm)

Sample 1

13

39

1,080
Sample 2

10

43

1,120

CORROSION TEST RESULTS, RUNS 353-4 (14 days at $399^{\circ} \mathrm{C}, 1.03 \times 10^{7} \mathrm{~N} / \mathrm{m}^{2}$ )

\begin{tabular}{|c|c|c|}
\hline Sample & $\begin{array}{l}\text { Weight Gain } \\
\left(\mathrm{mg} / \mathrm{dm}^{2}\right)\end{array}$ & Appearance \\
\hline 7 & 26 & Acceptable, No Visible \\
\hline 2 & 25 & Corrosion Defects \\
\hline
\end{tabular}

HARDNESS (BHN)

$\begin{array}{ll}\text { Range } & 170 \text { to } 183 \\ \text { Average } & 178\end{array}$



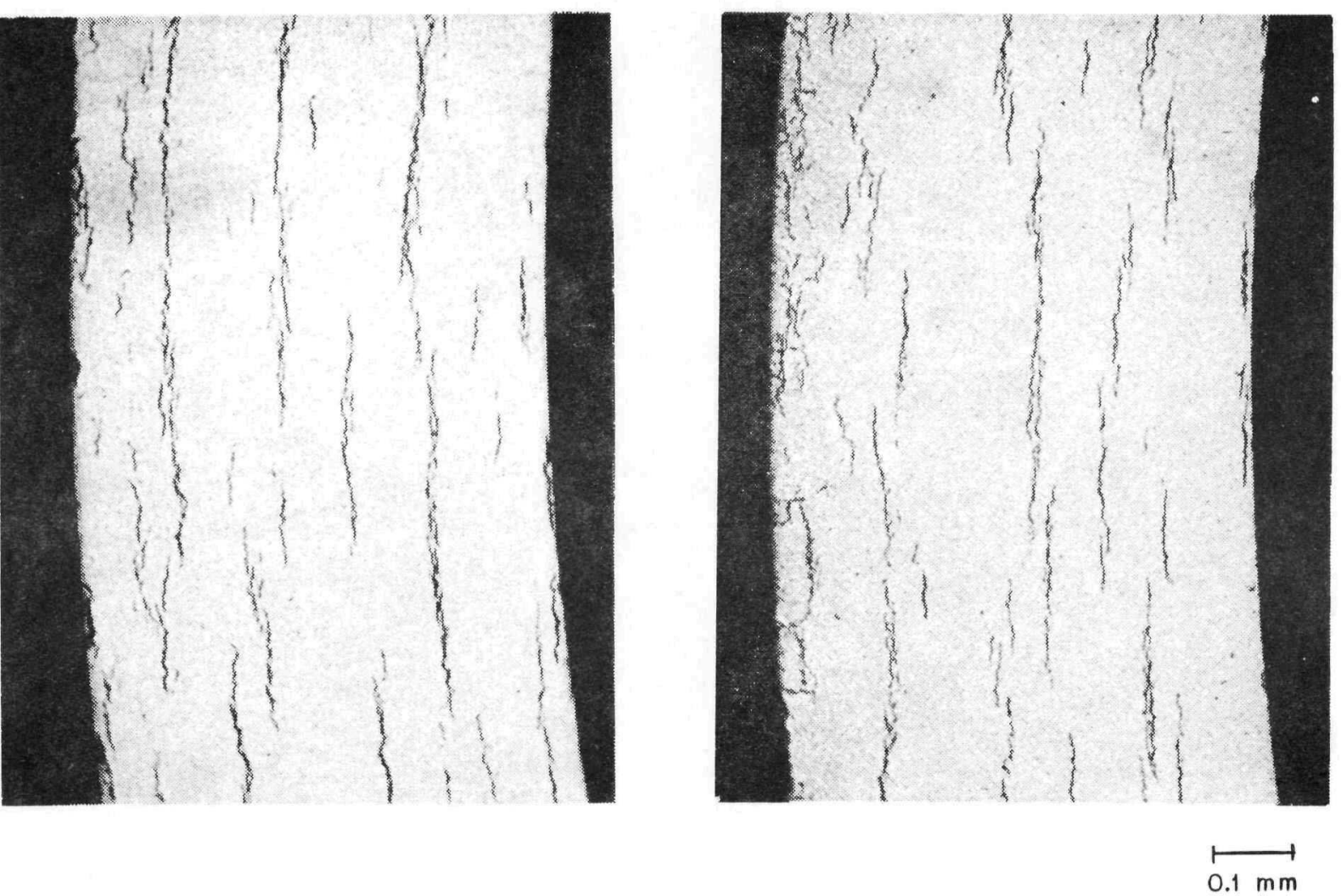

Fig. A-4 Lot 84003 hydride orientation. 


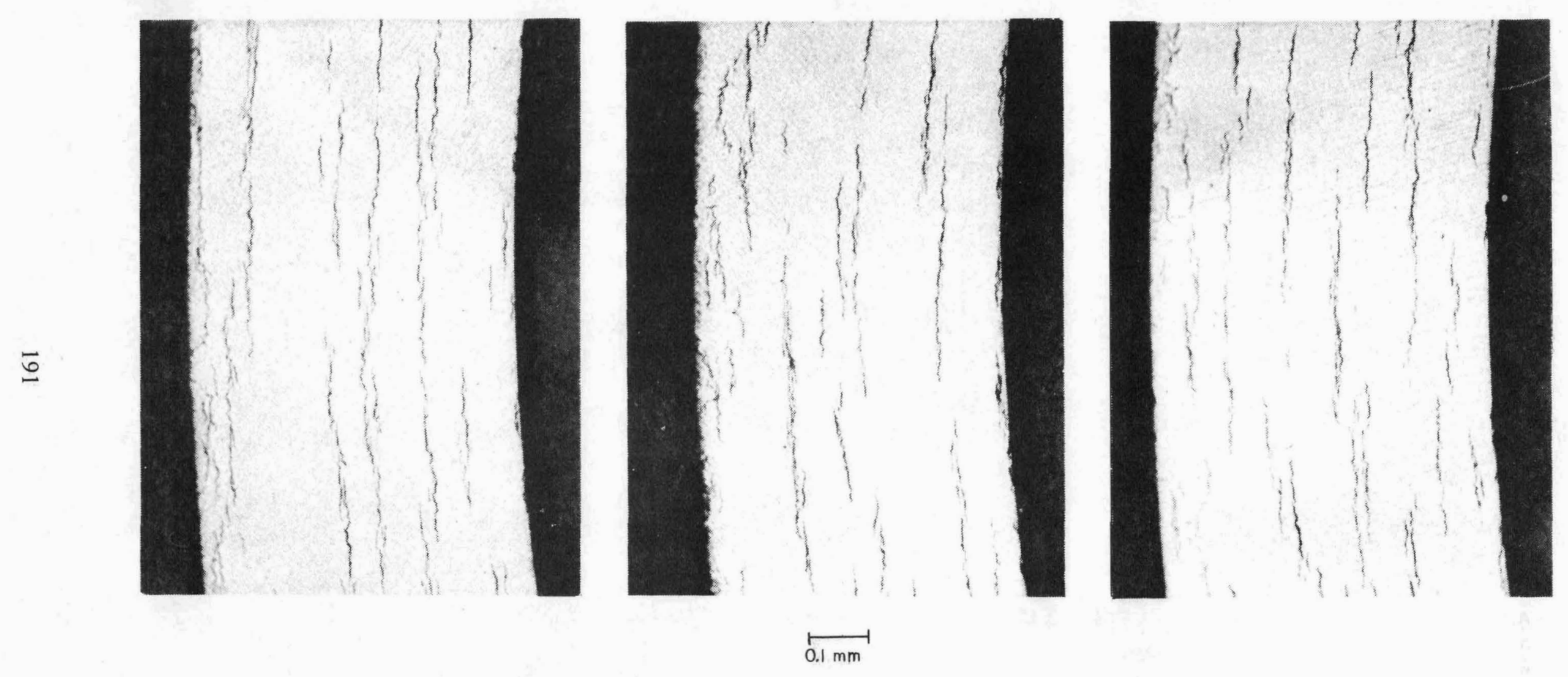

Fig. A-5 Lot 74001 hydride orientation. 
TABLE A-IX

RESULTS OF PHYSICAL AND CHEMICAL ANALYSIS OF PLAIN END PLUG BAR STOCK

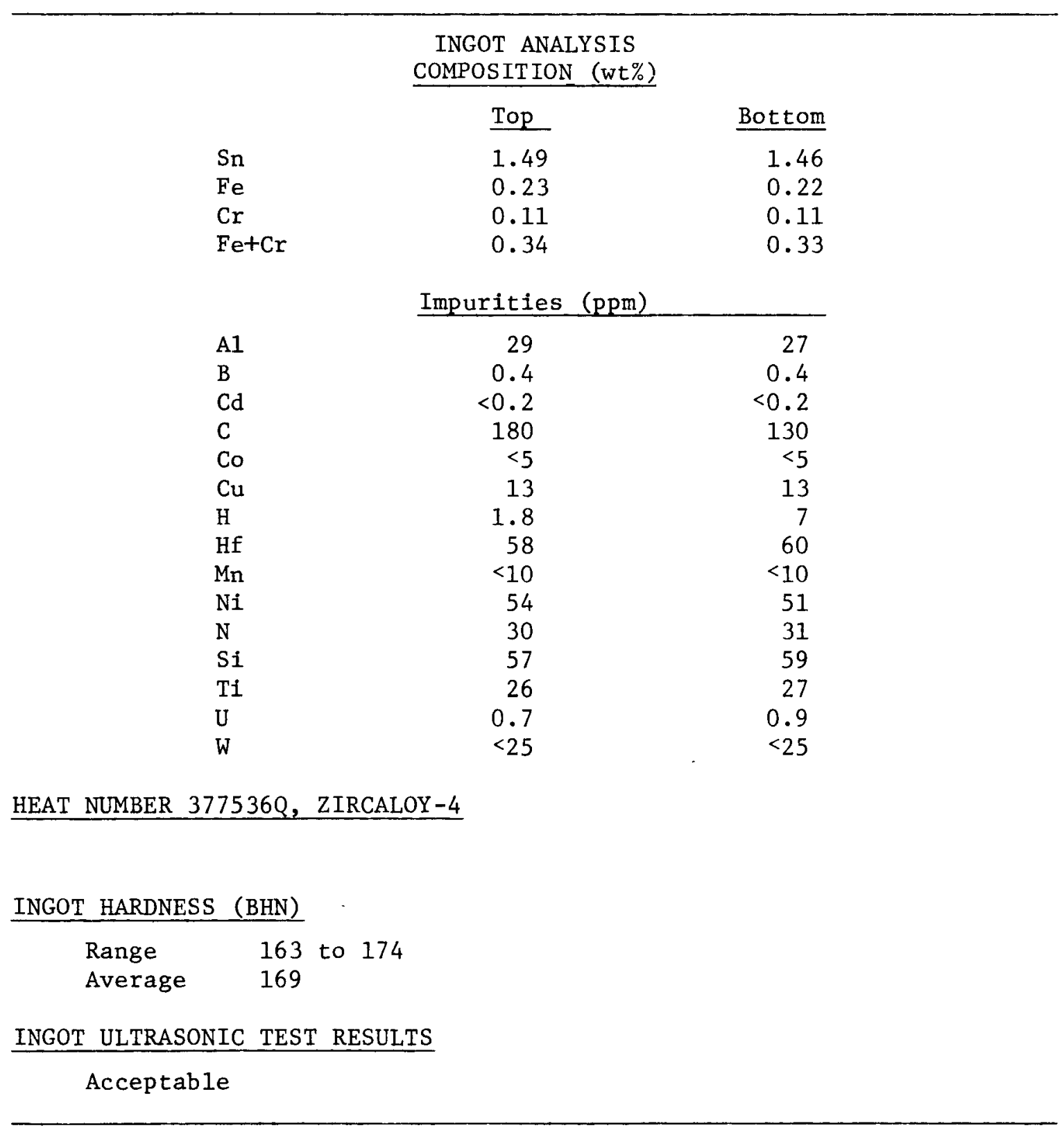




\section{TABLE A-X}

RESULTS OF CHEMICAL ANALYSIS OF HALDEN INSTRUMENTATION BAR STOCK

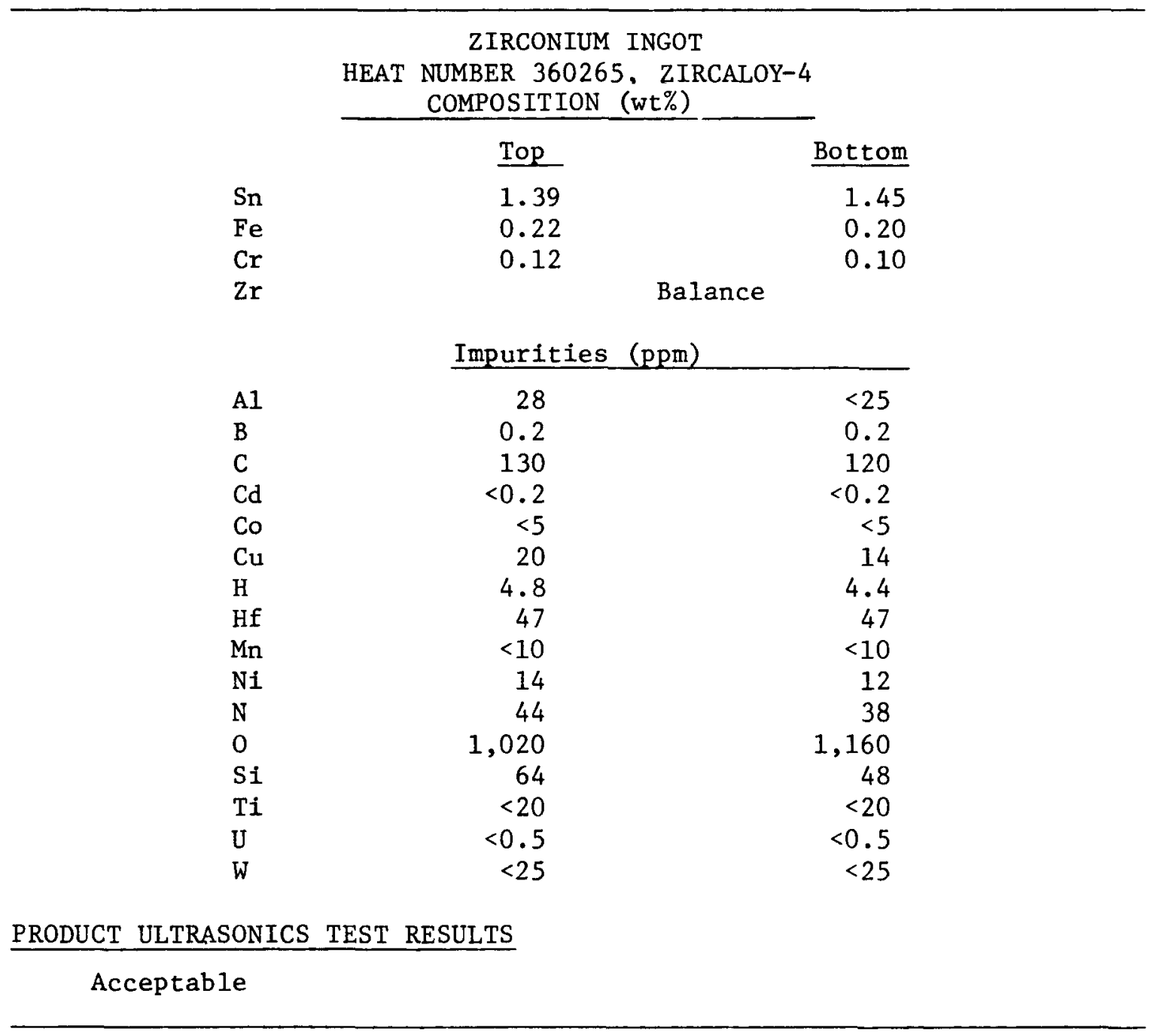


$\underline{\text { TABLE A-XI }}$

RESULTS OF PHYSICAL AND CHEMICAL ANALYSIS OF GROOVED END PLUG BAR STOCK

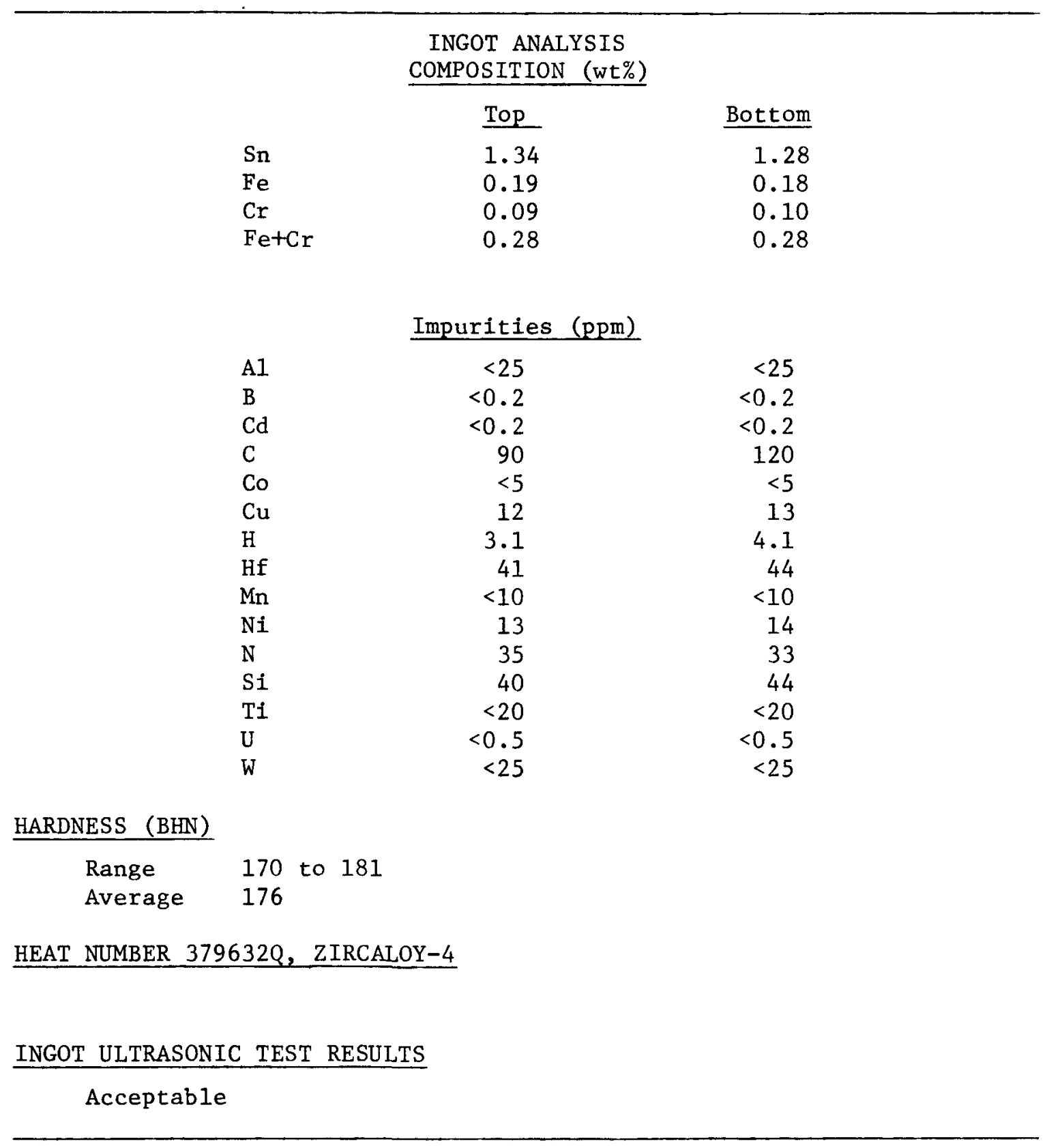




\section{ROD FABRICATION}

After the necessary cleaning of the tubing and end plugs had been completed, the test pins were assembled as follows:

(1) The bottom end plug was welded to the tubing (tungsten inert gas welding was used)

(2) The tube was loaded with fuel pellets

(3) The plenum spring was inserted

(4) The loaded tube was placed in the weld chamber and backfilled with helium at one atmosphere

(5) The top end plug was welded into place (with the exception of Rods AB, AC, $\mathrm{AD}, \mathrm{AK}$, and $\mathrm{AO}$, which had mechanical end plugs on one end and Rods AA and $\mathrm{AE}$ which had mechanical end plugs at both ends. These rods were later sealed and welded shut at the Halden project.)

At the start and finish of each welding cycle, a small weld sample was prepared for each type of end plug design. Each sample was X-rayed, cut lengthwise, examined metallographically, and corrosion tested. The results of the metallographic examinations showed that no cracks or porosity were present in the region of the end plug welds. The highest measured local wall reduction was $14 \%$, but the averige value was only $4 \%$. Figure A-6 presents two typical photomicrographs of the sample weld region.

Welded and cleaned samples from Lots 1 and 2 were corrosion tested at Battelle Memorial Institute, Columbus, Ohio. The weight gain after 3 days in $750^{\circ} \mathrm{F}, 1,500$-psi steam varied from 13.2 to $17.2 \mathrm{mg} / \mathrm{dm}^{2}$ and fell within the range often reported for good quality zircaloy -4 . The tubing appeared slightly grey, the end caps were lustrous black and an intermittent white oxide band was observed at the weld-tubing fusion line after the corrosion test. The intermittent oxide band was found to be the result of superficial contamination on the surface.

The end plug welds were also examined radiographically. Several defective welds appeared, most of which were due to an undercut of the inside diameter. Those welds which exhibited full wall thickness with no evidence of porosity as shown on the radiograph were considered to be satisfactory. Only one rod showed porosity (Rod AM), and was subsequently repaired by welding. All the rods were pickled just before shipment to Halden (approximately 0.003 in. of material was removed).

During the fabrication process, several diameter and density measurements were made of the finished pellets and zircaloy tubing. The results of these measurements are presented in Tables A-XII and A-XIII. The axial profiles of the pellet diameter and the cladding inside diameter were determined for selected rods and are presented in Figures A-6 through A-12. 

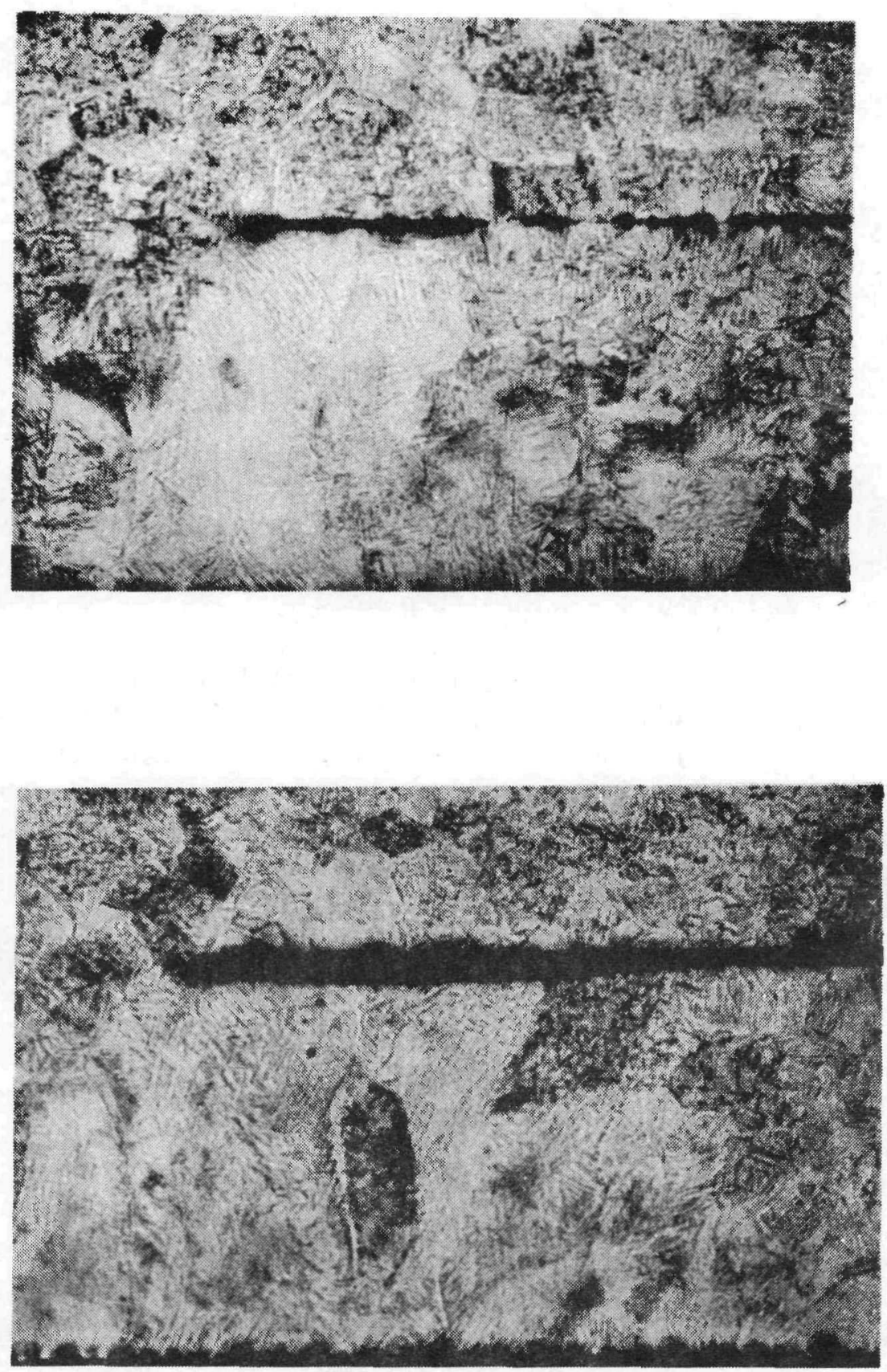

Fig. A-6 Typical weld metallography of cladding. 


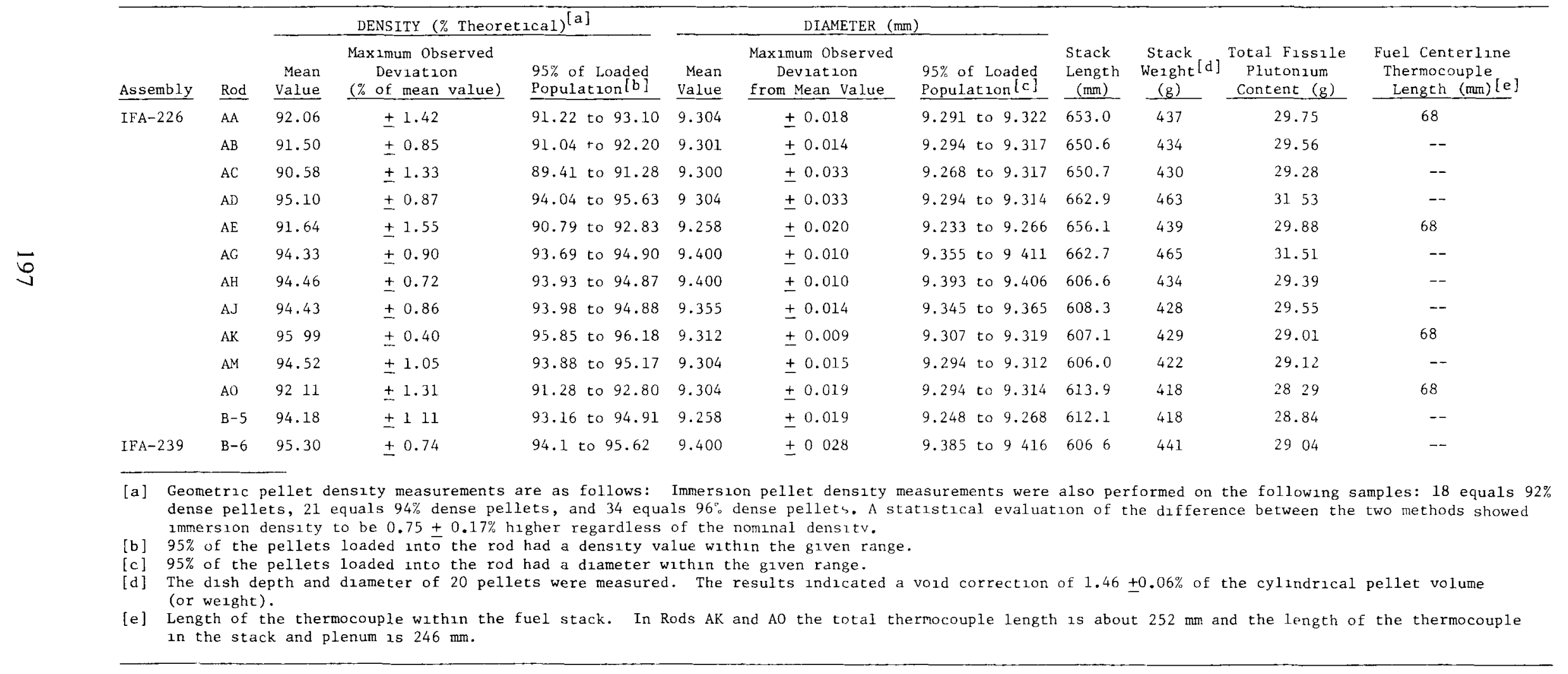


TABLE A-XIII

TUBE AND PLENUM DATA

\begin{tabular}{|c|c|c|c|c|c|c|c|c|c|c|}
\hline \multirow[b]{2}{*}{ Assemb ly } & \multirow[b]{2}{*}{ Rod } & \multicolumn{7}{|c|}{ TUBE DATA ${ }^{[\mathrm{a}]}(\mathrm{mm})$} & \multirow[b]{2}{*}{$\begin{array}{l}\text { Plenum [b] } \\
\text { Length } \\
(\mathrm{mm}) \\
\end{array}$} & \multirow[b]{2}{*}{$\begin{array}{l}\text { Tubing } \\
\text { Lot No. }\end{array}$} \\
\hline & & Mean OD & $\begin{array}{c}\text { Maximum Observed } \\
\text { Deviation } \\
\text { from Mean OD } \\
\end{array}$ & Mean ID & $\begin{array}{c}\text { Maximum Observed } \\
\text { Deviation } \\
\text { from Mean ID } \\
\end{array}$ & Ovality & $\begin{array}{r}\operatorname{Maxi} \\
\text { from } \\
\end{array}$ & $\begin{array}{l}\text { imum Observed } \\
\text { Deviation } \\
\text { Ovality Value }\end{array}$ & & \\
\hline \multirow[t]{12}{*}{ IFA-226 } & $\mathrm{AA}$ & 10.69 & \pm 0.002 & 9.510 & \pm 0.0046 & 0.0020 & & \pm 0.0046 & 135 & 74001 \\
\hline & $\mathrm{AB}$ & 10.65 & \pm 0.025 & 9.515 & \pm 0.0070 & 0.0020 & & \pm 0.0089 & 131 & 74001 \\
\hline & $\mathrm{AC}$ & 10.66 & \pm 0.016 & 9.507 & \pm 0.0069 & 0.0018 & & \pm 0.0064 & 134 & 74001 \\
\hline & $A D$ & 10.64 & \pm 0.037 & 9.515 & \pm 0.0060 & 0.0008 & & \pm 0.0046 & 121 & 74001 \\
\hline & $\mathrm{AE}$ & 10.68 & \pm 0.025 & 9.515 & \pm 0.0076 & 0.0010 & & \pm 0.0041 & 126 & 74001 \\
\hline & $A G$ & 10.68 & \pm 0.016 & 9.500 & \pm 0.0058 & 0.0025 & & \pm 0.0041 & 125 & 84003 \\
\hline & $\mathrm{AH}$ & 10.69 & \pm 0.008 & 9.492 & \pm 0.0050 & 0.0025 & & \pm 0.0051 & 177 & 84003 \\
\hline & AJ & 10.67 & \pm 0.000 & 9.495 & \pm 0.0050 & 0.0025 & & \pm 0.0051 & 177 & 84003 \\
\hline & $\mathrm{AK}$ & 10.67 & \pm 0.041 & 9.512 & \pm 0.0038 & 0.0025 & & \pm 0.0051 & 178 & 74001 \\
\hline & $\mathrm{AM}$ & 10.68 & \pm 0.073 & 9.502 & \pm 0.0043 & 0.0025 & & \pm 0.0051 & 180 & 84003 \\
\hline & $\mathrm{AO}$ & 10.66 & \pm 0.008 & 9.515 & \pm 0.0036 & 0.0012 & & \pm 0.0036 & 172 & 74001 \\
\hline & $B-5$ & 10.67 & \pm 0.081 & 9.510 & \pm 0.0076 & 0.0012 & & \pm 0.0102 & 174 & 84003 \\
\hline IFA-239 & $B-6$ & 10.69 & \pm 0.010 & 9.507 & \pm 0.0046 & 0.0008 & & \pm 0.0076 & 183 & 84003 \\
\hline \multicolumn{11}{|c|}{$\begin{array}{l}\text { [a] All tubing was made of zircaloy-4. } \\
\text { [b] Plenum spring OD }=9.35 \mathrm{~mm} \\
\text { Plenum spring wire diameter }=1.30 \mathrm{~mm} \\
\text { Each plenum spring had } 20 \text { turns. }\end{array}$} \\
\hline
\end{tabular}




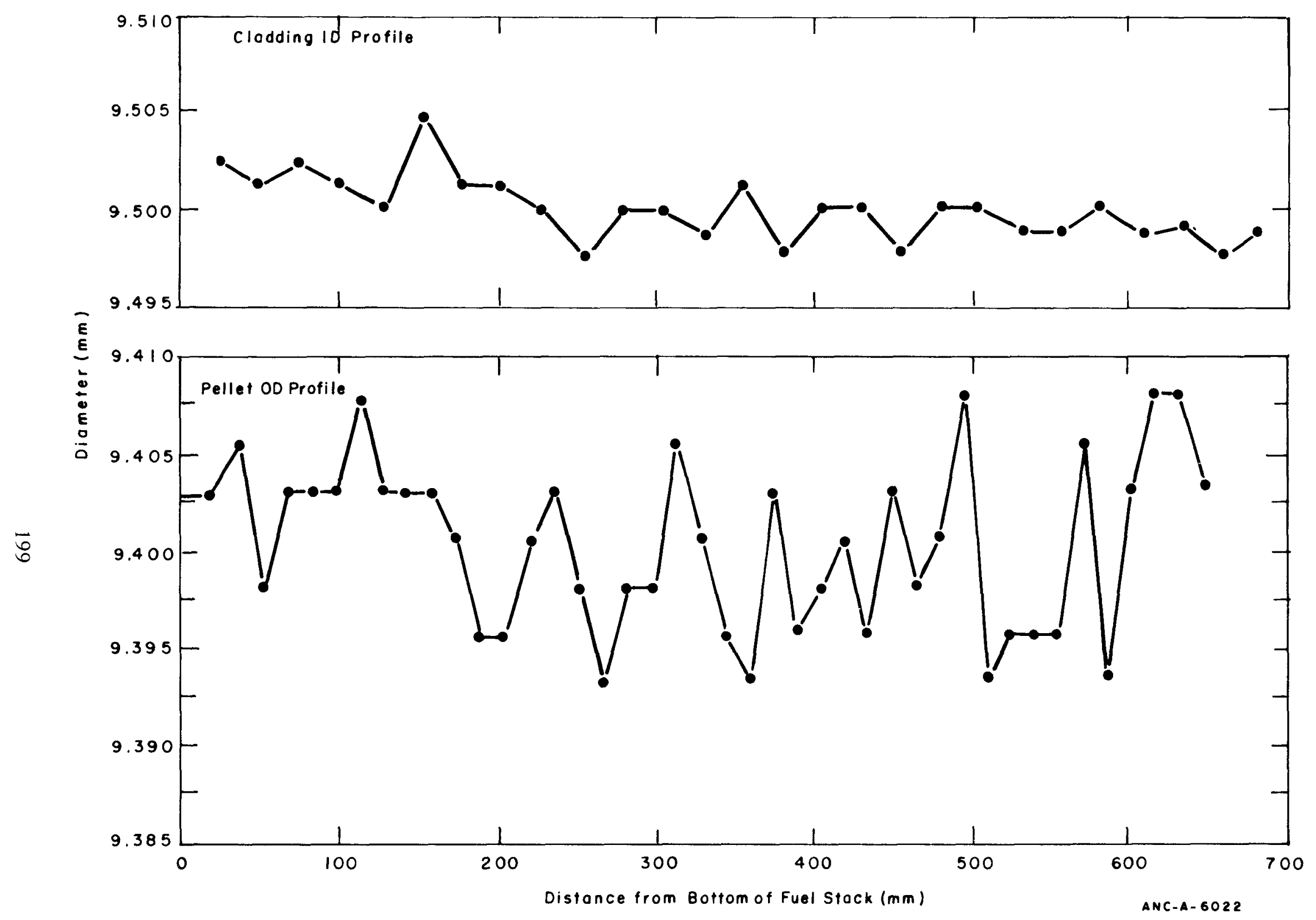

Fig. A-7 Dimensional profile of Rod AG. 

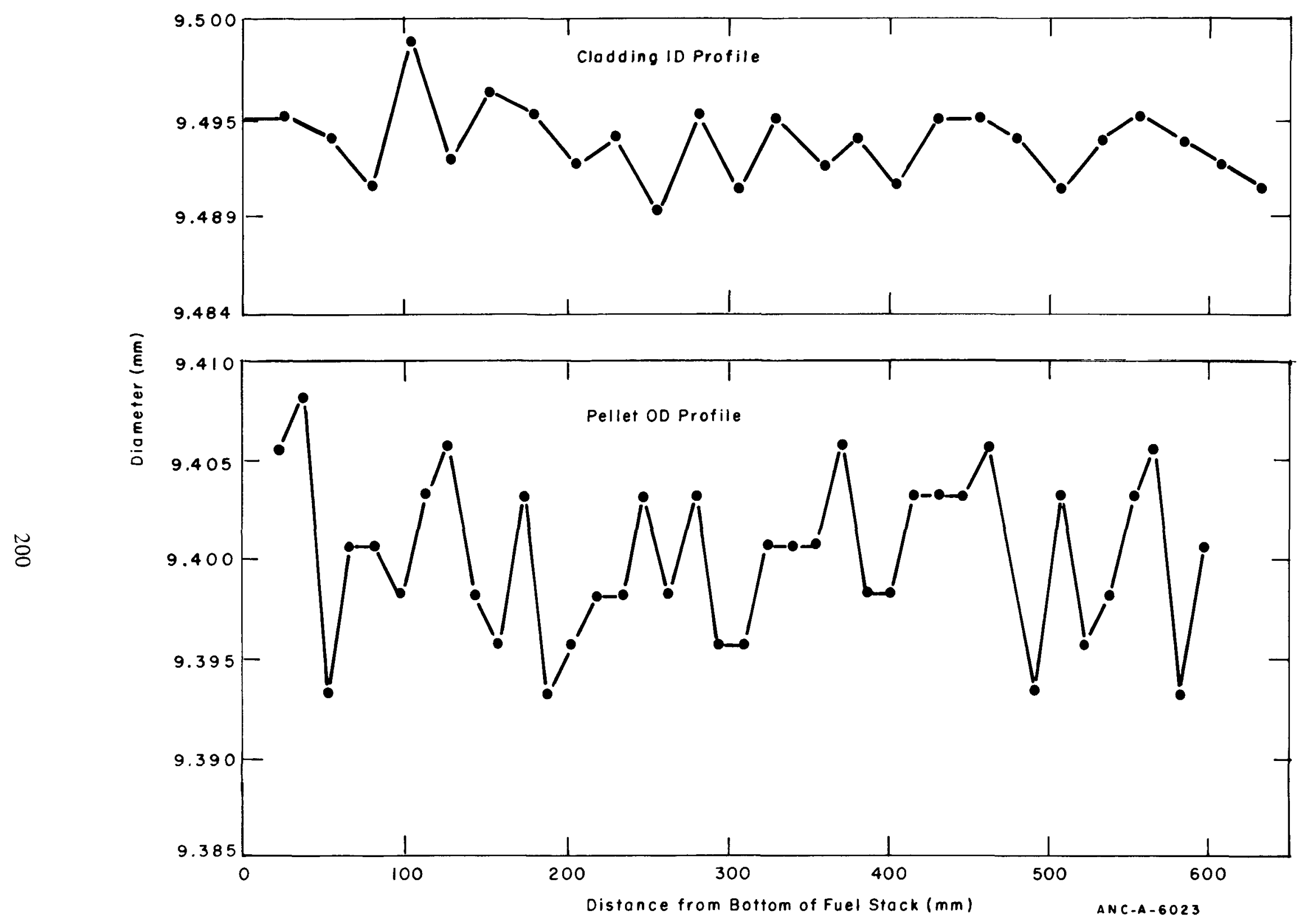

Fig. A-8 Dimensional profile of Rod AH. 

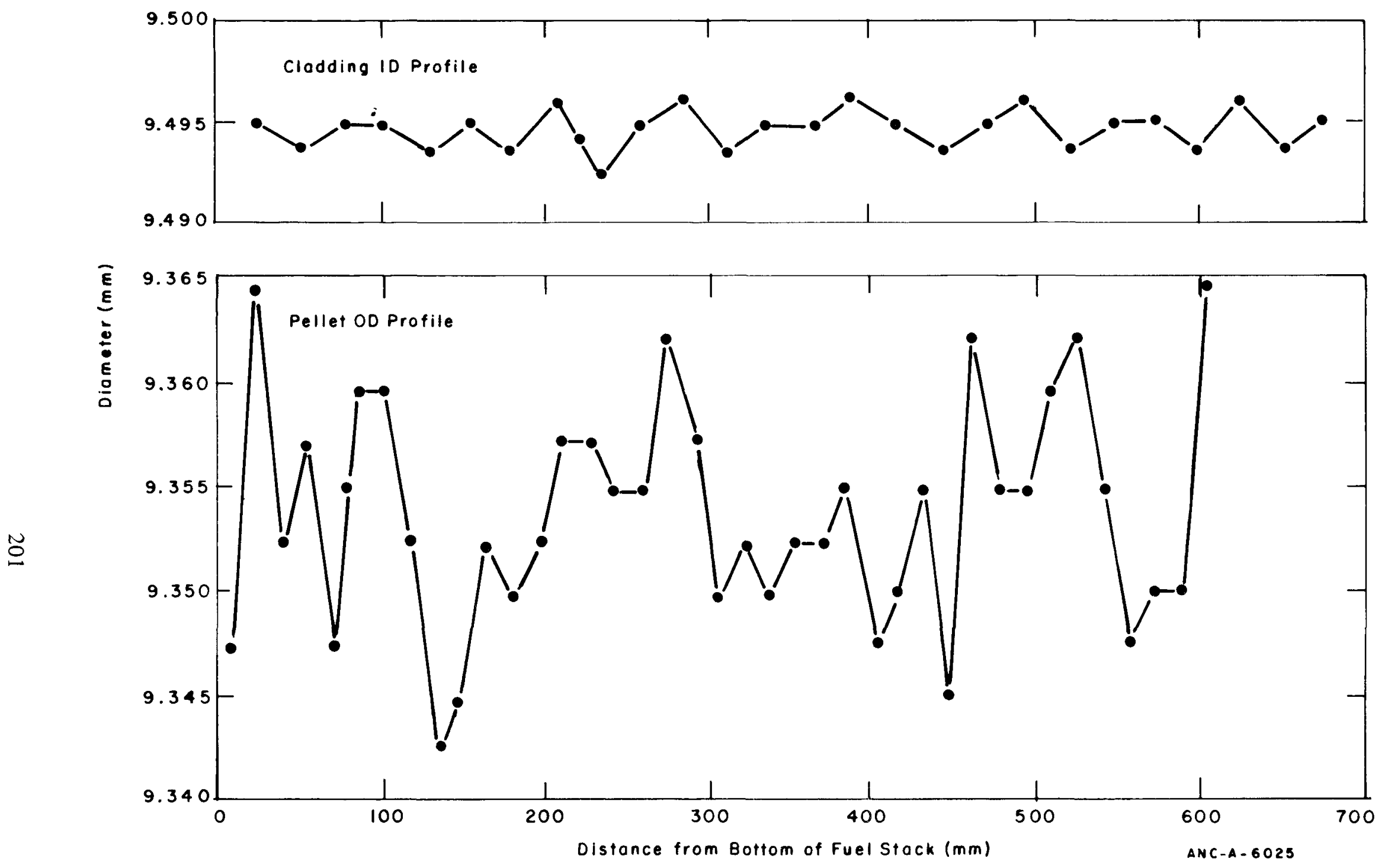

Fig. A-9 Dimensiona1 profile of Rod AJ. 


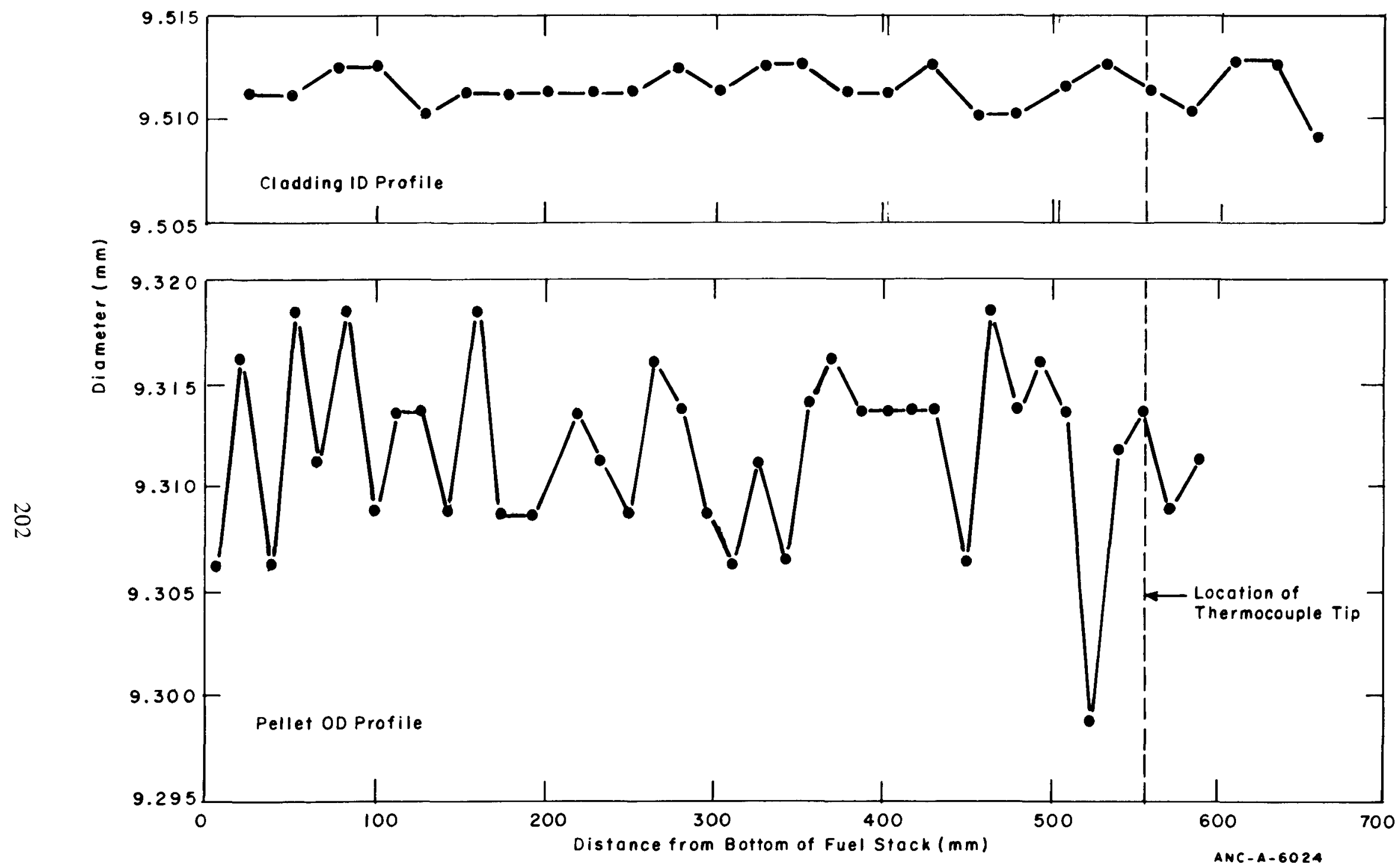

Fig. A-10 Dimensional profile of Rod AK. 

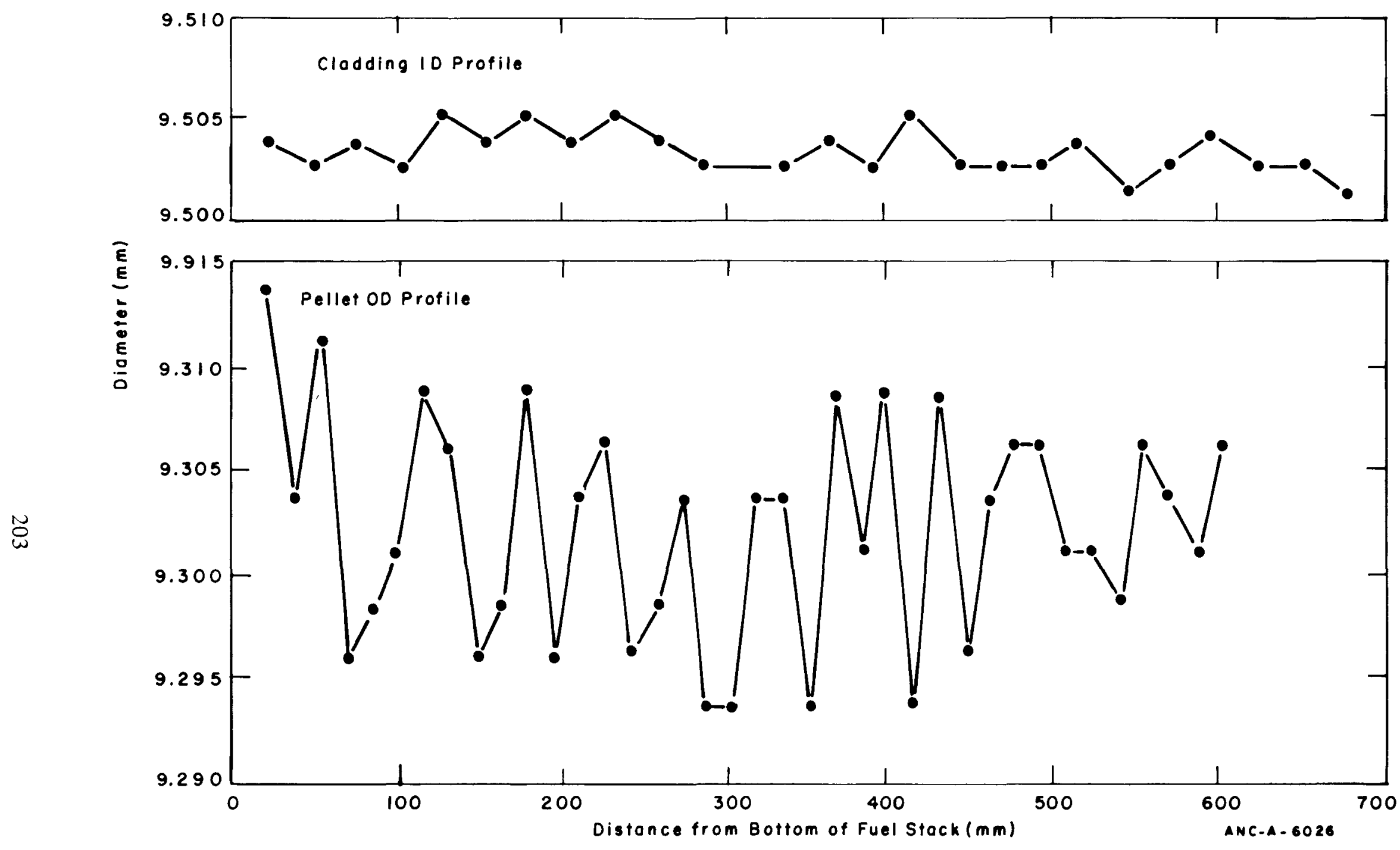

Fig. A-11 Dimensional profile of Rod AM. 


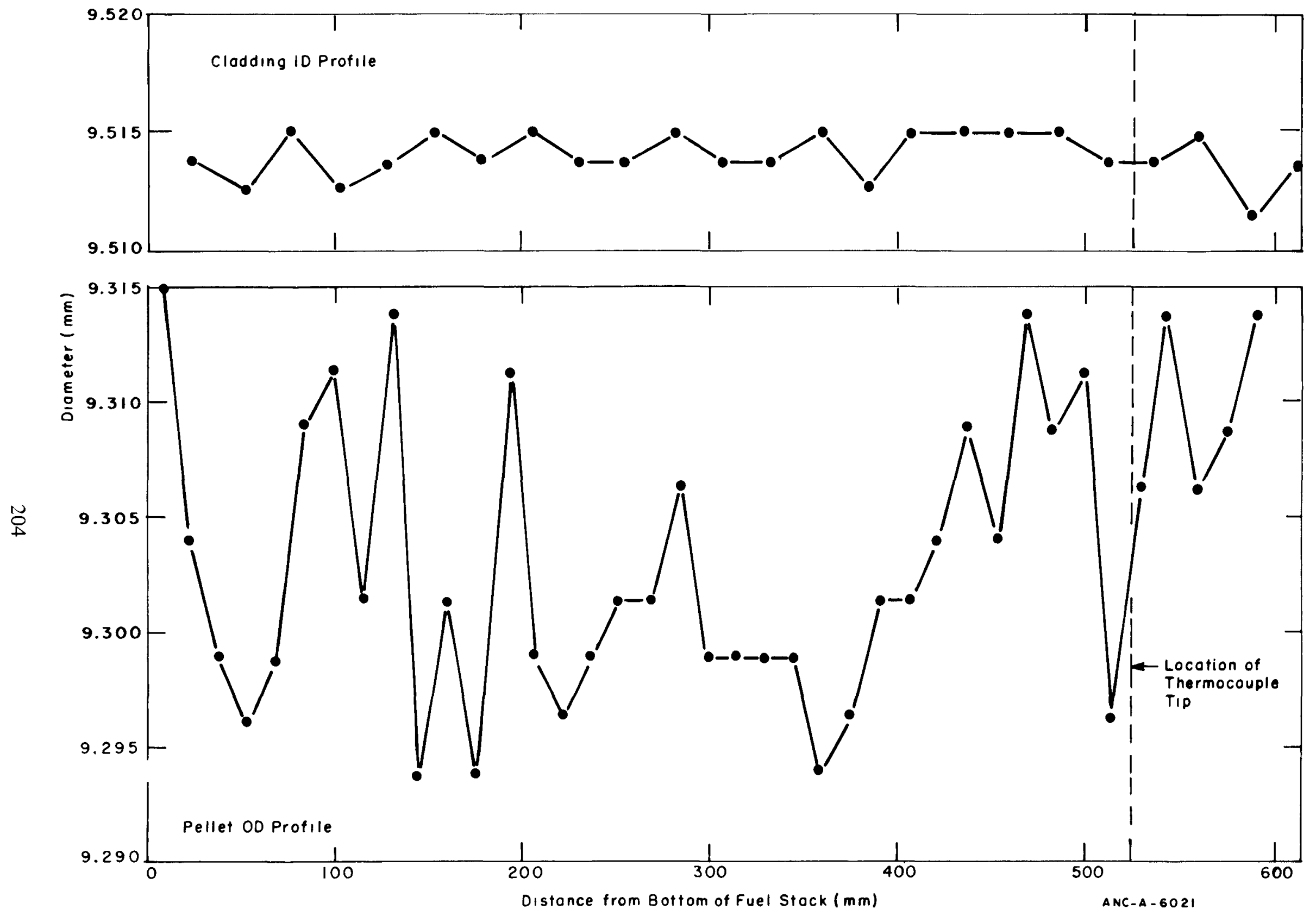

Fig. A-12 Dimensional profile of Rod AO. 


\section{INSTRUMENTATION INSERTION}

After the test rods had been successfully fabricated and tested, the rods were shipped to the Halden reactor project. The fuel centerline thermocouple and pressure sensor instrumentation were then added to the appropriate rods by the OECD Halden reactor project staff. The end plugs were welded into place, examined radiographically and metallographically, and subjected to a steam corrosion test. Upon successful completion of these tests, the test rods were deemed acceptable and were subsequently mounted in the test assembly. Table A-XIV presents pertinent data describing the finished assembly.

TABLE A-XIV

FINISHED ASSEMBLY DATA

\begin{tabular}{lcc}
\hline & IFA-226 & IFA-239 \\
Number of Clusters & 2 & 1 \\
Number of Rods per Cluster & 6 & 1 \\
Pitch Distance (mm) & 46 & - \\
Shroud Material & Aluminum & Stainless Steel \\
Shroud ID (mm) & 71 & 71 \\
\hline
\end{tabular}


○ 
APPENDIX B

CALIBRATION RESULTS 


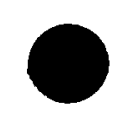

,

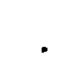




\section{APPENDIX B}

\section{CALIBRATION RESULTS}

This appendix briefly describes the calibration procedure for the various instruments in the IFA-226 and IFA-239 test assemblies and presents the calibration constants for those instruments.

\section{CLADDING ELONGATION SENSOR CALIBRATION}

The elongation sensors (differential transformers) were calibrated prior to installation in the test assembly. These preinstallation tests were conducted in order to determine the sensitivity characteristics ( $\mathrm{mV}$ output versus elongation in $\mathrm{mm}$ ) of each sensor. The measured values were obtained at room temperature and at $240^{\circ} \mathrm{C}$ in air. The values at $240^{\circ} \mathrm{C}$ are used for signal conversion when the cladding elongation is reported in millimeters.

The results of the preinstallation tests of the IFA-226 sensors at $240^{\circ} \mathrm{C}$ are shown in Figures B-1 through B- 6 . The results at $240^{\circ} \mathrm{C}$ for the IFA-239 sensor were not available for this report. However, some data which were obtained at room temperature are presented in Figure B-7.

\section{FUEL CENTERLINE THERMOCOUPLE CALIBRATION}

No direct calibration of fuel centerline thermocouples was made. But an indication of the accuracy can be determined from the data at very low reactor power where the temperature difference between the fuel center and the moderator is small. At these powers and temperatures, the output from all thermocouples is nearly identical at beginning-of-life, about $25^{\circ} \mathrm{C}$ above moderator temperature, and no major discrepancies are observed. The difference between the measured temperature and the moderator temperature reduces to about $20^{\circ} \mathrm{C}$ at about $160^{\circ} \mathrm{C}$ moderator temperature. Also, the fuel centerline temperature versus power curves extrapolate to about the coolant saturation temperature $\left(240^{\circ} \mathrm{C}\right)$. This is true not only at beginning-of-life, but also throughout the lifetime of the thermocouples.

After the reactor had been shut down for 1.5 hours following a period of high power

operation (at beginning-of-life), and thermal equilibrium had been reached between the fuel and the moderator, the thermocouples indicated nearly identical temperatures with respect to each other and to the moderator temperature. The conclusion can, therefore, be reached from these results that the fuel centerline thermocouples were performing reasonably well. 


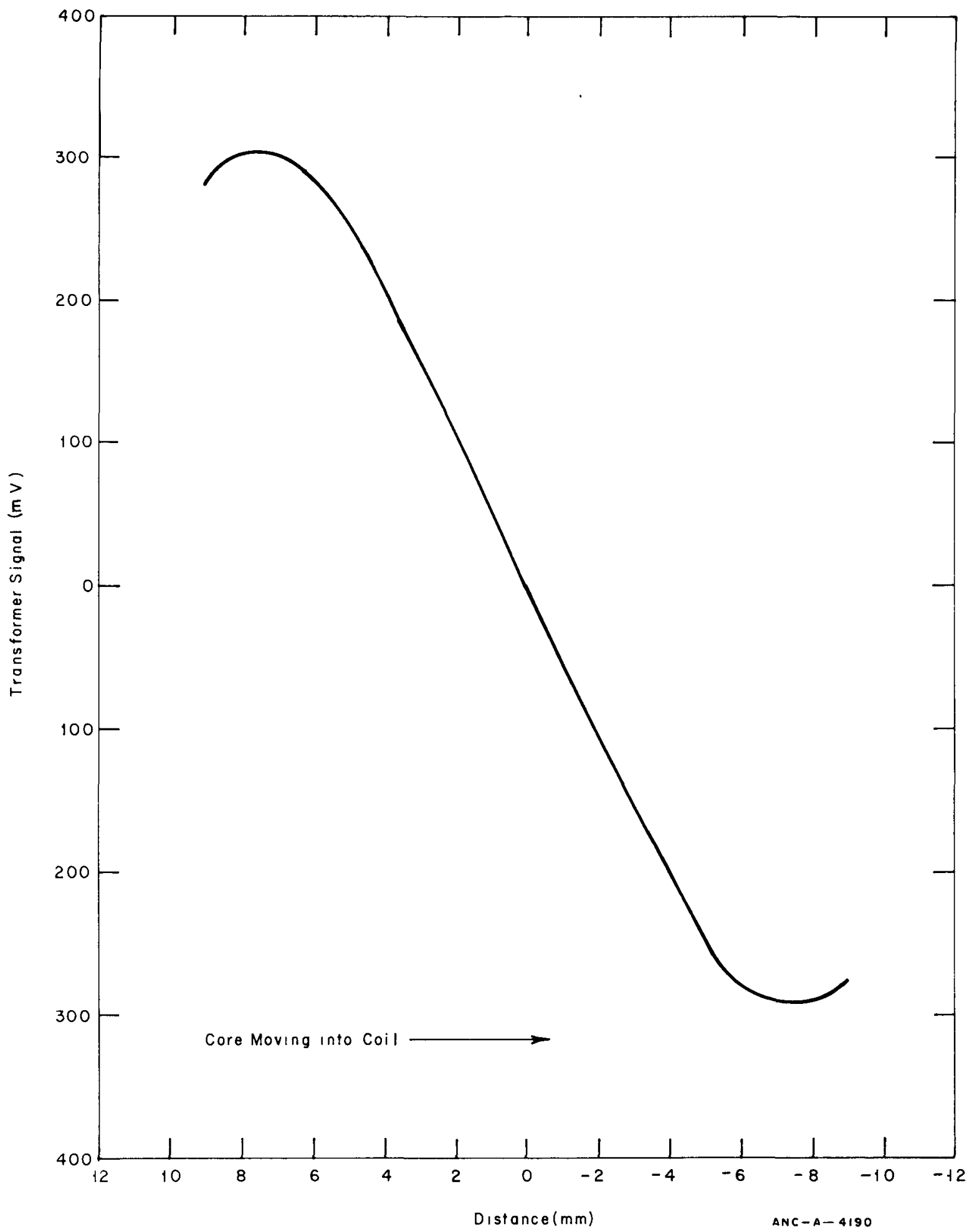

Fig. B-1 Calibration curve at $240^{\circ} \mathrm{C}$ for the elongation sensor on IFA-226 Test Rod AG. 


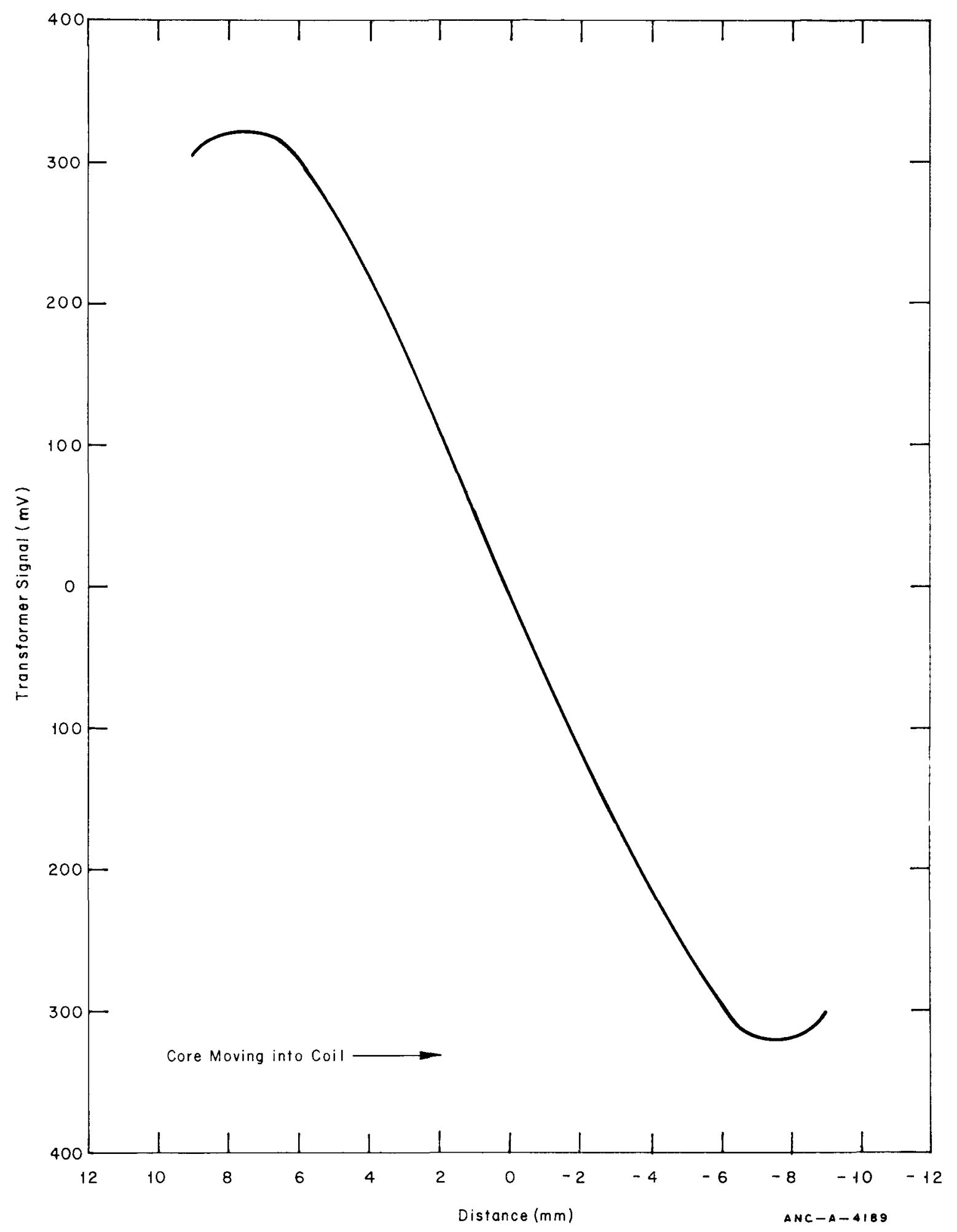

Fig. B-2 Calibration curve at $240^{\circ} \mathrm{C}$ for the elongation sensor on IFA-226 Test Rod AH. 


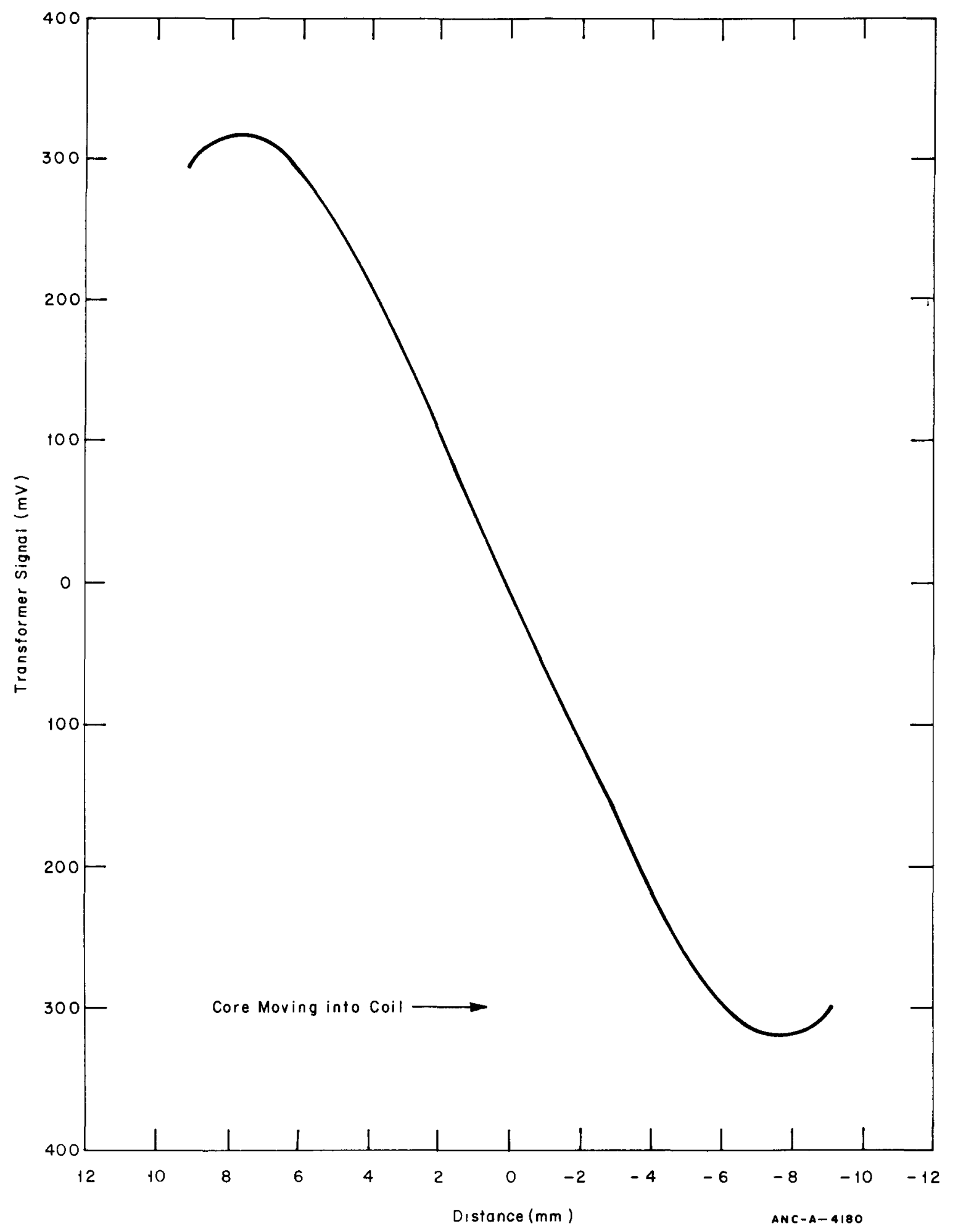

Fig. B-3 Calibration curve at $240^{\circ} \mathrm{C}$ for the elongation sensor on IFA- 226 Test Rod AJ. 


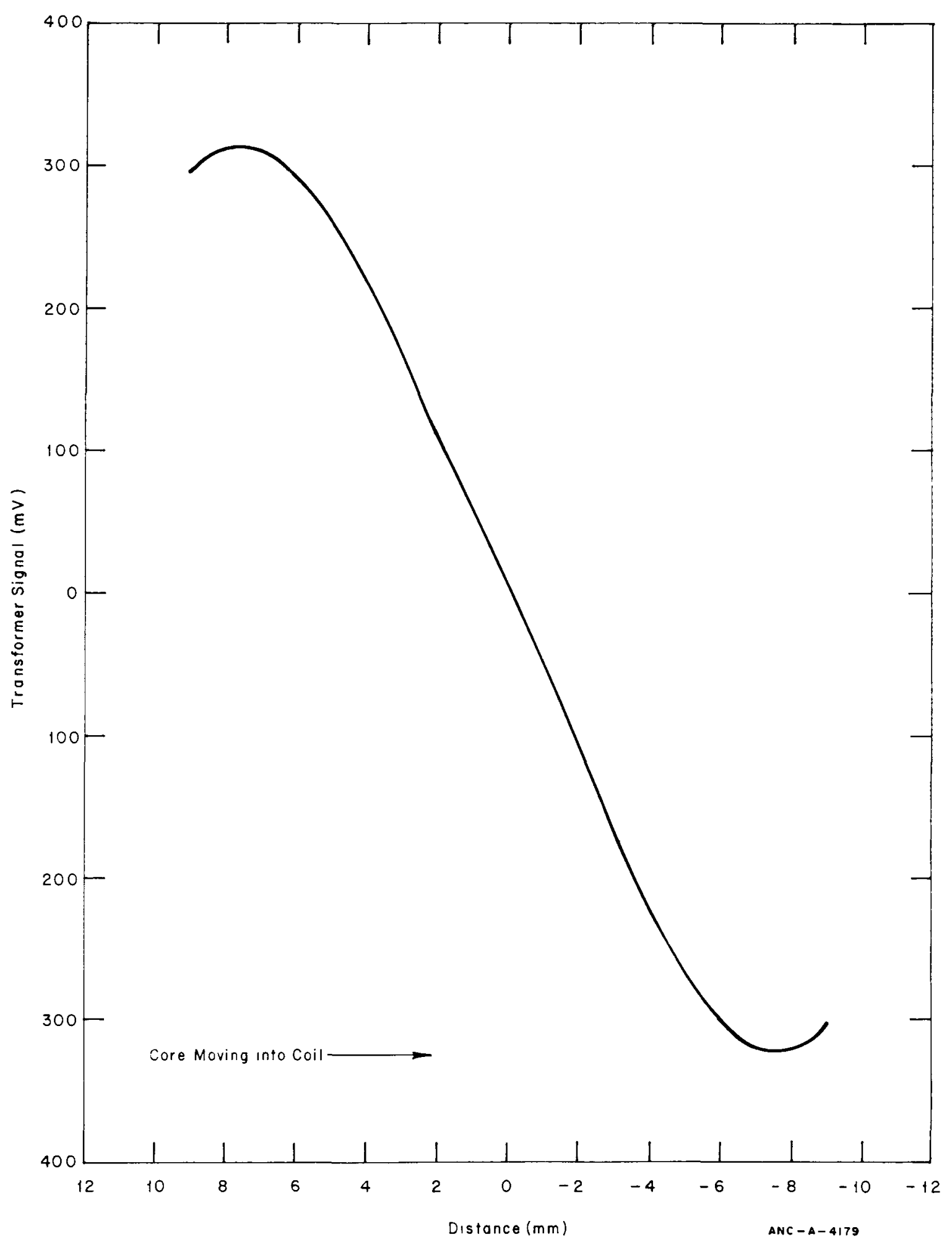

Fig. B-4 Calibration curve at $240^{\circ} \mathrm{C}$ for the elongation sensor on IFA-226 Test Rod AK. 


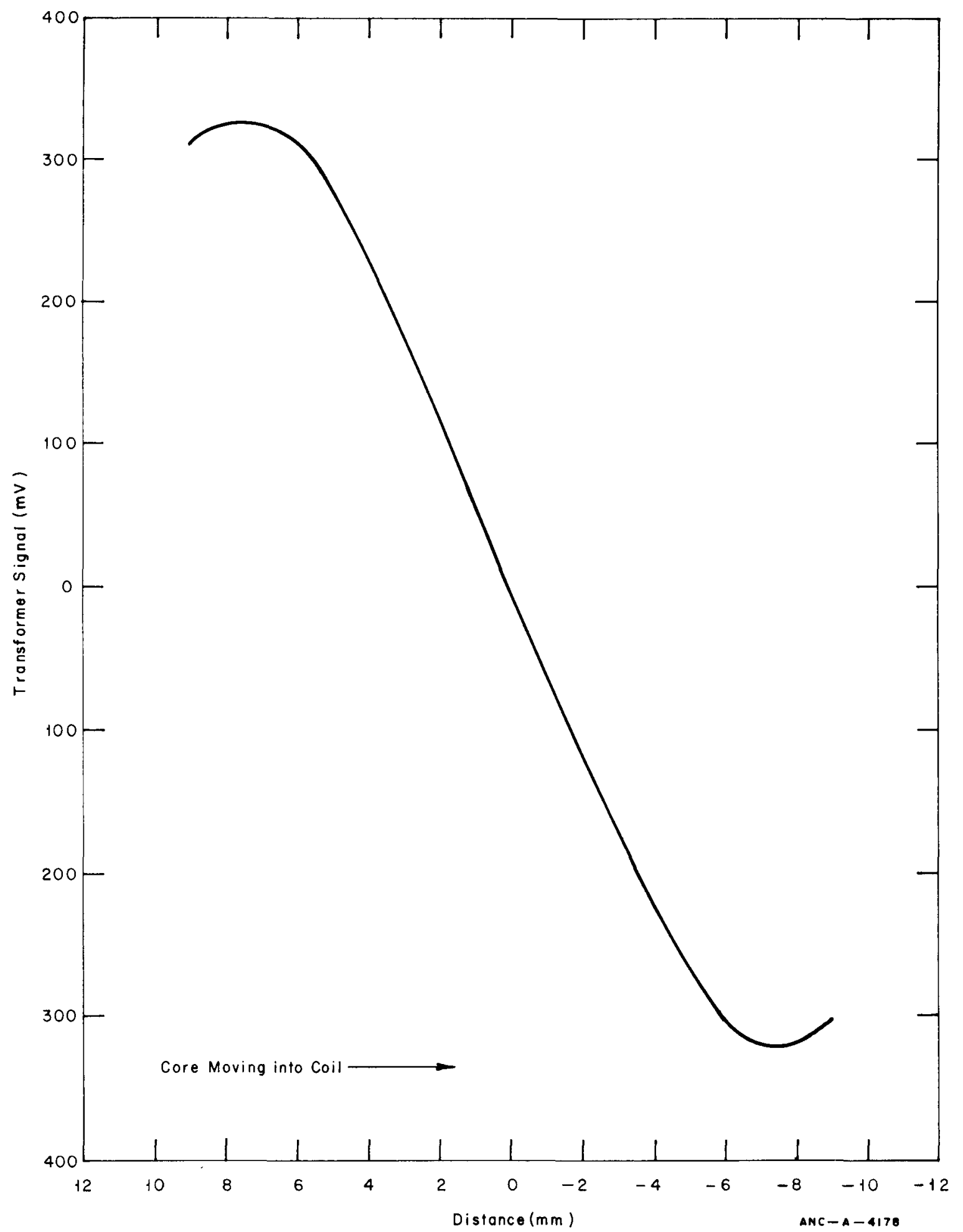

Fig. B-5 Calibration curve at $240^{\circ} \mathrm{C}$ for the elongation sensor on IFA-226 Test Rod AM. 


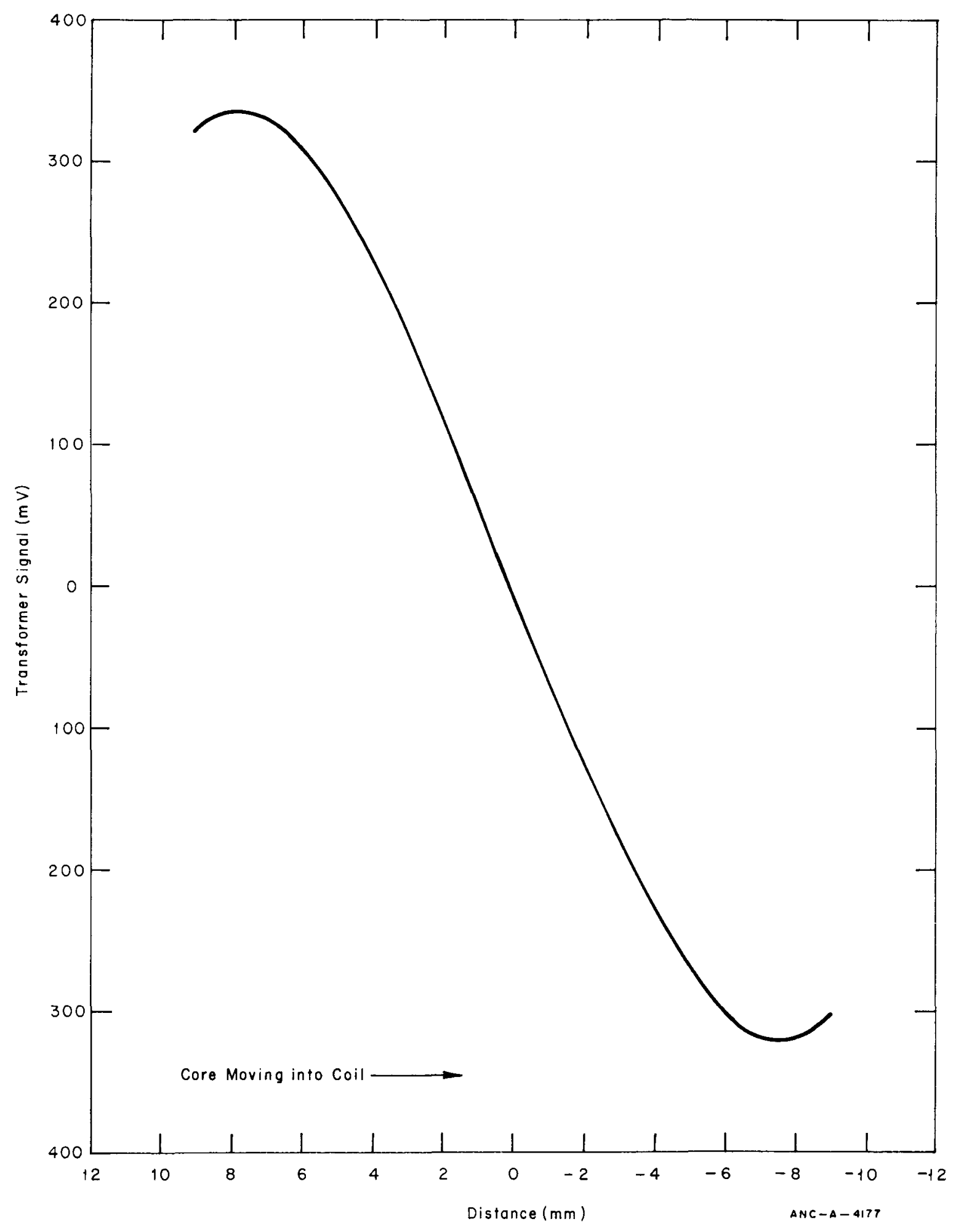

Fig. B-6 Calibration curve at $240^{\circ} \mathrm{C}$ for the elongation sensor on IFA-226 Test Rod A0. 


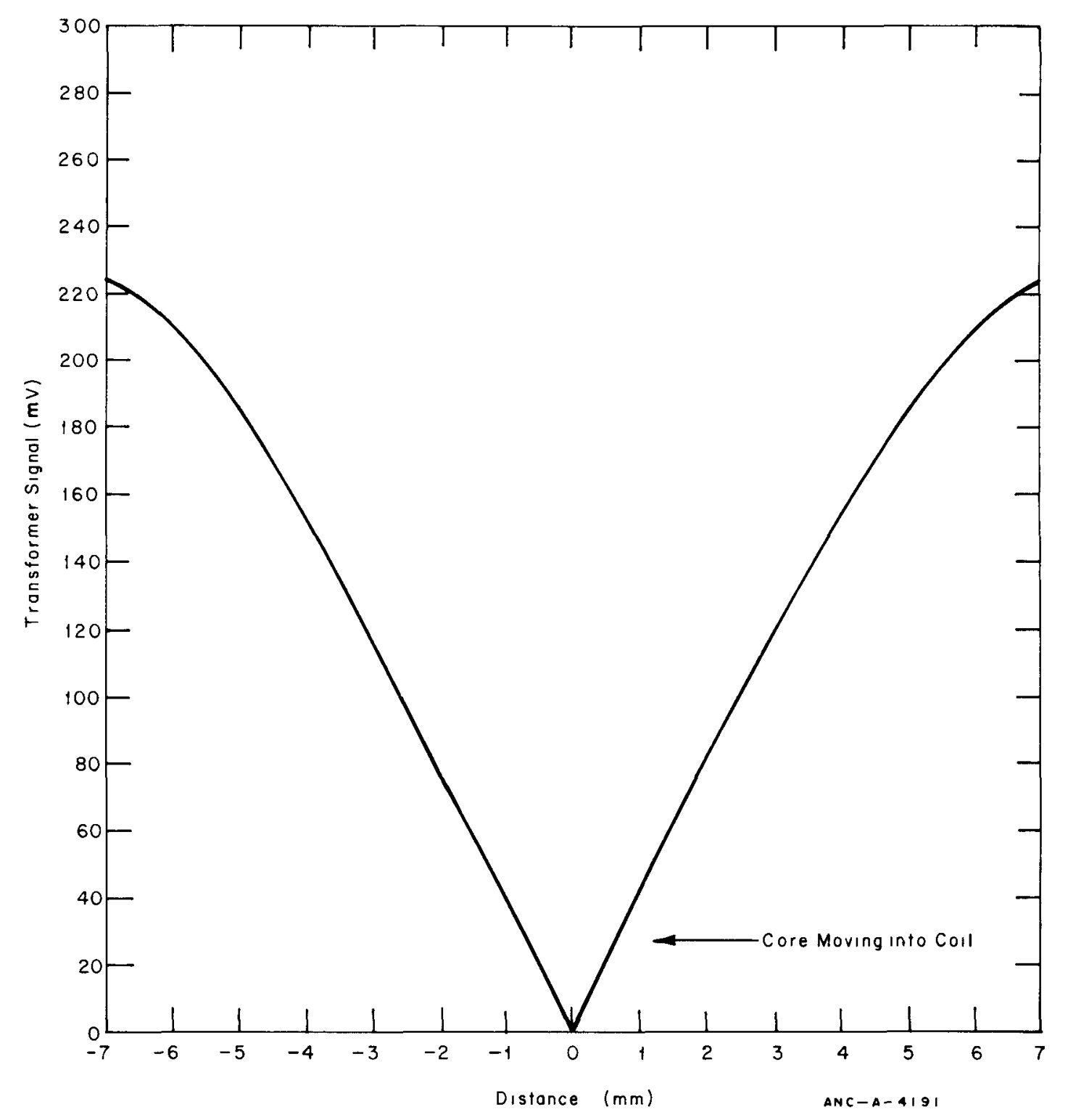

Fig. B-7 Calibration curve at $240^{\circ} \mathrm{C}$ for the elongation sensor on IFA-226 Test Rod B-6. 
A wiring diagram of the fuel centerline thermocouple configuration is presented in Figure B-8.

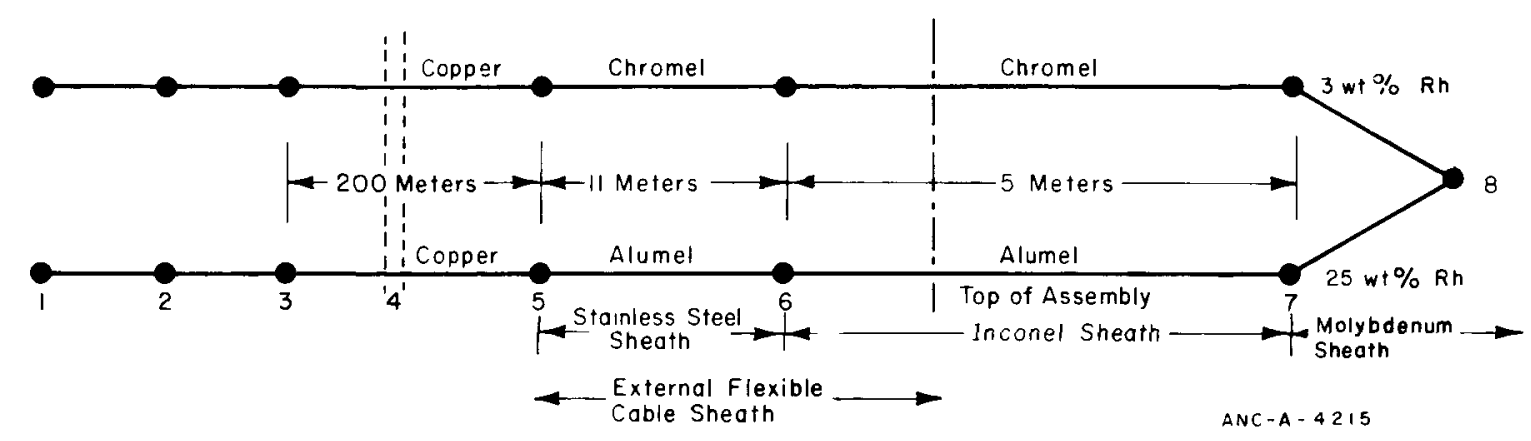

Fig. B-8 Wiring diagram of a fuel centerline thermocouple.

\section{TURBINE FLOWMETER CALIBRATION}

The inlet and outlet turbine flowmeters for IFA-226 and the inlet turbine flowmeter for IFA-239 were calibrated prior to installation into their respective assemblies. This calibration was accomplished by utilizing the output from a digital clock and a pulse counter connected to each flowmeter. When a prescribed quantity of water had flowed through the assembly equal to the tare weight on the scale holding the collection tank, the counter and clock were stopped and the turbine flowmeter pulse rate was determined.

At least two measurements were made at each water quantity with the calibration valve in the natural circulation position, and at least two measurements with the valve in the forced circulation position. The repeatability of the pulse count versus water quantity was very good, less than $1 \%$ difference between all measurements of a particular water quantity. In Figure B-9, the individual flowmeter signals converted to pulses/ 1 are plotted versus $1 / \mathrm{sec}$ for IFA-226.

The data shown in Figure B-9 for the outlet turbine flowmeter indicated no major performance difference between the natural and forced circulation operations. This lack of difference in performance is to be expected because any entrance effects caused by the position of the calibration valve should not be detectable at the location of the outlet turbine flowmeter. The data for the inlet turbine do indicate a difference between natural and forced circulation operations. The spread in the data at high flow rates $(>1.51 / \mathrm{sec})$ is less than $1 \%$. Since the typical inlet velocity of IFA-226 is about $21 / \mathrm{sec}$, the spread in the calibration data at this velocity was about $0.5 \%$, which was assumed negligible.

The calibration data for the turbine flowmeter in IFA-239 also indicated the same degree of repeatability of the pulse count versus water quantity. This repeatability was observed when operation was in either the natural or forced circulation mode. 


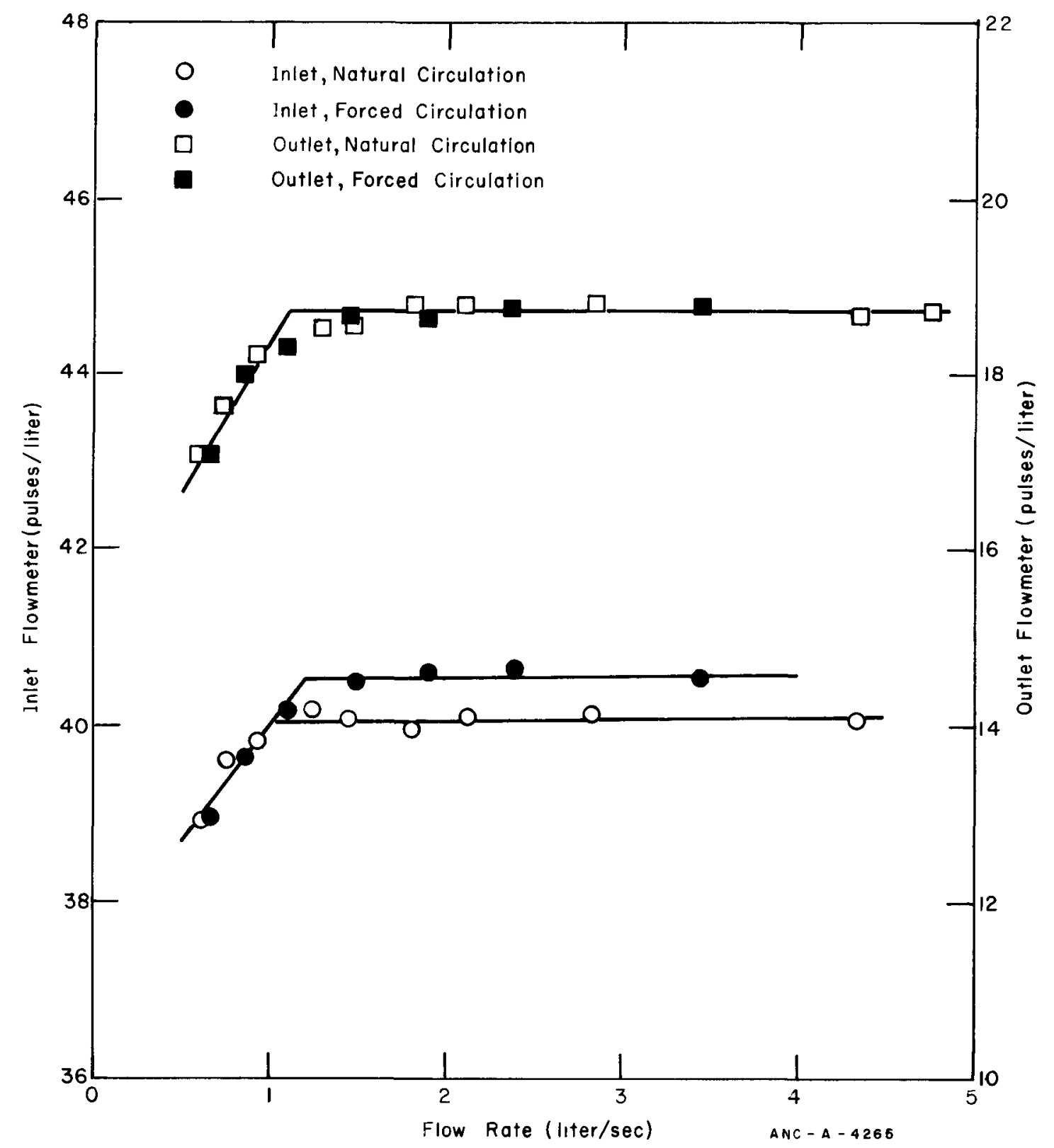

Fig. B-9 Calibration curves for the IFA-226 inlet and outlet flowmeters.

During the startup period, an intercalibration of the inlet and outlet turbine flowmeters in IFA-226 was performed while the assembly was operating in the forced circulation mode. This intercalibration suggested that an entrance length effect occurred during operation of the inlet turbine flowmeter in forced circulation. Due to these entrance effects, the inlet turbine flowmeter indicated a $2 \%$ higher flow than the outlet turbine flowme ter. 


\section{FISSION GAS PRESSURE TRANSDUCER CALIBRATION}

The Halden pressure transducers used in the IFA-226 assembly were calibrated individually out-of-pile prior to installation (welding) onto the test rods. As stated in Section III, the basic sensing mechanism in the transducer is a thin membrane which is, on one side, exposed to fission and fill gas of unknown pressure, and the other side is exposed to externally controlled helium gas pressure. The pressure balance across the membrane is indicated by the opening and closing of a circuit which is formed between the membrane and a contact normally resting against the membrane.

The switch point sensitivity of each transducer was measured as a function of temperature and pressure. These data are presented in Figures B-10 through B-14. The transducers exhibited very good switch point constancy over wide ranges of pressures and temperatures. The single exception was Transducer PF5 (Rod AE). The calibration performance by Transducer PF5 was not good, but the in-pile performance appears to be acceptable. 

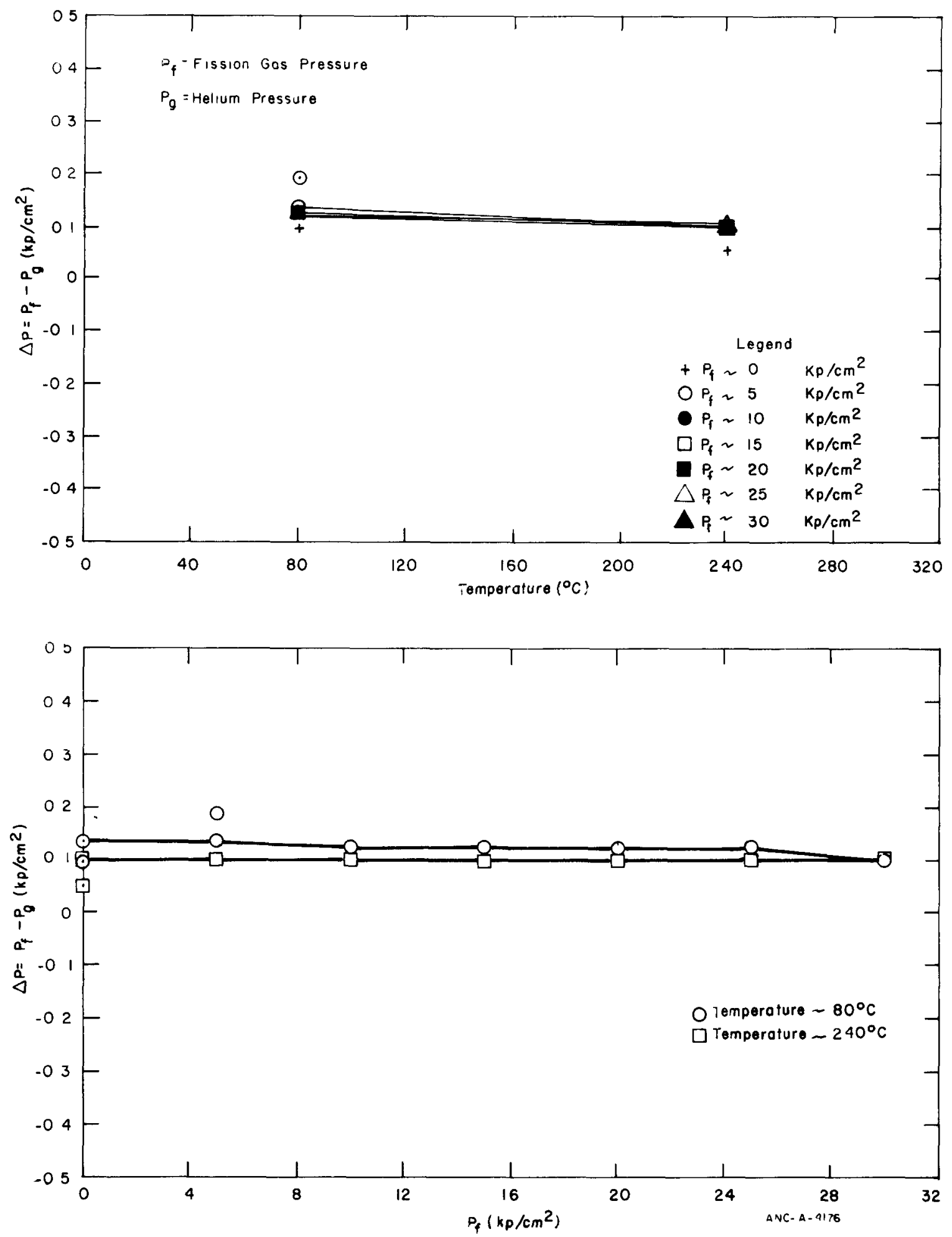

Fig. B-10 Switch point consistency of the pressure transducer in Rod AA. 

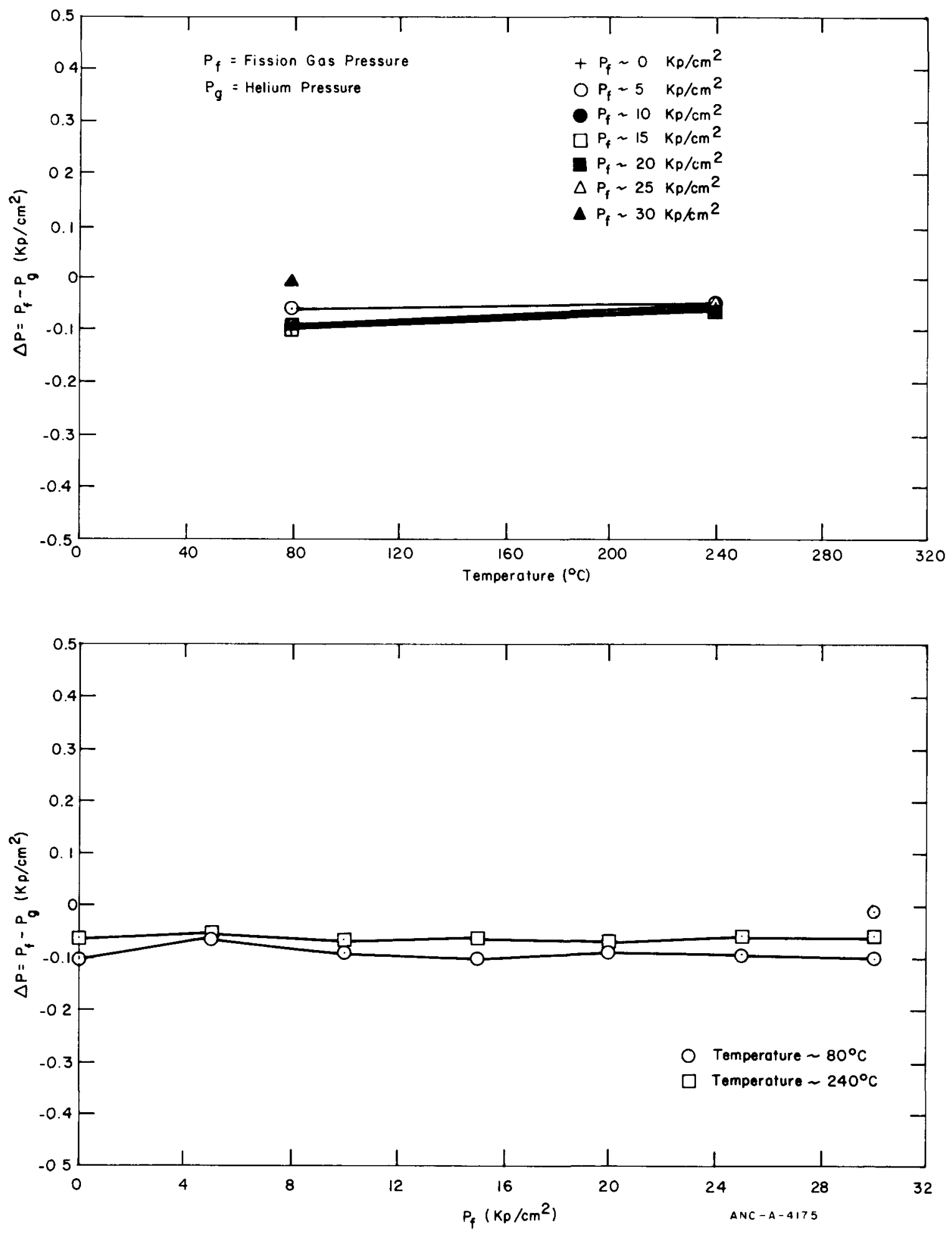

Fig. B-11 Switch point consistency of the pressure transducer in Rod $A B$. 

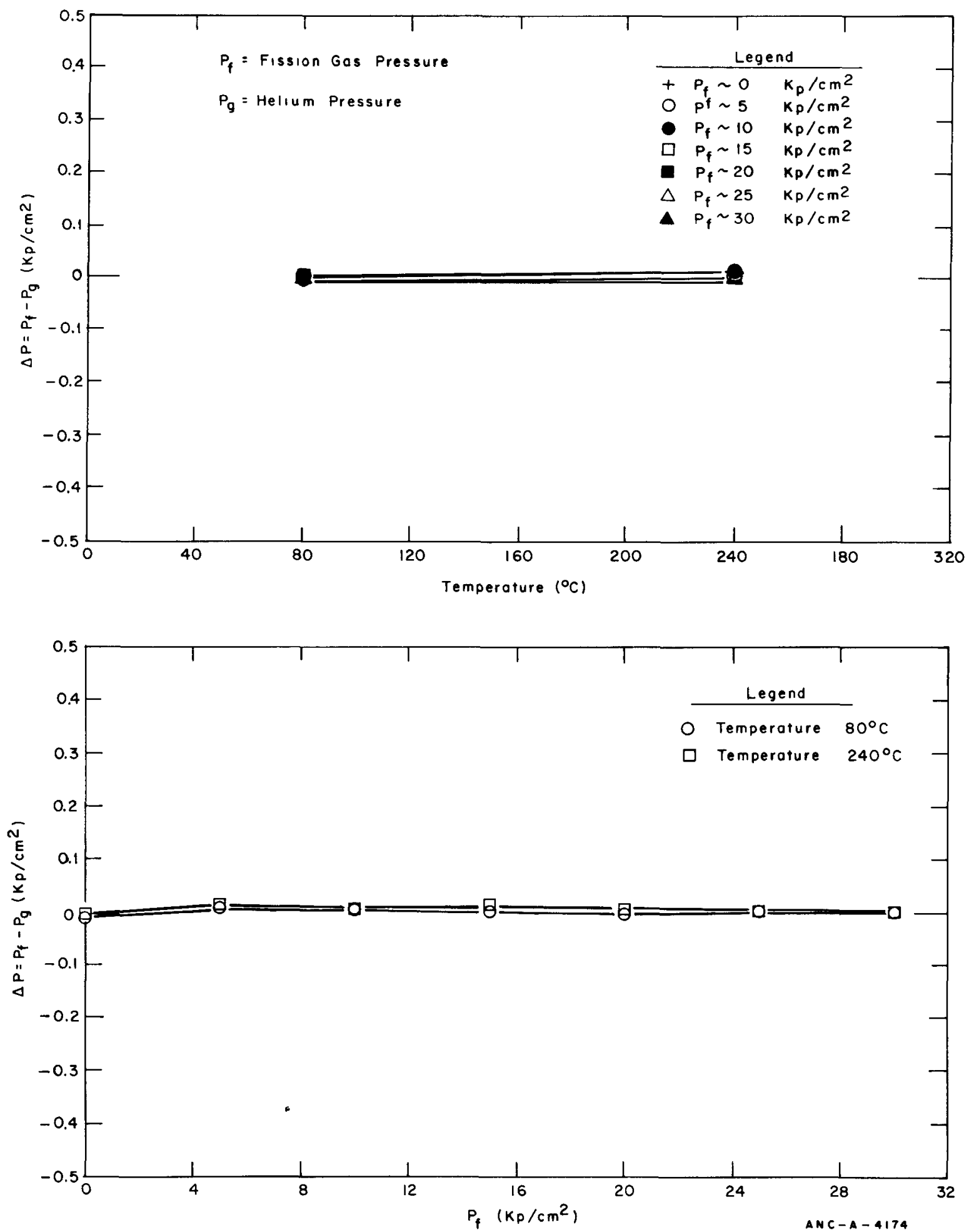

Fig. B-12 Switch point consistency of the pressure transducer in Rod AC. 

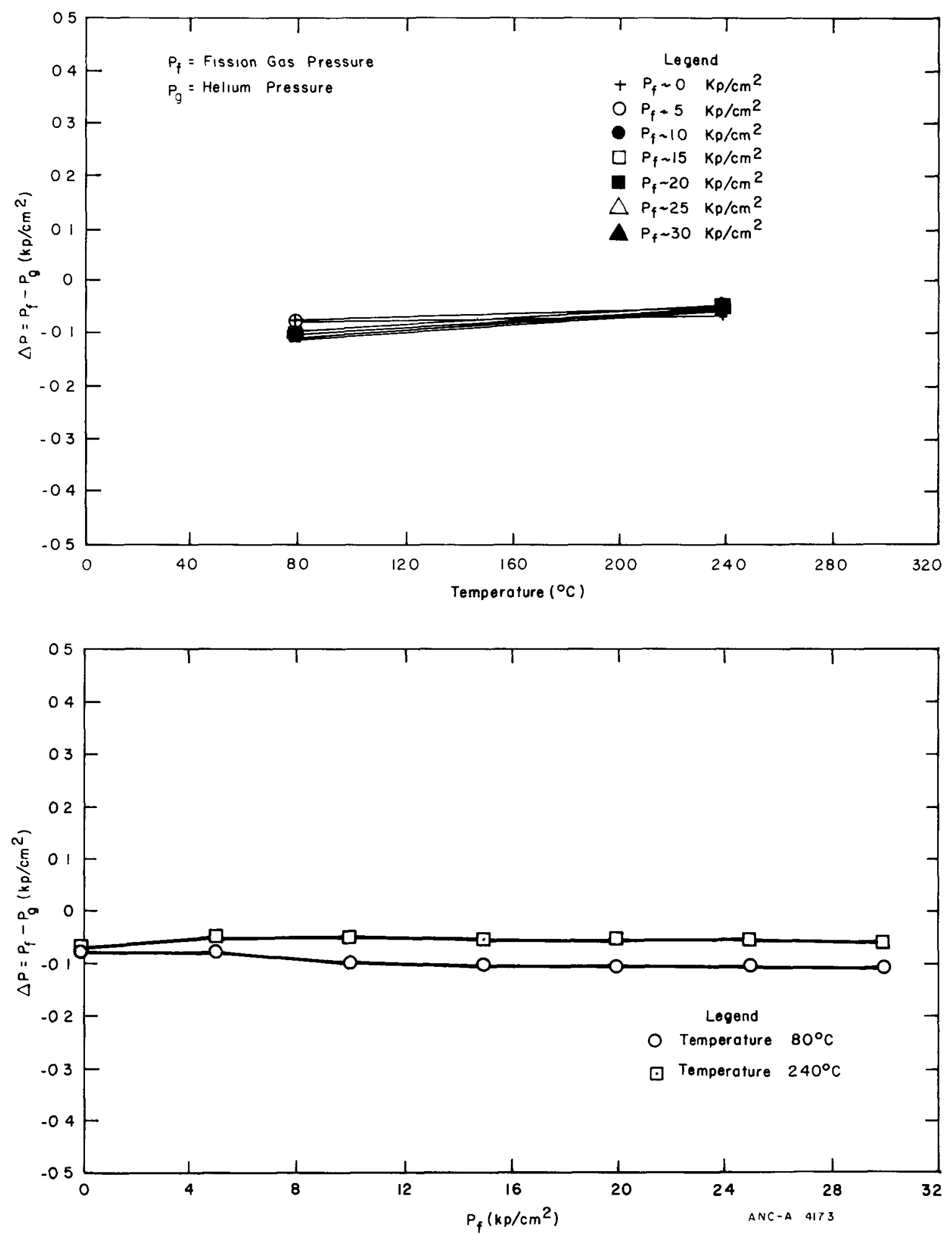

Fig. B-13 Switch point consistency of the pressure transducer in Rod $A D$. 

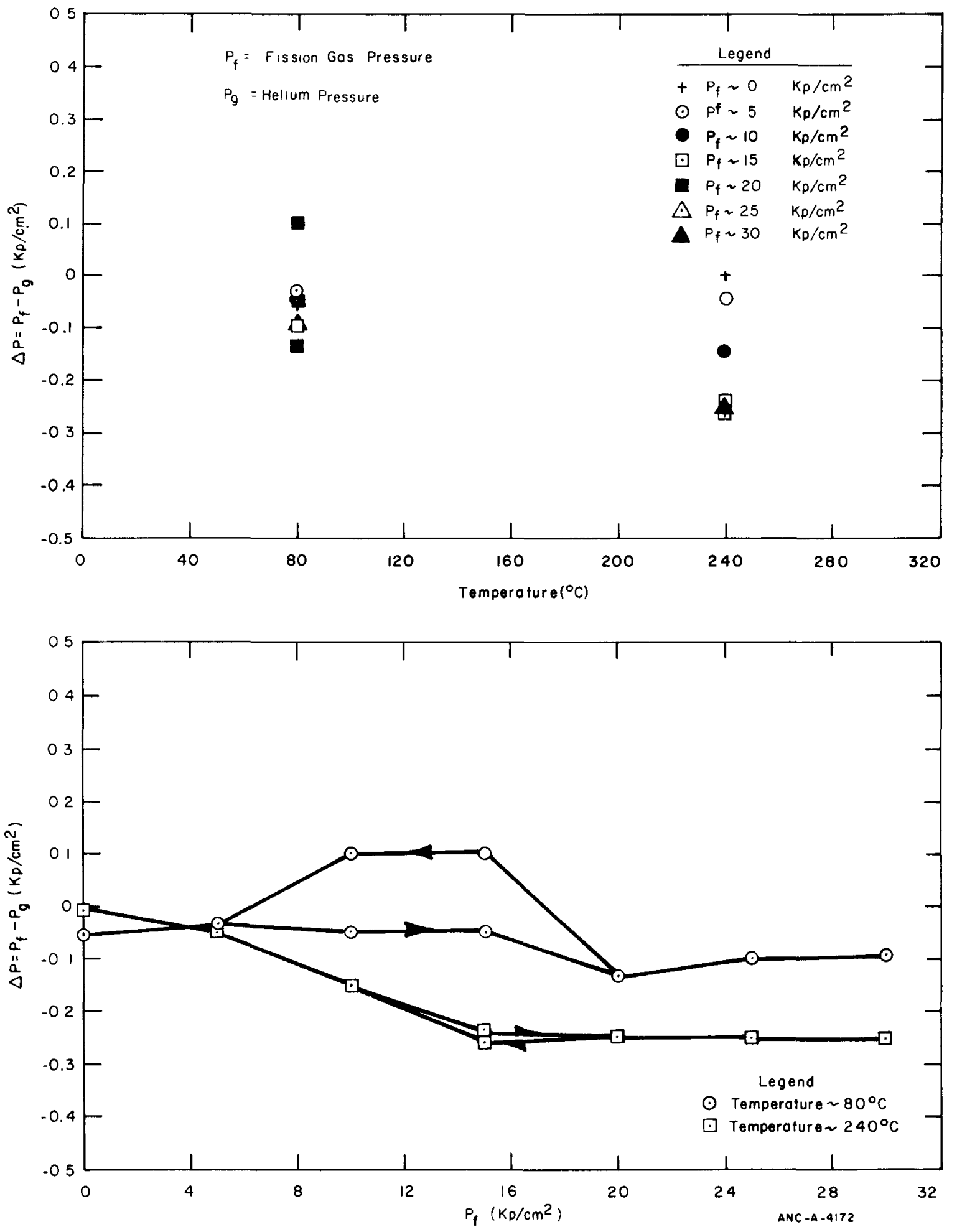

Fig. B-14 Switch point consistency of the pressure transducer in Rod AE. 


\section{NEUTRON DETECTOR CHARACTERISTICS}

The vanadium neutron detectors in IFA-226 and IFA-239 are $10 \mathrm{~cm}$ in length by 2 $\mathrm{mm}$ in diameter. They were purchased from $\mathrm{AB}$ Atomenergi of Sweden.

The characteristics of the neutron detectors are presented in Table B-I. These results indicate a small difference in detector sensitivities to presumably the same neutron flux, although the absolute flux value was known only to within $\pm 2 \%$. (The measurements were obtained in the $\mathrm{R} 2$ reactor at Studsvik.) The range of emitter current about the average is $-1.7 \%$ to $2.9 \%$, based on corrections for the different gamma compensation-current value of each detector.

The normalization factors in the last column of Table B-I were used in the calibration computer code to modify the signals from the neutron detectors so that all signals were relative to the same detector sensitivity.

The calibration data for the neutron detectors in IFA-239 are not available. Since the in-pile performance of these detectors was very predictable and consistent, no reason exists to believe that these detectors were not operating as desired. 
$\underline{\text { TABLE B-I }}$

IFA-226 NEUTRON DETECTOR CHARACTERISTICS

\begin{tabular}{|c|c|c|c|c|c|c|c|}
\hline Detector & $\begin{array}{l}\text { Emitter }{ }^{[a]} \\
\text { Weight } \\
\quad(\mathrm{g}) \\
\end{array}$ & $\frac{\mathrm{W}_{\mathrm{e}}}{\mathrm{W}_{\mathrm{e}}}$ & $\begin{array}{c}\text { Emitter } \\
\text { Current } \\
\text { (nA) }\end{array}$ & $\frac{\mathrm{I}_{\mathrm{e}}}{\mathrm{I}_{\mathrm{e}}}$ & $\begin{array}{l}\text { Gamma Compen- } \\
\text { sation Current } \\
\quad(\mathrm{pA}) \\
\end{array}$ & $\begin{array}{l}I_{e}-I_{c} \\
(n A) \\
\end{array}$ & $\frac{I_{e}-I_{c}}{\left(I_{e}-I_{c}\right.}$ \\
\hline ND 1 & 1.8468 & 0.9923 & 53.0 & 1.025 & 6.2 & 52.38 & 1.021 \\
\hline ND 2 & 1.8970 & 1.0094 & 50.9 & 0.985 & 4.5 & 50.45 & 0.983 \\
\hline ND 3 & 1.8705 & 0.9953 & 52.2 & 1.010 & 3.9 & 51.81 & 1.010 \\
\hline ND 4 & 1.8790 & 0.9998 & 50.9 & 0.985 & 4.5 & 50.45 & 0.983 \\
\hline ND 5 & 1.8985 & 1.0102 & 50.9 & 0.985 & 4.3 & 50.47 & 0.984 \\
\hline ND 6 & 1.8741 & 0.9972 & 53.0 & 1.025 & 2.2 & 52.78 & 1.029 \\
\hline ND 7 & 1.8562 & 0.9881 & 51.0 & 0.986 & 3.5 & 50.65 & 0.987 \\
\hline ND 8 & 1.8940 & 1.0078 & 51.8 & 1.002 & 3.4 & 51.46 & 1.003 \\
\hline Average & 1.8792 & -- & 51.7 & - & 4.06 & 51.31 & -- \\
\hline \multicolumn{8}{|c|}{ Note: Thermal neutron flux $1.1 \times 10^{11} \mathrm{n} / \mathrm{cm}^{2}-\mathrm{sec}$} \\
\hline \multicolumn{8}{|c|}{ [a] $\begin{aligned} W_{e} & =\text { emitter weight } \\
I_{e} & =\text { emitter electrical current } \\
I_{c} & =\text { compensation for gamma-induced electrical current. }\end{aligned}$} \\
\hline
\end{tabular}




\section{DIAMETRAL PROFILE CALIBRATION (IFA-239)}

Two components which were used to determine the diametral profiles required pretest calibration: the diameter gauge transformer (which was used to measure test pin diameter) and the long range transformer [which was used to indicate the axial position (elevation) of the diameter gauge] .

The results of the diameter gauge calibration are shown in Figure B-15. The setpoint of the diameter gauge was adjusted in order to use the portion of the curve between 0.375 and $0.720 \mathrm{~mm}$, which appeared to be nearly linear. This assumption of curve linearity is accurate to within $\pm 3 \mu \mathrm{m}$.

The results of the long range transformer calibration are presented in Figure B-16. Except for a short distance near both ends of the coil, the output is linear with respect to transformer core position. 


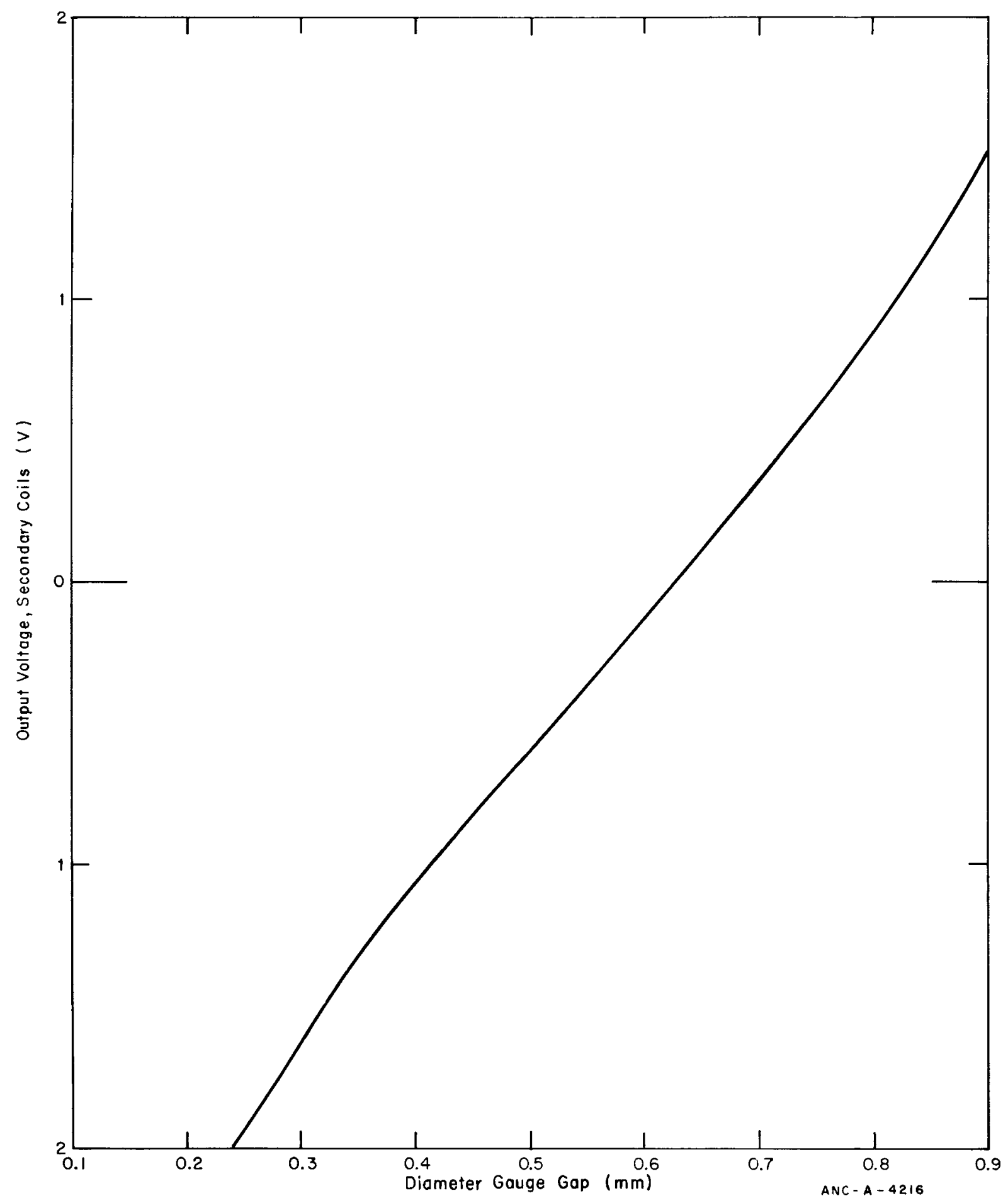

Fig. B-15 Calibration curve for the diameter gauge transformer. 


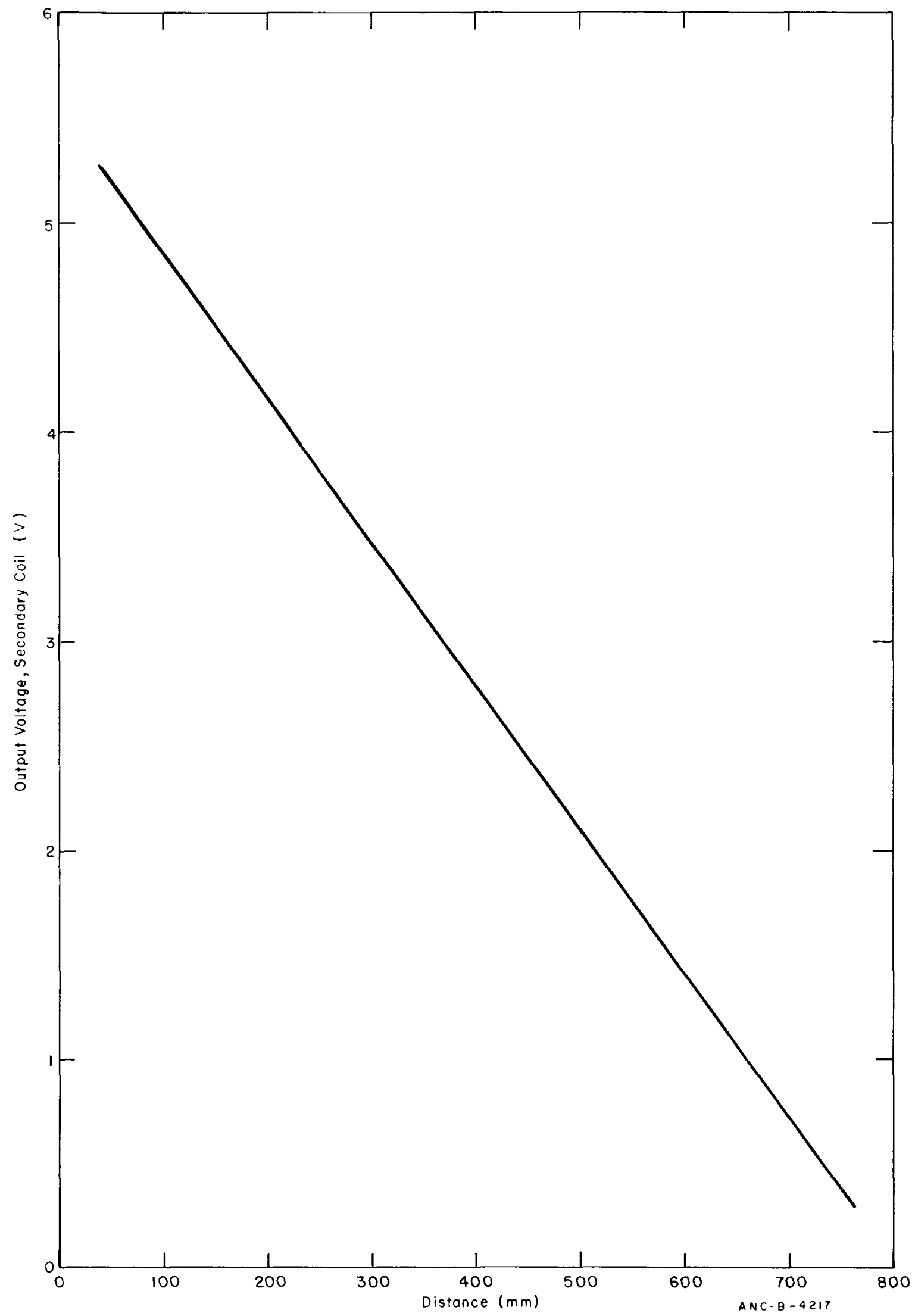

Fig. B-16 Calibration curve for the long range linear transformer. 


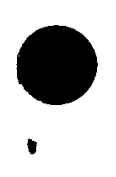


APPENDIX C

DATA REDUCTION TECHNIQUES 
-

h

, 


\section{APPENDIX C}

\section{DATA REDUCTION TECHNIQUES}

The neutron detector data which were obtained from both assemblies were interpreted and analyzed in order to obtain more meaningful power history information. A different procedure was used for each assembly.

\section{IFA-226 NEUTRON DETECTOR DATA}

A FORTRAN computer program was developed and used to determine the power of the IFA-226 test assembly and the inaividual test rods within that assembly. The assembly power was determined by utilizing the signals from the neutron detectors which were axially and radially positioned throughout the assembly. First, an axial flux profile was fit to the detector signals. Since only four axial locations are occupied by the neutron detectors, a single value was used for each of the four locations. At the two axial locations where more than one detector was located, an average value of all signals at that location was used to represent the local value. The axial flux profile was then represented by a Fourier sine series expressed as

$$
\phi(x)=\sum_{n=1}^{4} B_{n} \sin \left(\frac{n \pi x}{L}\right)
$$

where

$$
\begin{aligned}
& \mathrm{L}=\begin{array}{l}
\text { effective length of core; that is, length at which the flux extrapolates to } \\
\text { zero }
\end{array} \\
& \mathrm{x}=\text { location for evaluation of the flux } \\
& \mathbf{B}_{\mathbf{n}}=\text { Fourier coefficients. }
\end{aligned}
$$

The Fourier coefficients were solved by the simultaneous solution of

$$
\begin{array}{cc}
\mathrm{ND}\left(\mathrm{x}_{1}\right)= & \sum_{n=1}^{4} \mathrm{~B}_{\mathrm{n}} \sin \left(\frac{\mathrm{n} \pi \mathrm{x}_{1}}{\mathrm{~L}}\right) \\
\dot{\cdot} & \dot{\cdot} \\
\mathrm{ND}\left(\mathrm{x}_{4}\right)=\sum_{\mathrm{n}=1}^{4} \mathrm{~B}_{\mathrm{n}} \sin \left(\frac{\mathrm{n} \pi \mathrm{x}_{4}}{\mathrm{~L}}\right)
\end{array}
$$


where $\mathrm{ND}\left(\mathrm{x}_{1}\right)$ and $\mathrm{ND}\left(\mathrm{x}_{4}\right)$ were the detector signals at the $\mathrm{x}_{1}$ and $\mathrm{x}_{4}$ axial locations, respectively. Since all of the unknown parameters (the Fourier coefficients) have been obtained, $\phi(\mathrm{x})$ can be evaluated at any $\mathrm{x}$.

Through use of the axial flux profile determined, the code then calculated the power of the test assembly. This power was determined by first integrating the total area above each cluster and then by multiplying this integrated area by a constant of proportionality, or:

$$
\text { Power }=k \int_{\mathrm{x}_{1}}^{\mathrm{x}_{2}} \phi(x) \mathrm{dx}+\mathrm{k} \int_{\mathrm{x}_{3}}^{\mathrm{x}_{4}} \phi(\mathrm{x}) \mathrm{dx}
$$

where

$$
\begin{aligned}
& \mathrm{x}_{1} \text { to } \mathrm{x}_{2}=\quad \text { active length of fuel in one cluster } \\
& x_{3} \text { to } x_{4}=\quad \text { active length of fuel in other cluster } \\
& \mathrm{k}=\quad \text { constant of proportionality. The value of } \mathrm{k} \text { was determined by }
\end{aligned}
$$

The peak and the average powers of an individual rod within a cluster were determined in a similar manner. First, the average cluster power was calculated by the equation,

$$
\overline{\mathrm{P}}_{\text {cluster }}=\mathrm{k} \frac{\int_{\mathrm{x}_{1}}^{\mathrm{x}_{2}} \phi(\mathrm{x}) \mathrm{dx}}{\mathrm{x}_{2}-\mathrm{x}_{1}} .
$$

A radial peaking factor was then determined for each rod, one cluster of rods at a time. A plane was determined first for the lower cluster from the output of the three radially distributed neutron flux detectors within the cluster. The flux value at each rod position was normalized to the midpoint of the plane. The same procedure was repeated to determine the radial peaking factors for the upper cluster rods.

The average rod power was then calculated by the expression

$$
\mathrm{P}_{\text {avg rod }}=\frac{\overline{\mathrm{P}}_{\text {cluster }} \mathrm{f}_{\mathrm{rp}}}{\mathrm{N}}
$$


where

$$
\begin{array}{ll}
\mathrm{P}_{\text {avg rod }} & =\text { average rod power } \\
\mathrm{f}_{\mathrm{rp}} & =\text { radial peaking factor of that rod } \\
\mathrm{N} & =\text { number of rods within the cluster. }
\end{array}
$$

The peak rod power was determined by multiplying the average rod power by the cluster axial peaking factor which was obtained from the previously determined axial flux profile.

\section{IFA-239 NEUTRON DETECTOR DATA}

The power of the IFA-239 test assembly was determined by averaging the signals from the neutron detectors which were positioned at three different axial locations. This average value was multiplied by a calibration constant to convert the neutron detector signal directly to assembly power in $\mathrm{kW}$. The calibration constant was determined by comparing the average of the neutron detector signals with the assembly power as calculated from the thermal-hydraulic (flow rate and differential temperature) measurements. A value of 0.201 $\mathrm{kW} / \mathrm{nA}$ was determined from the data which were obtained during the first two weeks of assembly operation at beginning-of-life operation.

When a detector failure occurred, the power was thereafter determined from the data of the remaining operative detectors. The value of the calibration constant was recalculated from the beginning-of-life data, excluding the data from the detector which failed. The integrity of the assembly power value obviously decreases as more detectors become inoperative. 